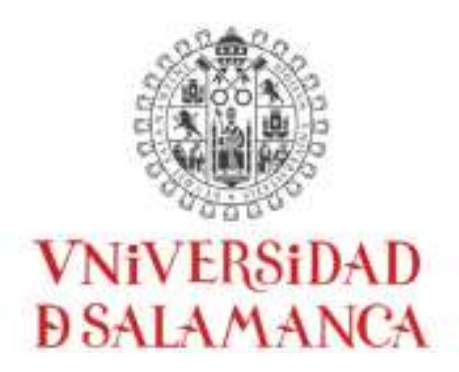

\title{
Género, desigualdad y trabajo: un enfoque desde la responsabilidad social.
}

\section{Lina Margarita Marrugo Salas.}

\author{
Tesis doctoral
}

Dirige: Prof. Dr. Enrique Cabero Morán

Dpto. Derecho del Trabajo y Trabajo Social

\section{Escuela de Doctorado}

Salamanca, 2017

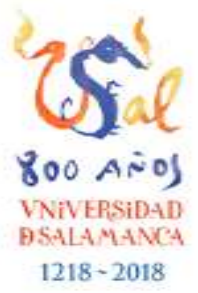




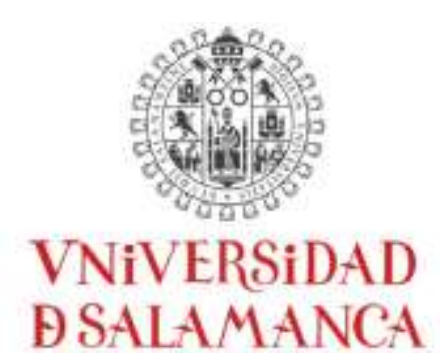

DEPART AMENTO DE DERECHO ADMINISTRATIVO, FINANCIERO Y PROCESAL PROGRAMA DE DOCTORADO EN ESTUDIOS INTERDISCIPLINARES DE GÉNERO

\section{GÉNERO, DESIGUALDAD Y TRABAJO: UN ENFOQUE DESDE LA RESPONSABILIDAD SOCIAL.}

Memoria de tesis doctoral presentada por Lina Margarita Marrugo Salas para obtener el grado académico de Doctor por la Universidad de Salamanca (España), dirigida por el Dr. D. Enrique Cabero Morán, profesor titular del Departamento de Derecho del trabajo y trabajo social de la Universidad de Salamanca.

Vํㅡํำ director

Fdo. Lina Marrugo Salas

Fdo. Enrique Cabero Morán 


\section{VNiVERSiDAD \\ BSALAMANCA \\ CAMPUS DE EXCELENCIA INT ERWACOCONAL}

\section{ARCHIVO DE LA TESIS DOCTORAL EN FORMATO ELECTRONICO ABIERTO EN EL REPOSITORIO INSTITUCIONAL DE LA UNIVERSIDAD DE SALAMANCA.}

Dạ. LINA MARGARITA MARRUGO SALAS, autora de la tesis doctoral titulada Género, desigualdad y trabajo: un enfoque desde la responsabilidad social, dirigida por D. DR. ENRIQUE CABERO MORÁN y elaborada en el Programa de Doctorado ESTUDIOS INTERDISCIPLINARES DE GÉNERO.

Declara conocer que una vez finalizada la evaluación de la citada tesis doctoral, la Universidad de Salamanca se ocupará de su archivo en formato electrónico abierto en un repositorio institucional y remitirá, en formato electrónico, un ejemplar de la misma así como toda la información complementaria que fuera necesaria al Ministerio de Educación a los efectos oportunos, de acuerdo con lo dispuesto en el Real Decreto 99/2011, de 28 de enero, por el que se regulan las enseñanzas oficiales de doctorado.

Así mismo, en aplicación del Reglamento de Doctorado de la Universidad de Salamanca aprobado por el Consejo de Gobierno de 25 de octubre de 2011:

AUTORIZA que el citado archivo se realice sobre una copia íntegra de su tesis doctoral.

En Salamanca, a los días del mes de julio de 2017

$$
\text { Voํ․ . }
$$
El autor de la Tesis.
El director de la tesis.

El presidente de la Comisión Académica. 


\section{Portada}

Resumen de la tesis: Partiendo de un problema histórico y cultural, la adquisición de derechos de las mujeres no ha sido nada fácil, sin embargo, se ha hecho más visible las desigualdades existentes en diferentes ámbitos sociales, uno de ellos el mercado de trabajo y se ha intentado combatir aquellas barreras que impiden la igualdad de oportunidades entre mujeres y hombres. Aunque el acceso al empleo por parte del llamado "sexo débil" en cargos de responsabilidad y poder en cualquier ámbito sigue considerándose un asunto pendiente, es de conocimiento que los estereotipos culturales fuertemente arraigados no lo han permitido, es por ello que este trabajo desde una perspectiva interdisciplinaria intenta demostrarlo, que existe una patología en nuestros sistemas económicos y sociales, para ello se visualizará las razones por las cuales sigue sucediendo este fenómeno, que en efecto resulta del todo arbitrario mediante una revisión de la doctrina existente. Para ello, se enfatizará en las diferenciaciones existentes entre mujeres y hombres, por un lado, entre las responsabilidades familiares situación que tiene un componente histórico-cultural y por el otro, de las habilidades y competencias directivas cuyo componente es psicológico-social. Por lo que se resaltará el papel activo y dinámico que debe tener cada actor social comenzando con los poderes públicos y priorizando el rol que juegan las empresas. Es por ello que al final, el aporte será el de resaltar el liderazgo social mediante un enfoque aplicable de la responsabilidad social que busque la integración efectiva y transversal del género en cualquier tipo de organización, basados en prácticas y perspectivas existentes, pues es un hecho que nuestras organizaciones necesitan de la presencia y la participación de más mujeres líderes.

Palabras Clave: Desigualdad, Diversidad, Empleo, Empoderamiento, Género, Dirección, Igualdad, Liderazgo, Responsabilidad Social, Trabajo. 
Quiero agradecer la confianza depositada por mi director el profesor Enrique Cabero Morán, por su orientación durante estos años. Su sensibilidad, su experiencia, su conocimiento y disposición ha permitido la culminación de este trabajo. Dedico este logro a mi mamá, mis abuelos y mis hermanitas quienes me han apoyado siempre en todas mis aventuras. A mi hermosa ciudad Salamanca que me acogió por cinco años, los mejores de mi vida hasta ahora. A Dios por todas sus bendiciones, y al resto de personas que estuvieron siempre conmigo motivándome. 


\section{Índice de contenido}

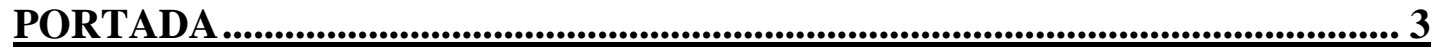

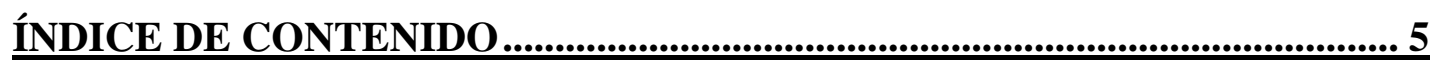

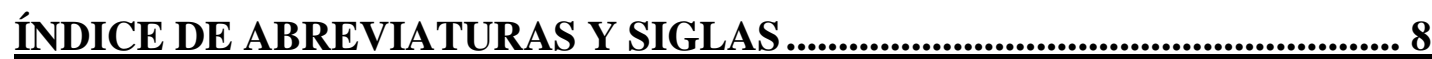

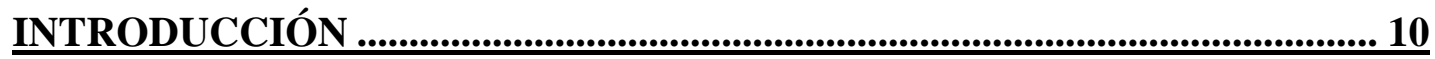

(I.) INTERÉS Y RAZONES DE ELECCIÓN DEL OBJETO DE ESTUDIO ........................................10

(II.) Planteamiento de la inVestigación, ESQuema Y PRECisiones

METODOLÓGICAS......................................................................................................................27

CAPÍTULO UNO. ACERCAMIENTO HISTÓRICO, CONCEPTUAL Y

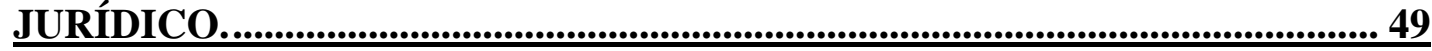

1.1. PERSPECTIVA HISTÓRICA: LAS MUJERES Y EL TRABAJO..............................................51

1.2. MARCO NORMATIVO EN MATERIA DE IGUALDAD Y NO DISCRIMINACIÓN EN EL

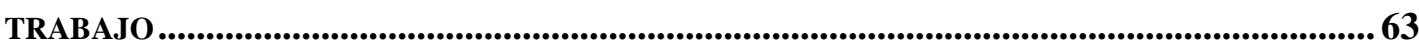

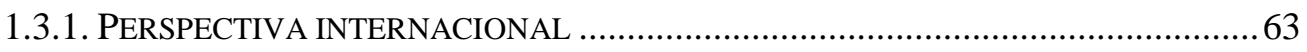

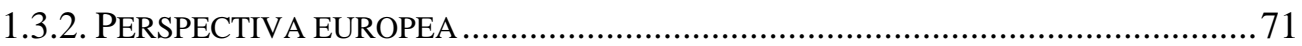

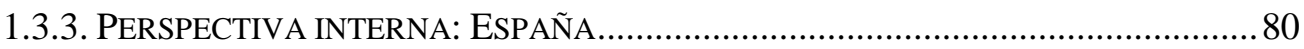

1.3.4. LA LEY ORGÁNICA 3/2007, DE 22 DE MARZO, PARA LA IGUALDAD EFECTIVA DE MUJERES Y HOMBRES 87

CAPÍTULO DOS. IGUALDAD, GÉNERO Y TRABAJO EN ESPAÑA.......... 95

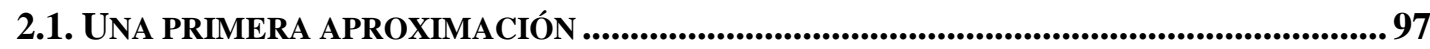

2.2. EVIDENCIA DE LA PARTICIPACIÓN DE LA MUJER EN EL MERCADO DE TRABAJO..... 99

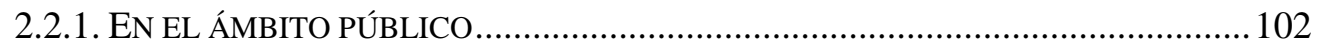

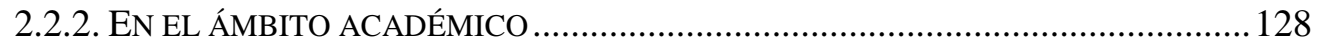

2.3. EL FENÓMENO DE LA DISCRIMINACIÓN MÚLTIPLE ..............................................139

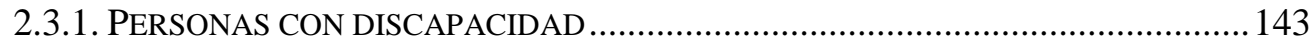


CAPÍTULO TRES. EL ACCESO DE LA MUJER A CARGOS DE TOMA DE DECISIONES EN EL ÁMBITO PRIVADO: EMPRESAS COTIZADAS..... 167

3.1. Planteamiento introductorio. 169

3.2. ¿POR QUÉ ES TAN DIFÍCIL EL ACCESO DE LA MUJER A CARgOS DE MAYOR RESPONSABILIDAD? 172

CONCILIACIÓN DE LA VIDA FAMILIAR, PERSONAL Y LABORAL 188

3.2.1 LA RELACIÓN POSITIVA ENTRE LA MUJER Y LA DIRECCIÓN 190

3.2.2. INFORME DE LA OIT Y LA PERSPECTIVA INTERNACIONAL 197

3.3. SITUACIÓN DE LAS EMPRESAS COTIZADAS: EL CASO DE ESPAÑA........................... 203

3.4. TEORÍAS Y ESTILOS DE DIRECCIÓN: LIDERAZGO EN LAS ORGANIZACIONES........... 211

CAPÍTULO CUATRO. EL PAPEL DE LA RESPONSABILIDAD SOCIAL EN LAS ORGANIZACIONES................................................................. 221

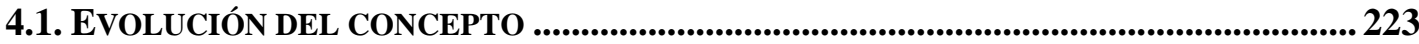

4.2. LA RELACIÓN CON EL PRINCIPIO DE IGUALDAD Y NO DISCRIMINACIÓN 232 4.3. ACCIONES CONCRETAS DE LAS EMPRESAS ESPAÑOLAS EN IGUALDAD DE GÉNERO

4.3.1. ANÁLISIS DE CASO: BANCO BBVA 246

4.3.2. ANÁLISIS DE CASO: BANCO SANTANDER 249

4.3.3. ANÁLISIS DE CASO: IBERDROLA 250

4.3.4. ANÁLISIS DE CASO: INDITEX 253

4.3.5. ANÁLISIS DE CASO: TELEFÓNICA 256

4.3.6. ANÁLISIS DE CASO: RENFE 259

4.3.7. CONCLUSIONES PRELIMINARES

4.4. HACIA UN MODELO DE RSE CON ENFOQUE DE GÉNERO. 264

4.4.1 INICIATIVAS QUE BUSCAN LA PROMOCIÓN DE LA IGUALDAD DE GÉNERO EN EL LUGAR DE TRABAJO 268 
5. APARTADO ESPECIAL, UNA VISIÓN DE COLOMBIA.........................280

DESCRIPCIÓN, METODOLOGÍA Y RESULTADOS DEL ESTUDIO .............................................. 282

¿CÓMO SE COMBATE EL PROBLEMA? ..............................................................................287

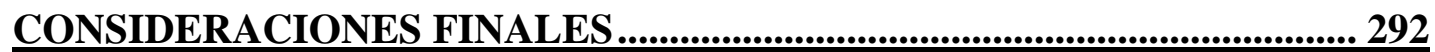

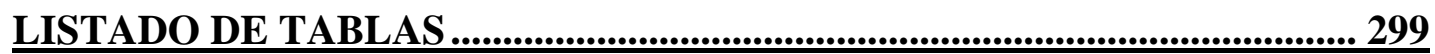

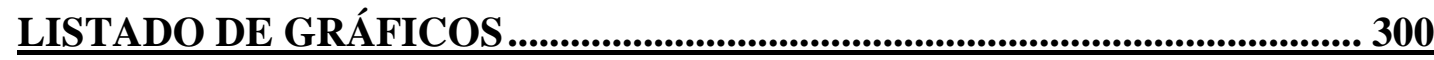

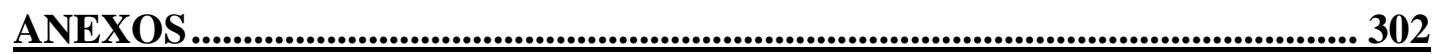

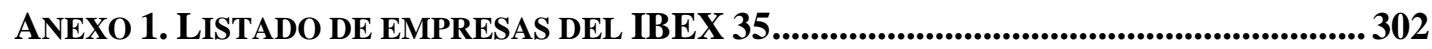

ANEXO 2. LISTADO DE EMPRESAS ESPAÑOLAS PERTENECIENTES AL PACTO MUNDIAL. 303

ANEXO 3. LISTADO DE EMPRESAS ESPAÑOLAS QUE SE ADHIRIERON AL PROYECTO “MÁS

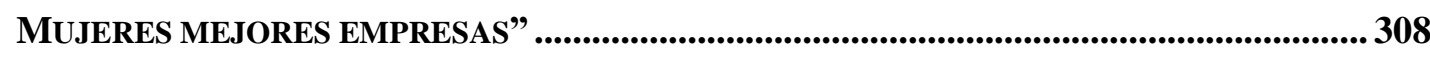

Anexo 4. Pasos Para COMbatir el PRejuicio inconsciente (CATAlyst-d, 2015) 309

ANEXO 5. INDICADORES PARA LA EVALUACIÓN DE LA IGUALDAD DE GÉNERO EN LAS ORGANIZACIONES (DEPARTAMENTO DEL TRABAJO, 2010, PP. 25-56) 310

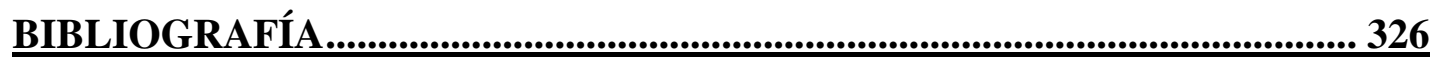




\section{Índice de abreviaturas y siglas}

\begin{tabular}{|c|c|}
\hline $\mathrm{BOE}$ & Boletín Oficial del Estado Español. \\
\hline $\mathrm{CA}$ & Consejos de Administración. \\
\hline $\mathrm{CCOO}$ & Confederación Sindical de Comisiones Obreras. \\
\hline CE & Constitución Española. \\
\hline CE & Comisión Europea. \\
\hline CEE & Comunidad Económica Europea. \\
\hline CEO & Chief Executive Officer, Director Ejecutivo. \\
\hline CEPAL & Comisión Económica para América Latina y el Caribe. \\
\hline CEPC & Centro de Estudios Políticos y Constitucionales. \\
\hline CINDA & Centro Interuniversitario de Desarrollo \\
\hline CNMV & Comisión Nacional del Mercado de Valores. \\
\hline CTI & Ciencia, Tecnología e Innovación \\
\hline DANE & Departamento Administrativo Nacional de Estadística. \\
\hline DIRCE & Directorio Central de Empresas. \\
\hline EU & Estados Unidos \\
\hline $\mathrm{IDH}$ & Índice de Desarrollo Humano. \\
\hline IM & Instituto de la Mujer. \\
\hline ISO & International Organization for Standardization. \\
\hline GRI & Global Reporting Initiative. \\
\hline LOIMH-LOI & $\begin{array}{l}\text { Ley Orgánica 3/2007, de } 22 \text { de marzo, para la igualdad } \\
\text { efectiva de mujeres y hombres. }\end{array}$ \\
\hline MBA & Master in Business Administration. \\
\hline OCDE & Organización para la Cooperación y el Desarrollo Económicos. \\
\hline ODM & Objetivos de Desarrollo del Milenio. \\
\hline ODS & Objetivos de Desarrollo Sostenible. \\
\hline OIT & Organización Internacional del Trabajo. \\
\hline ONU & Organización de Naciones Unidas. \\
\hline PNUD & Programa de las Naciones Unidas para el Desarrollo. \\
\hline
\end{tabular}


PWC

PYMES

RS/RSE/RSC

RSG

SAI

SMA

UE

UNED

UNESCO
PriceWaterhouseCoopers.

Pequeñas y medianas empresas.

Responsabilidad Social, Empresarial, Corporativa.

Responsabilidad Social de Género.

Social Accountability International.

Salario Medio Anual.

Unión Europea.

Universidad Nacional de Educación a Distancia España.

Organización de las Naciones Unidas para la Educación, la Ciencia y la Cultura.

UGT

Unión General de Trabajadores.

WEF

Foro Económico Mundial. 


\section{Introducción}

"The late Kenyan Nobel peace laureate Wangari Maathai put it simply and well when she said, the higher you go, the fewer women there are." Chimamanda Ngozi Adichie, We Should All Be Feminists

\section{(i.) Interés y razones de elección del objeto de estudio}

La igualdad de género ${ }^{1}$ se ha convertido en un asunto prioritario de la agenda pública internacional, más que nada porque su promoción, su alcance, la autonomía y el empoderamiento de las mujeres se consolidó como uno de los Objetivos de Desarrollo del Milenio, ahora Objetivos de Desarrollo Sostenible ${ }^{2}$ de la Organización de Naciones Unidas [ONU], pues sin duda es

\footnotetext{
1 La igualdad de género implica garantizar la igualdad de oportunidades entre mujeres y hombres en todos los ámbitos sociales, es por ello que dicha igualdad según defiende Martínez et al. (2009, pp. 15-16) "...es un principio y un valor jurídico universal que se concreta, entre otros, en el derecho a la no discriminación por razón de sexo, esto es: en la ausencia de todo perjuicio o desventaja, directa o indirecta, como consecuencia de la consideración arbitraria del sexo. Especialmente cuando este trato perjudicial se vincula a la maternidad, a las obligaciones familiares o al estado civil. Es decir: la igualdad es un principio y/o valor y la no discriminación un derecho"
}

${ }^{2}$ Con la nueva agenda de Desarrollo Sostenible se adoptaron una serie de objetivos globales, específicamente 17 Objetivos de Desarrollo Sostenible; el número cinco, denominado igualdad de género consiste en "lograr la igualdad entre los géneros y empoderar a todas las mujeres y las niñas". En este sentido, la ONU insiste que, con la representación en los procesos de adopción de decisiones políticas y económicas, se impulsarán las economías sostenibles y se beneficiará a las sociedades y a la humanidad en su conjunto. Cfr. http://www.un.org/sustainabledevelopment/es/gender-equality/ 
considerado una pieza fundamental para el progreso del desarrollo humano y la lucha contra la pobreza ${ }^{3}$ a nivel global.

Es por ello, que se ha logrado impulsar el fomento de la igualdad de género no solo en el trabajo, sino en otros aspectos de la vida de las mujeres. No obstante, la lucha de ellas por la consecución del ejercicio de sus derechos históricamente no ha sido un camino nada fácil. De hecho, el informe del Programa de las Naciones Unidas para el Desarrollo [PNUD] sobre Desarrollo Humano (2015, pp. 3-4) evidenció aún la existencia de disparidades entre géneros ${ }^{4}$, es decir, que las mujeres sufren desventajas en diferentes ámbitos sociales, específicamente:

"En el ámbito del trabajo remunerado, participan menos que los hombres en la fuerza de trabajo, ganan menos, su trabajo suele ser más vulnerable, y están insuficientemente representadas en los cargos directivos superiores y los cargos decisorios. Por lo que se refiere al trabajo no remunerado, soportan una carga desproporcionada de los quehaceres domésticos y el trabajo de cuidados"5.

\footnotetext{
3 Según Amnistía Internacional (2009, p. 8) "La pobreza es algo más que falta de ingresos. También es falta de seguridad, de voz, de alternativa". En el caso de las mujeres "sufren los efectos de la pobreza de una manera especial debido al papel que desempeñan en la sociedad, la comunidad y la familia."

${ }^{4}$ De acuerdo con Pérez el género como término "tiene por objetivo hacer visible la realidad de la posición asimétrica de poder entre hombres y mujeres, realidad invisible en el término sexo, de connotaciones mucho más biológicas que culturales" (2006, p. 11).

${ }^{5}$ La razón por el cual se tiene en cuenta este informe se debe principalmente a que según el PNUD “El Informe adopta una visión amplia del trabajo, pues va más allá del empleo y tiene en cuenta actividades como el trabajo de cuidados no remunerado, el trabajo voluntario y el trabajo creativo, que contribuyen a la riqueza de las vidas humanas." $(2015$, p. 3)
} 
No hay que negar que en las últimas décadas ha aumentado la participación de la mujer en el mercado de trabajo (Cfr. The World Bank, 2011; OIT, 2011; OCDE, 2012) así como el fortalecimiento jurídico en este ámbito a nivel internacional, lo que ha logrado favorecer la tan anhelada igualdad de oportunidades en el empleo y la ocupación ${ }^{6}$. Sin embargo, las mujeres aún se enfrentan a numerosos impedimentos a la hora de alcanzar una efectiva igualdad en el ámbito laboral, esto se debe a que muchos de los sistemas jurídicos surgen de tradiciones culturales que aún tienen como base la discriminación (PNUD, 2014), lo que ha tenido además como consecuencia una marcada división social del trabajo ${ }^{7}$.

Así, pues, es notable un conjunto de desigualdades ${ }^{8}$ y situaciones aun presentes en el trabajo, como se demostrará más adelante los datos y estudios disponibles manifiestan que: ( $I$ ) es persistente la fisura salarial entre

${ }^{6}$ En el texto cuando se habla de empleo y la ocupación, se intenta englobar todos los aspectos característicos relacionados con el mercado de trabajo. Así, como se plasma en el artículo 1.3 del Convenio 111 de la OIT sobre la discriminación (empleo y ocupación) de 1958 "incluyen tanto el acceso a los medios de formación profesional y la admisión en el empleo y en las diversas ocupaciones como también las condiciones de trabajo."

7 Esa división social del trabajo, se da en la estructura de la fuerza de trabajo y en la organización del trabajo remunerado, lo cual es más evidente al momento de hacerlo por sexos.

${ }^{8}$ Las desigualdades sociales suponen la imposibilidad de una persona en desarrollar algún aspecto de la vida en todo su potencial, de hecho, tal como lo planteó Hernández (2008, p. 93) surge de la transformación socioeconómica y se intensifica con la aparición de procesos estructurales en nuestra sociedad que afectan diferentes colectivos en diversos ámbitos sociales. Para ello, el autor insiste en que se hace necesario el desarrollo de "....mecanismos de respuesta de carácter comunitario y socioeducativo, que construyan autonomía, que reconstruyan relaciones: la reconquista de los propios destinos vitales por parte de las personas o colectivos afectados por esas dinámicas o procesos de exclusión social." 
géneros, pues globalmente, las mujeres ganan un 24\% menos que los hombres (ONU, 2015), (ii) que las mujeres se siguen concentrando en determinados puestos de trabajo ${ }^{9}$, (iii) que existen dificultades importantes para que hombres y mujeres puedan conciliar la vida personal y laboral ${ }^{10}$, (iv) que existen discriminaciones ocultas ${ }^{11},(v)$ que existe poca presencia femenina en los cargos de poder y de responsabilidad ${ }^{12} y$, que cuando las

\footnotetext{
${ }^{9}$ Este fenómeno, en la literatura se denomina segregación horizontal, que ocurre cuando los sexos se concentran en determinadas actividades económicas. Lo cual repercute en una "feminización" o "masculinización" del mercado de trabajo.
}

A pesar de la evidencia de la transformación cultural en las últimas décadas, se ha comprobado que "la segregación laboral de género es un fenómeno presente en la mayoría de países, independientemente de las condiciones socioeconómicas y de la existencia de leyes antidiscriminatorias que velan por la plena ciudadanía de las mujeres" (Barberá, 2004, p. 39)

10 De hecho, el conflicto familia-trabajo es considerado en la actualidad uno de los factores más importantes que generan riesgos y enfermedades profesionales, como el estrés y el síndrome de burnout. El impacto económico que genera que las organizaciones no implementen políticas de conciliación puede repercutir de manera negativa en sus trabajadores y en la productividad (Martínez-Losa \& Sarrate, 2014).

${ }^{11}$ Según Lousada (2014, p. 165) la discriminación sexista directa oculta "se produce cuando quien discrimina toma en consideración alguna circunstancia que encubre la consideración del sexo de la victima y que es un elemento esencial dentro de la construcción social y cultural del género. El ejemplo más clasico es el estado civil de la mujer casada".

12 Este aspecto, es valorado durante todo el texto teniendo en cuenta que el énfasis es sobre el acceso de las mujeres a cargos de responsabilidad y toma de decisiones en distintos ámbitos sociales como las empresas, el sector público y la academia. Pues, en efecto, la asociación al poder tiene un fuerte componente cultural y diferenciado por género, que en palabras de Nicolson (1997, p. 10) "la masculinidad es equivalente al éxito, a la autorrealización y al poder, mientras que la feminidad es aún concebida por la mayoría de 
mujeres logran acceder a éstos puestos, $(v i)$ se encuentran aun con muchas más barreras y diferencias en las condiciones laborales (Nicolson, 1997).

A partir de la última afirmación Arredondo, Velázquez \& de la Garza exponen situaciones en las que las mujeres optan por salir del mercado de trabajo, una de las razones la poca flexibilidad ${ }^{13}$, y la falta de equilibrio entre las actividades familiares y laborales. En este sentido, proponen que "se requiere la participación tanto de la organización como del colaborador, lo cual implica que ambos estén de acuerdo y trabajen en conjunto para encontrar un punto en común entre las necesidades del colaborador y las necesidades de la empresa." (2013, p. 162).

No obstante, en respuesta a todo lo planteado, es evidente un incansable avance en políticas nacionales, marcos legislativos y tratados internacionales, así como la puesta en marcha de iniciativas, investigaciones y estudios sobre este escenario por parte de instituciones reconocidas que han decidido liderar este cambio.

Según Selva, Sahagún \& Pallarès (2011, p. 235) esto es más visible pues se logró determinar el creciente interés por la publicación ${ }^{14}$ de temáticas

los hombres y las mujeres bajo la forma anticuada y tradicional de una pasividad dependiente."

${ }^{13}$ Aunque, implementar programas de trabajo flexible requiere combatir la falsa creencia o la percepción de los empresarios y de los trabajadores que este tipo de medida supone un nivel inferior de compromiso y capacidad (Barberá, Sarrió \& Ramos, 2000-a, p. 204). Pues en general, en los entornos de trabajo se valora al personal que trabaja muchas horas.

14 De hecho, las revistas con mayor número de artículos, son aquéllas que tratan temáticas afines al mundo organizacional, es decir, revistas especializadas del ámbito empresarial. Lo cual anticipa desde ya la importancia de la mujer en las relaciones laborales. (Selva, Sahagún \& Pallarès, 2011, p. 235). 
que giran en torno a la trayectoria profesional de la mujer, en especial en los últimos seis años en distintos ámbitos y desde diferentes perspectivas.

Con respecto a la elaboración de informes específicos globales en este ámbito, la Organización Internacional del Trabajo [OIT] como entidad bandera en la promoción de los derechos laborales, tiene como uno de sus principios fundamentales, la eliminación de la discriminación ${ }^{15}$ en el empleo y la ocupación, que, a su vez hace parte de la Declaración relativa a los principios y derechos fundamentales en el trabajo adoptada en 1998. Por tal motivo, se realiza un seguimiento a esta declaración y en especial a este principio, a través de la publicación de un informe global periódico ${ }^{16}$.

Justamente, la OIT corroboró lo anterior al resaltar como uno de los aspectos positivos, el aumento de la legislación y de las iniciativas institucionales en cuanto a tendencias mundiales en materia de discriminación en el empleo, en este sentido, cita la referida institución “(...) aunque el clima mundial no lo propicie, las leyes relativas a la igualdad y a la no discriminación en el trabajo contemplan un conjunto cada vez más amplio de motivos de discriminación y estipulan una protección más completa". (2011, pp. 10-11). Además, algunos países occidentales ya cuentan con regulación específica que trata de asegurar una presencia mínima de mujeres

\footnotetext{
${ }^{15}$ La OIT definió este término como "cualquier distinción, exclusión o preferencia basada en motivos de raza, color, sexo, religión, opinión política, ascendencia nacional u origen social que tenga por efecto anular o alterar la igualdad de oportunidades o de trato en el empleo y la ocupación (...) cualquier otra distinción, exclusión o preferencia que tenga por efecto anular o alterar la igualdad de oportunidades o de trato en el empleo u ocupación". Véase. C111 Convenio sobre la discriminación (empleo y ocupación), 1958.
}

16 Para ampliar esta información se recomienda leer los informes que se han hecho hasta la fecha, desde el más reciente hasta el más antiguo. Cfr. OIT $(2015,2011)$ 
en los puestos de decisión en los distintos ámbitos sociales, aunque en la realidad esta medida genere grandes polémicas.

No obstante, para combatir las desigualdades no es suficiente con las reformas jurídicas, puesto que en la práctica la igualdad ante la ley no es automática (ONU mujeres, 2015) ni garantiza inmediatamente la eliminación de las desigualdades. Por eso se observa que, a pesar de que se han adoptado leyes sobre igualdad de género en países varios, esto no ha repercutido positivamente como se debería, puesto que las desigualdades profundamente arraigadas, la existencia de normas sociales discriminatorias, así como los patrones de desarrollo económico dominantes y, en general, aquellas prácticas culturales propias no permiten el completo desarrollo de la mujer y el ejercicio de sus derechos.

No hay que olvidar, que, aunque es mayor la concienciación en la sociedad, sigue quedando mucho por hacer, pues las mujeres todavía son víctimas de discriminación en cuanto a los empleos a los que pueden acceder, pues, aunque es cierto que lo que se ha ganado se refleja en mayor libertad y autonomía, también se manifiestan retrocesos como la precarización del trabajo, el subempleo y el paro en algunos sectores, sobre todo en las crisis económicas (Maruani, 2000).

De hecho, también en el puesto de trabajo las mujeres se pueden enfrentar a situaciones de desigualdad, en el caso de la desigualdad laboral, ésta se manifiesta socialmente a través de las discriminaciones, entendidas como dar un trato de inferioridad a una persona o colectividad por diversos motivos, pudiendo ser, por ejemplo, en la remuneración, en las prestaciones recibidas o en las condiciones de trabajo.

De ahí que, independiente de la esfera social en la cual se explore existen diferencias notorias en cuanto a la remuneración en los cargos 
desempeñados por las mujeres y por los hombres, como se verá más adelante investigaciones de diverso tipo han demostrado que las mujeres ganan en promedio entre un 70 y un 90 por ciento de lo que ganan los hombres (Aláez, Longas, \& Ullibarri, 2003).

Sobre la remuneración, al respecto se ha alertado que, al ritmo actual sin una acción dirigida, la igualdad salarial entre hombres y mujeres no será alcanzada antes de 2086, eso implica más de 68 años para la consecución de la igualdad (Oelz, Olney \& Tomei, 2013), o quizás en 2095, aproximadamente 78 años para la equidad de género en el lugar de trabajo (Zahidi, 2014). En el caso del cierre de la brecha de género, las cifras tampoco son muy alentadoras unos 170 años de acuerdo al Foro Económico Mundial (WEF, 2016).

Es acertada, la tesis que sobre esta diferenciación defiende Goldin (2014, p. 1091) al concluir que la brecha de género en los salarios "es un resumen estadístico de las diferencias de género en el trabajo", pues durante mucho tiempo, ha sido vista como una síntesis de las diferencias de capital humano entre géneros y de la productividad de un trato diferencial de hombres y mujeres, así como del mercado de trabajo.

Y aunque, se supone que esa brecha ha debido disminuir teniendo en cuenta un mayor acceso de las mujeres a la formación ${ }^{17}$ educativa y de la experiencia acumulada en el mercado de trabajo, la persistencia de la brecha

\footnotetext{
17 Hay que destacar, que existen casos como por ejemplo de emprendimiento femenino en los que se encuentran limitantes en la formación empresarial convencional, la cual "no aborda las limitaciones específicas de género que tienen las mujeres empresarias de bajos recursos porque se dirige principalmente a aspectos sobre cómo establecer, administrar o hacer crecer una empresa. Esto es una desventaja para las mujeres ya que esos servicios tienden a desarrollarse con una "perspectiva masculina" que refuerza las imágenes estereotipadas de los hombres y mujeres empresarios." (Bauer, Finnegan \& Haspels, 2011, p. 3).
} 
salarial de género puede responder a una discriminación real o, a las políticas aplicadas de promoción profesional en las organizaciones y, que tienen que ver directamente con la gestión humana; aunque para otros autores -véase los trabajos de (Goldberg, 1993; Carli, 2001; Browne, 1999)- sigue siendo una justificación, la menor capacidad de las mujeres para acceder a posiciones de poder.

En este sentido, tal como lo expresó Suddath (2014), cuando los empleados con un fuerte potencial están mal pagados, en referencia a la brecha salarial de género, tienen menos incentivos para seguir trabajando, lo que traería como consecuencia sopesar y dar prioridad a otros aspectos de la vida como, por ejemplo, formar una familia. En este sentido, aunque la autora reconoce que en el mundo empresarial es más que conocido que, las mujeres podrían ser un recurso más barato para las organizaciones en el corto plazo, a largo plazo, podría causar que las compañías tuviesen personal, sobre todo masculino, poco calificados, pagados en exceso y personal femenino desmotivado.

Sin contar con que "la discriminación salarial más acusada tiene lugar en la empresa privada. Las trabajadoras de empresas privadas tienen un salario relativamente peor, con relación a los hombres, que las mujeres que trabajan en empresas públicas." (de Cabo \& Rodríguez, 2014, p. 83) las desigualdades incluyen además contextos de violencia a nivel laboral ${ }^{18}$, no

\footnotetext{
${ }^{18}$ Al respecto, Pérez \& Nogareda (2012) afirmaron que esto supone un riesgo en el trabajo pues impacta en la salud y seguridad de las personas, y aunque se tiende a asociar la violencia con la agresión física, comprende otras "conductas susceptibles de violentar e intimidar al que las sufre", es decir, físicas o psicológicas que supongan amenazas, intimidación, abuso y acoso.

Igualmente, de acuerdo con la distinción que realiza Osborne (2011), en el entorno de trabajo hay mujeres que sufren directamente la violencia, otras que la sufren de manera indirecta y,
} 
queda duda que se magnifica con la evolución constante de las formas de trabajo, en este sentido, se considera al igual que Castro \& Casique (2008) que el mercado de trabajo se ha convertido en un lugar incierto, impactado por la flexibilidad y volatilidad donde se pueden presentar violaciones fragantes de derechos humanos, sobre todo en lo que refiere a la dignidad de la persona. Está claro que la violencia se puede dimensionar desde múltiples facetas ${ }^{19}$ y obvio que no excluye las agresiones físicas, aunque su existencia pudiera parecer inconcebible en la era de la información y de las nuevas tecnologías ${ }^{20}$.

$\mathrm{Y}$, aunque hay conciencia que la violencia de género no es atribuible a un solo sexo, pues se puede presentar de parte y parte, de hecho, apenas se está visibilizando cuando sucede de mujeres hacia hombres, la intención no consiste en prevalecer cuando sucede de hombres a mujeres, no obstante,

aquellas que sufren el efecto intimidatorio, al tener conocimiento acerca de dicha violencia que causa en el resto de sus compañeras.

19 Dentro de los tipos de violencia en el trabajo, que está tomando importancia en los últimos tiempos debido a su complejidad no solo en cuanto a regulación sino en cuanto a la determinación es el acoso psicológico o mobbing, En este sentido, Ballester (2006) insiste en que hay que tener cuidado en saber diferenciar entre acoso psicológico y exceso en las prerrogativas empresariales pues hay una línea delgada entre estas actuaciones. La autora identifica dos tipos de acoso psicológico, (i) vertical que proviene directamente del empresario o de la persona en quien recae la potestad de dirección empresarial y (ii) horizontal, en donde existen agresiones grupales frente a individuos.

20 En la era digital, el uso de las nuevas tecnologías está siendo utilizado para ejercer violencia machista y puede impactar de manera positiva o negativamente en la igualdad de género, prácticas como el sexting o el grooming, son nuevos ejemplos de agresión en las redes sociales. Según Bustos (2015, p. 1) "Estas conductas no suelen ser percibidas como agresiones por las víctimas, por los propios agresores ni, tampoco, por sus iguales; como consecuencia de ello, se consienten y se normalizan" 
hay que poner de manifiesto que de acuerdo con Osborne (2011, p. 536) "ellos agreden mucho más que las mujeres, lo hacen de forma más violenta y con una finalidad diferente: controlar las vidas de aquéllas"

Ello sin contar con que, pese a que las mujeres se enfrentan a la discriminación solo por el hecho de ser mujer, en la doctrina se ha expuesto que otros factores sumados al sexo ${ }^{21}$ vistos a través de la diversificación de motivos como la raza, la edad, o la orientación sexual, o, la conjunción de varios de ellos puede incrementar la explotación y los abusos en el mercado de trabajo. Así este fenómeno se hace aún más visible y preocupante cuando se analiza directamente el acceso a los puestos de trabajo y las condiciones de trabajo en el caso de los grupos sociales en riesgo de exclusión como, por ejemplo, las trabajadoras migrantes (Amnistía Internacional, 2009)

De hecho, esta misma entidad ha demostrado que "muchas mujeres se enfrentan a discriminación y hostigamiento en el trabajo, y las trabajadoras migrantes están especialmente expuestas a la explotación y los abusos. La pobreza puede empujarlas a formas de empleo ilegales o semilegales, a menudo segregadas por sexos, como el servicio doméstico, las fábricas donde se explota al personal o la industria del sexo. Muchas se ven atrapadas

\footnotetext{
${ }^{21}$ En este sentido, el texto se refiere al fenómeno de la discriminación múltiple que son aquellas situaciones donde la intersección de distintos factores como: edad, sexo, orientación sexual y origen étnico, religión o discapacidad, dan lugar a una situación de discriminación.
}

Para explicar mejor esta situación, situemos a una mujer asiática accediendo a un puesto en el mercado laboral español, ésta puede ser objeto de discriminación por la relación que existe entre el hecho de ser mujer y su descendencia, es decir, coexisten dos discriminaciones, por lo que la víctima acumula diversas experiencias de discriminación, diversas por el momento en que se sufren y por la causa o factor que las motiva. En la doctrina también suele conocerse como discriminación acumulativa (Cfr. Rey, 2008; Schiek \& Lawson, 2011). 
como víctimas de la trata de personas $u$ otras formas contemporáneas de la esclavitud (2009, p. 14).

Pero lo más preocupante es, que cuando todo parece indicar que se avanza hacia un cambio de mentalidad por parte de las personas, se evidencia una dificultad de las mujeres en el acceso a puestos de toma de decisiones, así como a cargos de responsabilidad y poder, pues se confirmará que las cifras en general ${ }^{22}$ determinan que los hombres están, en mayor medida, al frente de estos puestos ${ }^{23}$.

En España, un estudio de ICSA Grupo y EADA Business School (2016), que se hace anualmente sobre las diferencias salariales y la cuota de presencia femenina en el mercado español, arrojó, por una parte, que la proporción de mujeres directivas ha caído desde el 19,5\% en 2008 hasta el $11,8 \%$ en 2016. Por otra parte, aunque las directivas están mejor formadas, se han aumentado las diferencias salariales pasando de un $11,9 \%$ a un $17,1 \%$, lo que permite concluir que la crisis económica ha impactado de

\footnotetext{
22 De hecho, en Latinoamérica "las mujeres ocupan sólo el $5 \%$ de los altos cargos en las empresas" (Álvaro, 2013, p. 1), lo cual muestra que hace falta la implementación de buenas prácticas de gobernanza de las compañías, haciendo énfasis en la igualdad en órganos de dirección y administración. En este sentido, "la región tiene aún mucho camino que recorrer en igualdad y buen gobierno corporativo".
}

${ }^{23}$ Según estudios de la consultora Grant Thornton International quien realiza investigaciones anuales desde hace más de 10 años acerca de acceso de las mujeres a cargos superiores a nivel internacional mostró que "el porcentaje de puestos directivos ocupados por mujeres varía enormemente en función del sector. Las mujeres suelen tener una mayor representación en los sectores de servicios, tales como educación, atención sanitaria y hostelería, mientras que los equipos directivos de las industrias primarias, más tradicionales, como fabricación, transporte, construcción, inmobiliaria y minería, están compuestos en su mayoría por hombres." (2016, p. 8). 
manera negativa en el acceso de las mismas no solo a estos cargos de responsabilidad, sino en los temas salariales.

En referencia a la administración pública, de acuerdo con ONU Mujeres (2014, p. 1) si bien los avances en la participación política de las mujeres siguen siendo muy positivos en todo el mundo "(...) los techos de cristal continúan firmes para las mujeres en los niveles más altos". Y aunque la participación de las mujeres en los parlamentos nacionales a nivel global se ha duplicado desde 1995, es decir, pasando de un 11,3\% hasta un $23 \%$ en la actualidad ${ }^{24}$, el proceso ha sido muy lento y el resultado insuficiente.

Este fenómeno fue igualmente constatado por la Comisión de Derechos de la Mujer e Igualdad de Género del Parlamento Europeo (2011) quien afirmó que "(...) existe un desequilibrio en la participación de las mujeres y los hombres en la toma de decisiones en los ámbitos político y público, así como una clara insuficiencia en la representación de las mujeres en los cargos políticos".

En la esfera académica ${ }^{25}$, considerado uno de los sectores más feminizados principalmente en la educación básica (Díez et al., 2003) la

\footnotetext{
24 Véase datos actualizados en la entidad Inter-Parliamentary Union, toda la información se encuentra disponible en la sección Women in Parliaments URL: http://www.ipu.org/wmne/world.htm
}

25 No obstante, Arranz describió la comunidad científica (refiriéndose a los que se desempeñan en las áreas de investigación o ciclos muy superiores) no sólo como "numéricamente masculina", sino que, además reconocida como "autoridad masculina". "Es un conflicto con el que tienen que enfrentarse las mujeres profesionales de este medio es el dominio masculino sobre el conocimiento y la práctica científica. Conocimiento y práctica científica androcéntricas que vienen camufladas bajo los principios básicos de la ciencia: racionalidad, neutralidad y objetividad" (2004, p. 238). 
proporción femenina disminuye en los ciclos superiores, o en los cargos jerárquicos mejor remunerados, así lo demuestra el informe de la UNESCO (2015) sobre la educación superior a nivel global, mientras las mujeres superan a los hombres con una proporción del 54\% del alumnado, sólo representan en promedio un $35 \%$ del personal docente ${ }^{26}$.

Según el informe de Centro Interuniversitario de Desarrollo, en adelante CINDA (2015, p. 354) sobre la educación superior en Iberoamérica mostró la discordancia entre el porcentaje de mujeres con doctorado y las que se encontraban trabajando como investigadoras en España, al respecto un $51,84 \%$ estaban doctoradas y un $38,4 \%$ se encontraban trabajando como investigadoras.

Un estudio publicado en Harvard Business Review elaborado por Hansen, Ibarra, \& Peyer (2015) mostró cuales eran los mejores cien CEOs de empresas con excelente desempeño a nivel mundial, es decir, quien ocupa el cargo mas alto en las destacadas empresas multinacionales y, solo un $2 \%$ de mujeres estaban en esa lista versus el $98 \%$ de hombres. Los estudios previos de los mismos autores $(2010 ; 2013)$ mostraron que el porcentaje no ha variado mucho, un $1,5 \%$ en 2010 y un $1,9 \%$ en 2013 . De este modo, se evidencia en un primer acercamiento cuan dificil es el acceso de directivas mujeres a cargos tan importantes.

Sin contar con el hecho, que la información precisa sobre representación de las mujeres en el trabajo en distintos ámbitos y países,

\footnotetext{
${ }^{26}$ Según un estudio de CINDA (2010, p. 95) sobre la educación superior en Iberoamérica en cuanto a la participación de las mujeres en la investigación y el desarrollo "la situación es mejor en lberoamérica que en Europa, ya que en el primer caso se sitúa alrededor del $40 \%$, mientras que en Europa es globalmente del 30\%, con notables diferencias según el sector ( $23 \%$ en empresas y $45 \%$ en entidades de educación superior)."
} 
como, por ejemplo, en los gobiernos locales es actualmente desconocida, lo cual implica una brecha importante de conocimiento y no permite visibilizar la existencia de un fenómeno de discriminación o de participación.

Para describir esta patología del sistema, en la doctrina se ha venido utilizando el término glass ceiling ${ }^{27}$ o techo de cristal en su versión en español, expresión creada en la década de los ochenta para distinguir una barrera invisible que impide a las mujeres cualificadas, como grupo, alcanzar puestos de responsabilidad en las organizaciones en las que trabajan (Molero et al., 2009) siendo una consecuencia natural de los estereotipos de género.

En palabras de Martínez et al. (2009, p. 20) "se alude con esta expresión a la circunstancia, no siempre fácil de explicar, de que alcanzado cierto coto los ascensos profesionales de las mujeres parecen frenarse por una barrera tan invisible -no responde a previsiones legales, ni convencionales, ni a regla perceptible alguna- como infranqueable. $\mathrm{Y}$ el resultado es que a medida que ascendemos en el escalafón jerárquico de las organizaciones, aparecen menos mujeres"

No obstante, Eagly \& Carli (2007) confrontan dicha teoría pues a pesar de que se comprueba el sesgo general contra las mujeres en todos los niveles, el fenómeno de acceso a cargos superiores tiene que ver con la escasez de mujeres, es decir, la suma de la discriminación que ha funcionado en todas las filas, no la evidencia de un obstáculo para el progreso a medida que las mujeres se acercan a la cima. El problema, en otras palabras, no es un techo de cristal.

\footnotetext{
${ }^{27}$ Al respecto, en Estados Unidos en su momento se creó el organismo federal Glass Ceiling Commission, éste definió el glass ceiling como aquellas barreras artificiales basadas en el sesgo de actitud o de organización que impiden que las personas calificadas avancen hacia arriba en su organización en los puestos de gestión. (Cfr. Johns, 2013).
} 
Independientemente de lo anterior, en este contexto, las consecuencias que se generan tanto a nivel individual o social pueden ser adversas puesto que, en el primer caso, dificulta el total desarrollo integral y potencial de una persona, simplemente por el hecho de ser mujer, con la frustración y desmotivación que ello conlleva. En el segundo caso, porque para la sociedad hace que se pierda un importante potencial y recurso de liderazgo ${ }^{28}$ que puede ser aplicable en diferentes ámbitos sociales.

Es por ello que es necesario el aumento de la cantidad de mujeres involucradas en las decisiones políticas, económicas y empresariales, pues cuando se alcanza un número categórico, sus decisiones las cuales toman en cuenta las necesidades de un segmento más amplio de la sociedad, conducen a resultados más incluyentes ${ }^{29}$.

Por otro lado, pero igual de importante, merece especial cuidado la protección a la maternidad, de hecho, Abramo $(2006$, p. 16) insistió en que "la situación actual, futura o probable de la mujer como madre y principal

${ }^{28}$ Es interesante, el planteamiento de Contreras, Pedraza \& Mejía (2012, p. 190) quienes afirmaron que "en muchas sociedades, la definición de un buen líder tiene marcados rasgos masculinos, que van en contravía con las características asociadas a las mujeres, lo cual explicaría por qué, en ocasiones, algunas mujeres que alcanzan altos cargos directivos pueden comportarse de manera más ruda, controladora y menos sensible que lo que harían sus contrapartes masculinos."

${ }^{29}$ El potencial de las mujeres para el éxito económico, se ve reflejado en un claro ejemplo propuesto por Amnistía Internacional: el Comité para el Desarrollo Rural de Bangladesh. "EI Comité se convirtió en la organización de base para el desarrollo más grande del mundo al colocar a las mujeres y las niñas en el centro de sus estrategias contra la pobreza y potenciarlas como agentes activas del cambio. A lo largo de los años, el Comité ha organizado a mujeres y niñas y, con su participación activa, ha introducido, refinado y ampliado vías prácticas para aumentar su acceso a los recursos y apoyarlas como empresarias" (2009, p. 10). 
responsable del cuidado doméstico y familiar, sigue siendo la principal causa de su discriminación en el trabajo".

Esto implica para la situación laboral de las mujeres que la maternidad ${ }^{30}$ o la responsabilidad por su descendencia puede ser un factor relevante, excluyente y decisivo en los procesos de selección, principalmente en cargos de responsabilidad, lo que no sucede del mismo modo con sus colegas hombres, de hecho, según Eagly \& Carli (2007) "el matrimonio y la paternidad están asociados con mayores salarios para los hombres pero no para las mujeres".

Con lo cual, debe quedar claro que las mujeres tienen derecho a no ser discriminadas por factores asociados a su capacidad reproductiva porque esa responsabilidad por el cuidado familiar y de los hijos no debe ser atribuible exclusivamente a ellas.

Paralelamente, hay que conocer que son cada vez más las mujeres que se reintegran al trabajo después de haber dado a luz (Birgin et al., 2000), por lo tanto, habría que garantizar ese derecho de volver a su puesto de trabajo en igualdad de oportunidades y que puedan seguir escalando puestos en las compañías de las cuales hagan parte.

Por último, "reconocer las diferencias entre hombres y mujeres, y a través de ellas lograr la equidad es un reto importante y necesario en el

\footnotetext{
30 En este sentido, hay que resaltar que hoy en día," las mujeres están cada vez menos dispuestas a abandonar su carrera. Aunque la maternidad sigue siendo una parte fundamental de la identidad de género femenina, se observa un importante cambio generacional con respecto a otras épocas, por lo que el aspecto interno de esta barrera actualmente tiene menor peso en la explicación del "techo de cristal"." (Barberá, Estellés \&
} Dema, 2009, p. 138). 
mundo moderno, en el que se reconoce ampliamente la importancia de la diversidad" (Contreras, Pedraza \& Mejía, 2012, p. 191).

\section{(ii.) Planteamiento de la investigación, esquema y precisiones metodológicas}

Ahora bien, sin alejarnos de nuestro objetivo, el texto que aquí se presenta parte de una premisa central ¿por qué es tan minoritario el acceso de la mujer a cargos de toma de decisiones en los diferentes ámbitos sociales? El objetivo principal consistirá en demostrarlo e intentará responder por qué las mujeres no pueden acceder tan fácilmente a cargos de responsabilidad, para ello se profundizará en los beneficios que traería la igualdad y la gestión de la diversidad ${ }^{31}$ en la organización enfocada en términos multidisciplinares, lo cual requiere de los planteamientos que se dan desde distintas disciplinas como la psicología social, el derecho, la sociología, el management, entre otras.

En efecto, para responder dichas inquietudes es preciso indicar la existencia de este fenómeno por lo que será necesario valorarlo durante todo el texto desde dos enfoques, por una parte, el rol de la mujer en el mercado

\footnotetext{
31 Según Barberá (2004, p. 40) "La idea central del concepto de diversidad es el máximo aprovechamiento del potencial ofrecido por grupos heterogéneos, es decir, diversos en cuanto a sexo, edad, etnia, nacionalidad, orientación sexual, etc. Se enfatiza la variabilidad interindividual, de manera que cada persona se valora por lo que es y lo que puede aportar, sea cual sea su procedencia o características personales. En este sentido, la estrategia de la diversidad ofrece a las organizaciones la posibilidad de atraer y mantener talentos diversos representativos de ambos sexos."
} 
de trabajo y, por otra parte, desde las características ${ }^{32}$ y competencias $^{33}$ de la mujer en la dirección, pues no cabe duda la existencia de teorías y especulaciones sobre la forma en que los estilos de liderazgo ${ }^{34}$ varían entre mujeres y hombres.

De cualquier modo, no queda duda que los beneficios asociados a una mayor representación y visibilidad de las mujeres en éste y otros ámbitos de poder acarrearían mejoras en la posición de ellas en la sociedad y en el ejercicio de sus derechos. Así como la participación y el activismo de

32 Por ejemplo, un estudio de Gómez \& Sánchez mostró que dentro de las características que atribuyen los empresarios a las mujeres trabajadoras: "destacan como virtudes el orden, la prolijidad y delicadeza, la disciplina, la tolerancia a trabajos rutinarios, la eficiencia, concentración y responsabilidad, adaptabilidad y capacidad para establecer relaciones humanas, honradez, compromiso y lealtad. Y como defectos la debilidad física; "el abuso", en ciertas situaciones, de una imagen de debilidad; la conflictividad, competitividad y cierta violencia solapada entre mujeres." (2009, p. 121).

33 De acuerdo con Marchant (2005, p. 65) "Las competencias son características fundamentales del hombre e indican formas de comportamiento o de pensar, que generalizan diferentes situaciones y duran por un largo período de tiempo. Una competencia tiene tres componentes: el saber hacer (conocimientos), el querer hacer (factores emocionales y motivacionales) y el poder hacer (factores situacionales y de estructura de la organización)".

34 Tampoco se trata de establecer cual estilo de liderazgo es mejor que otro, sino promover en las organizaciones que el criterio fundamental que habría que aplicar es el del mérito y el hecho de saber hacer un trabajo, y no otras características intrascendentes que son discriminatorias (OIT, 2003, p. 63).

No obstante, se encuentra argumentos en la doctrina, por ejemplo, de Arredondo, Velásquez y de la Garza (2013, p. 162) en el que exponen que "uno de los hallazgos de la participación de la mujer en puestos directivos es la verificación de que ella dirige y toma decisiones de forma diferente al hombre, ya que busca considerar las necesidades del grupo, lo que interviene en sus decisiones de apoyo a las políticas de flexibilidad y diversidad laboral." 
mujeres ${ }^{35}$ en aquellos grupos de interés social y colectivo como, por ejemplo, en programas de mentoría ${ }^{36}$ o, en la negociación colectiva ${ }^{37}$, que no solo mejoraría sino consolidaría la organización pues integraría en mayor medida las consideraciones de género en busca de una representación equilibrada de hombres y mujeres en el ámbito laboral.

Ésta última teoría es reforzada por la hipótesis sobre homosocial reproduction de Kanter (1977) sobre los directivos, en este sentido, se refuerza la creencia de quienes están en posiciones clave 0 de responsabilidad buscan personas con afines características, como por ejemplo, el género o el sexo; este fenómeno es válido por cuanto sabemos que los puestos de responsabilidad en los que se decide la selección y la

\footnotetext{
35 Por ejemplo, en España la Asociación Española de Ejecutivas y consejeras que nació en mayo de 2015 por iniciativa de 110 ejecutivas mediante la participación en un programa ejecutivo de Mujeres en la Alta Dirección, la cual tiene como objetivo incorporar y visibilizar mujeres en cargos de responsabilidad. (https://ejecon.org/)
}

${ }^{36}$ Asimismo, otra herramienta interesante en la construcción de redes de apoyo para las mujeres son los programas de mentoría, Medina-Vicent $(2015$, p. 3) defendió que "el mentoring o mentorización puede ser una herramienta educativa de gran poder a la hora de subvertir dicha situación, ya que permitiría que las pocas mujeres líderes trasladasen sus conocimientos y experiencias a otras mujeres, promoviendo que cada vez sean más las que intenten desarrollar su carrera profesional en la empresa, e incluso ocupar cargos de liderazgo. Una buena mentorización es clave para el desarrollo de cualquier carrera profesional, pero en el caso de las mujeres, su papel es mucho más importante y la necesidad apremiante."

${ }^{37}$ Al respecto, es interesante conocer la posición de Valdés (2010, p. 58) con respecto al aporte de la negociación colectiva, pues consideró que los convenios colectivos han tenido una doble función como generadores de discriminaciones y la vez en promotores de igualdad, en la segunda la forma en la que se "ha intentado combatir las conductas discriminatorias y fomentar la igualdad es ejerciendo "una labor pedagógica"” 
promoción del personal han sido ocupados tradicionalmente por hombres (Carrasco \& Laffarga, 2007) en los que se ha perpetuado y se continua perpetuando en el tiempo.

Por otro lado, la afirmación de que las mujeres no lideran ni dirigen tan bien como los hombres ${ }^{38}$, pues utilizan estilos de liderazgo diferentes ${ }^{39}$ se ha utilizado como una poderosa justificación del porqué las mujeres no acceden a los niveles más altos de la jerarquía organizacional (Cuadrado, Navas, \& Molero, 2006). La intención del texto no consiste en priorizar la forma de liderar de un sexo u otro, ni tampoco menospreciar el talento de los hombres, sino en promover la diversidad en las organizaciones, entendiendo que la exclusión de un segmento igual de importante en la población, en este caso, el talento de las mujeres se está desperdiciando.

Como ya se ha mencionado, en la doctrina se encuentra un volumen de factores explicativos del fenómeno planteado, así se encuentran (i) las variables personales, (ii) las enfocadas en su situación laboral y personal, y

\footnotetext{
${ }^{38}$ Aunque hay investigaciones que refutan esta afirmación, como por ejemplo la de Godoy \& Mladinic (2009, p. 59) dentro de sus hallazgos "la ausencia de diferencias significativas en la evaluación que recibió el hombre gerente y la mujer gerente en el ámbito laboral, y más aún, que ello ocurra con independencia del sexo de los evaluadores. Esta similitud de las evaluaciones se dio tanto en relación a sus habilidades para tener éxito en las tareas encomendadas y lograr los objetivos (Efectividad de Liderazgo) como en las recomendaciones de promoción, contratación y aumentos salariales que reciben (Recompensas Organizacionales)."

39 De acuerdo con Charlo \& Núñez (2007, p. 2592) "las teorías conductuales sobre la organización identifican dos tipos de comportamiento directivo: el autocrático o transaccional y el democrático o transformacional. Ambos se relacionan con estereotipos de género. Así, el primero suele asociarse a características culturalmente relacionadas con lo masculino, y el segundo a lo femenino."
} 
(iii) las que parten de la existencia de un fenómeno de discriminación por razón de sexo.

Aunque, los aspectos socioculturales en los distintos entornos son la principal justificación, de hecho "una de las principales barreras con la que tropiezan las mujeres que quieren acceder a cargos directivos es la cultura organizacional, en la que predominan los valores masculinos y en la que todavía existen prejuicios contra las mujeres" (Barberá, Sarrió \& Ramos, 2000-b, p. 51).

En la misma línea, el planteamiento de Carrillo (2011) que sustentó dichas desigualdades al explicar que tienen su origen en las sociedades capitalistas neoliberales que han reforzado los mecanismos de división y exclusión justificados en las diferencias, lo que ha llevado a obstaculizar la promoción profesional de las mujeres.

De igual manera, como lo resaltó González (1999) la asignación de roles $^{40}$ de género limita y no visibiliza la proyección laboral de las mujeres pues a éstas se les sigue viendo con características diferentes y poco objetivas a la de los hombres, incluyendo la existencia de muchas actividades sociales vinculadas a determinados roles a pesar del cambio ideológico, es por ello que muchas mujeres no se plantean dejar de atender las obligaciones del ámbito doméstico ${ }^{41}$ para poder tener una mayor participación en otros

\footnotetext{
40 Según el Instituto de la mujer (2005, p. 5) "Las formas de comportamiento se concretan a través de roles, que no son otra cosa, que los papeles que se juegan en la vida social. Representan las distintas funciones que ejercemos cotidianamente".

${ }^{41}$ Al respecto, Galindo (2000, p. 33) afirmó que en referencia a las actividades domésticas y familiares que realizan las mujeres "no se encuentran además ni socialmente reconocidas ni mucho menos remuneradas. El trabajo doméstico, que no aparece como un valor expresado monetariamente en el mercado, permanece oculto en tanto trabajo. A tal efecto podemos
} 
ámbitos. Por lo tanto, es sumamente importante que en la visión de una sociedad igualitaria los hombres accedan a roles considerados de tradición femeninos, así como las mujeres a roles masculinos.

Si se analiza a fondo, el tema de los roles de género, se logra observar que ha tenido efectos en el mercado de trabajo (Instituto de la mujer, 2005), por una parte, el acceso y la promoción en el mercado de trabajo, están sujetos a las responsabilidades familiares ${ }^{42}$, por otra parte, a los hombres el mercado de trabajo les demanda mayor disponibilidad, lo que les resta tiempo para la atención del ámbito doméstico, por último, las mujeres y hombres gestionan de forma diferente su vida laboral y familiar, porque no queda del todo claro sus responsabilidades.

Como consecuencia general, podemos señalar que existe una gran diferencia de acceso a los recursos y de desarrollo personal para uno y otro sexo, en función del ámbito en el que nos encontremos. No hay que olvidar que, muchas de las desigualdades proceden de la misma organización patriarcal de la sociedad, es decir, del fuerte arraigo cultural que opera en todas las esferas sociales: en las empresas, en las universidades, en la familia y en otras instituciones, pero no es atribuible a diferencias biológicas entre mujeres y hombres.

Hay que tener en cuenta que los obstáculos a los que se enfrentan las mujeres están amarrados a los estereotipos o las falsas creencias en dichas

afirmar que "las mujeres subvencionan la economía debido a la enorme cantidad de trabajo no remunerado que llevan a cabo"."

42 Esta situación se ve claramente cuando por ejemplo en los procesos de selección, al realizarse entrevistas de trabajo para acceder a un cargo o para ascender dentro de la compañía, a las mujeres es a las que generalmente se les pregunta por el cuidado familiar, cuando sabemos que está responsabilidad debería ser compartida. 
esferas sociales, nada más por poner un ejemplo retratado por Cuadrado, Navas, \& Molero (2006), los autores concluyen que en ocasiones se menosprecia el trabajo de la mujer, pues en la mentalidad de algunos empresarios puede existir la convicción de que solo es un "dulce" para atraer clientes, lo que ocasiona que éstas desempeñen mayor trabajo administrativo y menos estratégico, de esta manera se logra impactar en su situación profesional al impedirles ascender a puestos más altos y ni qué decir de aquellas que se quejan de esta situación.

En efecto, el potencial de la mujer se encuentra subestimado (Groysberg \& Connolly, 2013) e infravalorado (Gregorio \& Ramírez, 2000) pues a las mujeres no se les da la importancia que merecen ya que no se les concibe en la sociedad como una fuente de generación de ingresos en la familia, debido a que su trabajo en el hogar es considerado débil y de poco valor, aunque sea productivo.

Lo que se manifiesta es que el trabajo de la mujer desempeñado por fuera del hogar como asalariada, es considerado más como una ayuda que como lo que es, las mujeres también son productoras de ingresos al igual que los hombres y tienen las capacidades para aportar a la economía de los países.

En cierto modo, el concepto de emprendimiento y liderazgo económico por parte de las mujeres debe transformarse integralmente, pasando de una visión asistencial a una empresarial, los grupos de interés deberían ofrecer habilidades prácticas sobre conocimiento y desarrollo empresarial que son cruciales para el éxito organizacional, pero no basadas en la mentalidad 
convencional pues muchas veces estas últimas refuerzan los estereotipos discriminatorios ${ }^{43}$, deben estar basadas en un nuevo enfoque incluyente.

Este último enfoque con perspectiva de género es valorado recientemente como una oportunidad (ONU Mujeres, 2014), pues acepta la existencia de una relación directa con el desarrollo sostenible ${ }^{44}$, dirigiéndose más allá de un simple imperativo moral y ético, en efecto, no se puede seguir ignorando la capacidad de más de la mitad de la población del mundo, resulta ya indudable el conocimiento que tienen las mujeres y que pueden aportar ${ }^{45}$ en diversos ámbitos sociales.

Justamente, la investigación de Groysberg \& Connolly (2013) mostró la respuesta de ejecutivos a quienes se les preguntó por qué promover la diversidad en las organizaciones era tan importante para ellos, los resultados se enfocaron en una doble justificación: empresarial y moral, por una parte, es necesario para la competitividad de las empresas y por el otro, es un imperativo moral debido a sus experiencias y valores individuales.

Esta idea, es consolidada por la Comisión Europea (2012) quien insiste en la necesidad de integrar positivamente a las mujeres en cualquier tipo de

\footnotetext{
${ }^{43}$ En el trabajo al hablar sobre estereotipos, estereotipos discriminatorios, o los estereotipos de género, significa las creencias que se mantienen sobre cómo son y cómo deberían comportarse las mujeres y los hombres (Fernández, 2002).
}

${ }^{44}$ El desarrollo sostenible ha emergido como el principio rector para el desarrollo mundial a largo plazo (Colom, 2000). Consta de tres pilares, trata de lograr, de manera equilibrada, el desarrollo económico, social y la protección del medio ambiente.

45 De hecho, en la doctrina planteamientos como el de Díez et al. (2003, p. 5) precisan que "si los valores asociados tradicionalmente a las mujeres tuvieran mayor reconocimiento social dejarían de existir guerras, industria armamentística y la cultura machista que domina y conforma el ejercicio del poder habitualmente." 
organización, de hecho, sostiene que, el no contar con una participación equilibrada y justa, equivale a desaprovechar un capital humano calificado presente, lo cual repercute significativamente en la competitividad no solo de las organizaciones sino también de los mercados globales pues no cabe duda, que en este mundo cada vez más complejo e interconectado, la clave del éxito reside en la utilización de todos los recursos sociales y económicos.

En este sentido, refiriéndose a estos mercados Carrasco \& Laffarga (2007, p. 5) corroboraron esa necesidad pues basándose en esa complejidad empresarial es cierto que su gestión "requiere de personas poseedoras de cualidades, habilidades y capacidades necesarias para gestionar adecuadamente en entornos complejos".

Dicho esto, en cierto modo el trabajador -hombre o mujer- se convierte en la fuente imprescindible de ventaja competitiva de las organizaciones (Corral, 2007). De ahí que es necesario dar respuesta a todas las desigualdades planteadas, ya que los trabajadores elegirán trabajar en aquellas compañías que cuenten con una alta gestión y optimización del talento humano, en el cual se garantice políticas que premien realmente el desempeño, el desarrollo de la promoción profesional y la meritocracia ${ }^{46}$; en la que se aproveche el talento de los mejores sin diferenciar si es hombre o mujer y en donde se sientan reconocidos por sus capacidades.

\footnotetext{
46 De acuerdo con Fernández existen diversas concepciones del mérito, en este sentido "Éste se suele asociar a la inteligencia (esto es, al talento, o, de modo más amplio, a las habilidades, capacidades o aptitudes, intelectuales o técnicas, naturales o adquiridas); a la virtud; al rendimiento (achievement), esto es, a la contribución al servicio o beneficio de los demás y al esfuerzo." (2003, pp. 122-123).
} 
A pesar de los beneficios de la diversidad, las empresas aún son poco conscientes de su importancia ${ }^{47}$, para ello, resulta fundamental involucrar a los actores principales en materia laboral para lograr la erradicación y prevención de las desigualdades proyectadas, entendiendo esta preocupación es necesario conocer los avances, así como lo que falta para superar la diferencia existente entre la retórica y la realidad.

Hay que entender que en el fondo "la empresa es una construcción humana más, realizada por y para personas, las cuales consideran que la función de las empresas generadoras de riqueza no tiene que estar reñida con la obtención de un mayor bienestar social." (Carneiro, 2009, p. 63).

Aquí, es donde salta a relucir el papel de los empresarios ${ }^{48}$ y del sector privado $^{49}$, a través de las iniciativas de Responsabilidad Social Empresarial

47 En su momento, Barberá (2004, p. 41) evidenció que "la actual cultura y políticas organizacionales tienden a la creación de entornos no inclusivos de la diferencia humana, dando lugar a equipos homogéneos mayoritariamente masculinos, lo cual, a largo plazo, provoca ineficacia y pérdida de competitividad y adaptación a la sociedad global actual."

${ }^{48}$ Se ha puesto de manifiesto que "las empresas siguen sin dar respuesta a las necesidades personales de los profesionales y en concreto de las mujeres, que quieren desarrollar carrera profesional, a pesar de la introducción cada vez más extendida de los programas de flexibilidad. Posiblemente esta falta de ajuste entre las necesidades personales y las políticas organizativas ha causado en parte la marcha de muchas mujeres con talento, así como el efecto "techo de cristal"." (Cabanas, Morales \& Molinero, 2014, p. 41). Con lo cual, es una buena oportunidad para que desde la responsabilidad de las empresas se logre dar respuesta a dichos desafíos.

49 En este sentido, es válida la posición de Giner al afirmar que las empresas en general y en particular las multinacionales "actúan como «personas» o «agentes morales» que, por tanto, son responsables morales de las acciones que llevan a cabo en el ámbito social, al igual que lo son las personas reales. Además, tienen la responsabilidad social de proteger 
[RSE] que en palabras de Martínez, Guilló, Santero, \& Castro (2011, p. 8) empieza con "(...) el respeto por la dignidad y los derechos de los empleados y demás implicados por la actividad empresarial (...)" en este sentido, se logra apreciar por primera vez, la relación existente con la igualdad de oportunidades para poder afrontar este problema social.

Si se observa las iniciativas, acciones, programas y políticas que se adoptan por las organizaciones, a través de sus políticas de Responsabilidad Social ${ }^{50}$ se puede demostrar que existe un sinfín de formas en que las empresas pueden contribuir al avance de la autonomía de las mujeres en todo el mundo, por ejemplo, con programas de apadrinamiento de mujeres ejecutivas, la creación de bases de datos de posibles mujeres consejeras, o incluso, mediante el asunción voluntaria de cuotas (Gómez \& Sánchez, 2009).

Es por ello, que en España con la Ley Orgánica 3/2007, de 22 de marzo, para la Igualdad Efectiva de Mujeres y Hombres [en adelante, LOIMH] se abrió un espacio a las empresas para la asunción voluntaria de acciones y compromisos en materia de responsabilidad social, que busquen promover unas mejores condiciones de igualdad entre las mujeres y los hombres en el seno de la empresa o en su entorno social.

Así, ésta ley en su Título VII propone tres preceptos multidisciplinarios básicos en los que la empresa debería enfocarse: las acciones de responsabilidad social en el ámbito de la igualdad en el ámbito laboral, la

los intereses del pueblo local con el que trabajan y promover el bienestar de la región en la que están operando" (2008, p. 72 ).

${ }^{50}$ Al respecto, por ejemplo, un estudio de Arredondo, Velásquez y de la Garza (2013, p. 166) concluyó que la mujer "por sus características de género, es quien impulsa políticas internas de RSE vinculadas a la diversidad y a la flexibilidad laboral. En ella reside una importante fuerza motora para detonar estas prácticas de RSE interna". 
comunicación de las acciones de responsabilidad social y, la representación equitativa y participación de las mujeres en los consejos de administración de las sociedades mercantiles, insistiendo en que la incorporación deba hacerse por talento y rendimiento profesional y no de factores discriminatorios.

En este sentido, los consejos de administración pueden hacer la diferencia en términos de establecer apoyo para el liderazgo y la autoridad de las mujeres. Cuando la diversidad es importante para esta entidad, se vuelve importante para la empresa.

También se observa que con la Ley $2 / 2011$, de 4 de marzo, de Economía Sostenible, se buscó la promoción de la responsabilidad social de las organizaciones, comprometiendo a las Administraciones Públicas a mantener una política basada en la responsabilidad social, difundiendo su conocimiento y las mejores prácticas existentes lideradas por las empresas; estimulando la investigación sobre los efectos que tiene en materia de competitividad empresarial.

Por todo lo anterior, partiendo del ideal de contar con organizaciones socialmente responsables ${ }^{51}$, la elección como el desarrollo del tema, llevan a estructurar a partir de la igualdad un marco que desde una dimensión interna ${ }^{52}$, equipare no sólo el respeto por el derecho fundamental de la

\footnotetext{
51 Una de las recomendaciones a las empresas con respecto a la igualdad de género de la CEPAL et al. (2013, p. 221) sustentó que "perfilarse como una empresa que apoya la igualdad de oportunidades es determinante para lograr una buena imagen pública. Esto es parte de la tendencia a la promoción de empresas socialmente responsables, un sello institucional que permite atraer clientes, potenciales trabajadores y mejorar las relaciones con otras compañías y la administración pública."

52 Esa dimensión interna debe partir por "la aplicación de la perspectiva de género (mainstreaming de género) y la valoración del potencial ofrecido por la diferencia (gestión de
} 
igualdad pensado, por y para las relaciones laborales ${ }^{53}$, sino para que a través de dicha igualdad, en las organizaciones privadas y públicas exista como política interna, la eliminación de todo tipo de desigualdades y la evaluación del impacto de género ${ }^{54}$. En este sentido, la dimensión interna corresponde principalmente a los trabajadores y directivos, los cuales son sujetos de la investigación al establecer la relación entre la Igualdad y la RSE.

De hecho, en el marco del compromiso ético de las organizaciones, como una decisión voluntaria, la RSE está en la búsqueda de la integración de aspectos económicos, así como con aspectos sociales y ambientales. En efecto, el respeto de la igualdad y la diversidad favorecen la apertura de la empresa a su entorno, consiguiendo legitimidad ante sus grupos de interés,

la diversidad) se combinan para lograr la reorganización de las prácticas y políticas organizacionales hacia la creación de un espacio donde la aportación femenina pueda desarrollarse en igualdad de condiciones." (Barberá, 2004, p. 41).

53 De hecho, según la OIT "El principio de la igualdad en el trabajo implica que todos los individuos deben tener las mismas oportunidades para adquirir plenamente los conocimientos teóricos y prácticos y la formación y capacidad que se requieren para las actividades económicas que deseen llevar a cabo" (2003, p. 64).

${ }^{54}$ La evaluación del impacto de género según Fundación MUJERES (2008, p. 43) se refiere "al análisis realizado con el objetivo de identificar qué efecto puede tener en mujeres y en hombres una decisión que se vaya a tomar en cualquier área de gestión. Trata de dar respuesta a: ¿Se beneficiarán mujeres y hombres de la misma manera? Es decir, busca profundizar en los efectos de una decisión que aunque parezca neutra puede provocar un mayor desequilibrio entre mujeres y hombres, tanto de carácter cuantitativo como cualitativo. En la gestión de los recursos humanos de una empresa resulta especialmente útil pues permite prevenir decisiones y actuaciones erróneas desde el punto de vista de la igualdad de oportunidades y que sólo serían visibles una vez desarrolladas." 
lo cual, de paso le proporciona un plus, así como una mayor flexibilidad y capacidad de adaptación a los cambios (Castro \& Álvarez, s.f.).

En este sentido, la preocupación por promover la diversidad en las organizaciones consiste en un "proceso de selección, incorporación y gestión de grupos de personas que se distinguen de acuerdo con distintos factores como la edad, el sexo, la etnia, la procedencia, sus actitudes, sus conductas, sus expectativas, sus hábitos, sus motivaciones, entre otras características propias" (López, 2011, p. 63). Dicho enfoque busca el compromiso de convertir esa diversidad en una fuente de motivación, crecimiento y desarrollo para las personas y para la propia organización.

Y es que como se sustentará en los capítulos posteriores, la RSE tiene dentro de sus objetivos la consecución de la igualdad, intentando en lo posible ofrecer unas condiciones de trabajo en las que haya igualdad efectiva, incidiendo en la medida de las necesidades en ( $(i)$ el sistema de selección y contratación ${ }^{55}$ en (ii) la promoción, en (iii) el sistema de retribuciones, en (iv) la formación, en $(v)$ la conciliación de la vida profesional, familiar y personal, entre otros muchos más aspectos.

La búsqueda de la igualdad y el fomento de la diversidad son los cimientos de la RSE, y las empresas se han convertido en el lugar donde se

\footnotetext{
${ }^{55} \mathrm{Al}$ respecto, hay que tener en cuenta los cambios en los modelos de contratación laboral pues de acuerdo con López \& Santos $(2013,164)$ "han ido cambiando con el tiempo y en el momento actual en el que nos encontramos la seguridad y estabilidad en el empleo no se asocia necesariamente en términos de "puesto fijo en la misma empresa para toda la vida" sino que debemos aspirar a modelos de flexibilidad y seguridad en el empleo (conocidos como flexicurity), en los que el Estado juega un papel fundamental al garantizar una seguridad básica en las relaciones de trabajo de los ciudadanos, hombres y mujeres."
} 
propicia la lucha contra las desigualdades, no solo como una necesidad ${ }^{56}$ moral sino empresarial. En este sentido, la igualdad se ha ido incorporando en la gestión empresarial, como un proceso continuo para asegurar la supervivencia futura a través de una estrategia que consiste en la preocupación por su capital humano. A través del potencial que tiene poseer equipos diversos ${ }^{57}$, por ello es que cada vez más los departamentos de gestión humana en las compañías deben trabajar para que la diversidad forme parte de su cultura organizacional (Abay Analistas Económicos y Sociales, 2011)

Para ello, es necesario la evaluación de las políticas de gestión humana en las organizaciones, lo que implicará además evolucionar de organizaciones mono-culturales a multiculturales como estrategias de desarrollo organizacional (Cfr. Marchant, 2005, pp. 88-91), esto significa la integración ${ }^{58}$ plena de la diversidad en la estructura empresarial a través de la gestión equilibrada de la diferenciación y la integración.

\footnotetext{
${ }^{56}$ En este sentido, la igualdad de oportunidades es un "buen negocio" porque permite no solo cumplir con la legislación vigente, sino optimizar los recursos humanos de la organización y consolidar la Responsabilidad Social Corporativa (Fundación MUJERES, 2008)

${ }^{57}$ El informe de Catalyst (2015-b, p. 3) sugiere que los equipos diversos son buenos para los negocios y la sociedad. Las empresas con mujeres y hombres en los consejos de administración están mejor equipados para supervisar las acciones corporativas y garantizar que se cumplan y se superan. Lo cual repercute en la construcción de empresas más fuertes y más sostenibles.
}

58 Al respecto, "sea cual sea la parte que proponga la integración de la igualdad de oportunidades en la organización, el éxito de ésta dependerá de la negociación con cada una de las otras partes para obtener el consenso, compromiso y voluntad. No es cuestión de "obligar" a una nueva gestión, el éxito de la iniciativa requiere el compromiso y el convencimiento de cada una." (Fundación MUJERES, 2008, p. 19). 
Pues tal como lo plantea López (2002, p. 133) "No cabe duda, por tanto, que la formación y el fomento de la cultura ética en las organizaciones es el factor clave del éxito, ya que sin el compromiso de las personas que de verdad mueven las compañías, de verdad es muy difícil."

Sin olvidar que, "la dimensión de género en el manejo del talento es crecientemente importante para una variedad de corporaciones alrededor del mundo" (Maxfield, Cárdenas \& Heller, 2008, p. 248) la cuestión de fondo y lo más difícil es la interpretación del contexto cultural de las diferentes regiones, que tienen un alto impacto en las desigualdades en el mercado de trabajo.

Así pues, la intención de esta tesis doctoral es analizar la situación actual de las mujeres en el mercado de trabajo, tomando en consideración el derecho del trabajo, para demostrar que éstas todavía son víctimas de situaciones de discriminación en el empleo y la ocupación realizando una especial referencia al acceso de las mujeres a los cargos de responsabilidad mediante una revisión teórica. Es por ello que este trabajo analizará las diferentes desigualdades que se dan en las organizaciones, a partir del acceso al empleo (inclusión laboral), teniendo siempre como punto de mira, el desarrollo de la relación laboral que incluye la integración de la igualdad dentro de la cultura de las organizaciones.

Ahora bien, será necesario entender de qué manera los diferentes grupos de interés ${ }^{59}$ están contribuyendo a la eliminación de las barreras que impiden la igualdad de oportunidades, por lo que se adoptará el enfoque que

\footnotetext{
59 De acuerdo con Cabanas, Morales \& Molinero (2014, p. 42) "la responsabilidad de mejorar la representación femenina en la Alta Dirección no es exclusivamente de las empresas. El gobierno tiene también a su disposición medidas que pueden afectar positivamente a la diversidad de género, como los incentivos fiscales o el apoyo en el cuidado de los hijos o en las bajas de maternidad."
} 
se da desde la responsabilidad social en las empresas, lo cual en principio favorece el ambiente laboral que permite la igualdad de oportunidades en el trabajo, todo ello, sin olvidar además el papel que juega el desarrollo de políticas públicas a favor de este objetivo.

De hecho, estos cambios se fundamentan en un aspecto denominado "corresponsabilidad social" en "la que intervienen los diferentes agentes sociales, cada uno de ellos, asumiendo y desempeñando un papel determinado y participando en el desarrollo de diferentes medidas y estrategias dirigidas a buscar la armonía entre los intereses y las necesidades de las personas, mujeres y hombres." (Fundación MUJERES, 2010, p. 4). Estos agentes sociales, son las administraciones públicas, las empresas, los sindicatos, la ciudadanía en general entre otros.

Sin embargo, como se mencionará será imprescindible un cambio cultural estructural para combatir de raíz las desigualdades señaladas. Lo anterior, pues no cabe duda que, con la actual crisis económica ${ }^{60}$, se ha dado lugar a un mayor riesgo de discriminación contra ciertos grupos sociales.

En este punto, es necesario resaltar que tanto mujeres como hombres sufren de manera diferenciada los efectos de las coyunturas económicas.

60 Sobre las crisis, es importante traer a colación en este punto una investigación de Glass \& Cook (2016, p. 60) en el cual analizaron las condiciones bajo las cuales las mujeres son promovidas a posiciones de liderazgo y los desafíos que enfrentan post-promoción, en este sentido, uno de los desafíos que enfrentan las mujeres en ambientes dominados por los hombres las lleva a buscar posiciones de mayor riesgo para demostrar su temple como líderes, es decir, se erigen como gerentes de crisis y agentes de cambio con lo cual concluyeron que "las mujeres CEOs tienen más probabilidades que los hombres de ser nombradas en empresas que están luchando, con asignaciones de alto riesgo o son nombradas para posiciones de alto riesgo, o son promovidas a posiciones que son extremadamente arriesgados." 
Según Galvés \& Rodríguez (2012) esta situación se debe a que ambos ocupan una posición diferenciada, en la mayoría de los casos desigual y desequilibrada en el acceso a los recursos económicos incluyendo el empleo.

El error está en creer que las necesidades familiares y responsabilidades son solo de las mujeres también son de los hombres. Al igual que ellas, los hombres también tienen preocupaciones por los hijos y esto les puede afectar mientras trabajan. En este sentido, los sentimientos no son sexistas por lo que jugará un papel importante la conciliación de la vida laboral y personal.

No se está de acuerdo tal como lo planteó Cuadrado, Navas, \& Molero (2006), al afirmar que los hombres, nunca se enfrentaban a este dilema, ni se esperaba que lo hicieran, pues aunque se supone que las mujeres siempre han demandado mejores programas de conciliación de la vida familiar y personal para su desarrollo y promoción profesional, también los hombres son los que cada vez más, exigen más flexibilidad y equilibrio en sus vidas (Kolhatkar, 2014).

Esta tesis doctoral también intentará demostrar que las desigualdades más fuertes en el ámbito laboral se encuentran en el acceso de la mujer a puestos y cargos de responsabilidad, independientemente del sector económico en el cual se encuentre; evidenciar además que la discriminación múltiple es un fenómeno que pasa desapercibido y, señalar que la RSE ha contribuido positivamente dentro de lo que cabe a una mayor transparencia, en cuanto a datos y acciones para promover la igualdad de oportunidades.

Por lo que, para el análisis de este problema, la tesis doctoral está estructurada de la siguiente manera, en el primer capítulo se realizará un pequeño acercamiento histórico del origen de las desigualdades y la evolución de la incorporación de las mujeres en el mercado de trabajo. 
Durante el desarrollo de la tesis doctoral se irá aportando los conceptos claves al hablar sobre las desigualdades, el trabajo y el género. Asimismo, se realizará un acercamiento normativo para conocer la legislación aplicable al tema de discriminación laboral por razón de sexo y género mediante un recorrido a nivel internacional, comunitario europeo, pero siempre aterrizándolo a la situación de España.

Posteriormente, en el segundo capítulo se analizará las diferentes situaciones de desigualdad a las que se enfrentan las mujeres, mediante una revisión teórica y proporcionando estadísticas de la proporción de mujeres sobre hombres en los cargos superiores cuyas fuentes son oficiales en el ámbito público (político) y el académico (educación superior). También se abordará muy brevemente las diversas formas de discriminación en el trabajo como la brecha salarial y la discriminación múltiple.

En el tercer capítulo se analizará la situación de la mujer a puestos de toma de decisiones y de responsabilidad en las empresas del IBEX35 en España, principalmente en los consejos de administración, a través del análisis de los resultados proporcionados, se pondrá de manifiesto la importancia de la actuación de los diferentes actores sociales, principalmente las empresas y el gobierno, como impulsores clave de la igualdad de oportunidades.

Se insistirá como se ha dicho, en el papel de las empresas, a través de una mayor responsabilidad social e implementación de acciones preventivas, además del fortalecimiento jurídico que permita garantizar la igualdad real por ejemplo a través de mejores políticas públicas transversales en pro de este objetivo y en donde juega un papel fundamental la 
administración pública, todo ello sin dejar de lado, la educación ${ }^{61}$ como eje cardinal para el cambio de esta realidad.

Por eso, en el capítulo cuatro se realizará un acercamiento conceptual del concepto de responsabilidad social empresarial, seguidamente el papel que juega este concepto en la consecución de la igualdad en las organizaciones, y como está incorporada la igualdad de oportunidades entre mujeres y hombres en las distintas iniciativas internacionales. Asimismo, se proporcionará las prácticas que en esta materia están realizando las empresas, principalmente las del IBEX 35 así como otro tipo de programas nacionales e internacionales que promueven la igualdad en las organizaciones.

En este sentido, hay que tener en cuenta que los instrumentos proporcionados implican el desarrollo de iniciativas más allá de lo legalmente exigido con lo cual se aporta a la lucha contra todas las desigualdades que se analizarán a lo largo del texto.

Seguidamente, como un apartado especial se mostrarán los resultados de una investigación realizada sobre el acceso de las mujeres en cargos de toma de decisiones de las empresas que cotizan en la Bolsa de Valores de Colombia, esto se realizó teniendo en cuenta el origen nacional de la autora. Por último, se finalizará con una serie de recomendaciones y retos en materia de igualdad en el trabajo a modo de conclusiones.

61 De hecho, en España la LOIMH contempla dentro de sus acciones administrativas, la educación como parte necesaria, de igual manera, integra el principio de igualdad en la política educativa, así como el fomento en la educación superior a través de la investigación. Según el artículo 23 "el sistema educativo incluirá, dentro de sus principios de calidad, la eliminación de los obstáculos que dificultan la igualdad efectiva entre mujeres y hombres y el fomento de la igualdad plena entre unas y otros." 
El aporte de esta tesis doctoral comprende una revisión teórica y doctrinal, que será complementado con la evidencia del difícil acceso de la mujer a cargos de responsabilidad y toma de decisiones en los diferentes ámbitos explorados, aunque también se mostrará aquellas que han logrado derrumbar el techo de cristal, lo cual representa una oportunidad y un desafío para aquellas que están en ese camino y que al final, como en todo, romper esas barreras, aunque es un camino difícil no resulta imposible. 
Capítulo Uno. Acercamiento histórico, conceptual y jurídico. 


\subsection{Perspectiva histórica: las mujeres y el trabajo.}

Los periodos historicos marcaron el papel variable que desempeñó la mujer en las sociedades, caracterizados por los fluctuantes avances y retrocesos de la relación existente entre el trabajo y el género, por tanto no queda duda que en la historia se encuentra parte de las razones del porqué las mujeres no pueden acceder tan facilmente a cargos de poder ${ }^{62}$. De manera que, en los inicios, es decir, desde epocas pasadas se encuentra una vinculación del trabajo femenino especificamente con labores domesticas como la reproducción de la prole y los trabajos manuales ${ }^{63}$

Aunque eso no quiere decir, que no se encuentre en la historia representaciones femeninas que se hayan destacado por su relación con el poder. De hecho, se puede rescatar el papel que cumplieron algunas mujeres y que con el paso del tiempo quedaron grabadas en el desarrollo de las sociedades de esas épocas hasta nuestros días.

Es el caso, por ejemplo de la Edad Antigua, Monroy (2013) resaltó el rol de tres mujeres: (i) Hatshepsut, reina-faraón de la dinastía XVIII de Egipto,

62 Con respecto al poder en sí, muy acertadamente el autor Foucault previamente esquematizó lo que, en nuestras sociedades actuales, son las instituciones creadas para regular la vida de los individuos, ya sean hombres o mujeres, en este sentido se ejerce a través de cuatro funciones: el control del tiempo de los individuos, el control del cuerpo, el micropoder económico, político y judicial y, el poder epistemológico. (Vizcarra, 2005, p.14), quienes toman las decisiones influyen en dichos aspectos. Se parte, de la exclusión de las mujeres del poder.

63 Los principales trabajos desempeñados por las mujeres eran tareas artesanales llevados a cabo en el lecho de la economía doméstica tales como la elaboración de productos de alimentación básicos, hilaban, tejían y confeccionaban la ropa, recogían y transportaban el agua. Era antinatural, que ellas impusiesen autoridad o mandaran. 
fue la mujer que más tiempo estuvo en ese trono a través de alianzas con los sacerdotes, se le reconoce además por ser alentadora de grandes obras arquitectonicas del antiguo Egipto; (ii) Cleopatra VII, siendo la última reina del antiguo Egipto, hablaba varios idiomas e instruida en distintos campos, estuvo muy de cerca con el poder y, (iii) la virgen María, que más alla de su historia como la madre de Cristo tiene un fuerte componente religioso.

Ahora bien, sin alejarnos del tema, a nivel general la discriminación ha sido una constante en las sociedades patriarcales (Kahale, 2013, p. 15) donde han sido los hombres quienes han accedido por derecho natural al poder y las mujeres ignoradas y marginadas. Acto seguido, la nulidad absoluta de poder legal y económico, pues no hay que olvidar que en esta época histórica e incluso más adelante, en el terreno de los derechos. "la mujer permanecía durante toda su vida como una menor. En el momento de su casamiento pasaba de la tutela de su padre a la de su marido y, si quedaba viuda, a la de su hijo." (González et al.,1992, p. 24).

Igualmente, con una tendencia al interior en contraposición al mundo exterior, de hecho, por poner un ejemplo, en Atenas el nacimiento de los hijos tenía un significado diferente para cada uno de los sexos, pues la bienvenida era simbolizada por objetos particulares, en efecto desde ya, era claro "el oscuro trabajo que aguardaba a la niña y de la brillante carrera que se esperaba del otro."

Si bien es cierto que en la historia ha primado la fuerza fisica, consecuencia de ello es que los hombres eran quienes y han dominado el mundo, además quienes tenian acceso directo y gozaban de actividades consideradas nobles, porque eran aparentemente los mas "capaces" especialmente en la política, la filosofia y el arte. 
Posteriormente, durante el periodo monárquico, las mujeres eran excluidas de toda decisión económica pues los hombres como jefes de la economía doméstica eran los únicos titulares de los derechos sobre las personas (mujeres, hijos y esclavos), de los bienes y de las obligaciones jurídicas, es decir, "sólo el hombre existía" al menos jurídicamente hablando.

En la República, con el desarrollo de la propiedad individual, las mujeres participaban en el comercio y gozaron de mejores actividades antes impensables debido a las fortunas mobiliarias de la epoca (González et al. 1992, p. 27). En este sentido, con cierta capacitación jurídica podian optar por ejercer acciones de compra, venta, especulación y préstamos monetarios, lo que les permitió rapidamente acceder a profesiones como la abogacía, no obstante, era evidente que éstas lo hacian muy bien por lo que mas adelante se les negó la posibilidad de ejercer cualquier clase de actividad judicial.

Sin embargo, durante la Edad Media, epoca que ha sido considerada negra para las mujeres debido a sus condiciones juridicas desfavorables ${ }^{64}, \mathrm{y}$ con la instauración del regimen señorial, vigente por los siglos venideros, se muestra la dependencia jerárquica entre los grandes propietarios, el campesinado con tierras y sin tierras; los últimos destinados a la servidumbre y a la esclavitud. Por lo que también era visible, en el proceso del trabajo cierta organización entre sexos, así: “... las mujeres trabajaban siempre bajo la autoridad permanente del padre, del marido, del hermano...Ellas no eran

\footnotetext{
${ }^{64}$ Los trabajos desempeñados por las mujeres campesinas eran especialmente duros y abarcaban todo tipo de labores agrícolas en campos y pastizales compartidos con los hombres: siembra, siega y cosecha, cuidado del ganado, entre otros. No obstante, adicionalmente eran las encargadas de las labores domésticas como la búsqueda de agua, los cuidados familiares, la alimentación del hogar, y la confección de los vestidos.
} 
dueñas del producto de su trabajo, no controlaban la utilización o distribución que se haría posteriormente de tal producto" (González et al. 1992, p. 30).

Es por ello, que las mujeres alcanzan a ser contratadas para todo tipo de labores por ser mano de obra barata, abundante y moldeable, principalmente en el trabajo agricola, textil y de labores domesticas en haciendas señoriales, todo ello de acuerdo con la temporada anual, lo que les permitia contribuir a mejorar la economia familiar, aunque sus posesiones los administrara directamente su marido, incluso después de morir, pues se excluía a las mujeres la posibilidad de heredar. Hay que aclarar en este punto que no todas las categorias de mujeres gozaban de los mismos derechos, es el caso de las monjas, quienes tenian una autonomía muy superior a la que poseía el resto.

Al final del periodo medieval, se producirá un desarrollo del comercio, los gremios y las ciudades surgiendo la burguesía como nueva clase social cuya base economica ya no era la tierra. Por lo que será una epoca considerablemente productiva para el acceso de las mujeres al mercado laboral, aunque en distinto grado dependiendo de su clase social, con una división sexual del trabajo delimitada y con salarios inferiores ${ }^{65}$ en todos los aspectos, es decir, nunca en igualdad de condiciones que los hombres, asi como la existencia de trabajos excluidos y marginales. Se encuentra entonces, los oficios tradicionalmente femeninos como los desempeñados en la industria textil; en la producción y venta de productos varios; curanderas y,

\footnotetext{
${ }^{65}$ En referencia a estas diferencias salariales entre sexos, de acuerdo con González et al. (1992, p. 34), la proporción del salario de mujeres sobre el de los hombres fue variable de acuerdo a las epocas históricas y estuvo en decadencia a medida del paso del tiempo, así, se estimó que la representación fue de un $80 \%$ en el siglo XII, un $75 \%$ en el siglo XIV y un $50 \%$ en el siglo XV.
} 
la prostitución, en definitiva, nada alejado de las costumbres históricas: sus labores domésticas.

Con el Renacimiento, las mujeres progresivamente fueron apartadas y expulsadas del trabajo y mas encaminadas a las funciones del hogar, se les descarta de la formación profesional y se desmejoran sus condiciones laborales, economicas y jurídicas sobretodo en lo que respecta a las sucesiones, por lo que la división sexual resulta especialmente marcada: las mujeres heredan el mobiliario y los hombres las tierras.

En el caso de la profesión de las mujeres curanderas (también llamadas en una epoca brujas), cuyos conocimientos tradicionales fueron adquiridos con la experiencia y el traslado por generaciones, éstas se vieron marginadas y perseguidas por sus homólogos masculinos pues ellos crearon el nuevo oficio de médico que si era validado, protegido y reconocido en la sociedad, sobretodo en las mejores clases sociales.

En la Edad Moderna, o a partir del siglo XVIII66 ocurren una serie de hitos y transformaciones que marcaron la sociedad actual $y$ en donde comienzan a reivindicarse paulatinamente los derechos laborales de las mujeres perdidos previamente, el incremento del poder del Estado, el progreso de la burguesía, la disminución progresiva del poder de la Iglesia, la

66 De hecho, en este periodo según Varela (2008) "El feminismo ya nació siendo teoría y práctica. Además de los escritos de Olimpia de Gouges y Mary Wollstonecraft, muchas mujeres en aquella época comenzaban a vivir de forma distinta, cuestionando su reclusión obligatoria en la esfera doméstica. Las propias teóricas, De Gouges y Wollstonecraf, eran mujeres que no acababan de encajar en su época por la forma de vida que tuvieron. Pero junto a ellas, en la Francia del siglo XVIII, las mujeres fueron activas en todos los campos y crearon los salones literarios y políticos donde se gestaba buena parte de la cultura y la política del momento." 
revalorización del trabajo como fuente de riqueza, la revolución francesa entre otros acontecimientos marcaron este periodo (González et al, 1992).

Con respecto a la familia, los hombres con una posición social resaltan el papel de sus esposas como mantenidas, para ello, las exhiben de un modo caracteristico y aunque las eximen de las tareas relacionadas con el cuidado familiar, éstas deben continuar con su función de incrementar la descendencia y, de la dedicación exclusiva por y para el marido. Es por ello, que la vida laboral pública y privada estaría garantizada solo para el hombre, no obstante, si hubo mujeres que opusieron resistencia a tales cambios, y se enmarcaron en la informalidad en los sectores tradicionalmente femeninos que ocupaban.

Con el capitalismo, además surgió la definición de salario justo con la idea de que con esta remuneración, a los hombres les alcanzaría para sostener a su familia, por lo tanto el sistema que no lograse este objetivo era considerado injusto.

Durante este periodo, las mujeres sufrían condiciones de trabajo deprorables mediante jornadas extensas de labores principalmente, en la agricultura, el trabajo doméstico y a domicilio. Muchas mujeres buscando mejorar su realidad social o simplemente para sobrevivir, emigraron de las zonas rurales a las urbanas, accediendo a $\operatorname{trabajos}^{67}$ en condiciones

\footnotetext{
${ }^{67}$ Dentro de los trabajos desempeñados por la mano de obra femenina en las zonas urbanas se encontraban: los servicios de aseo general en locales públicos, los de preparación de alimentos y de servicio en cantinas, bares o cafés, venta ambulante, vendedoras de bienes, enfermeras, entre otros. Estos oficios eran considerados "tareas subalternas, sucias, monótonas o mal pagadas" (González et al., 1992, pp. 52-54)
} 
precarias como la servidumbre doméstica, o, en el mercado de nodrizas ${ }^{68}$; además en esta epoca fue especialmente relevante que las mujeres no se pudiesen afiliar a un gremio porque era prohibido. No obstante, con el creciente desarrollo de la industria, se crearon además nuevos oficios para las mujeres pero no alejados de su función en el interior del hogar, los relacionados con el encaje y el bordado.

La revolución francesa, acontecimiento que originó la evolución de los derechos laborales de la epoca actual sirvió de gancho para el reclamo de mejores condiciones de trabajo de miles de trabajadores y trabajadoras. Por ejemplo, la exigencia de al menos algunos oficios reservados para las mujeres, como la industria textil, teniendo en cuenta que la mayoría de la población evoluciona de las labores agricolas a la industria, es decir, los productos y servicios manufacturados.

Poco a poco se va dejando atrás, las labores domésticas de las mujeres para situarse en nuevos sectores como las fábricas y las oficinas, con condiciones laborales claramente marcadas entre sexos principalmente el salario, llegando a ser "... por término medio, menos de la mitad que un hombre en el mismo trabajo" además del trabajo infantil, sumado al hecho que, legalmente seguían siendo propiedad del hombre, pues necesitaban de su autorización para ejercer un oficio.

68 De acuerdo con Martínez, la nodriza como una figura del servicio doméstico "es una mujer que amamanta a un lactante que no es su hijo, hoy en desuso en la mayor parte de Occidente, el empleo de amas de cría se remonta a la Prehistoria y fue común hasta el siglo XIX para alimentar a niños cuyas madres no podían o no deseaban hacerlo." (2014, p. 12). Durante casi más de tres siglos, muchos niños fueron criados por nodrizas, las cuales podían recibir una compensación mucho mayor en comparación con otros oficios femeninos de la época (2014, p. 20) 
Ahora bien, este periodo fue de vital importancia para la adquisición de los futuros derechos de las mujeres, pues en respuesta a la prohibición previa de asociación en los gremios, éstas se constituyeron en colectivos muy bien organizados para la defensa de sus intereses, se está hablando de la visión de la corriente feminista o el feminismo69. Es decir, muchas mujeres en la busqueda de su supervivencia desecharon la pasividad y se convirtieron en lideres activas del cambio a través de las asociaciones.

De hecho, en palabras de Varela el feminismo cuestionaba el orden establecido, el cual "está muy bien establecido para quienes lo establecieron, es decir, para quienes se benefician de él.". En este sentido, "ellas, las que defendieron que esos derechos incluían a todos los seres humanos -también a las humanas-, terminaron en la guillotina mientras que ellos siguieron pensando que el nuevo orden establecido significaba que las libertades y los derechos sólo correspondían a los varones." $(2008$, p. 1)

También, en el siglo XIX crece con fuerza la teoria defendida por la mayoria de los hombres contra el empleo femenino en el que, las mujeres no debían acceder al trabajo remunerado porque descuidaban sus obligaciones familiares y deberes "naturales". Es decir, comienza en la sociedad ha crecer el ideal de la incompatibilidad de ambas labores por parte de las mujeres

\footnotetext{
69 Según de Miguel (2003, p. 131) "La teoría feminista es, ante todo, una teoría crítica de la sociedad (...) La teoría, pues, nos permite ver cosas que sin ella no vemos, por lo que, en este sentido, el acceso al feminismo supone la adquisición de un nuevo marco de referencia, "unas gafas" que muestran a menudo una realidad ciertamente distinta de la que percibe la mayor parte de la gente."
}

Asimismo, según la autora es crucial "que las mujeres lleguen a deslegitimar "dentro y fuera" de ellas mismas un sistema que se ha levantado sobre el axioma de su inferioridad y su subordinación a los varones." (de Miguel, 2003, p. 132). 
como excusa, y en el que se deberia dar prioridad a la maternidad, el cuidado de sus propios hijos.

La lucha contra la exclusión femenina en el mercado de trabajo ${ }^{70}$ fue dura y desarrollada por los trabajadores masculinos a través de los sindicatos mediante los mecanismos convencionales como la presion social y las huelgas, pero especialmente con la legislación a favor de los hombres que buscaba una desmejora continua de las condiciones laborales del empleo femenino, como por ejemplo en la reducción legal de las jornadas de trabajo para motivar a que los empresarios no las contratasen.

Pero las mujeres asalariadas no se quedaron atrás ante esta situación, con la creación de diversas organizaciones sindicales femeninas especializadas y agrupadas entre sí efectuaron diversas huelgas con especial relevancia en este periodo, obviamente ellas pedian que se reivindicaran sus derechos laborales en igualdad de condiciones a sus colegas masculinos, sobretodo en lo concerniente a los salarios. Tuvieron éxito fundamentalmente en los oficios en donde ellas tenian una mayor representación numérica.

Paralelamente debido al crecimiento urbano y situaciones particulares, se fueron desplegando nuevas oportunidades para las mujeres, el desarrollo de nuevas ocupaciones y oficios como: maestras de escuelas, enfermera de profesión -no como algo benéfico-, papeles en actividades artisticas, algunas

\footnotetext{
70 Sin alejarse del punto, hay que rescatar las características del trabajo desempeñado por hombres y mujeres, en este sentido, según Boderías (2007, p.15) se enmarca en un sector primario y secundario, pues "mientras los hombres seguían un aprendizaje oficialmente reconocido, tenían trabajos fijos y estaban sujetos a las reglas de los mercados internos, el trabajo de las mujeres era flexible e irregular -sometido a la estacionalidad- y el aprendizaje era informal por lo que al no haber reconocimiento de la cualificación sus salarios eran muy bajos."
} 
profesiones liberales y, el secretariado debido a las invenciones de la epoca como las maquinas de escribir y el teléfono.

Hay que aclarar que como ha sido caracteristico en la historia de las mujeres, los cambios fueron progresivos pues la lucha comenzaba en la modificación de legislaciones en cuanto al acceso a la educación profesional y después el poder ejercer su labor.

Con la llegada de la Primera Guerra Mundial empieza la autonomía económica de las mujeres debido a la incorporación masiva ${ }^{71}$ de las mujeres en numerosos campos productivos fomentada por las convocatorias de los gobiernos incluso en la industria de la guerra, precisando por estos últimos que estas acciones eran circunstanciales. Un acontecimiento importante en este periodo fue la creación de la estructura de la OIT en 1919, que invocaba el respeto por los derechos laborales y la responsabilidad de suprimir las discriminaciones, principalmente del colectivo femenino. Asimismo, en referencia a la remuneración se reconoció en 1951 el principio "a trabajo igual, salario igual"72

\footnotetext{
${ }^{71}$ En este sentido, vale la pena rescatar la teoría de Monroy (2013, p. 2) el autor afirmó que "Parece ser que cuando una sociedad llega a un punto de alta evolución, pasado un periodo de guerras expansión o defensa, cuando se llega a este punto gobiernan las mujeres", además agregó que, con ello, "su manera de gestionar el país es productiva y se llega a una cierta edad dorada".

72 Este reconocimiento es visible en dos momentos históricos: la declaración en 1951 y su posterior ratificación del Convenio \#100 de la OIT sobre la Igualdad de Remuneración, en el cual se establecía el compromiso a los estados que lo ratificaran el garantizar a todos los asalariados la aplicación del principio de igualdad de remuneración entre la mano de obra masculina y la mano de obra femenina para un trabajo de igual valor (OIT, 1951).
} 
Despues de finalizada la guerra y durante la crisis de 1929, el desempleo de las mujeres aumentó debido a los despidos masivos ${ }^{73}$, aquellas que permanecieron lo hicieron en oficios y sectores desechados por los hombres por considerarse rutinarios, muchas también se hallaron con mayores responsabilidades familiares - de los jovenes y mayores en parodebido a las condiciones económicas del periodo en cuestión. Ya para esta epoca, hay que tener en cuenta que muchas mujeres se encontraban irreprochablemente capacitadas para muchas ocupaciones, lo que originó el deseo en ellas de no retroceder y batallar por lo ya alcanzado.

Con la Segunda Guerra Mundial, y la sucesiva movilización de los hombres a ella, las mujeres fueron relevandolos de numerosos oficios por la necesidad de mano de obra, sin duda, la incorporación fue indiscutiblemente parecida decadas atrás con la primera guerra. Al finalizar este periodo y contrario a todos los pronósticos, se experimentó un crecimiento económico acelerado caracterizado por el desarrollo de la industria, el consumismo y la entrada de la tecnología a los hogares, lo que permitió que el empleo

Y, con los tratados de Roma firmado en 1957 para la constitución de la Comunidad Económica Europea, el constitutivo establecía en su artículo 118-119 que, con respecto a los diferentes aspectos del derecho del trabajo, la ocupación y todas sus formas, los estados miembros debían velar por la igualdad retributiva entre hombres y mujeres por un trabajo de igual valor, sin ningún tipo de discriminación (Comunità Economica Europea , 1957, p. 99100)

${ }^{73}$ Como se comentará posteriormente ciertos grupos sociales, y en especial las mujeres son más sensibles a los cambios económicos, es decir, en las épocas de desarrollo o de crisis son los primeros que reciben un impacto social determinante. Así "las mujeres constituyen un ejército de reserva de mano de obra, utilizado en períodos de expansión, pero expulsado en épocas de recesión" (González et al., 1992, p. 57) 
femenino se conservase estable ${ }^{74}$ y disminuyera su proporción de participación en el trabajo agrícola fruto del proceso de industrialización.

Con referencia a España, no olvidemos que hasta 1976, año en el que se implanta la Ley de Relaciones Laborales, el permiso del marido era un requisito legal necesario para que la esposa pudiera ejercer el derecho al trabajo.

Para finalizar este apartado histórico, hay que resaltar como uno de los aspectos positivos que han desarrollado la igualdad formal entre hombres y mujeres, la existencia de un conjunto de cambios institucionales y normativos (Alba, 2000) que tuvieron lugar en el proceso de transición democratico, comenzando con la creación de la Constitución Española en 1978, del Estatuto de los Trabajadores en 1980, la reforma del Código Cívil en 1981, la creación del Instituto de la Mujer en 1983 y, la principal, el ingreso de España en la Comunidad Económica Europea que como se verá mas adelante en el marco normativo implicará para el país la adopción y trasposición de las directivas comunitarias en materia de igualdad de oportunidades.

\footnotetext{
${ }^{74}$ A pesar de todas estas aparentes buenas noticias, se evidenciaron dos hechos que marcaron la relación de las mujeres y el trabajo, por una parte, la "estabilidad" no implicó en ningún caso la disminución de las diferencias salariales, ni que estas pudiesen acceder a categorías profesionales superiores o sectores económicos tradicionalmente ocupados por hombres. Por otra parte, pero no menos importante empieza la preocupación sobre la realidad de las mujeres en relación a sus responsabilidades familiares y trabajo en el hogar, pero sin ninguna voluntad de cambio real llegando a una conclusión acertada "la jornada laboral de un ama de casa es siempre superior a la jornada de cualquier trabajador o trabajadora asalariado/a". Ibidem. pp. 60-61
} 


\subsection{Marco normativo en materia de igualdad y no discriminación en el trabajo}

\subsubsection{Perspectiva internacional}

La igualdad de oportunidades en el empleo constituye uno de los instrumentos esenciales para garantizar un igual disfrute de los derechos fundamentales, al tiempo que se convierte en una garantía de protección contra la exclusión social. A nivel internacional, un conjunto de entidades lidera la promoción de la igualdad de género en los diferentes ámbitos sociales, por lo que a través de los tratados internacionales los estados ${ }^{75}$ adquieren compromisos jurídicamente vinculantes que buscan respetar, proteger y garantizar los derechos humanos, en especial los de las mujeres.

En primera medida, tenemos el papel de la Organización de Naciones Unidas la cual desde 1948, proclamó el derecho a la no discriminación en el trabajo y salarial por razón de sexo, que se encuentra recogido en el artículo veintitrés [complementado por los artículos uno, dos y siete] de la Declaración Universal de Derechos Humanos de las Naciones Unidas, de 10 de diciembre de 1948.

\footnotetext{
${ }^{75}$ En este sentido, hay que resaltar que "Los tratados y otras normas internacionales exigen que todos los Estados protejan, respeten y hagan realidad la igualdad de derechos para las mujeres, pero en la mayoría de los países se les niega efectivamente el ejercicio de los mismos derechos de que disfrutan los hombres. Esta situación puede observarse en áreas como los derechos a la propiedad y la herencia, la protección frente a la violencia, las leyes sobre el matrimonio y el divorcio, la libertad de circulación y la plenitud de capacidad e igualdad ante la ley." (Amnistía Internacional, 2009, p. 9)
} 
En la esfera pública, con la entrada en vigor en 1954, de la Convención sobre los Derechos Políticos de la Mujer, y su posterior ratificación por parte de España en 1973 según BOE del 23-4-74, aparte del derecho al voto, en su artículo dos y tres "Las mujeres serán elegibles para todos los organismos públicos electivos establecidos por la legislación nacional, en condiciones de igualdad con los hombres, sin discriminación alguna". "Las mujeres tendrán derecho a ocupar cargos públicos y a ejercer todas las funciones públicas establecidas por la legislación nacional, en igualdad de condiciones con los hombres, sin discriminación alguna".

En la esfera privada, con la entrada en vigor en 1969, de la Convención Internacional sobre la Eliminación de Todas las Formas de Discriminación Racial, y su adhesión por parte de España en 1968 según BOE del 17-5-69, una de las formas de discriminación por origen racial también hace referencia a las mujeres aunque expresamente no se vea, en este sentido, el artículo cinco se refiere al goce de derechos “i) El derecho al trabajo, a la libre elección de trabajo, a condiciones equitativas y satisfactorias de trabajo, a la protección contra el desempleo, a igual salario por trabajo igual y a una remuneración equitativa y satisfactoria" por lo que para estos efectos, nos referiremos a la discriminación múltiple que tiene que ver con aquellas mujeres que además de ser discriminadas por el hecho de ser mujer, también dichos prejuicios son "basados en motivos de raza, color, linaje u origen nacional o étnico".

Por medio del Pacto Internacional de Derechos Civiles y Políticos ratificado por España en 1977 según BOE del 30-4-1977, en su artículo tres, los Estados se comprometen a garantizar a hombres y mujeres la igualdad en el goce de todos los derechos civiles y políticos. Sus disposiciones consagran la igualdad de las personas ante la ley, la prohibición de la discriminación [en su artículo 4.1], la protección igual y efectiva ante cualquier 
discriminación a los diferentes grupos o minorías sociales [artículo veintiséis y veintisiete] incluyendo la oposición ante el trabajo forzoso, obligatorio, degradante, inhumano y esclavista [artículo siete].

Al igual que el Pacto Internacional de Derechos Económicos, Sociales y Culturales ratificado por España en 1977 según BOE del 30-4-1977, que ya contempla en mayor medida los aspectos laborales, en su artículo dos punto dos, tres y diez punto tres, que busca garantizar la igualdad de oportunidades de los mujeres y los hombres sin discriminación alguna en el goce de sus derechos económicos, sociales y culturales, específicamente el derecho al trabajo y sus condiciones laborales como la remuneración equitativa, la protección frente a los riesgos laborales, la promoción y sus prestaciones sociales incluyendo en todo caso el derecho a la negociación colectiva [artículo seis y siete].

Haciendo referencia a las personas con algún tipo de discapacidad, en su momento la Declaración de los Derechos de los Impedidos de 9 de Diciembre de 1975, promulgó los derechos de los pactos establecidos con anterioridad, en condiciones de igualdad y sin discriminación alguna para este grupo social en su artículo dos, específicamente en su artículo siete, a tener un empleo y a laborar en un entorno saludable pero en especial, a ser protegido contra toda explotación y trato discriminatorio [artículo diez].

Con respecto a la igualdad de género, desde la ONU se confirmó que la elaboración y promulgación de una normativa relativa a la igualdad, no era suficiente ni garantizaba la eliminación de las discriminaciones que sufren las mujeres. Por este motivo, en los años 70 , se celebra la primera Conferencia Mundial de la Mujer y, a partir de ese momento, será dentro de las estas reuniones donde se llegará a los acuerdos que determinarán el avance en la promoción del principio de igualdad de oportunidades entre de mujeres y 
hombres, a través de la puesta en marcha de instrumentos concretos de carácter político y técnico.

Resultado de lo anterior, entrando en vigor como tratado internacional en 1981 y su posterior ratificación en 1983 por España, según BOE del 21-31984 la Convención sobre la Eliminación de todas las Formas de Discriminación contra la Mujer, tal como lo establece el artículo once buscaba la garantía de la igualdad de oportunidades en el empleo concretamente de la mujer, incluso en lo referente a matrimonio y maternidad procurando la salvaguarda de su función reproductiva.

Con la entrada en vigor en 1990 de la Declaración sobre la eliminación de la violencia contra la mujer, en su artículo dos estipuló expresamente la prohibición en el ámbito laboral, en este sentido, "La violencia física, sexual y sicológica perpetrada dentro de la comunidad en general, inclusive la violación, el abuso sexual, el acoso y la intimidación sexuales en el trabajo, en instituciones educacionales y en otros lugares, la trata de mujeres y la prostitución forzada...". Además, en su artículo tres figuran unos derechos específicos de la mujer dentro de ellos: a verse libre de todas las formas de discriminación y unas condiciones de trabajo justas y favorables.

Con respecto a los trabajadores inmigrantes, otro grupo en riesgo de exclusión social, con la ratificación de España en 1990, de la Convención internacional sobre la protección de los derechos de todos los trabajadores migratorios y de sus familiares, en lo concerniente a la no discriminación en el reconocimiento de derechos para este grupo en su artículo 7. De igual manera, como lo expresa el artículo 25:

"1. Los trabajadores migratorios gozarán de un trato que no sea menos favorable que el que reciben los nacionales del Estado de empleo en lo tocante a remuneración y de: a) Otras condiciones de trabajo, es decir, horas 
extraordinarias, horario de trabajo, descanso semanal, vacaciones pagadas, seguridad, salud, fin de la relación de empleo y cualesquiera otras condiciones de trabajo que, conforme a la legislación y la práctica nacionales, estén comprendidas en este término; b) Otras condiciones de empleo, es decir, edad mínima de empleo, restricción del trabajo a domicilio y cualesquiera otros asuntos que, conforme a la legislación y la práctica nacionales, se consideren condiciones de empleo...".

Por otra parte, la OIT establece dos tratados para la eliminación de la Discriminación en Materia de Empleo y Ocupación: por una parte, el Convenio 100 relativo a la Igualdad de Remuneración entre la Mano de Obra Masculina y la Mano de Obra Femenina por un Trabajo de Igual Valor y el Convenio 111 relativo a la Discriminación en Materia de Empleo y Ocupación, ambos ratificados por España en 1967 y en vigor. Estos son parte de los convenios fundamentales ${ }^{76}$ todos también ratificados por España y que hacen parte de la Declaración de la OIT Relativa a Los Principios y Derechos Fundamentales en el Trabajo. España, no ha ratificado un convenio de la OIT que amplía derechos a las empleadas domésticas, C189-Convenio sobre las trabajadoras y los trabajadores domésticos, 2011 (núm. 189) a pesar de que el documento se firmó en 2011.

${ }^{76}$ La OIT identificó ocho convenios calificándolos de fundamentales para garantizar los derechos de los seres humanos en el trabajo y son conocidos bajo el término «normas fundamentales» en el trabajo (OIT, 2003, pp. 7-8), los clasificó en cuatro grupos así: (i) La Libertad de Asociación, la Libertad Sindical y el Reconocimiento Efectivo del Derecho de Negociación Colectiva (núm. 87 y 98), (ii) La Eliminación de Todas las Formas de Trabajo Forzoso u Obligatorio (núm. 29 y 105), (iii) La Abolición Efectiva del Trabajo Infantil (núm.138 y 182) y, (iv) la Eliminación de la Discriminación en Materia de Empleo y Ocupación (núm. 100 y 111$)$. 
Según la OIT, la fecha de entrada en vigor del C189 - Convenio sobre las trabajadoras y los trabajadores domésticos, 2011 (núm. 189) fue el 5 septiembre 2013, sólo ha tenido 23 países que lo han ratificado a la fecha. En la Unión Europea, Alemania, Bélgica, Finlandia, Irlanda, Italia, Portugal y Suiza son los únicos que lo han hecho y ya lo tienen en vigor. El objetivo de este convenio es garantizar que los trabajadores domésticos sin importar el género disfruten de condiciones de empleo equitativas y condiciones de trabajo decente.

La importancia de este convenio radica en que las mujeres son las que mayormente se ven implicadas en un sector tan informal como lo es el del servicio doméstico, es un "ámbito de trabajo característico para la mujer" aunado al hecho que también son inmigrantes, lo cual repercute significativamente en la realidad diaria vivida como empleadas de hogar ${ }^{77} \mathrm{y}$ que está sujeto a muchas situaciones de discriminación (Marcu, 2009, p. 465). Generalmente, se ha dado a través de la atracción de mujeres que provienen de países menos desarrollados a llenar esas plazas de servicio doméstico en todo el mundo, principalmente en las economías desarrolladas, con lo cual ha pasado desapercibido y es un mercado de trabajo válido y que debe estar sujeto a condiciones de igualdad.

Existen otros convenios de la OIT igual de importantes porque proporcionan un marco complementario para la protección de las mujeres en las relaciones laborales de principio a fin, en la tabla 1 a continuación se

\footnotetext{
77 En este sentido, según las investigaciones en España de Marcu (2009, p. 474) el trabajo doméstico se realiza básicamente en dos modalidades "el de trabajadora interna y el de externa (trabajadoras a jornada completa y por horas). Las inmigrantes que se incorporan a este ámbito trabajan habitualmente primero como internas, hasta que después de uno o varios años logran dar el salto a la modalidad externa, aunque algunas permanecen como internas durante mucho tiempo."
} 
encuentra el listado de convenios ratificados por España que merece la pena destacar teniendo en cuenta la existencia de una relación con el principio de igualdad de oportunidades en el trabajo.

\begin{tabular}{|c|c|c|c|}
\hline Convenios & Ratificación España & Status & Relación \\
\hline $\begin{array}{c}\text { C097 - Convenio } \\
\text { sobre los trabajadores } \\
\text { migrantes (revisado), } \\
1949 \text { (núm. 97) }\end{array}$ & 21-mar-67 & $\begin{array}{l}\text { En } \\
\text { vigor }\end{array}$ & $\begin{array}{l}\text { El artículo } 6 \text { establece la } \\
\text { obligación de aplicar los } \\
\text { beneficios laborales, como } \\
\text { por ejemplo en la } \\
\text { remuneración o los } \\
\text { ascensos sin que sean } \\
\text { objeto de discriminación } \\
\text { por distintos factores uno } \\
\text { de ellos el sexo. }\end{array}$ \\
\hline $\begin{array}{l}\text { C103 - Convenio } \\
\text { sobre la protección de } \\
\text { la maternidad } \\
\text { (revisado), } 1952 \\
\text { (núm. 103) Con } \\
\text { excepción de las } \\
\text { personas a que se } \\
\text { refiere el artículo 7, } \\
\text { párrafo 1, d). }\end{array}$ & 17-ago-65 & $\begin{array}{l}\text { En } \\
\text { vigor }\end{array}$ & $\begin{array}{l}\text { Protección frente a casos } \\
\text { de discriminación por el } \\
\text { hecho de convertirse en } \\
\text { madre y al disfrute de las } \\
\text { prestaciones sociales } \\
\text { correspondientes. }\end{array}$ \\
\hline $\begin{array}{l}\text { C140 - Convenio } \\
\text { sobre la licencia } \\
\text { pagada de estudios, } \\
1974 \text { (núm. 140) }\end{array}$ & 18-sep-78 & $\begin{array}{l}\text { En } \\
\text { vigor }\end{array}$ & $\begin{array}{l}\text { Según el artículo } 8 \text {, la } \\
\text { licencia pagada de } \\
\text { estudios no deberá } \\
\text { negarse a los trabajadores } \\
\text { por motivos de sexo u otro } \\
\text { factor de } \\
\text { Este discriminación. }\end{array}$ \\
\hline
\end{tabular}




\begin{tabular}{|c|c|c|c|}
\hline & & & $\begin{array}{l}\text { importante porque } \\
\text { repercute en la promoción } \\
\text { y el desarrollo profesional. } \\
\text { Las mujeres deberían } \\
\text { tener acceso en igualdad } \\
\text { de condiciones que los } \\
\text { hombres }\end{array}$ \\
\hline $\begin{array}{c}\text { C142 - Convenio } \\
\text { sobre el desarrollo de } \\
\text { los recursos humanos, } \\
1975 \text { (núm. 142) }\end{array}$ & 16-may-77 & $\begin{array}{c}\text { En } \\
\text { vigor }\end{array}$ & 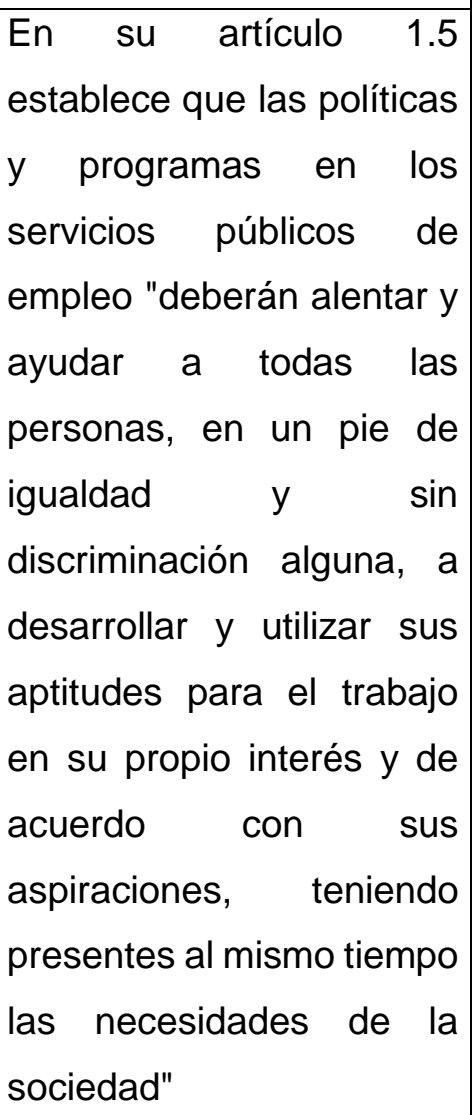 \\
\hline $\begin{array}{c}\text { C156 - Convenio } \\
\text { sobre los trabajadores } \\
\text { con responsabilidades } \\
\text { familiares, 1981 } \\
\text { (núm. 156) }\end{array}$ & 11-sep-85 & $\begin{array}{c}\text { En } \\
\text { vigor }\end{array}$ & $\begin{array}{l}\text { El artículo } 7 \text { y } 8 \text { establece } \\
\text { que "La responsabilidad } \\
\text { familiar no debe constituir } \\
\text { de por sí una causa } \\
\text { justificada para poner fin a } \\
\text { la relación de trabajo" y } \\
\text { además }\end{array}$ \\
\hline
\end{tabular}




\begin{tabular}{|c|c|c|c|}
\hline & & & $\begin{array}{l}\text { trabajadores } \\
\text { independientes del sexo } \\
\text { "puedan integrarse y } \\
\text { permanecer en la fuerza } \\
\text { de trabajo". }\end{array}$ \\
\hline $\begin{array}{l}\text { C158 - Convenio } \\
\text { sobre la terminación } \\
\text { de la relación de } \\
\text { trabajo, } 1982 \\
\text { (núm. 158) }\end{array}$ & $26-a b r-85$ & $\begin{array}{c}\text { En } \\
\text { vigor }\end{array}$ & $\begin{array}{l}\text { En su artículo } 5 \text { establece } \\
\text { que no constituirán causa } \\
\text { justificada para la } \\
\text { terminación de la relación } \\
\text { de trabajo el sexo u otros } \\
\text { factores de discriminación } \\
\text { además de la ausencia del } \\
\text { trabajo durante la licencia } \\
\text { de maternidad. }\end{array}$ \\
\hline
\end{tabular}

Tabla 1. Convenios complementarios de la OIT ratificados por España con base en la OIT. Fuente: OIT (1949, 1952, 1974, 1975, 1981, 1982). Elaboración propia.

\subsubsection{Perspectiva europea}

A nivel europeo, con el Tratado de Ámsterdam ${ }^{78}$, tratado constitutivo de la CEE se sentaron las bases para una lucha común por la igualdad pues debe integrarse en todas las políticas y acciones de la Unión Europea y de sus

78 Tratado de Ámsterdam por el que se modifican el Tratado de la Unión Europea, los Tratados Constitutivos de las Comunidades Europeas y determinados actos conexos, este Tratado, que entró en vigor el 1 de mayo de 1999, ha sido ratificado por España por Instrumento de 23 de diciembre de 1998 («BOE» núm. 109, de 7 de mayo de 1999). 
miembros. Desde su firma en Roma en 1957, la Unión Europea ha adoptado trece directivas (Comisión Europea, 2008) tal como lo vemos en la Tabla 2 en el ámbito de la igualdad de género que, entre otras cosas, regulan el derecho a la igualdad de trato entre hombres y mujeres en el trabajo, las retribuciones laborales, la seguridad social y el acceso a bienes y servicios. Asimismo, ofrecen un régimen especial de protección a las mujeres embarazadas y a las que acaban de tener hijos, establecen una normativa común en cuanto a las mujeres que ejercen una actividad laboral autónoma y a los cónyuges que les ayudan.

Un primer paso se dio a través de la Directiva 2000/78/CE relativa al establecimiento de un marco general para la igualdad de trato en el empleo y la ocupación, consagrada a prohibir fielmente la discriminación por diversas razones. Adicionalmente, la Directiva 2006/54/CE relativa a la aplicación del principio de igualdad de oportunidades e igualdad de trato entre hombres y mujeres en asuntos de empleo y ocupación, cierra el sistema europeo de protección frente a la discriminación por razón de género.

Con la Directiva 2006/54/CE, de 26 julio 2006, relativa a la aplicación del principio de igualdad de oportunidades e igualdad de trato entre hombres y mujeres en asuntos de empleo y ocupación, ejerce la obligación de trasposición a los estados miembros y el establecimiento de sanciones efectivas por el incumplimiento de lo incorporado en la directiva. Los temas principales abordados son: la discriminación directa e indirecta por razón de género, el acoso sexual, la diferencia retributiva, acciones positivas entre otros. Incluso, a través de la prevención de la discriminación, incluye a los empresarios, como actores clave para la implementación de medidas pertinentes que logren la igualdad efectiva y real de oportunidades. Con la adopción de esta última Directiva su propósito consistió en refundir y simplificar todas las anteriores directivas, entró en vigor el 15 de agosto de 
2009, fecha a partir de la cual quedaron revocadas las Directivas 75/117/CEE, 76/207/CEE, 86/378/CEE y 97/80/CE.

\begin{tabular}{|c|c|c|}
\hline Año/Década & Norma & Concepto \\
\hline 1957 & $\begin{array}{l}\text { Tratado de } \\
\text { Ámsterdam }\end{array}$ & Tratado constitutivo de la CEE. \\
\hline & $\begin{array}{c}\text { Directiva } \\
\text { 75/117/CEE }\end{array}$ & $\begin{array}{l}\text { Relativa a la igualdad de retribución entre los } \\
\text { trabajadores y las trabajadoras. }\end{array}$ \\
\hline & $\begin{array}{c}\text { Directiva } \\
\text { 76/207/CEE }\end{array}$ & $\begin{array}{l}\text { Relativa a la igualdad de trato en lo que se } \\
\text { refiere al empleo, a la formación profesional y } \\
\text { a las condiciones de trabajo (modificada en } \\
\text { 2002). }\end{array}$ \\
\hline 1970 & Directiva 79/7/CEE & $\begin{array}{l}\text { Relativa a la igualdad de trato en materia de } \\
\text { seguridad social. }\end{array}$ \\
\hline & $\begin{array}{c}\text { Directiva } \\
\text { 86/378/CEE }\end{array}$ & $\begin{array}{c}\text { Relativa a la igualdad de trato en los } \\
\text { regímenes profesionales de seguridad social } \\
\text { (modificada en 1996). }\end{array}$ \\
\hline 1980 & $\begin{array}{c}\text { Directiva } \\
\text { 86/613/CEE }\end{array}$ & $\begin{array}{l}\text { Relativa a la igualdad de trato entre hombres } \\
\text { y mujeres que ejerzan una actividad } \\
\text { autónoma, así como sobre la protección de la } \\
\text { maternidad. }\end{array}$ \\
\hline 1990 & $\begin{array}{c}\text { Directiva } \\
\text { 92/85/CEE }\end{array}$ & $\begin{array}{c}\text { Relativa a la promoción de la seguridad y de } \\
\text { la salud en el trabajo de la trabajadora } \\
\text { embarazada, que haya dado a luz o esté en } \\
\text { período de lactancia. }\end{array}$ \\
\hline
\end{tabular}




\begin{tabular}{|c|c|c|}
\hline & Directiva 96/34/CE & $\begin{array}{l}\text { Relativa al acuerdo marco sobre permiso } \\
\text { parental. }\end{array}$ \\
\hline & Directiva 97/80/CE & $\begin{array}{l}\text { Relativa a la carga de la prueba en los casos } \\
\text { de discriminación por razón de sexo. }\end{array}$ \\
\hline \multirow[b]{2}{*}{2000} & $\begin{array}{c}\text { Directiva } \\
\text { 2004/113/CE }\end{array}$ & $\begin{array}{l}\text { Relativa a la igualdad en cuanto al acceso a } \\
\text { bienes y servicios y a su suministro. }\end{array}$ \\
\hline & $\begin{array}{l}\text { Directiva } \\
\text { 2006/54/CE }\end{array}$ & $\begin{array}{l}\text { Relativa a la aplicación del principio de } \\
\text { igualdad de oportunidades e igualdad de trato } \\
\text { entre hombres y mujeres en asuntos de } \\
\text { empleo y ocupación (refundición). }\end{array}$ \\
\hline \multirow[b]{3}{*}{2010} & $\begin{array}{c}\text { Directiva } \\
\text { 2010/18/UE del } \\
\text { Consejo, de } 8 \text { de } \\
\text { marzo de } 2010\end{array}$ & $\begin{array}{l}\text { Por la que se aplica el Acuerdo marco } \\
\text { revisado sobre el permiso parental, celebrado } \\
\text { por Businesseurope, la Ueapme, el CEEP y la } \\
\text { CES, y se deroga la Directiva 96/34/CE. }\end{array}$ \\
\hline & $\begin{array}{c}\text { Directiva } \\
\text { 2010/41/UE, de } 7 \\
\text { de julio de } 2010\end{array}$ & $\begin{array}{c}\text { En la que se establecen objetivos para la } \\
\text { aplicación del principio de igualdad de trato } \\
\text { entre hombres y mujeres que ejercen una } \\
\text { actividad autónoma, incluidas las actividades } \\
\text { agrícolas, así como sobre la protección de la } \\
\text { maternidad, y por la que se deroga la } \\
\text { Directiva 86/613/CEE del Consejo. }\end{array}$ \\
\hline & $\begin{array}{l}\text { Propuesta de } \\
\text { Directiva } \\
\text { 2012/0299 }\end{array}$ & $\begin{array}{l}\text { Destinada a mejorar el equilibrio de género } \\
\text { entre los administradores no ejecutivos de las } \\
\text { empresas cotizadas y por la que se } \\
\text { establecen medidas afines }\end{array}$ \\
\hline
\end{tabular}

Tabla 2. Listado de Directivas Europeas que promueven la igualdad de género a nivel laboral. Fuente. Comisión Europea (2008) y Schonard (2017). Elaboración propia. 
Con respecto al seguimiento de la propuesta de Directiva 2012/0299, destinada a mejorar el equilibrio de género entre los administradores no ejecutivos de las empresas cotizadas y por la que se establecen medidas afines, el Parlamento Europeo emitió una resolución legislativa en 2013, uno de las modificaciones al respecto, se hizo en la edición de un término, se reemplazó el término mujeres por miembros: dentro de la justificación se había alentado a las empresas cotizadas en la Unión Europea a "aumentar el número de miembros del género menos representado presentes en sus consejos mediante medidas de autorregulación y a contraer compromisos voluntarios concretos a ese respecto" $(2013$, p. 4) lo cual garantiza que no se promueva la discriminación inversa. Se resaltó además el papel de países como Noruega que consiguió alcanzar el 40 \% en tres años, aunque esos resultados se alcanzaron mediante medidas vinculantes.

Las acciones más recientes de la Unión Europea según Schonard (2017) en el ámbito de la igualdad entre hombres y mujeres en el empleo y la ocupación han sido las siguientes:

- Instituto Europeo de la Igualdad de Género (EIGE) ${ }^{79}$ : fue constituido en diciembre de 2006 por decisión del Parlamento y el Consejo Europeo el cual tiene sede en Vilna (Lituania), con el objetivo general de contribuir a fomentar y reforzar la igualdad entre hombres y mujeres con medidas como la integración de la dimensión de género en todas las políticas nacionales y de la Unión. El Instituto lucha asimismo contra la discriminación por razón de sexo y promueve la sensibilización sobre la igualdad entre hombres y mujeres mediante la

\footnotetext{
79 Para ampliar esta información véase http://eige.europa.eu/content/rdc en donde se podrá encontrar los contenidos en inglés y lituano.
} 
prestación de asistencia técnica a las instituciones europeas. Entre otras actividades, se dedica a la recopilación, el análisis y la difusión de datos y de herramientas metodológicas.

- La Carta de la Mujer y el Compromiso estratégico para la igualdad de género 2016-201980: fue aprobado por la Comisión Europea en marzo de 2010 y en diciembre de 2015 respectivamente, la primera busca promover de forma más eficaz la igualdad entre mujeres y hombres en Europa y en el mundo a través de los siguientes ámbitos de actuación: (i) independencia económica, (ii) igualdad en el salario, (iii) la representación de las mujeres en la toma de decisiones y en los puestos de responsabilidad, (iv) la dignidad e integridad de las mujeres, así como la erradicación de la violencia de género y (v) la acción exterior de la Unión Europea.

La segunda, dar continuidad al seguimiento de la estrategia para la igualdad entre mujeres y hombres 2010-2015. Dentro de los ámbitos prioritarios se encuentran: (i) el aumento de la participación de la mujer

80 Estos documentos son:

1. Comunicación de la Comisión de 5 de marzo de 2010 titulada «Un compromiso reforzado en favor de la igualdad entre mujeres y hombres - Una Carta de la Mujer: Declaración de la Comisión Europea con motivo del Día Internacional de la Mujer 2010 en conmemoración del 15º aniversario de la adopción de la Declaración y la Plataforma de Acción de la Conferencia Mundial de las Naciones Unidas sobre la Mujer celebrada en Pekín, y del 30ªniversario de la Convención de las Naciones Unidas sobre la Eliminación de todas las Formas de Discriminación contra la Mujer» [COM(2010) 78 final - no publicada en el Diario Oficial]. Véase en URL: http://eurlex.europa.eu/legal-content/ES/TXT/?uri=URISERV\%3Aem0033

2. Documento de trabajo de los servicios de la Comisión «Strategic engagement for gender equality 2016-2019" [Compromiso estratégico para la igualdad de género 2016-2019] [SWD (2015)0278]. Véase en URL: http://ec.europa.eu/justice/genderequality/files/documents/151203_strategic_engagement_en.pdf 
en el mercado laboral e igual independencia económica; (ii) la reducción de la brecha y la desigualdad salariales y de las pensiones $y$, por consiguiente, la lucha contra la pobreza entre las mujeres; (iii) la promoción de la igualdad entre mujeres y hombres en la toma de decisiones; (iv) lucha contra la violencia de género y protección y apoyo a las víctimas; $y,(v)$ promoción de la igualdad de género y los derechos de las mujeres en todo el mundo.

- El Plan de Acción en materia de género 2016-202081: adoptada por el Consejo Europeo el 26 de octubre de 2015, que busca la igualdad de todos los derechos humanos y las libertades fundamentales por parte de las mujeres y las niñas, mediante la contribución de la UE a la consecución del ODS número 5 sobre la igualdad de género y el empoderamiento de las mujeres y las niñas. Se establecieron unas prioridades temáticas de las cuales se desprenden unos objetivos, su medición a través de indicadores y las acciones mediante ejemplos de actividades. En la Tabla 3 , a continuación, se detallan algunos de los aspectos y medidas concretas que se está implementando desde las políticas estratégicas de la Unión Europea y sus estados miembros que tienen que ver específicamente con lo desarrollado en esta tesis y principalmente en el ámbito del empleo y la ocupación así:

81 Conclusiones del Consejo sobre el Plan de Acción en materia de género 2016-2020, adoptadas por el Consejo en su sesión n. 3420, celebrada el 26 de octubre de 2015. Véase en URL: http://data.consilium.europa.eu/doc/document/ST-13201-2015-INIT/es/pdf 


\begin{tabular}{|c|c|c|c|}
\hline $\begin{array}{c}\text { Prioridades } \\
\text { temáticas }\end{array}$ & Objetivo & Indicadores & $\begin{array}{l}\text { Ejemplos de } \\
\text { actividades }\end{array}$ \\
\hline $\begin{array}{l}\text { Cambio de la cultura } \\
\text { institucional en las } \\
\text { relaciones exteriores } \\
\text { de la Unión Europea }\end{array}$ & $\begin{array}{c}\text { Liderazgo } \\
\text { consagrado en } \\
\text { materia de } \\
\text { igualdad de } \\
\text { género y de } \\
\text { empoderamient } \\
\text { o de las } \\
\text { mujeres y las } \\
\text { niñas } \\
\text { establecido en } \\
\text { las instituciones } \\
\text { de la UE y los } \\
\text { Estados } \\
\text { miembros. }\end{array}$ & $\begin{array}{l}2.2 .1 . \\
\text { Proporción } \\
\text { de mujeres } \\
\text { que son } \\
\text { jefas de } \\
\text { misión de la } \\
\text { UE } \\
\text { (referencia } \\
\text { de } 2014: 24 \\
\%)\end{array}$ & $\begin{array}{l}\text { 2.2. Mejorar la } \\
\text { participación de las } \\
\text { mujeres en puestos } \\
\text { decisorios en el seno de } \\
\text { la UE. Actores implicados } \\
\text { CE, SEAE y Estados } \\
\text { miembros }\end{array}$ \\
\hline \multirow[t]{2}{*}{$\begin{array}{c}\text { Derechos } \\
\text { económicos, sociales } \\
\text { y culturales - } \\
\text { Empoderamiento } \\
\text { económico y social }\end{array}$} & $\begin{array}{l}\text { Igualdad de } \\
\text { acceso de las } \\
\text { mujeres y las } \\
\text { niñas a todos } \\
\text { los niveles de } \\
\text { educación y de } \\
\text { educación y } \\
\text { formación } \\
\text { profesionales } \\
\text { (EFP) sin } \\
\text { discriminación. }\end{array}$ & 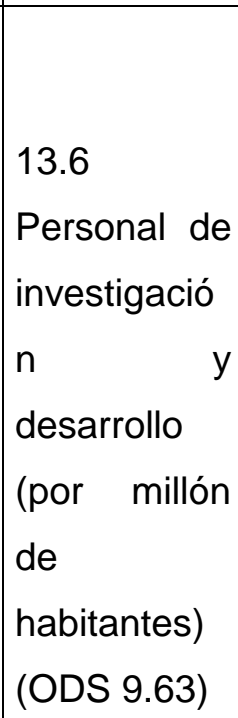 & $\begin{array}{l}\text { Promover modelos de } \\
\text { referencia igualitarios en } \\
\text { la transición de la } \\
\text { educación al mercado de } \\
\text { trabajo a través de los } \\
\text { currículos y de la paridad } \\
\text { de géneros entre } \\
\text { profesores. }\end{array}$ \\
\hline & $\begin{array}{c}\text { Acceso a un } \\
\text { trabajo digno de } \\
\text { mujeres de } \\
\text { cualquier edad }\end{array}$ & $\begin{array}{l}14.2 . \\
\text { Número } \\
\text { medio de } \\
\text { horas }\end{array}$ & $\begin{array}{l}\text { Apoyar los desafíos a las } \\
\text { normas y actitudes } \\
\text { sociales que dificultan el } \\
\text { empoderamiento }\end{array}$ \\
\hline
\end{tabular}




\begin{tabular}{|c|c|c|}
\hline & $\begin{array}{l}\text { dedicadas al } \\
\text { trabajo } \\
\text { remunerado } \\
\text { y } \\
\text { remunerado } \\
\text { combinados } \\
\text { (carga total } \\
\text { de } \\
\text { por trabajo) } \\
\text { (ODS } 5.42)\end{array}$ & $\begin{array}{l}\text { económico de las } \\
\text { mujeres, en particular el } \\
\text { reconocimiento } \\
\text { económico y social de } \\
\text { trabajos asistenciales y } \\
\text { no remunerados. }\end{array}$ \\
\hline & $\begin{array}{l}\text { Proporción } \\
\text { de la } \\
\text { población } \\
\text { empleada } \\
\text { por género y } \\
\text { grupo de } \\
\text { edad (15- } \\
64) \quad \text { (ODS } \\
8.5)\end{array}$ & $\begin{array}{l}\text { Apoyar las reformas } \\
\text { legislativas y de las } \\
\text { finanzas públicas } \\
\text { sensibles con respecto al } \\
\text { género, que dan cuenta } \\
\text { del papel de las mujeres } \\
\text { en la economía } \\
\text { asistencial, el trabajo no } \\
\text { asalariado, la distribución } \\
\text { desigual por género de } \\
\text { las responsabilidades } \\
\text { familiares, la } \\
\text { representación excesiva } \\
\text { en la economía informal, } \\
\text { las mujeres en la } \\
\text { agricultura y la brecha } \\
\text { salarial por razón de } \\
\text { género }\end{array}$ \\
\hline $\begin{array}{l}\text { 15. Igualdad de } \\
\text { acceso de las } \\
\text { mujeres a los }\end{array}$ & $\begin{array}{l}\text { 15.3. Brecha } \\
\text { salarial por } \\
\text { razón de }\end{array}$ & $\begin{array}{l}\text { Apoyar la iniciativa } \\
\text { emprendedora de las } \\
\text { mujeres, así como los }\end{array}$ \\
\hline
\end{tabular}




\begin{tabular}{|c|c|l|l|} 
servicios & sexo, por & centros de asistencia que \\
financieros y los & sector de & atienden a las familias. \\
recursos & actividad & \\
productivos, & económica & \\
entre ellos la & (ODS 1.5) & \\
tierra, el & & \\
comercio y la & & \\
iniciativa & & \\
emprendedora. & & \\
\hline
\end{tabular}

Tabla 3. Selección de acciones puntuales en materia de la igualdad de género en el Empleo y Ocupación de la UE. Fuente. Consejo de la Unión Europea (2015). Elaboración propia.

\subsubsection{Perspectiva interna: España}

No es desconocido que, en todo Estado Social de Derecho, la igualdad sea considerada como uno de los valores supremos de todo ordenamiento jurídico, y, no solo como el artículo 1 de la Constitución Española (CE) de 1978 lo refleja, sino también el artículo 14 define formalmente el principio de la igualdad y la no discriminación por cualquier condición y/o circunstancia personal o social, al referirse en la expresión "los españoles son iguales ante la ley".

El reconocimiento constitucional del derecho a la igualdad ha significado la superación, por lo menos en las democracias occidentales, de situaciones anteriores de negación absoluta de las demandas de igualdad planteadas por las mujeres. En el empleo y la ocupación, la legislación 
también proclama el derecho al trabajo sin discriminación alguna a través del artículo 35 de la CE. En el mismo ya se incluye específicamente como factor el sexo, dentro de un conjunto amplio de factores, para “... la libre elección de profesión u oficio, a la promoción a través del trabajo y a una remuneración suficiente...".

En la relación laboral por cuenta ajena, dos son los preceptos básicos del Estatuto de los Trabajadores que se refieren a este tema: el artículo 4.2 c) en donde se enumeran los derechos reconocidos a los trabajadores en el marco de la relación de trabajo, uno de ellos a no ser discriminado por diferentes razones o factores dentro de ellos, el sexo.

Por otro lado, el artículo 17, que bajo el título de «no discriminación en las relaciones laborales» se vuelve a insistir en el derecho que tienen todos los trabajadores a no ser discriminados directa o indirectamente bajo ningún concepto convirtiéndose en "...nulos y sin efecto los preceptos reglamentarios, las cláusulas de los convenios colectivos, los pactos individuales y las decisiones unilaterales del empresario que den lugar en el empleo, así como en materia de retribuciones, jornada y demás condiciones de trabajo" que generen dichas situaciones.

Se encuentra también el artículo 28 que, bajo el título de Igualdad de remuneración por razón de sexo, obliga al empresario "...a pagar por la prestación de un trabajo de igual valor la misma retribución, satisfecha directa o indirectamente, y cualquiera que sea la naturaleza de la misma, salarial o extra salarial, sin que pueda producirse discriminación alguna por razón de sexo en ninguno de los elementos o condiciones de aquélla"

Asimismo, en el marco de los convenios colectivos, según el artículo 90.6 otorga poderes a las autoridades laborales para velar por el respeto al principio de igualdad de oportunidades entre mujeres y hombres. Está claro 
que el principio de la igualdad en el derecho del trabajo ${ }^{82}$ busca la dignidad de la persona, considerado un principio eje en el orden constitucional se configura además como un derecho fundamental.

El artículo 14 de la CE busca evitar la creación de desigualdades de todos los ciudadanos en los diferentes ámbitos sociales uno de ellos a nivel laboral. Por lo que, en principio, busca asegurar no solo el desarrollo de una democracia igualitaria [igualdad ante la ley] sino también en la ley, es decir, el tratamiento igual por parte de la ley (Dirección General del Servicio Jurídico del Estado, 1991-a; 1991-b)

En este sentido, trata de tutelar no solo el acto justo, sino que trata de modo igualitario a todos los que están sometidos a las mismas reglas, es decir, mujeres y hombres españoles, por lo que evita las distinciones injustificadas y en definitiva la arbitrariedad. La consecución y búsqueda de una igualdad real en el derecho del trabajo y la lucha contra las discriminaciones, es un compromiso con las libertades y la dignidad de la persona.

Sin embargo, esto no evita que existan diversos problemas asociados a la interpretación de la norma, en efecto, se concluiría que la misma pudiese admitir desigualdades. De hecho, dicho problema tiene que ver con la relatividad ya que no se ofrecen criterios claros sobre los límites de lo admisible y lo rechazable, por lo que en principio es preciso decir, que puede que existan discusiones sobre la verdadera garantía real del principio de igualdad.

\footnotetext{
82 El derecho del trabajo es una disciplina especializada basada en un equilibrio entre el intervencionismo estatal y el papel de la autonomía colectiva y con una función de protección del trabajo humano
} 
Es posible, pensar que la igualdad como garantía y derecho constitucional sea flexible, con un contenido variable; esto se debe a que, en el ámbito laboral, es un hecho que existan diferenciaciones normativas puesto que determinados sectores de la economía tienen mejores condiciones de empleo que otras, lo que se debe también a la negociación colectiva. Ahora bien, en la norma no queda claro cuando se habla de situaciones laborales equiparables, el derecho a la igualdad ante la ley significa que en dichas situaciones o supuestos de hecho equiparables las trabajadoras $y$ trabajadores tienen derecho a ser tratados por la ley de modo igualitario.

La exclusión de los trabajadores temporales resulta otro problema complejo, pues es contrario al principio a la igualdad, pues estos incluso en los convenios colectivos carecen de poder negociador por si solos y por consiguiente reciben un tratamiento menos favorable. Si se analiza dicha situación, aunque existan diferencias objetivas [el tipo de contrato], el trabajo prestado debería ser el criterio más objetivo para comparar a los trabajadores, por lo que es claro que no debería existir una diferencia en relación con la labor de los trabajadores fijos o eventuales y los que están a tiempo completo.

Pero, es en el ejercicio de los poderes empresariales donde son más frecuentes las desigualdades [asignación de turnos nocturnos, los puestos, la promoción profesional, los traslados y que tipo de formación deben recibir]. La lucha contra la discriminación requiere de la legislación en este ámbito, no obstante, por sí sola no es suficiente debido a todos los aspectos planteados con anterioridad, dicho esto la responsabilidad recae sobre los diferentes grupos de interés, el estado, las empresas, los sindicatos, y diferentes organismos públicos; absolutamente todos tienen un papel que desempeñar.

El artículo 17.1 del estatuto de los trabajadores establece las causas vetadas de discriminación, es decir, una prohibición de factores específicos y no una imposición de igualdad de trato, aparece como un mecanismo para 
crear limites a ejercicio empresarial de los poderes derivados del contrato de trabajo como una limitación de la autonomía privada que integra y se integra en el contrato de trabajo, debe de respetar la libertad y la dignidad humana del trabajador y constituye un vínculo especifico al desarrollo de la actividad empresarial y hace legitimo el uso de las prerrogativas y de los poderes empresariales de forma que dañe la igualdad y por ello la dignidad social del trabajador.

En referencia al trabajador por cuenta propia, cuya relación laboral está regulada por el estatuto del trabajador autónomo, el artículo 4.1 establece sus derechos profesionales al estipular que también ellos "...tienen derecho al ejercicio de los derechos fundamentales y libertades públicas reconocidos en la Constitución Española y en los tratados y acuerdos internacionales ratificados por España sobre la materia". Por lo que en el artículo 4.2 (a) y 4.3 respectivamente se confirma el derecho al trabajo y a la libre elección de profesión u oficio, y a la igualdad ante la ley y a no ser discriminados, directa o indirectamente, por cualquier razón, incluyendo la protección frente al acoso sexual y por razón de sexo.

Con la Ley 5/2011, de 29 de marzo, de Economía Social, en su artículo 4(c) refiriéndose a uno de los principios orientadores la "...promoción de la solidaridad interna y con la sociedad que favorezca el compromiso con el desarrollo local, la igualdad de oportunidades entre hombres y mujeres, la cohesión social, la inserción de personas en riesgo de exclusión social, la generación de empleo estable y de calidad, la conciliación de la vida personal, familiar y laboral y la sostenibilidad.". Además, en su artículo 8 con respecto a las competencias de los poderes públicos, consiste en "...Involucrar a las entidades de la economía social en las políticas activas de empleo, especialmente en favor de los sectores más afectados por el desempleo, mujeres, jóvenes y parados de larga duración." 
Otro conjunto de normas que tienen especial repercusión en cuanto a la igualdad de género en las relaciones laborales se puede observar a continuación. La Ley Orgánica 3/2007, de 22 de marzo, para la igualdad efectiva de mujeres y hombres, tendrá un apartado más completo posteriormente, pues contiene la justificación principal de lo contenido en esta tesis doctoral, la igualdad de oportunidades entre mujeres y hombres. A continuación, en la Tabla 4, se enumeran y describe la normativa complementaria que también está relacionada con este objetivo.

\begin{tabular}{|c|c|}
\hline & \\
\hline $\begin{array}{c}\text { Ley } 39 / 1999 \text {, de } 5 \text { de } \\
\text { noviembre, para } \\
\text { promover la conciliación } \\
\text { de la vida familiar y } \\
\text { laboral de las personas } \\
\text { trabajadoras. }\end{array}$ & $\begin{array}{l}\text { Trata de guardar un equilibrio para favorecer los } \\
\text { permisos por maternidad y paternidad sin que ello afecte } \\
\text { negativamente a las posibilidades de acceso al empleo, } \\
\text { a las condiciones del trabajo y al acceso a puestos de } \\
\text { especial responsabilidad de las mujeres. Al mismo } \\
\text { tiempo se facilita que los hombres puedan ser } \\
\text { copartícipes del cuidado de sus hijos desde el mismo } \\
\text { momento del nacimiento o de su incorporación a la } \\
\text { familia. }\end{array}$ \\
\hline $\begin{array}{r}\text { Ley } 30 / 2003 \\
\text { octubre, sobr } \\
\text { para incor } \\
\text { valoración d } \\
\text { de génerc } \\
\text { disposic } \\
\text { normativas q } \\
\text { el Gobi }\end{array}$ & $\begin{array}{l}\text { Esta reforma establece que los proyectos de ley y las } \\
\text { disposiciones reglamentarias irán acompañadas de un } \\
\text { informe, sobre el impacto por razón de género, de las } \\
\text { medidas que contienen. Según el Instituto de la mujer } \\
(2005, \text { p.5) "El Gobierno asume la responsabilidad de } \\
\text { aportar información sobre la incorporación de la } \\
\text { perspectiva de género y la valoración de los efectos que } \\
\text { las normas aprobadas van a tener, de forma separada, } \\
\text { sobre los hombres y las mujeres". }\end{array}$ \\
\hline
\end{tabular}


Ley 62/2003, de 30 de diciembre, de medidas fiscales, administrativas

y del orden social.

Ley Orgánica 1/2004, de 28 de diciembre, de Medidas de Protección Integral contra la Violencia de Género.

ey 40/2006, de 14 de

diciembre, del Estatuto de la ciudadanía española en el exterior.
En la sección 3 sobre medidas en materia de igualdad de trato y no discriminación en el trabajo, para que sea real y efectivo en el acceso al empleo, la afiliación y la participación en las organizaciones sindicales y empresariales, las condiciones de trabajo, la promoción profesional y la formación profesional ocupacional y continua, así como en el acceso a la actividad por cuenta propia y al ejercicio profesional y la incorporación y participación en cualquier organización cuyos miembros desempeñen una profesión concreta. Estas medidas pueden ser de acción positiva.

Establece las medidas de sensibilización, prevención y detección e intervención en diferentes ámbitos. Con respecto a los derechos de las mujeres víctimas de violencia, se garantiza el derecho de acceso a la información y a la asistencia social integrada. También derechos económicos y medidas de protección en el ámbito social, para justificar las ausencias del puesto de trabajo de las víctimas de la violencia de género, posibilitar su movilidad geográfica, la suspensión con reserva del puesto de trabajo y la extinción del contrato.

El artículo 16 y el 22 contemplan los temas de igualdad de género en cuanto a los derechos y prestaciones incluyendo el ámbito del empleo y la ocupación, con mención especial a las mujeres aún más vulnerables que tuvieron que emigrar con la doble jornada: laboral y familiar, que después quieren retornar (Kahale, 2013). 
Ley Orgánica 3/2007, de 22 de marzo, para la igualdad efectiva de mujeres y hombres.
Esta ley proclama transversalidad, por lo que afecta directamente a todo un conjunto de normas de derecho. El Título IV se ocupa del derecho al trabajo en igualdad de oportunidades, incorporando medidas para garantizar la igualdad entre mujeres y hombres en el acceso al empleo, en la formación y en la promoción profesionales, y en las condiciones de trabajo. Se incluye, además, entre los derechos laborales de los trabajadores y las trabajadoras, la protección frente al acoso sexual y al acoso por razón de sexo. La obligación por parte de las empresas de negociar planes de igualdad en las empresas de más de doscientos cincuenta trabajadores o trabajadoras.

Tabla 4. Legislación española complementaria de igualdad de género. Fuente. BOE.

Elaboración propia.

\subsubsection{La Ley Orgánica 3/2007, de 22 de marzo, para la igualdad efectiva de mujeres y hombres}

Según el CEPC (2010, p. 1) esta ley en España tiene "un elemento de carácter innovador por la especial atención que prestan a la prevención de conductas discriminatorias y al énfasis en la aplicación del principio de igualdad, de manera transversal, a todos los órganos de la Administración." 
Esta ley tiene por objeto hacer efectivo el derecho de igualdad de trato $^{83}$ y de oportunidades entre mujeres y hombres, en particular mediante la eliminación de la discriminación de la mujer, sea cual fuere su circunstancia o condición, en cualesquiera de los ámbitos de la vida y, singularmente, en las diferentes esferas sociales para, en el desarrollo de los artículos 9.2 y 14 de la Constitución, alcanzar una sociedad más democrática, más justa y más solidaria.

Hay que tener en cuenta que esta ley utiliza el término sexo de forma neutra $y$, por tanto, reconociendo un derecho de carácter bidireccional que protege las desigualdades sufridas tanto por las mujeres como por los hombres. Además, a la hora de valorar la existencia de discriminaciones no habrá solo que atender al hecho físico de ser hombre y mujer, sino que, desde una amplia y ya comentada perspectiva de género, habrá que considerar las diferencias de trato que puedan derivar de los estereotipos y roles sociales asumidos por unos y otros.

Específicamente el título IV de la LOIMH se ocupa del derecho al trabajo en igualdad de oportunidades "incorporando medidas para garantizar la igualdad entre mujeres y hombres en el acceso al empleo, en la formación y en la promoción profesionales, y en las condiciones de trabajo. Se incluye,

\footnotetext{
${ }^{83}$ Según el artículo 5 de la LOIMH "el principio de igualdad de trato y de oportunidades entre mujeres y hombres, aplicable en el ámbito del empleo privado y en el del empleo público, se garantizará, en los términos previstos en la normativa aplicable, en el acceso al empleo, incluso al trabajo por cuenta propia, en la formación profesional, en la promoción profesional, en las condiciones de trabajo, incluidas las retributivas y las de despido, y en la afiliación y participación en las organizaciones sindicales y empresariales, o en cualquier organización cuyos miembros ejerzan una profesión concreta, incluidas las prestaciones concedidas por las mismas."
} 
además, entre los derechos laborales de los trabajadores y las trabajadoras, la protección frente al acoso sexual y al acoso por razón de sexo."

De acuerdo con Albiol et al. (2007, p. 24) con esta ley se pueden extraer tres conclusiones interesantes: (i) "los deberes establecidos en la LOI se imponen tanto a las personas físicas como a las jurídicas, pudiendo ser éstas, como aclara su art. 1.2, tanto públicas como privadas", (ii) "los destinatarios de las obligaciones de la LOI son dos: por un lado, desde luego, los poderes públicos (v.gr art. I .2 y Título II); pero, por otro, también los particulares --entre ellos, por tanto, los sujetos de la relación laboral-“, y (iii) "las personas físicas o jurídicas obligadas no sólo son españolas, sino también extranjeras"

Los objetivos principales a los cuales va encaminada esta ley son: prevenir y penalizar conductas discriminatorias contra las mujeres como bien protegido, prevenir y penalizar conductas de acoso, potenciar las medidas de conciliación de la vida personal y profesional, potenciar la corresponsabilidad ${ }^{84}$ en las labores domésticas y en la atención a la familia,

\footnotetext{
${ }^{84}$ Este concepto es la evolución de la conciliación e implica la "asunción equitativa por parte de hombres y mujeres de las responsabilidades, derechos, deberes y oportunidades asociados al ámbito de lo doméstico, la familia y los cuidados". Es decir, parte de la corresponsabilidad entre varones y mujeres, rompiendo así con las relaciones de género tradicionales, sigue con la corresponsabilidad entre los diferentes miembros de la familia, que habitúe a la responsabilización colectiva en el sostenimiento económico-afectivo del hogar. (Instituto de la mujer, 2008, pp. 86-87)
}

En este sentido, es importante que en las organizaciones se fomente e implemente "medidas de conciliación destinadas específicamente para los hombres con la finalidad de conseguir una corresponsabilidad real y efectiva" (Bodelón et al., 2014, p. 79) pues en general quienes acceden a estos programas son las mujeres, lo cual sigue perpetuando las desigualdades. 
entre mujeres y hombres, garantizar la presencia efectiva de la mujer en los distintos ámbitos empresariales, políticos y económicos a través del nuevo concepto de presencia equilibrada "con la regla del 60/40, ninguno de ambos sexos debería tener un porcentaje inferior a dicha cuantía" en este sentido, dotó de 8 años para su cumplimiento desde su entrada en vigor.

Según la LOIMH la medida más innovadora para favorecer la conciliación de la vida personal, familiar y laboral es el permiso de paternidad de trece días de duración, ampliable en caso de parto múltiple en dos días más por cada hijo o hija a partir del segundo. "Se trata de un derecho individual y exclusivo del padre, que se reconoce tanto en los supuestos de paternidad biológica como en los de adopción y acogimiento. También se introducen mejoras en el actual permiso de maternidad, ampliándolo en dos semanas para los supuestos de hijo o hija con discapacidad, pudiendo hacer uso de esta ampliación indistintamente ambos progenitores."

La batería de medidas previstas en esta ley parte desde la integración ${ }^{85}$ de la igualdad de oportunidades en las organizaciones y comprende aspectos como los planes de igualdad ${ }^{86}$, la creación de códigos

85 El proceso de integración de la igualdad de oportunidades entre mujeres y hombres requiere de una serie de pasos que según la Fundación MUJERES (2008, p. 21) inicia con el acuerdo de incorporación de la igualdad en la gestión empresarial, sigue con la formación del Comité de Igualdad (paritario empresa-representación sindical), continua con la información y formación de la plantilla, la realización del diagnóstico, la definición y desarrollo del Plan de Igualdad (de aquellas empresas obligadas por la ley y las que lo hacen voluntariamente) y finaliza con el seguimiento y evaluación del Plan de Consolidación del principio de igualdad en la gestión.

${ }^{86}$ En una investigación de Bodelón et al. (2014, p. 35) se especificó una serie de aspectos que podrían ser mejorables teniendo en cuenta el impacto que han tenido los planes de igualdad en las compañías, estos comprenden "la necesidad de una reglamentación 
internos en la empresa para prevenir las distintas formas de discriminación como el acoso, el distintivo empresarial en materia de igualdad, la búsqueda permanente en la ley del principio de "Presencia Equilibrada" en los distintos ámbitos sociales, incluidos los Consejos de Administración y las acciones positivas, con el fin de hacer efectivo el derecho constitucional de la igualdad.

Se justifica la elaboración de los planes de igualdad en las empresas pues con ello "pueden promover cambios en su organización y estructura que permitan que las personas trabajadoras puedan desarrollar sus potencialidades. Sólo así la empresa aprovechará todo el talento de su plantilla." (Departamento del trabajo, 2010, p. 7)

Según el artículo 46 de la LOIMH los planes de igualdad son un conjunto ordenado de medidas, adoptadas después de hacer un diagnóstico ${ }^{87}$ de situación, tendentes a alcanzar en la empresa la igualdad de

específica de la ley, la obligatoriedad de los planes para todas las empresas y establecer requisitos para especificar quiénes pueden realizar un plan de igualdad, así mismo, se indicó la conveniencia de realizar adecuaciones en las formas de reconocimiento en la elaboración de planes de igualdad; por último, se señaló la necesidad de establecer precisiones conceptuales en torno a los términos "negociar", "consultar" y "acordar"”

${ }^{87}$ Para realizar el diagnóstico completo en una organización con miras al plan de igualdad, se debería empezar con (i) el diseño de un modelo de indicadores (o selección de indicadores), (ii) la definición de las fuentes de información y técnicas de obtención: base de datos, entrevista, encuesta, (iii) la recogida de la información y, (iv) el procesamiento y análisis de la información y valoración de los indicadores. (Departamento del trabajo, 2010, p. 12)

Los ámbitos que se proponen para la actuación en este sentido, de acuerdo con (Departamento del trabajo, 2010, p. 23): 1. Adopción por parte de la dirección de una gestión organizativa que tiene en cuenta la igualdad de oportunidades. 2. Participación e implicación del personal de la empresa en el desarrollo de acciones en favor de la igualdad de 
trato y de oportunidades entre mujeres y hombres y a eliminar la discriminación por razón de sexo.

Adicionalmente, con respecto a los motivos de las conductas discriminatorias no solo incluye un hecho biológico como la maternidad sino también otros con mayor significado sociocultural como son el estado civil o la asunción de obligaciones familiares. En este sentido, es uno de los motivos principales de fondo por el cual las mujeres dejan de lado su carrera profesional.

A través de esta previsión se trata de combatir el trato desfavorable que muchas veces acompaña al rol sexista de la asunción del cuidado de los hijos y otros familiares, que tradicionalmente ha desempeñado la mujer, con las posibles consecuencias perjudiciales que ello conlleva para su vida, y en concreto, para su faceta laboral: contratación a tiempo parcial, reducciones de jomada con la consiguiente rebaja retributiva, salida absoluta del mercado de trabajo con dificultades de reingreso, interrupciones de su contrato a través de suspensiones o excedencias con posibles efectos negativos para su formación, promoción profesional entre otras.

La asunción por la mujer de este papel estereotipado responde, sin duda, como se ha venido insistiendo a razones socioculturales, aunque también, desde una perspectiva más pragmática y en una especie de círculo

oportunidades. 3. Uso no discriminatorio en el lenguaje y la comunicación corporativa. 4. Participación igualitaria de mujeres y hombres en los puestos de trabajo de la empresa. 5. Presencia de mujeres en cargos directivos o de responsabilidad. 6. Medidas implantadas para mejorar la compatibilidad de la vida personal y laboral. 7. Adopción de medidas de prevención de salud y riesgos laborales con perspectiva de género. 8. Igualdad retributiva entre mujeres y hombres. 9. Condiciones laborales igualitarias para mujeres y hombres. 10. Promoción de medidas de gestión de la movilidad que permitan un acceso igualitario de las mujeres y los hombres en el puesto de trabajo. 
o cadena discriminatoria, encuentra explicación en su normalmente menor salario y la consiguiente menor incidencia sobre la economía familiar de su desvinculación total o parcial del trabajo.

Es de resaltar que el ordenamiento jurídico español ha intervenido en los últimos años la dirección de la conciliación, no sólo ampliando los derechos de conciliación, sino también reconociendo que su ejercicio puede ser asimismo asumido por los hombres: unas veces, como derecho sometido a la voluntad de cesión de la mujer, es el caso del permiso de lactancia y de maternidad, y otras, como derecho de titularidad individual del trabajador es el caso de los permisos por enfermedad, la reducción de jornada o las excedencias. No obstante, los esfuerzos normativos en este terreno no se han traducido en un cambio real en el reparto de las cargas familiares. También aquí las estadísticas demuestran que siguen siendo las mujeres las que asumen estas responsabilidades y las que, por tanto, mayoritariamente ejercen los derechos de conciliación de la vida laboral y personal.

Por último, según Perán (2014, p. 59) con la LOIMH se "persigue la consecución de un nuevo orden social. Es decil tiene una profunda vocación de cambio y transformación social lo que implica que no bastan las reglas que ordenen conductas y actuaciones sino que las normas deben tender a subvertir situaciones consolidadas históricamente y refrendadas durante siglos por reglas jurídicas, por normas religiosas y por costumbres sociales." 


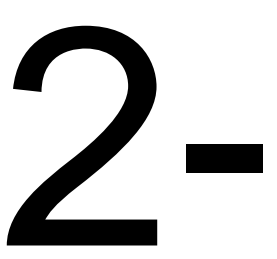

Capítulo Dos. Igualdad, género y trabajo en España. 


\subsection{Una primera aproximación}

De acuerdo con el Foro Económico Mundial [en adelante, WEF], España ocupa la posición número 29 del ranking global de la medición del índice Gender Gap ${ }^{88}$ de 142 países evaluados (2014, p. 8), cayendo casi 20 posiciones desde 2006 lo que evidencia un empeoramiento en las condiciones de las mujeres en este país también impulsada por la crisis económica ${ }^{89}$ que ha afrontado en los últimos años. Como vemos en la Tabla 5 , en comparativa con el año inmediatamente anterior, aunque se nota un retroceso de una posición en el índice global, se constatan incrementos sustantivos en los subíndices, lo que puede suponer que el país en vez de buscar cerrar las brechas de género, éstas se están incrementando. En efecto, la situación y la posición varían cuando se realiza el análisis y la medición por cuatro pilares específicos.

\footnotetext{
88 Un instrumento internacional para conocer el estado de los países en materia de igualdad de género es el "Global Gender Gap Report", publicado anualmente desde 2006 por el Foro Económico Mundial. Las dimensiones que se utilizan en este reporte son cuatro: participación económica y oportunidades, educación, salud y poder político. Cada dimensión contiene una serie de indicadores que permite evaluar algunos aspectos de la igualdad entre mujeres y hombres en el mundo. Para un reporte más actualizado y detallado véase http://reports.weforum.org/global-gender-gap-report-2016/
}

\footnotetext{
${ }^{89}$ Al respecto, Galvés y Rodríguez (2012, p. 114) explicaron varias pautas históricas que se tienen cuando se pasa por las crisis económicas y el impacto en la igualdad de género en el trabajo "La primera es que de las crisis se sale con una intensificación del trabajo de las mujeres, incluyendo el trabajo remunerado y, sobre todo, el no remunerado. La segunda que tras la crisis el empleo masculino se recupera siempre antes que el femenino y éste último acaba siempre aún más precarizado que cuando se inicia la crisis; y la tercera que de las crisis se sale con retrocesos en los avances en igualdad conseguidos en épocas de bonanza en lo relativo a la regulación, las políticas de igualdad y las reglas de juego en general"
} 
Por una parte, la (I) participación económica y oportunidades, que mide las brechas existentes en la participación en la fuerza laboral, la remuneración y los cargos jerárquicos; los (ii) logros educativos, que calcula el grado de alfabetización y los niveles educativos; la (iii) salud y supervivencia, que evalúa aspectos como la esperanza de vida y el nacimiento y, por último, el (iv) empoderamiento político, que mide la brecha entre el más alto cargo de toma de decisiones políticas.

En este sentido, de acuerdo al WEF en España las mujeres gozan de mejores condiciones principalmente en cuanto al ámbito político, también en el educativo mientras que ellas quedan rezagadas en el resto de esferas. Así, se confirma que la situación en el mercado de trabajo no es la mejor.

\begin{tabular}{|c|c|c|c|c|c|}
\hline \multicolumn{7}{|c|}{ Ranking Spain Gender Gap } \\
\hline Año & Global & (i) & (ii) & (iii) & (iv) \\
\hline 2013 & 30 & 76 & 40 & 75 & 27 \\
\hline 2014 & 29 & 84 & 44 & 87 & 23 \\
\hline Variación & $-3 \%$ & $11 \%$ & $10 \%$ & $16 \%$ & $-15 \%$ \\
\hline
\end{tabular}

Tabla 5. Ranking Spain Gender Gap. Fuente. (WEF, 2014). Elaboración propia

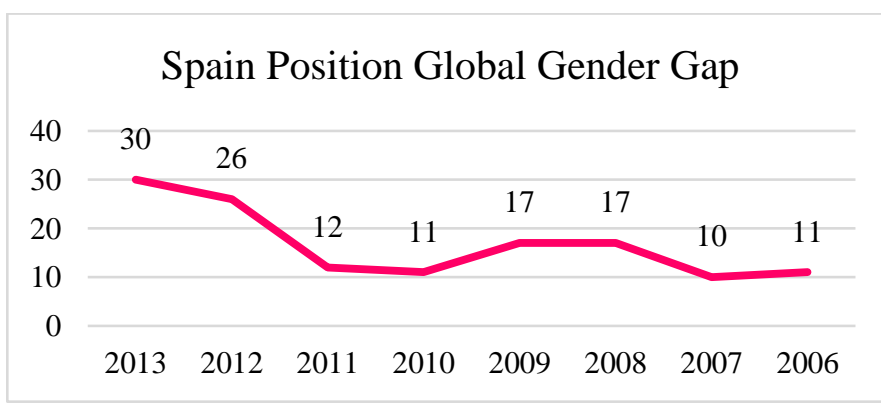

Gráfico 1. Spain Position Global Gender Gap. Fuente. (WEF, 2014). Elaboración propia. 


\subsection{Evidencia de la participación de la mujer en el mercado de trabajo.}

Para evaluar las situaciones de desigualdad de género en España que puede ser concebida desde un disímil reparto de cargos en el marco de las relaciones laborales, debemos remitirnos a estadísticas. Es por ello que el Instituto de la Mujer ${ }^{90}$ publica los resultados históricos y actualizados obtenidos de diversas fuentes oficiales, en diversos ámbitos sociales relacionados con la igualdad de género, pues sirven como punto de partida para reflejar el escenario en el que se encuentran las mujeres y poder proponer alternativas de solución ante estos hechos.

Así pues, el objetivo de este capítulo es analizar la situación laboral histórica y actual de las mujeres a nivel internacional, pero siempre aterrizándolo a España en los distintos ámbitos sociales en los cuales éstas se desempeñan, pues es necesaria91 la obtención de esta evidencia empírica,

\footnotetext{
90 El Instituto de la Mujer dispone de una base de datos muy completa, denominada Mujeres en Cifras, que está compuesta por un conjunto de indicadores que reflejan la situación de las mujeres en los distintos ámbitos de la sociedad, agrupados así: (i) Demografía, (ii) Familia y hogares, (iii) Educación, (iv) Ciencia y tecnología, (v) Empleo y prestaciones sociales, (vi) Conciliación, (vii) Salud, (viii) Poder y toma de decisiones, (ix) Reconocimiento social, (x) Violencia, (xi) Vulnerabilidad y múltiple discriminación, (xii) Indicadores de la UE y NNUU y (xiii) Mujeres y Hombres en España.

Para esta tesis doctoral, la base principal con la cual se extrajeron los datos y se realizaron los gráficos y los respectivos análisis partieron del grupo denominado "Poder y toma de decisiones". Para más información, véase:
} http://www.inmujer.gob.es/MujerCifras/Home.htm

${ }^{11}$ Según el decálogo de prioridades para la intervención pública del último informe de la ONU, el número diez consiste precisamente en la obtención de esa evidencia. Cfr. (ONU, 2015) 
pues permite evaluar los avances en el ámbito de los derechos económicos y sociales de las mujeres.

Es importante, antes de continuar, apuntar que a nivel internacional la crisis económica ha influido en las economías de los países y ha ido acrecentando las desigualdades sociales sobre todo interrumpiendo en lo que se había avanzado a través de los últimos años en cuanto a la participación de la mujer en el mercado de trabajo.

Evidencia de ello, el informe de la OIT (2012) ${ }^{92}$ reveló importantes conclusiones al respecto, por ejemplo en los países en desarrollo, las mujeres fueron particularmente afectadas en diversos sectores económicos, en términos de desempleo "de 2002 a 2007, la tasa de desempleo femenina se situó en 5,8 por ciento, comparada con 5,3 por ciento para los hombres, la crisis incrementó esta disparidad de 0,5 a 0,7 puntos porcentuales, y destruyó 13 millones de empleos para las mujeres", además el indicador de segregación ${ }^{93}$ profesional indicó que "las mujeres continúan estando

\footnotetext{
92 El informe Global Employment Trends 2012: Preventing a deeper jobs crisis (Tendencias mundiales del empleo 2012: Prevenir una crisis mayor del empleo, en español) analizó las desigualdades de género en materia de desempleo, empleo, participación de la fuerza de trabajo, vulnerabilidad, y segregación sectorial y profesional a nivel global. Véase (OIT, 2012)

${ }^{93}$ Con respecto a España, un estudio de (Dueñas, Iglesias \& Llorente, 2013, p. 105) permitió observar que "en primer lugar que es el colectivo masculino el que de forma predominante ha contribuido al crecimiento de la segregación laboral entre los años 1996 y 2007, ya que tanto para el conjunto nacional como para todas las regiones se observa una tasa de variación positiva del Índice de Gini entre ambos años. En segundo lugar, que es el colectivo femenino el que de forma predominante ha contribuido a la disminución de la segregación laboral entre los años 2007 y 2010, ya que tanto para el conjunto nacional como para todas las regiones se observa una tasa de variación negativa entre ambos años."
} 
segregadas en ciertos tipos específicos de profesión". En las economías desarrolladas, el empleo de las mujeres en la industria se redujo a la mitad, desplazando a 85 por ciento de ellas en los servicios, sobre todo en la educación y la salud.

Posteriormente en el informe de la OIT $(2014)^{94}$ se resaltó la caída de las tasas de participación en la mayoría de regiones a nivel mundial, principalmente en el mercado asiático donde muchas mujeres han abandonado el mercado de trabajo. A partir de todo lo anterior, muchas personas en respuesta a las pérdidas de empleo formal, se han reincorporado al mercado de trabajo, a menudo en empleos informales para compensar la

Además, concluyó que "entre 2007 y 2010 la disminución de la segregación se debe al efecto distribución, es decir, a la reducción porcentual del peso relativo de aquellos sectoresocupaciones que aglutinaban un mayor nivel de segregación, aunque en este caso solamente en España y en 7 de sus regiones."

Hay que tener en cuenta que "en muchos casos la segregación tiene un componente de decisión personal de las mujeres, normalmente condicionado por los roles tradicionales de género, y que en ocasiones pueden plantear su desarrollo profesional de una manera muy diferente a los hombres, ya que éstas toman más en cuenta sus expectativas familiares y el ejercicio de la maternidad, que conlleva la interrupción de su carrera por un tiempo, la solicitud de jornadas reducidas, trabajo a tiempo parcial, etc." (Forética \& Secretaria de Estado de Igualdad, 2010, p. 44)

${ }^{94} \mathrm{El}$ informe Global Employment Trends 2014: The risk of a jobless recovery (Tendencias Mundiales del Empleo 2014: ¿Hacia una recuperación sin creación de empleos?, en español) presentó los últimos datos y proyecciones sobre varios indicadores del mercado laboral a nivel mundial, incluyendo el empleo, el desempleo, la pobreza laboral y el empleo vulnerable. La débil recuperación de la economía mundial ha fracasado en generar una mejora en los mercados laborales, con el desempleo alcanzando los 202 millones a nivel global en 2013. Véase (OIT, 2014). 
pérdida de ingresos familiares, lo que en efecto visibiliza como la calidad del trabajo se ha visto reducida sobre todo para los grupos vulnerables como los jóvenes y las mujeres y, aunque la influencia de la crisis económica no es el objetivo de esta tesis doctoral, era importante conocer los impactos que en materia de igualdad de género ha generado.

Después de realizar una pequeña introducción sobre el impacto de la crisis económica a nivel global y como ha repercutido en la situación laboral de las mujeres, a continuación, se analizará la situación y la incorporación de las mujeres en los cargos políticos a nivel internacional, pero aterrizándolo a España.

\subsubsection{En el ámbito público}

Es bien sabido, que, en el último siglo, la sociedad ha experimentado considerables cambios en lo que respecta a las sociedades democráticas, esto sin duda ha influido en la presencia de las mujeres en posiciones políticas relevantes ${ }^{95}$, pues en su momento era muy difícil encontrarlas en dichos cargos.

De hecho, "las mujeres se consideran de forma creciente como sujetos políticos plenos potencialmente activos, por lo que sus niveles de interés y de

\footnotetext{
${ }^{95}$ En la doctrina, se puede encontrar posiciones como las de Barberá, Sarrió \& Ramos (2000b, p. 51) en las que refiriéndose a la 'feminización del poder', hacían alusión "a la creencia de que las mujeres pueden regenerar el degradado ejercicio de la política y restablecer su sentido original de servicio, así como incorporar un nuevo estilo en los modos de gestionar las empresas".
} 
información políticos irán equiparándose a los de los varones. Lo más significativo, no obstante, es que ellas piensen que los asuntos públicos son una cuestión de su competencia y que sean capaces no sólo de entenderlos sino de implicarse potencialmente en ellos. Distintos estudios han mostrado que la idea de que las mujeres pueden actuar en política de forma competente y están plenamente capacitadas para ocupar puestos de liderazgo ha ido extendiéndose entre ellas mismas así como entre los hombres." (Morán, 2011, p. 55)

De acuerdo con la ONU (2015, p. 5) "las mujeres han ganado terreno en la representación parlamentaria en casi el $90 \%$ de los 174 países para los que se dispone de datos. La proporción promedio de mujeres en el parlamento casi se ha duplicado en el mismo período; sin embargo, todavía solo uno de cada cinco miembros es mujer"

De hecho, una imagen actual a nivel global del resumen del acceso de mujeres a cargos políticos como presidenta y jefa de gobierno, puestos que se consideran la más alta autoridad política, lo proporcionó el periódico el país ${ }^{96}$ de España, el Gráfico 2 a continuación muestra que: "En el mundo, 57 países han tenido en algún momento de su historia a una mujer como primera ministra o como presidenta. En 20 de ellos una mandataria ha ocupado ambos cargos, en ocho solo el de presidenta y en 29 solo el de jefa del Ejecutivo". Los países que aparecen sin ningún color son los que, en efecto,

\footnotetext{
${ }^{96}$ El reportaje publicado el 7 de marzo de 2017 ¿Cuántas mujeres presidentas están en el poder?, con el objetivo de conmemorar el día de la mujer, mostró los países donde ha habido o hay mujeres en el poder por sufragio o elección democrática. Para ampliar la información véase:

http://internacional.elpais.com/internacional/2017/03/07/actualidad/1488879380_710686.ht ml?id_externo_rsoc=TW_CC
} 
no se les ha dado la oportunidad a las mujeres de ocupar dichos cargos, España uno de ellos.

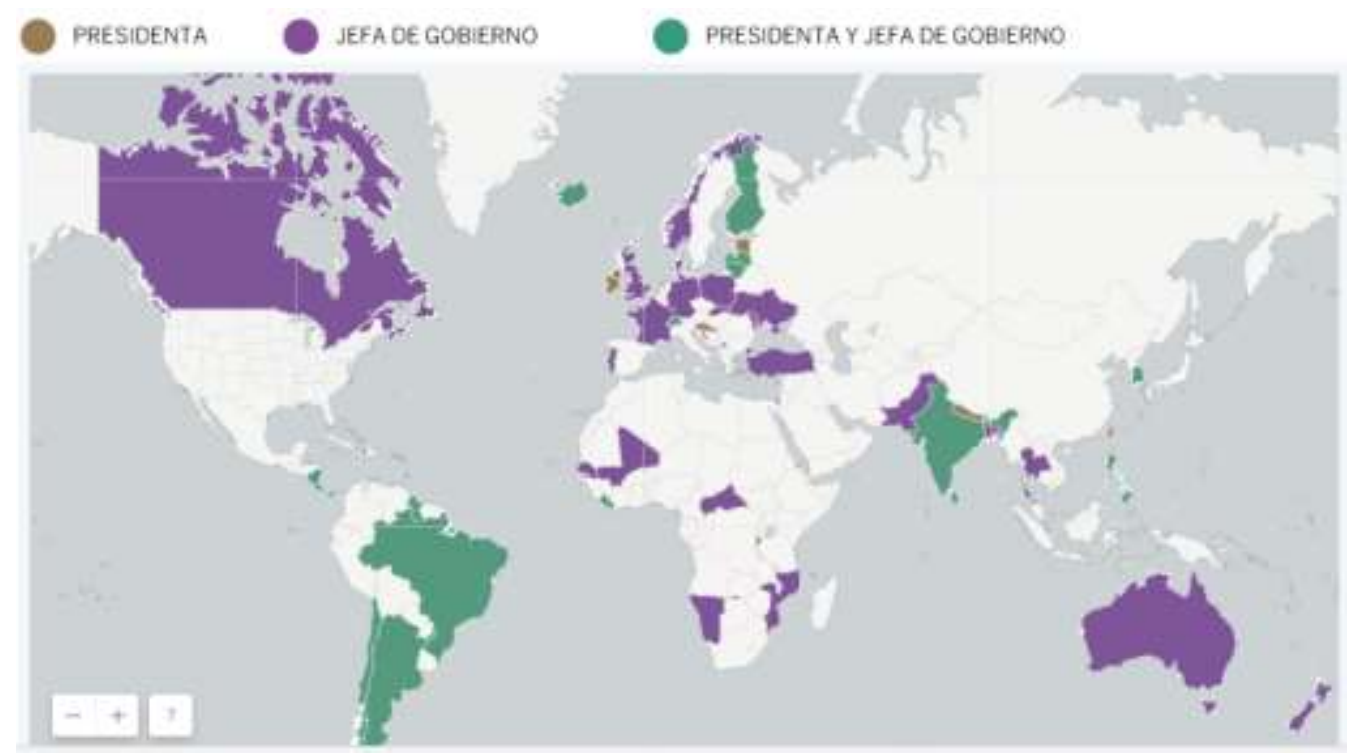

Gráfico 2. ¿Cuántas mujeres presidentas están en el poder? Fuente: El país (2017)

Esta información, permite validar que mujeres han logrado derrumbar el techo de cristal en algunos cargos políticos en distintos países a nivel internacional y que detrás de estas elecciones se ha forjado unas carreras brillantes $^{97}$ a través de los ascensos, sucediendo cargos políticos y ministeriales, sin contar con además algunas se les ha permitido ser

\footnotetext{
${ }^{97}$ Según Arranz (2004, p. 238) las mujeres con carreras exitosas «super-mujeres» tienen la opción de elegir, algunas lo hacen sin que eso implique renunciar a nada, es decir "son mujeres que quieren destacar profesionalmente tanto como sus compañeros mientras al mismo tiempo se ocupan del hogar, de la crianza, educación y cuidados de hijos y progenitores, además de permanecer siempre bellas y jóvenes"
} 
reelegidas. En la Tabla 6 que se muestra a continuación se encuentra un listado de las mujeres que han alcanzado el más alto cargo político en sus países, además en que periodos gobernaron. Las resaltadas en negrilla gobiernan en la actualidad ${ }^{98}$, en la Unión Europea los países que están presididos por mujeres son: Alemania, Reino Unido, Lituania, Noruega y Polonia.

\begin{tabular}{|c|c|c|c|}
\hline País & Cargo & Nombre & Periodo \\
\hline ALEMANIA & CANCILLER & Angela Merkel & 2005-actualidad \\
\hline ANTILLAS Neerlandesas & PRIMERA MINISTRA & Maria Liberia Peters & 1984-1986 \\
\hline ANTILLAS Neerlandesas & PRIMERA MINISTRA & Maria Liberia Peters & 1988-1994 \\
\hline ARGENTINA & PRESIDENTA & María Estela Martínez & $1974-1976$ \\
\hline ARGENTINA & PRESIDENTA & Cristina Fernández & $2007-2011$ \\
\hline ARGENTINA & PRESIDENTA & Cristina Fernández & $2011-2015$ \\
\hline AUSTRALIA & PRIMERA MINISTRA & Julia Eileen Gillard & $2010-2013$ \\
\hline BANGLADESH & PRIMERA MINISTRA & Khaleda Zia & 1991-1996 \\
\hline BANGLADESH & PRIMERA MINISTRA & Khaleda Zia & 2001-2006 \\
\hline BANGLADESH & PRIMERA MINISTRA & Sheikh Hasina & $1996-2001$ \\
\hline BANGLADESH & PRIMERA MINISTRA & Sheikh Hasina & 2009-actualidad \\
\hline BOLIVIA & PRESIDENTA & Lidia Gueiler & $1979-1980$ \\
\hline BRASIL & PRESIDENTA & Dilma Rousseff & $2011-2016$ \\
\hline BURUNDI & PRESIDENTA & Sylvie Kinigi & $1993-1993$ \\
\hline CANADA & PRIMERA MINISTRA & Kim Campbell & $1993-1993$ \\
\hline CHILE & PRESIDENTA & Michelle Bachelet & $2006-2010$ \\
\hline CHILE & PRESIDENTA & Michelle Bachelet & 2014-actualidad \\
\hline COREA DEL SUR & PRIMERA MINISTRA & Han Myung-Sook. & $2006-2007$ \\
\hline COREA DEL SUR & PRESIDENTA & Park Geun-Hye & $2013-2017$ \\
\hline COSTA RICA & PRESIDENTA & Laura Chinchilla & $2010-2014$ \\
\hline DINAMARCA & PRIMERA MINISTRA & Helle Thorning-Schmidt & $2011-2015$ \\
\hline
\end{tabular}

${ }^{98} \mathrm{La}$ actualidad significa a mayo de 2017 que es la fecha final de entrega de la tesis doctoral. 


\begin{tabular}{|c|c|c|c|}
\hline ESLOVENIA & PRIMERA MINISTRA & Alenka Bratusek & 2013-2014 \\
\hline FILIPINAS & PRESIDENTA & $\begin{array}{c}\text { Gloria Macapagal- } \\
\text { Arroyo }\end{array}$ & 2001-2010 \\
\hline FILIPINAS & PRESIDENTA & Corazón Aquino & $1986-1992$ \\
\hline FINLANDIA & PRESIDENTA & Tarja K. Halonen & $2000-2006$ \\
\hline FINLANDIA & PRESIDENTA & Tarja K. Halonen & $2006-2012$ \\
\hline FRANCIA & PRIMERA MINISTRA & Edith Cresson & 1991-1992 \\
\hline GRAN BRETAÑA & PRIMERA MINISTRA & Margaret Thatcher & $1979-1990$ \\
\hline GUYANA & PRESIDENTA & Janet Rosenberg Jagan & 1997-1999 \\
\hline HAITI & PRESIDENTA & Ertha Pascal & $1990-1991$ \\
\hline HAITI & PRIMERA MINISTRA & Michelle Pierre-Louis & $2008-2009$ \\
\hline HAITI & PRIMERA MINISTRA & Claudette Werleigh & $1995-1996$ \\
\hline INDIA & PRIMERA MINISTRA & Indira Gandhi & $1980-1984$ \\
\hline INDIA & PRIMERA MINISTRA & Indira Gandhi & $1966-1977$ \\
\hline INDIA & PRESIDENTA & Pratibha Patil & $2007-2012$ \\
\hline INDONESIA & PRESIDENTA & Megawati Sukarnoputri & $2001-2004$ \\
\hline IRLANDA & PRESIDENTA & Mary Mcaleese & $1997-2004$ \\
\hline IRLANDA & PRESIDENTA & Mary Mcaleese & $2004-2011$ \\
\hline IRLANDA & PRESIDENTA & Mary Robinson & 1990-1997 \\
\hline ISLA DOMINICA & PRIMERA MINISTRA & Eugenia Charles & 1980-1995 \\
\hline ISLANDIA & PRIMERA MINISTRA & Jóhanna Sigurdardóttir & 2009-2013 \\
\hline ISLANDIA & PRESIDENTA & Vigdis Finnbogadottir & $1980-1996$ \\
\hline ISRAEL & PRIMERA MINISTRA & Golda Meir & $1969-1974$ \\
\hline JAMAICA & PRIMERA MINISTRA & Portia Simpson-Miller & $2006-2007$ \\
\hline JAMAICA & PRIMERA MINISTRA & Portia Simpson-Miller & $2012-2016$ \\
\hline LETONIA & PRESIDENTA & Vaira Vike-Freiberga & $1999-2007$ \\
\hline LIBERIA & PRESIDENTA & Ellen Johnson Sirleaf & 2006-actualidad \\
\hline LITUANIA & PRESIDENTA & Dalia Grybauskaite & 2009-actualidad \\
\hline MALAWI & PRESIDENTA & Joyce Banda & $2012-2014$ \\
\hline MALÍ & PRIMERA MINISTRA & Cissé Mariam Kaïdama & $2011-2012$ \\
\hline MALTA & PRESIDENTA & Agatha Barbara & $1982-1987$ \\
\hline MOZAMBIQUE & PRIMERA MINISTRA & Luisa Diogo & $2004-2010$ \\
\hline NAMIBIA & PRIMERA MINISTRA & Saara Kuugongelwa & 2015-actualidad \\
\hline NEPAL & PRESIDENTA & Bidhya Devi Bhandari & 2015-actualidad \\
\hline NICARAGUA & PRESIDENTA & Violeta Chamorro & 1990-1997 \\
\hline
\end{tabular}




\begin{tabular}{|c|c|c|c|}
\hline NORUEGA & PRIMERA MINISTRA & | Gro Harlem Brundtland | & 1981 \\
\hline NORUEGA & PRIMERA MINISTRA & Gro Harlem Brundtland & 1986-1989 \\
\hline NORUEGA & PRIMERA MINISTRA & Gro Harlem Brundtland & $1990-1996$ \\
\hline NORUEGA & PRIMERA MINISTRA & Erna Solberg & 2013-actualidad \\
\hline NUEVA ZELANDA & PRIMERA MINISTRA & Helen Clark & 1999-2008 \\
\hline NUEVA ZELANDA & PRIMERA MINISTRA & Jenny Shipley & 1997-1999 \\
\hline PAKISTAN & PRIMERA MINISTRA & Benazir Bhutto & $1988-1990$ \\
\hline PAKISTAN & PRIMERA MINISTRA & Benazir Bhutto & 1993-1996 \\
\hline PANAMA & PRESIDENTA & Mireya Moscoso & 1999-2004 \\
\hline POLONIA & PRIMERA MINISTRA & Hanna Suchocka & $1992-1993$ \\
\hline POLONIA & PRIMERA MINISTRA & Ewa Kopacz & $2014-2015$ \\
\hline POLONIA & PRIMERA MINISTRA & Beata Szydło & 2015-actualidad \\
\hline PORTUGAL & PRIMERA MINISTRA & $\begin{array}{c}\text { Maria De Lurdes } \\
\text { Pintasilgo }\end{array}$ & $1979-1980$ \\
\hline PUERTO RICO & GOBERNADORA & Sila Calderón & $2001-2005$ \\
\hline REINO UNIDO & PRIMERA MINISTRA & Theresa May & 2016-actualidad \\
\hline $\begin{array}{c}\text { REPÚBLICA } \\
\text { CENTROAFRICANA }\end{array}$ & PRIMERA MINISTRA & Elisabeth Domitien & $1975-1976$ \\
\hline $\begin{array}{l}\text { SANTO TOME Y } \\
\text { PRÍNCIPE }\end{array}$ & PRIMERA MINISTRA & $\begin{array}{c}\text { María Do Carmo } \\
\text { Silveira }\end{array}$ & $2005-2006$ \\
\hline SENEGAL & PRIMERA MINISTRA & Aminata Touré & 2013-2014 \\
\hline SENEGAL & PRIMERA MINISTRA & Madior Boye & $2001-2002$ \\
\hline SRI LANKA & PRESIDENTA & Chandrika Kumaratunga & $1994-2005$ \\
\hline SRI LANKA & PRIMERA MINISTRA & Sirimavo Bandaranaike & 1960-1965 (Ceylan) \\
\hline SRI LANKA & PRIMERA MINISTRA & Sirimavo Bandaranaike & 1970-1977 \\
\hline SRI LANKA & PRIMERA MINISTRA & Sirimavo Bandaranaike & $1994-2000$ \\
\hline SUIZA & $\begin{array}{l}\text { PRESIDENTA DE LA } \\
\text { CONFEDERACIÓN }\end{array}$ & $\begin{array}{l}\text { Eveline Widmer- } \\
\text { Schlumpf }\end{array}$ & 2012 \\
\hline SUIZA & $\begin{array}{l}\text { PRESIDENTA DE LA } \\
\text { CONFEDERACIÓN }\end{array}$ & Doris Leuthard & 2010 \\
\hline SUIZA & $\begin{array}{l}\text { PRESIDENTA DE LA } \\
\text { CONFEDERACIÓN }\end{array}$ & Simonetta Sommaruga & 2015 \\
\hline SUIZA & $\begin{array}{l}\text { PRESIDENTA DE LA } \\
\text { CONFEDERACIÓN }\end{array}$ & Ruth Dreifuss & 1999 \\
\hline
\end{tabular}




\begin{tabular}{|c|c|c|c|}
\hline SUIZA & $\begin{array}{c}\text { PRESIDENTA DE LA } \\
\text { CONFEDERACIÓN }\end{array}$ & Micheline Calmy-Rey & 2007 y 2011 \\
\hline SUIZA & $\begin{array}{c}\text { CANCILLER } \\
\text { CONFEDERAL }\end{array}$ & Annemarie Huber-Hotz & $2000-2007$ \\
\hline SUIZA & $\begin{array}{c}\text { CANCILLER } \\
\text { CONFEDERAL }\end{array}$ & Corina Casanova & $2008-2015$ \\
\hline TAILANDIA & PRIMERA MINISTRA & Yingluck Shinawatra & $2011-2014$ \\
\hline TRINIDAD TOBAGO & PRIMERA MINISTRA & $\begin{array}{c}\text { Kamla Persad- } \\
\text { Bissessar }\end{array}$ & $2010-2015$ \\
\hline TURQUÍA & PRIMERA MINISTRA & Tansu Ciller & $1993-1996$ \\
\hline UCRANIA & PRIMERA MINISTRA & Yulia Timoshenko & $2005-2005$ \\
\hline UCRANIA & PRIMERA MINISTRA & Yulia Timoshenko & $2007-2010$ \\
\hline
\end{tabular}

Tabla 6. Presidentas y Jefes De Gobierno Siglo del XX Y XXI. Fuente: El país (2017), Catalyst (2016-c) y el portal Womenceo. Elaboración propia.

Por lo que es incuestionable la capacidad que tienen las mujeres como líderes y agentes de cambio en cualquier esfera social, además del derecho que les corresponde para participar en condiciones de igualdad en la gobernanza democrática. Sin embargo, a pesar de todo lo anterior, las mujeres aun no alcanzan a ocupar un papel significativo en la política y en la administración pública. Tal vez es más común encontrar, a diferencia del siglo pasado, a una mujer con la titularidad de un ministerio ${ }^{99}$ o porque no, tener

99 De hecho, según Morales \& Cuadrado (2011, p. 30) "en algunos gobiernos de la democracia española el número de ministras llegó a superar esporádicamente al de ministros (en un determinado Gabinete de diecisiete miembros nueve eran mujeres) pero esta evidencia tiene un carácter anecdótico, ya que otros gobiernos de esa misma democracia no contaron con ninguna mujer en el Consejo de Ministros y que la práctica habitual es reservar a los varones los ministerios más importantes." 
un lugar en el congreso de diputados, pero, como se ha venido insistiendo, a la hora de evaluar si pueden llegar más alto la situación cambia.

Una de las razones debido al aumento de esta proporción no ha sido por una voluntad real de oportunidades para las mujeres de acuerdo con sus capacidades, el Informe de 2013 sobre los Objetivos de Desarrollo del Milenio manifestó que "las mujeres están asumiendo más poder en los parlamentos del mundo, apoyadas en los sistemas de cupos" (ONU, 2013, p. 22).

Justamente, la aplicación de la cuota legal de género ha producido, en España según Ortega, Torres \& Trujillo (2011, p. 119) "resultados diferenciales tanto en la magnitud como en el incremento de la presencia de las mujeres en las instituciones políticas, en los cuatro procesos de ámbito nacional."

De hecho, como sostiene González \& Rodríguez (2008) el principio de representación política viene de la mano con conceptos como la pluralidad y la diversidad social, por lo que es justo decir que deba existir por parte de representantes de diversos sectores sociodemográficos, por ejemplo, las mujeres, el poder acceder a los diversos cargos de elección popular. Bajo este marco, las reformas concernientes a las cuotas de género ${ }^{100}$ son entendibles, puesto que responden a una necesidad social de representación política y al principio de equidad.

Entre los factores que explican el grado de progresión en la presencia de las mujeres en el empleo público, Jerez \& Delgado (2011) destacaron la

\footnotetext{
100 En este sentido, se coincide con el planteamiento de Barberá, Sarrió \& Ramos (2000-b, p. 52) las autoras justifican las medidas de acción positiva como algo necesario, pero sin ser permanente, así "priorizar la promoción profesional de una mujer, frente a un varón, sólo se justifica como medida transitoria que tiene por objeto compensar parcialmente la discriminación de género que las mujeres han padecido durante muchos años.
} 
cultura política del país en cuestión, determinados factores institucionales y la propia composición partidista, y por ende ideológica, de las cámaras legislativas. Además, la investigación académica en este sentido ha sido poca y solo se ha desarrollado en las últimas décadas, lo que en efecto no ha generado la suficiente visibilidad que requiere.

Figueruelo et al. (2012, p. 206) defienden en este sentido los códigos éticos "por su vocación de persuadir e incentivar a los miembros de la organización para lograr determinados comportamientos éticos, frente a la sanción o coerción propias de la regla jurídica. La aprobación de códigos de conducta dirigidos a los servidores públicos, que se inserta en el marco éticojurídico de la actuación administrativa, constituye un instrumento para juridificar el fenómeno de la ética pública y garantizar un comportamiento ético de las Administraciones."

Los estudios de la relación existente entre la mujer y la política se vienen abordando desde dos perspectivas diferenciadas: una aproximación descriptiva y una sustantiva (Delgado \& Jerez, 2011). La primera consiste en el cálculo sobre la proporción de mujeres que ocupan posiciones políticas en los distintos niveles y ámbitos territoriales de poder y representación, así como en la búsqueda e identificación de las razones y los cambios que hayan podido experimentar a lo largo del tiempo. La segunda que consiste en la forma como gobiernan las mujeres y en las actividades que desarrollan con el objetivo de implementar la perspectiva de género en las políticas públicas. En efecto, esta tesis va más encaminado a la primera aproximación.

Ahora bien, uno de los obstáculos para el aumento de la proporción de las mujeres en el ámbito político tiene que ver con los estereotipos discriminatorios y sobre todo aspectos relacionados en la forma como socializan los sexos y que difieren respectivamente, es decir, generalmente las mujeres "...tienen menor probabilidad que los hombres de contar con la 
educación, los contactos y los recursos necesarios para convertirse en líderes eficaces"101

Ahora bien, a continuación, es importante conocer la evolución de la participación femenina en el ámbito político en España, para ello, se utilizarán los datos aportados por el Instituto de la Mujer en las distintas ramas del poder público, los cuales se trasladarán a distintos gráficos, que permitirán visibilizar de mejor manera dicha evolución, a partir de lo anterior, se analizará por cargos específicos y comunidades autónomas, utilizando como cierre el periodo 2013-2014.

Para empezar, en los gobiernos autonómicos, es decir, en las consejerías $^{102}$ ha aumentado muy lentamente durante los últimos años, esto se demostrará con el análisis de las estadísticas. Para el cargo de presidente ${ }^{103}$, en 2013 se situó en un $15,79 \%$ cifra que equivale a 3 presidentas de 19 consejos autonómicos.

Como se observa en el Gráfico 3, desde 1996 hasta 2003 ninguna mujer ocupó dicho cargo, en el periodo de 2004 hasta 2011 se mantuvo igual con una proporción del 5,26\% que equivale a una (1) sola mujer presidenta,

101 Es una de las razones que explica ONU Mujeres en su página web en el aspecto sobre liderazgo y participación política de las mujeres. Cfr. http://www.unwomen.org/es/what-wedo/leadership-and-political-participation

102 Se denomina consejería a cada una de las carteras en que se dividen los gobiernos de las comunidades autónomas de España. Se trata del equivalente a los ministerios en el reparto por funciones de los órganos de gobierno estatales. La cabecera de una consejería es regida por un responsable máximo, que se conoce como consejero. Asimismo, la dependencia o sede de cada consejería recibe la misma denominación.

${ }^{103}$ En este caso, se refiere al cargo de presidenta de las consejerías de las comunidades autónomas. 
cifra significativamente baja para una sociedad que había evolucionado en temas de género. El salto fue dado en 2011 llegando al 21,05\% aumentando en casi 15 puntos porcentuales, pero no hay que engañarse pues con respecto al 2013 era solo una mujer más, lo que en total significó que solo cuatro mujeres a esa fecha ocupaban el cargo de presidentas.

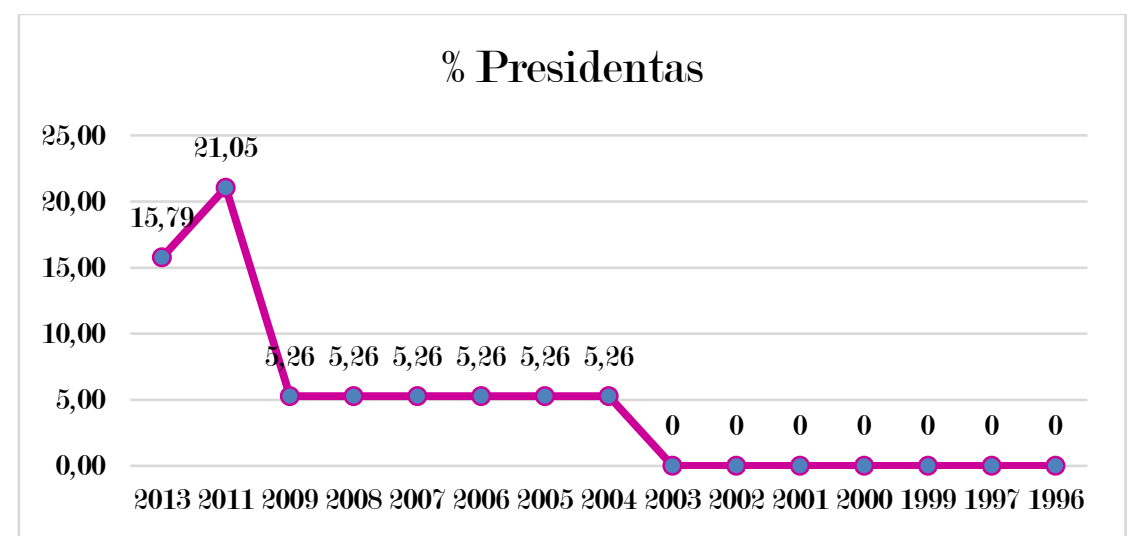

Gráfico 3. \% total mujeres presidentas en las consejerías autonómicas. Fuente. IM y FICESA. Elaboración propia

Ahora bien, en referencia a la proporción de consejeras en los gobiernos autonómicos, las cifras mejoran considerablemente, ganando más de veinte puntos porcentuales desde 1996 hasta el 2013, situándose a 2013 el total de las mujeres consejeras de los gobiernos autonómicos en España, en un $34,16 \%$ del total de consejeros, lo que representa unas 55 mujeres versus unos 106 hombres, es evidente que el género masculino duplica al femenino en estos cargos. Según el Gráfico 4, el punto máximo de representación fue alcanzado en 2009 cuando la proporción de mujeres se situó en casi un $42 \%$ llegando a 91 mujeres consejeras versus 126 varones. 
De ese 34,16\% de total de mujeres en consejerías en España en 2013, desglosándolo por gobierno autonómico, en el Gráfico 5 se observa que las Baleares no tenían a esa fecha a ninguna mujer en su consejería, y le siguen con porcentajes bajos la comunidad de Aragón y de Murcia con un $11 \%$ y un $13 \%$ respectivamente. Mientras que el porcentaje más alto de consejeras lo tenía Asturias con un $63 \%$, le sigue Cantabria y Galicia ambas con un 50\%.

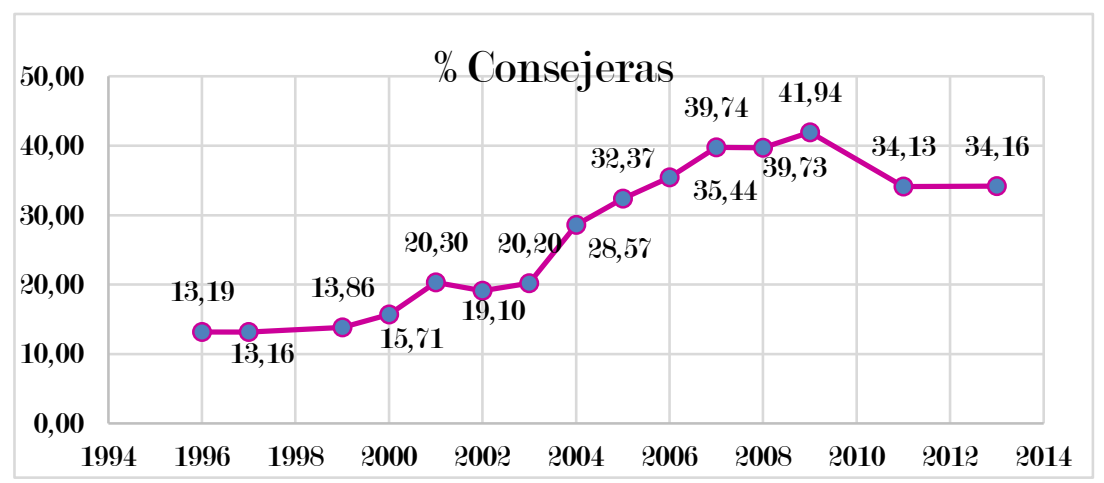

Gráfico 4. \% total mujeres consejeras en gobiernos autonómicos. Fuente. IM y FICESA. Elaboración propia

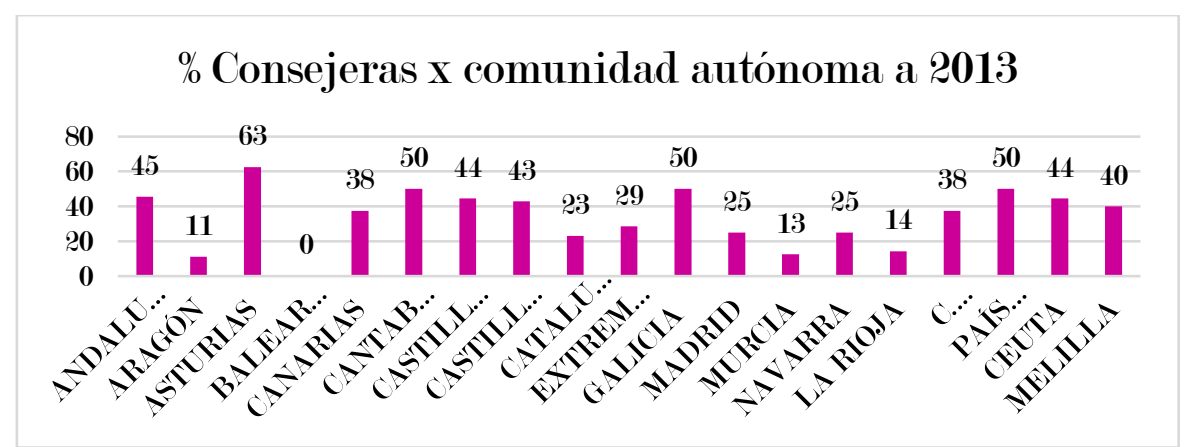

Gráfico 5. \% total mujeres consejeras por gobierno autonómico. Fuente. IM y FICESA. Elaboración propia 
Por otro lado, en referencia a la administración local, es decir el puesto de alcaldesas en España la tendencia ha sido positiva desde 1983 hasta 2014 tal como se observa en el Gráfico 6, llegando a una proporción de un 17,42\% el punto más alto durante todo el periodo en este ese año, es decir, de las 8.110 alcaldías existentes, eran ocupadas por mujeres 1.413 de ellas. A pesar de ser un porcentaje significativamente bajo, si se compara con el número de alcaldías ocupadas por mujeres en 1983 que era de 164, se evidencia un avance importante desde esa época hasta el periodo de cierre 2013-2014.

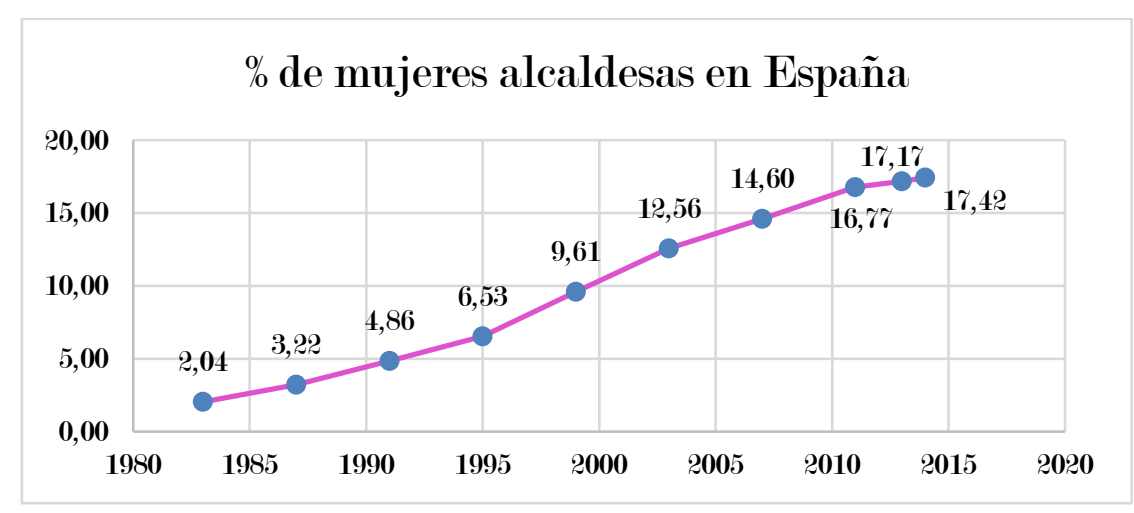

Gráfico 6. \% total mujeres alcaldesas en España. Fuente. IM y Ministerio de Hacienda. Elaboración propia

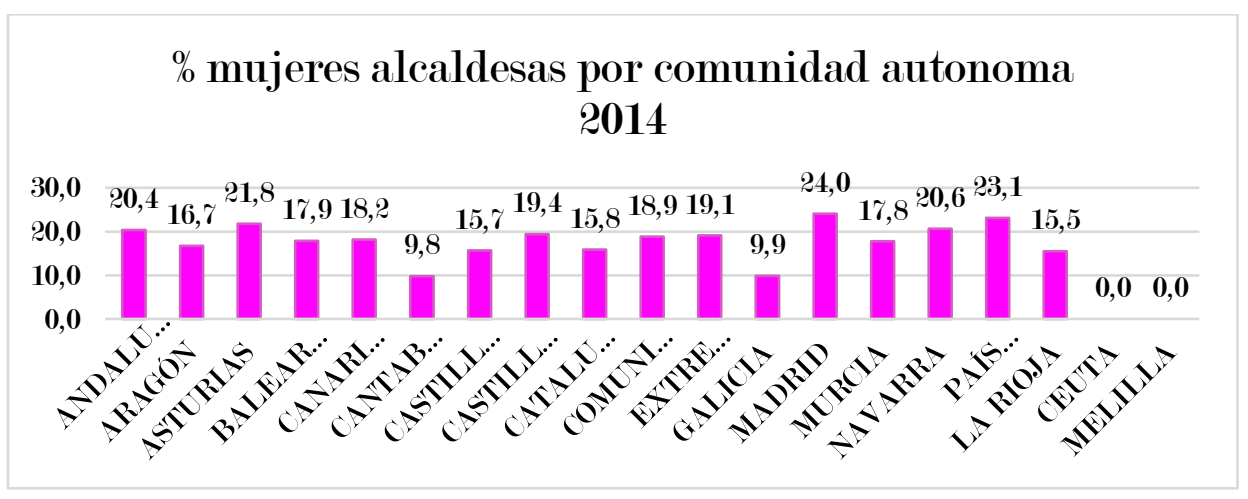

Gráfico 7. \% total mujeres alcaldesas por gobierno autonómico. Fuente. IM y Ministerio de Hacienda. Elaboración propia 
Con respecto al desglose de alcaldesas por comunidad autónoma en 2014, se observa en el Gráfico 7 que hay diferencias entre las mismas. Por un lado, de acuerdo a las cifras proporcionadas Ceuta y Melilla no han tenido a ninguna mujer alcaldesa desde 1999, cargo ocupado en general por el género masculino, situación que se puede sustentar debido a la posición territorial cercana a Marruecos y a la cultura machista tan fuertemente arraigada en este tipo de país islamista.

Le siguen las comunidades autónomas de Galicia y Cantabria cuyos porcentajes no alcanzan a superar el $10 \%$ para el periodo de 2014 . Por su parte, el mayor porcentaje lo obtuvo la comunidad de Madrid con un $24 \%$ de mujeres alcaldesas lo que representa aproximadamente un total de 43 mujeres versus 136 hombres, lo que no alcanza a ser suficiente. En este sentido, aunque sí que se ha avanzado en este tipo de cargos, lograr que las mujeres puedan desempeñar dichos puestos les corresponde a los partidos políticos, por lo que las alcaldías se constituyen como un verdadero reto para alcanzar la igualdad entre las mujeres y hombres que son candidatos.

En el poder legislativo, es decir, en el Senado y en el Congreso, históricamente las mujeres tampoco han tenido una participación significativa. Aunque, la participación del total de las mujeres en el senado al constituirse la cámara por grupo parlamentario ha tenido una evolución histórica positiva como lo vemos en el Gráfico 8, llegando en el último periodo legislativo analizado de 2011-2015 a un 33,33\% de proporción máxima lo que representa aproximadamente 86 mujeres de 261 miembros, a diferencia del periodo 1982-1986 que rondaba el $4 \%$ lo cual representaba 11 mujeres de 253 miembros.

En el desglose de ese $33,33 \%$ de ese último periodo, por grupo parlamentario quien lideró la lista de la mayor proporción de mujeres, es el CiU [Convergència i Unió, en español Convergencia y Unión], seguido muy de cerca por el partido Popular, partido del gobierno actual; no obstante, 
ambos no alcanzan a superar el $39 \%$. Una situación a resaltar es que la progresiva incorporación de las mujeres a los órganos directivos de los partidos políticos se aprecia incluso en algunas fuerzas políticas que no se han caracterizado por ser especialmente sensibles a esta cuestión en la elaboración de sus listas electorales (Cfr. Delgado \& Jerez, 2008)

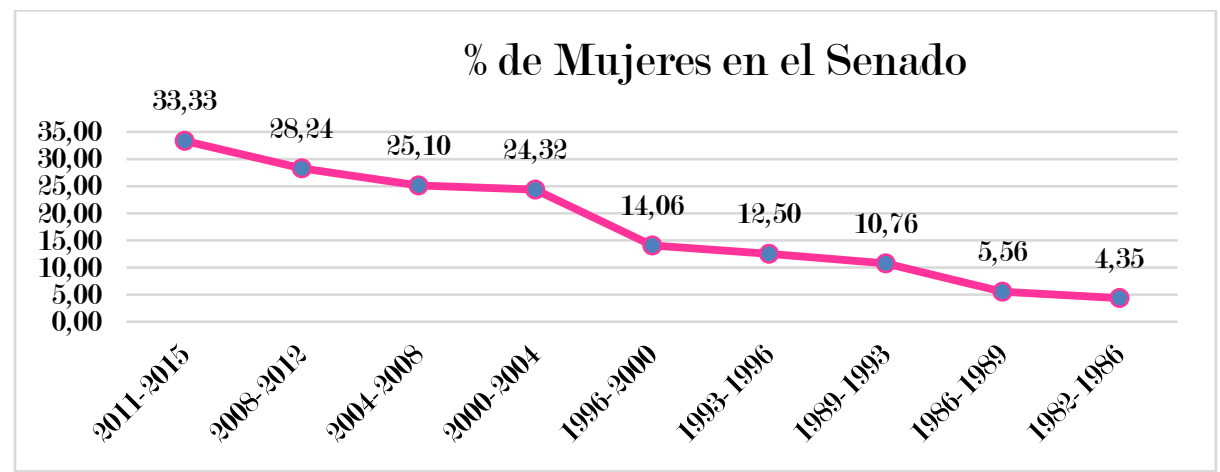

Gráfico 8. \% total mujeres senadoras por periodos legislativos. Fuente. IM. Elaboración propia

\begin{tabular}{|l|r|}
\hline Partido Político & \% Mujeres \\
\hline CiU & $38,46 \%$ \\
\hline Popular & $37,89 \%$ \\
\hline Vasco-PNV & $30 \%$ \\
\hline Entesa pel Progrés de Catalunya (2) & $30 \%$ \\
\hline Socialista & $22,41 \%$ \\
\hline Mixto & $22,22 \%$ \\
\hline
\end{tabular}

Tabla 7. \% total mujeres senadoras por grupos parlamentarios 2011-2015 de mayor a menor. Fuente. IM. Elaboración propia

Sin desviarnos de las estadísticas en España, las principales formaciones políticas han adoptado estrategias diferentes para incrementar 
la presencia de mujeres tanto en sus listas electorales como en sus órganos internos. Una de ellas, que la presencia de mujeres en las listas electorales es un factor atractivo para seducir a la mitad de los votantes, pero sea cual fuese la estrategia conveniente o no, ha contribuido a cambiar la mentalidad para favorecer la presencia del género femenino en la política.

Ahora bien, en el congreso, la situación es similar, aunque la evolución a medida que ha pasado los años ha sido positiva, la proporción de mujeres en el congreso al constituirse la cámara no ha logrado superar el $36 \%$ lo que supone 126 mujeres de 350 miembros situándose en ese mismo porcentaje en el periodo de 2011-2015, a diferencia del periodo 1982-1986 donde no superaba el $5 \%$ (véase Gráfico 9). Lo que evidentemente supone un incremento desde esa época hasta hoy de más de 30 puntos porcentuales. Por lo que es preciso concluir, que tanto en el senado como en el Congreso la variación de la presencia femenina en ambos órganos ha sido constante y progresiva, no obstante, el avance obtenido con el porcentaje a fecha de corte de esta investigación no es suficiente para alcanzar la paridad.

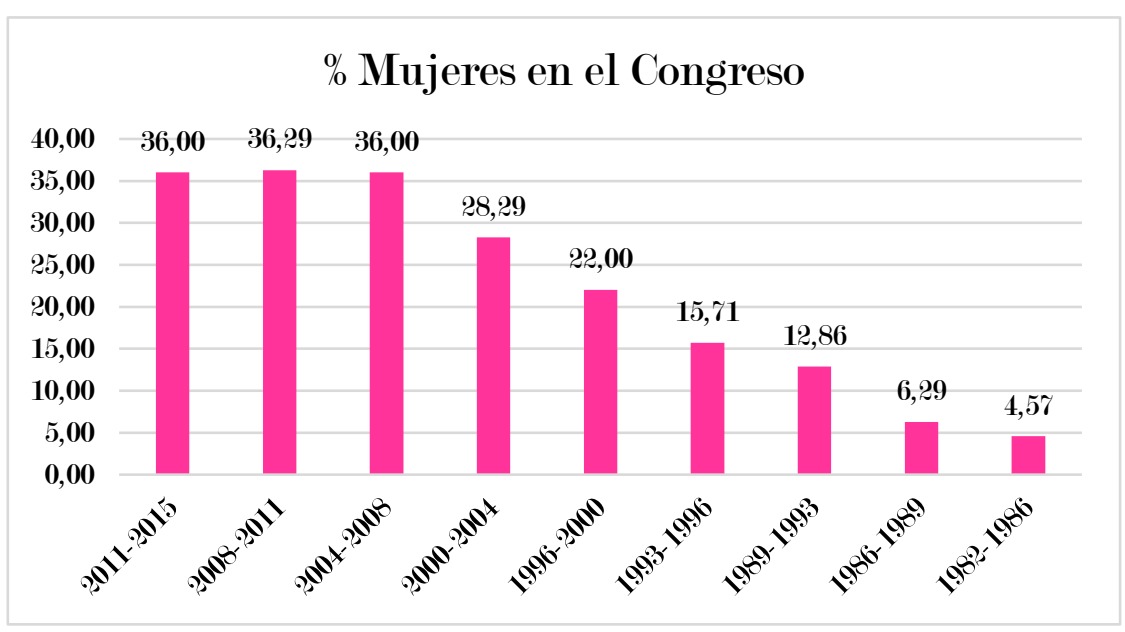

Gráfico 9. \% total mujeres diputadas por periodos legislativos. Fuente. IM. 
En el desglose de ese 36\% correspondiente al periodo de cierre acerca de la presencia femenina en el congreso, la distribución de mujeres por grupo parlamentario, la lista la lidera el partido Unión Progreso y Democracia con un $40 \%$ de mujeres sobre el total de sus diputados, seguido por el Partido Socialista Obrero Español con un 39\%. El porcentaje más bajo lo tiene el partido Vasco-PNV con un $20 \%$ tal como se observa en la Tabla 8.

Si se analiza a fondo no sería relevante el $40 \%$ de presencia femenina en el partido UPyD puesto que estaba representado en el congreso por 5 miembros de los cuales, 2 eran mujeres, este partido creó en 2011 un grupo parlamentario propio, gracias a un diputado de Foro Asturias que, tras la investidura, pasa a integrarse en el grupo mixto. Tal vez, si sea representativo en el caso del PSOE con el 39,09\% lo que representa 43 mujeres de un total de 110 diputados.

Con respecto a los grupos más representativos a lo largo de la historia, los Partidos Popular y Socialista, en cuanto a la proporción de mujeres del total de diputados en el congreso, el partido socialista siempre ha tenido una tendencia superior de mujeres diputadas que el partido popular tal como se observa en el Gráfico 10, llegando en el periodo de 2004-2008 como el punto máximo con una proporción del $46,30 \%$ de mujeres sobre el total de diputados, mientras que el punto máximo del partido popular ha sido en la legislatura de cierre de la investigación con un 36,22\%.

\begin{tabular}{|c|c|}
\hline Partido político & \% de Mujeres \\
\hline Unión Progreso y Democracia & $40 \%$ \\
\hline Socialista & $39,09 \%$ \\
\hline Popular & $36,22 \%$ \\
\hline Catalán-CiU & $31,25 \%$ \\
\hline IU-ICV & $28,57 \%$ \\
\hline Mixto & $26,67 \%$ \\
\hline Vasco-PNV & $20 \%$ \\
\hline
\end{tabular}


Tabla 8. \% total mujeres diputadas en el congreso por grupos parlamentarios 2011-2015 de mayor a menor. Fuente. IM.

Elaboración propia.

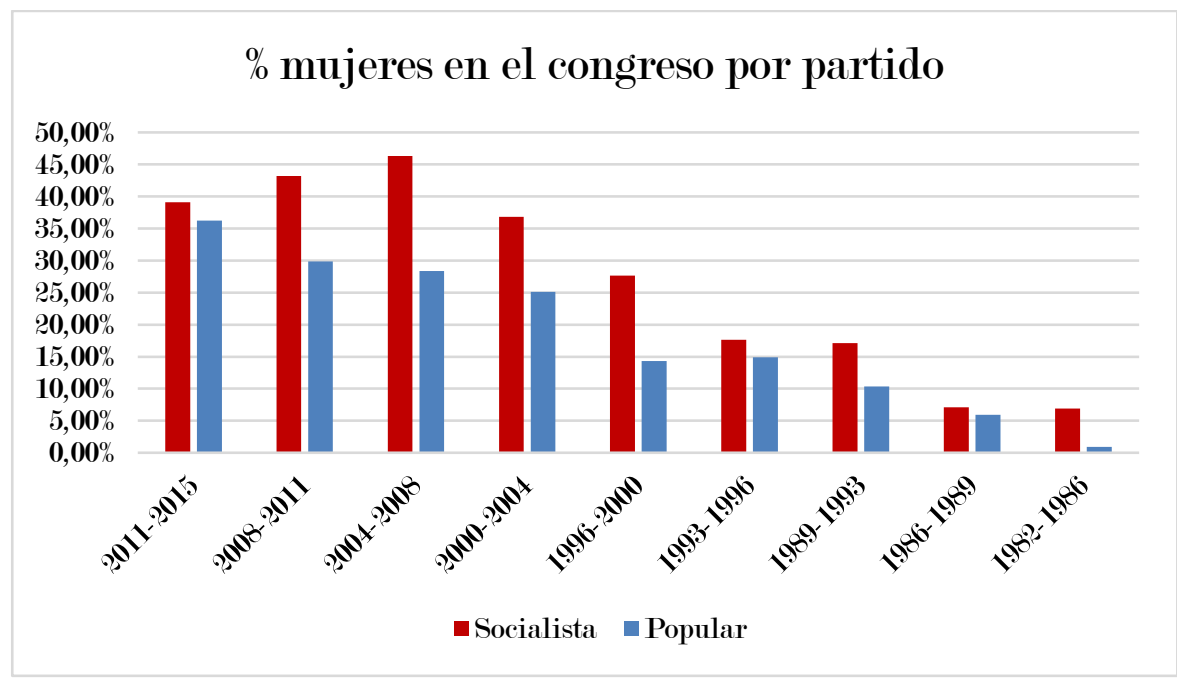

Gráfico 10. Comparativo de partidos y evolución del \% total mujeres diputadas en el congreso. Fuente. IM. Elaboración propia

Situación que ha sido muy diferente en los partidos más representativos a la hora de elegir a sus representantes del senado, pues la evolución histórica de la proporción de mujeres ha sido variable en ambos partidos tal como se observa en el Gráfico 11. Desde 1982 hasta 1996, la tendencia fue positiva en ambos partidos en las cuatro primeras legislaturas, con una mayor proporción de mujeres por parte del partido socialista.

Sin embargo, a partir de ahí se ha notado caídas en ambos partidos en cuanto a la proporción de mujeres, llegando el partido popular a una proporción máxima de mujeres en de un $38 \%$ en la legislatura de cierre de la investigación y el partido socialista con un $29 \%$ en la legislatura anterior 20082012. 


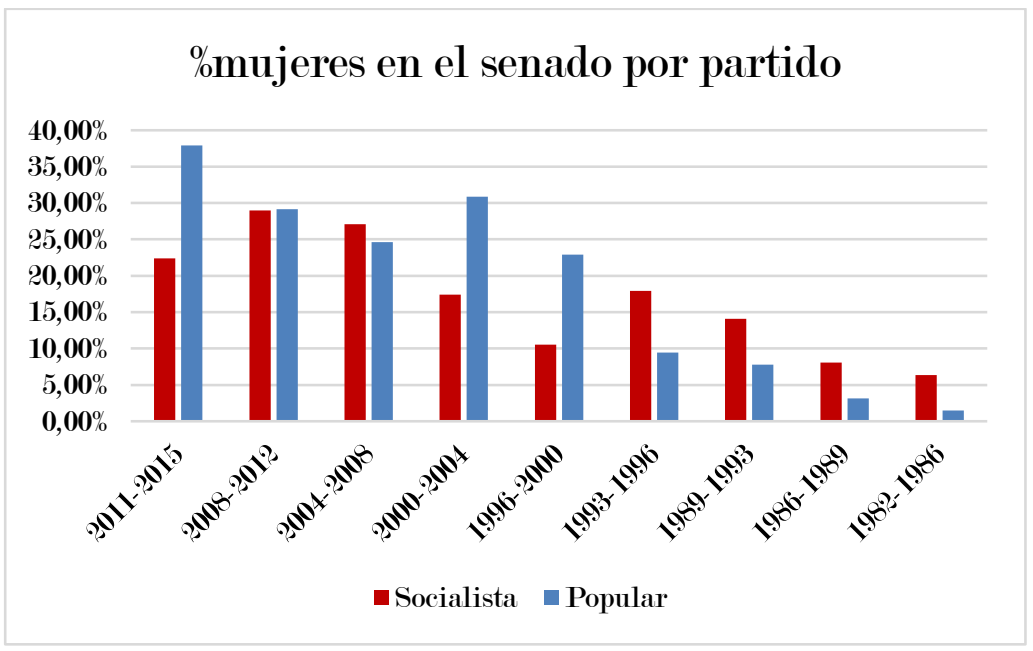

Gráfico 11. Comparativo de partidos y evolución del \% total mujeres diputadas en el senado. Fuente. IM. Elaboración propia

En los últimos años, diferentes partidos acordaron aplicar criterios de paridad $^{104}$ en la composición de las listas, y algunos incluso aprobaron que fuera por el sistema de cremallera (Mora, 2002) es decir, alternando hombres y mujeres desde el principio, para evitar que ellas vayan a parar a la parte final de la candidatura. Esta política ha incrementado notablemente la presencia de las mujeres en las cámaras legislativas.

\footnotetext{
104 Al respecto, en una investigación de Ortega, Torres \& Trujillo (2011, p. 131) se demostró que con estos criterios de paridad "el primer dato a destacar es que las reglas sobre composición equilibrada de los dos sexos se tradujeron, para el conjunto de las listas de ambos partidos, en una mayor presencia de hombres. Así, del total de candidatos titulares presentados (350 por cada partido), el 54,9\% y el 52,6\% eran hombres en las listas del PP y del PSOE, respectivamente. No obstante, sobre el total de elegidos, los hombres representaban el $70,1 \%$ en las filas del PP y el 56,8 \% en las del PSOE."
} 
Un caso, por ejemplo, del Partido Socialista Obrero Español ${ }^{105}$ quien ha utilizado como estrategia para promover la igualdad de género, que en sus listas se vayan intercalando mujeres y hombres para favorecer el acceso de las mujeres a cargos políticos. De hecho, esto es contrastado por Ortega, Torres \& Trujillo (2011, p. 136) quienes defendieron que el aumento del porcentaje de mujeres elegidas en 2008 se debe a que "fundamentalmente el PSOE como grupo mayoritario, ya venían aplicando voluntariamente medidas más favorables a la ordenación por tramos de las mujeres en sus listas electorales que las previstas legalmente."

Con respecto, a los altos cargos de la administración del estado, la situación histórica ha sido diferente para los ministerios, puesto que la proporción de las mujeres en estos cargos en general ha sido mayor. Llegando incluso en varios periodos a proporciones igualitarias entre mujeres y hombres tal y como se observa en el Gráfico 12, donde el porcentaje es un $50 \%$. Aunque en el periodo de cierre de la investigación, es decir, en el periodo 2013 no logró superar el 31\%, en conclusión, se ha disminuido esa tendencia, ciertamente esto ha sido impulsado por los partidos políticos que han gobernado en los periodos evaluados.

No se puede decir lo mismo de las embajadas de España en otros países, de los datos disponibles a 2005 por el Instituto de la Mujer, de 105 miembros que en total se reportaron, solo había 6 mujeres, es decir, casi un $6 \%$. Los embajadores de organismos internacionales no reportaron mujeres, es decir, un $100 \%$ de estos cargos estaban ocupados por hombres, lo cual debe mostrar una primera alerta del porqué las mujeres no han podido acceder específicamente a estos cargos en particular.

\footnotetext{
105 Esta información fue proporcionada por Enrique Cabero Morán, director de esta tesis doctoral en tutoría realizada en el mes de junio de 2016.
} 
En el cargo de las secretarías de estado, la evolución histórica de la proporción de las mujeres en este cargo también ha sido baja, llegando a un $20 \%$ en el periodo de 2013, es decir, 6 mujeres ocuparon el cargo de un total de 30 según se observa en el Gráfico 13.

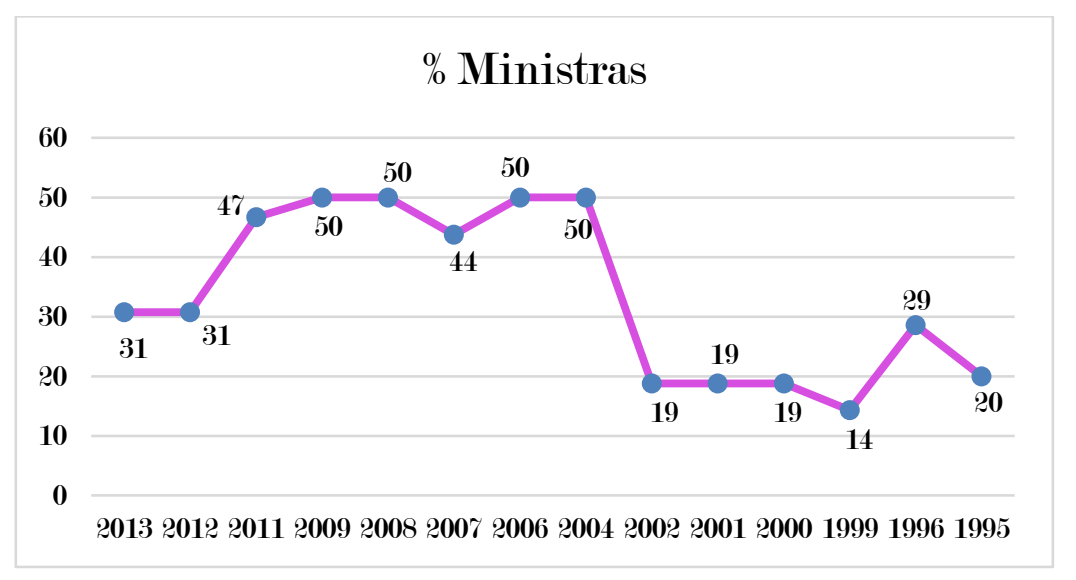

Gráfico 12. \% Mujeres ministras por año. Fuente. IM.

Elaboración propia

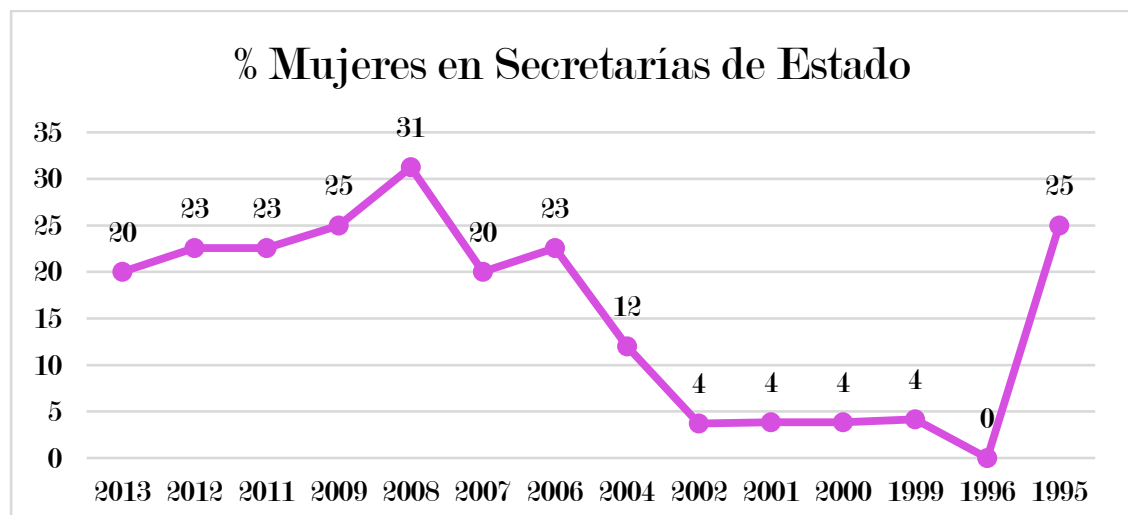

Gráfico 13. \% Mujeres en Secretarías de Estado por año. Fuente. IM. Elaboración propia 
En este punto, hay que hacer un paréntesis para justificar el aumento de la proporción de mujeres en la esfera política en España, sobre todo en la última década, pues no se debe solo a la voluntad política a favor de los derechos de la mujer como tal, sino a la entrada en vigor de la Ley de Igualdad la cual modificó la ley electoral en 2007, justificando el principio de presencia equilibrada de los candidatos femeninos y masculinos. El principal requisito consiste que, en las listas electorales del partido deben tener un mínimo de $40 \%$ [según el artículo 44 bis] y un máximo del $60 \%$ de ambos sexos entre sus candidatos en las elecciones a la Cámara Baja.

Ahora bien, continuando con el análisis de la evolución, con respecto al poder judicial en España, es decir los magistrados en el tribunal constitucional, resulta indiscutible que la proporción de las mujeres en estos cargos es baja considerándose un puesto para hombres históricamente, se observa como en 1998 todos eran del sexo masculino, a partir del siguiente año y hasta la fecha de cierre de la investigación ha estado variando, entre una y dos mujeres en el tribunal (Véase Gráfico 14). No obstante, hay que resaltar que durante el periodo de 2004 a 2010 una magistrada estuvo en el máximo cargo de presidente del tribunal convirtiéndose María Emilia Casas Baamonde en la primera mujer en presidir un órgano de tal envergadura.

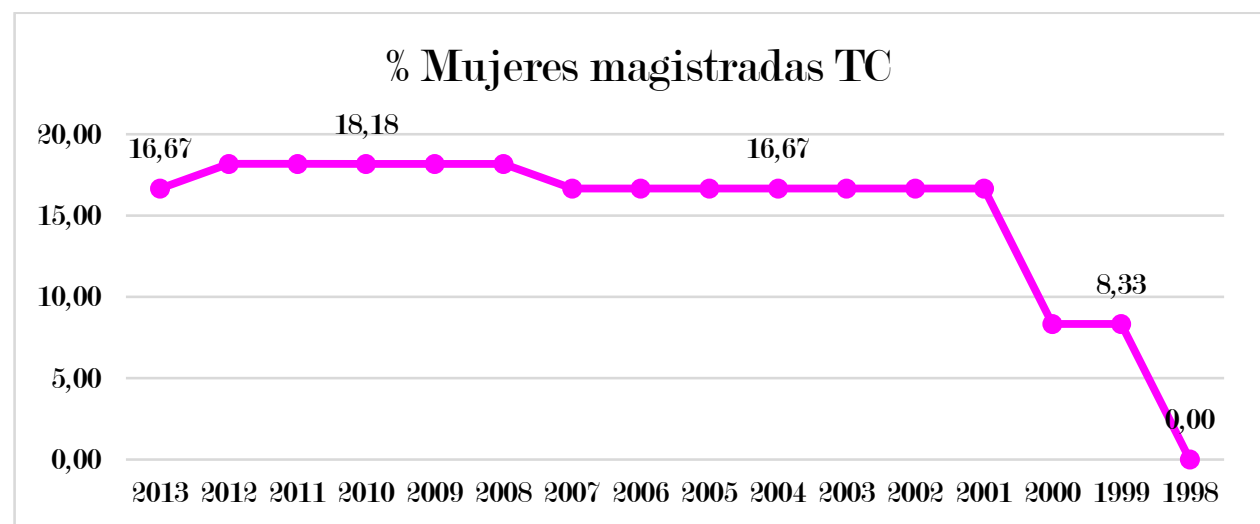


Gráfico 14. \% Mujeres Magistradas en Tribunal Constitucional por año. Fuente. IM. Elaboración propia

En el sistema judicial, aunque pareciese que existiese un equilibrio entre los jueces a nivel estatal, al especificar los cargos por jerarquía la situación cambia para las mujeres. Así pues, se observa la evolución histórica de las mujeres en cargos de fiscales y la proporción ha rondado entre un $40 \%$ y un 63\% tal como se observa en el Gráfico 15, llegando en 2013 a su máximo con un $62,40 \%$ lo que es una buena noticia teniendo en cuenta que las mujeres si han podido ocupar dichos cargos.

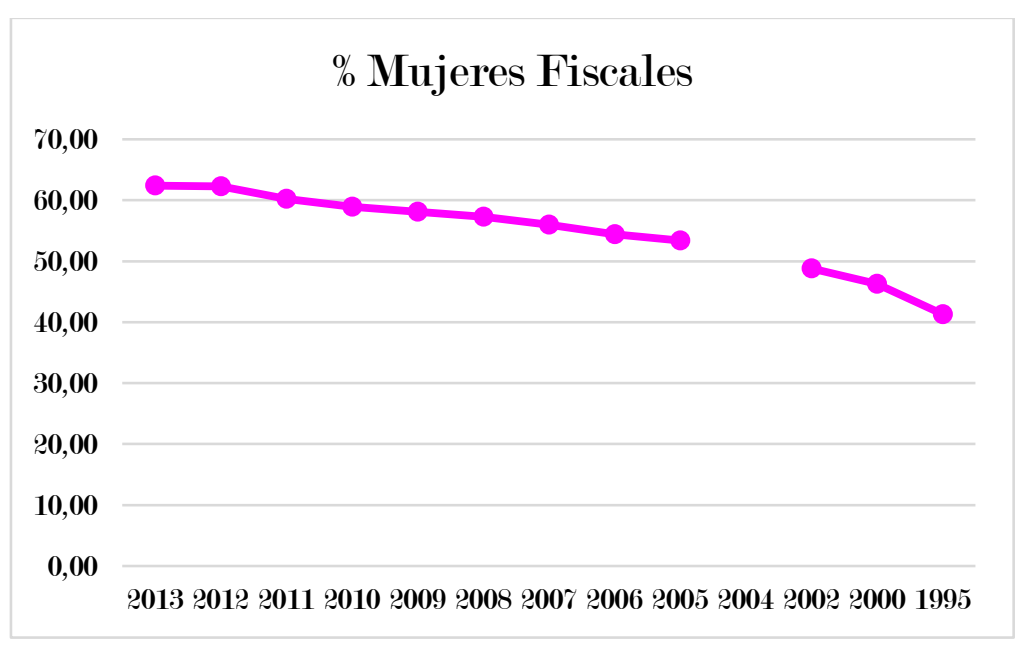

Gráfico 15. \% Mujeres Fiscales Poder Judicial por año. Fuente. IM. Elaboración propia 
Al desglosar por categoría ${ }^{106}$ a los fiscales se encuentra nuevamente la situación que las mujeres les es más difícil acceder a cargos de mayor jerarquía pues tal como se observa a continuación, en el Gráfico 16 la mayor proporción de mujeres se encuentra en la tercera categoría que es lo que hace que aumente el porcentaje total de fiscales mujeres a nivel nacional. Lo que significa que en la primera categoría correspondiente a la sala del tribunal supremo a lo largo de su historia no ha sobrepasado el $25 \%$ de mujeres en su proporción total situación que es confirmada además con las cifras anteriores de magistradas en el tribunal constitucional.

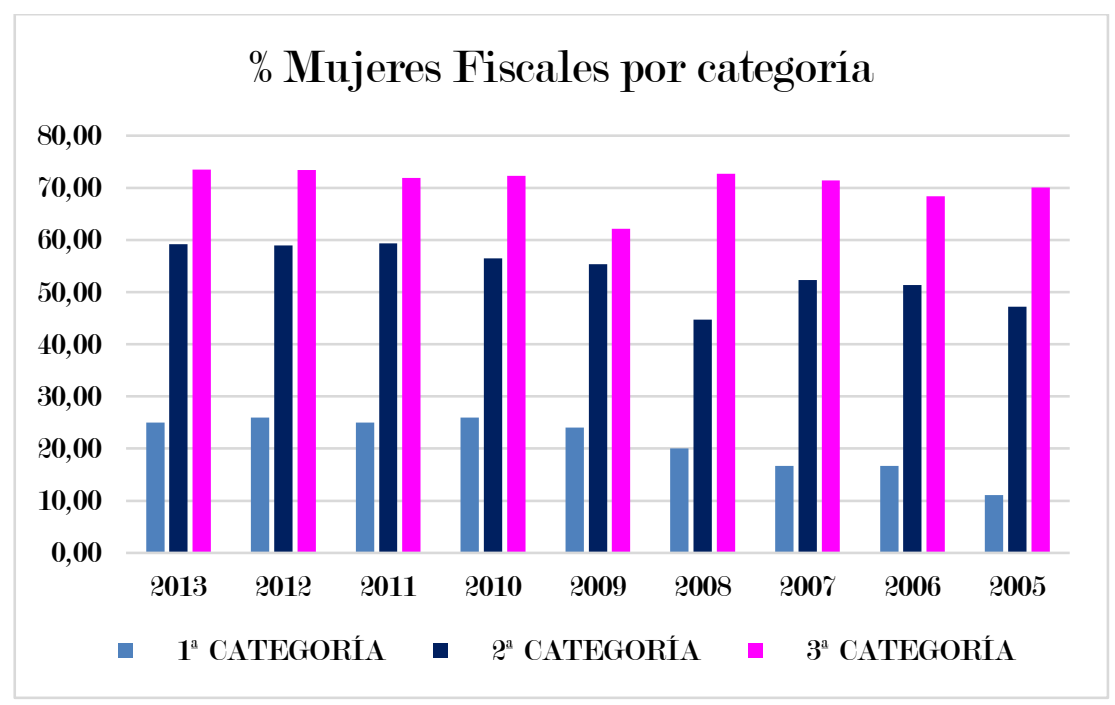

Gráfico 16. \% Mujeres Fiscales por categoría Poder Judicial por año. Fuente. IM. Elaboración propia

106 Según el artículo 34 de la Ley 50/1981, 30 diciembre, por la que se regula el Estatuto Orgánico del Ministerio Fiscal. Las categorías de la carrera fiscal serán las siguientes: $1^{\underline{a}}$ Fiscales de Sala del Tribunal Supremo, equiparados a Magistrados del Alto Tribunal. $2^{\underline{a}}$ Fiscales, equiparados a Magistrados. $3^{\text {a }}$ Abogados-Fiscales, equiparados a Jueces. 
En cuanto a cargos en diversos órganos constitucionales la proporción de mujeres en éstos es variada, así pues, se observa que por ejemplo en el cargo de defensor de pueblo107, desde 1992 ese cargo era ocupado por el sexo masculino logrando a fecha de cierre de la investigación ser ocupado por una mujer: Soledad Becerril Bustamante, la cual fue la primera mujer elegida en este cargo en 2012.

Después de hacer este recorrido del acceso de las mujeres al empleo público evaluando los distintos poderes públicos, es evidente como ha mejorado la situación para ellas en cuanto a la inclusión laboral, sin embargo, no en todos los cargos sucede de igual manera, en algunos la progresividad es más lenta mientras que en otros por lo menos se ha alcanzado la paridad.

Se constata el hecho que en los cargos con mayor autoridad disminuye la proporción de las mismas. Si bien es un paso importante, los cupos por sí mismos son insuficientes, las candidatas deberían figurar en las listas de los partidos electorales en posiciones en las que puedan tener opción de ser elegidas, y no simplemente por cumplir un requisito de diversidad para ello deben contar con el apoyo de los partidos políticos. La representación proporcional con el uso de listas de partidos sigue siendo el mejor sistema para cumplir con los cupos.

Según Bustelo (2004) las tres estrategias institucionales para la promoción de las mujeres en los procesos de decisión política incluyen planes y programas de igualdad de trato, oficinas de la mujer en los ejecutivos y

\footnotetext{
107 El Defensor del Pueblo es el Alto Comisionado de las Cortes Generales encargado de defender los derechos fundamentales y las libertades públicas de los ciudadanos mediante la supervisión de la actividad de las administraciones públicas.
} 
acciones afirmativas como las cuotas en el sistema legal, así como otras ${ }^{108}$ estrategias organizacionales.

A manera de conclusión preliminar se confirma la tesis que a medida que la mujer escale en posiciones de poder más difícil será acceder a estos cargos tal y como se ha observado al realizar el análisis en los puestos representativos en el ámbito público y político en España. No obstante, se resalta la progresiva incorporación de ellas en cargos que generalmente han sido denominados masculinos. Aunque, de acuerdo con lo planteado anteriormente, se genera la alerta en aquellos cargos en los cuales ellas no han podido acceder con lo cual se requiere de mayor voluntad política.

Por último, es importante destacar que existen diferencias en la incorporación de mujeres evaluándolas por comunidades autónomas ya que, de acuerdo al Gráfico 7, se ha logrado constatar que en algunas consejerías se ha alcanzado la paridad, sin embargo, queda mucho por hacer pues alcanzar estos cargos sigue siendo para una mujer, principalmente en el ámbito público, una tarea difícil sobre todo porque es un sector complejo que requiere no solo de competencias laborales sino de un conjunto de estrategias políticas lo cual se ve reflejado en una dificultad, especialmente para las mujeres.

\footnotetext{
108 Un informe de la entidad CEPAL et al. (2013, p. 220) sugiere el diálogo social y la promoción de los consensos tripartitos para la igualdad de género en el acceso al empleo, en este sentido "las organizaciones representativas de los empleadores y de los trabajadores no sólo deberían ser consultadas acerca del mercado de trabajo o los programas de formación profesional, sino que se debería lograr además su cooperación para elaborar políticas económicas más generales, que tengan transcendencia para la promoción del empleo."
} 


\subsubsection{En el ámbito académico}

La investigación de Cáceres et al. (2012, p. 71) comprobó "cómo la enseñanza es una profesión monopolizada por la presencia femenina en los niveles educativos básicos (Educación Infantil y Primaria) y conforme se va ascendiendo en el sistema educativo se va reduciendo el porcentaje de profesoras en la enseñanza; así como se mantiene en todo este recorrido una minoría de mujeres en la dirección de los centros siendo, en gran parte de ellos, superiores el número de profesoras al de profesores."

Tradicionalmente, las mujeres han optado por estudios ${ }^{109}$ relacionados con profesiones consideradas "femeninas" por lo que existe una relación entre la orientación y la motivación que han recibido las mujeres en las escuelas, eso sin contar con el vínculo de las responsabilidades familiares, lo

109 De acuerdo con el informe de CINDA (2015, p. 100) sobre la educación superior en Iberoamérica, se visibilizó que en la actualidad las mujeres han logrado entrar en los distintos niveles educativos, no obstante, "la feminización ha sido primero en el grado y se comienza a presentar en el posgrado y en la investigación, que eran áreas tradicionalmente masculinas. Se constató además la baja incidencia de las mujeres en las actividades de investigación."

Aunque, se evidenció que "en los últimos 30 años podemos ver en lberoamérica un aumento en el número de mujeres profesionales y estudiantes de ciencia. Esta tendencia no es suficiente para afirmar que la problemática de género ha sido resuelta" $(2015$, p. 353)

Asimismo, de acuerdo con el mismo informe se observó "la persistencia de segregación horizontal y vertical en el sector de CTI, ya que, por un lado, hay una mayoría de mujeres en campos de ciencias sociales y muy pocas en las ciencias básicas y, por otro, las mujeres no han llegado a espacios de decisión y de poder, incluso en las áreas feminizadas." (2015, p. 354) 
cual a primera vista muestra la razón por la que las mujeres no se han desarrollado en el ámbito científico y en la academia110.

Es un hecho, que el sexismo ha estado presente en todos los niveles educativos y tal como lo planteó Gonzáles (2002, pp. 173-174). en la educación superior "se encuentra presente en sus tres ámbitos principales: la docencia, la investigación y la acción social" y específicamente en la distribución de puestos directivos, docentes y de investigación entre otros.

Esto es sustentado, por Arranz quien en su investigación visibilizó la experiencia de mujeres profesoras y científicas quienes concluían que "la variable género había incidido en su carrera profesional de forma significativamente diferente a la de sus compañeros varones" (2004, p. 229). Lo cual ha permitido corroborar la existencia de discriminación ${ }^{111}$, y que específicamente en la academia es un fenómeno visible, pues "ha sido sostenida a nivel nacional e internacional" (Gonzáles, 2002, p.172).

De hecho, con la investigación de Escarrer et al. (2007, p. 3) pusieron de manifiesto que "las mujeres siguen abandonando en un elevado

\footnotetext{
110 De acuerdo con Martínez (2009, p. 36) la academia es el "termino con que se denomina a la sociedades científicas, literarias o artísticas establecidas y que gozan de cierta autoridad pública. De igual modo, se llama academia a la reunión del personal académico de una institución educativa." Para el presente texto, enmarca los profesionales en la educación superior, principalmente el profesorado.
}

111 La autora, de acuerdo con su investigación concluye que el sexismo ha estado presente en la academia, principalmente en aspectos como (i) La selección de los temas de investigación, (ii) La selección de las perspectivas teóricas, (iii) La aceptación de los resultados de la investigación, (iv) La elección de los criterios de evaluación, (v) La difusión de los resultados, (vi) El reconocimiento profesional y académico, (vii) Las normas y prácticas sociales de los colectivos creadores de ciencia o conocimiento especializado (Gonzáles, 2002, p.172). 
porcentaje la carrera científica profesional en diferentes fases antes de llegar a un cargo y, cuanto más alto es este en una determinada jerarquía, menor es el número de mujeres que lo ocupan".

Un estudio de Catalyst (2015-e) que mostró la situación de las mujeres en la academia de acuerdo con la investigación en distintas regiones, mostró que en Europa ellas tienen una proporción menor de posiciones académicas que los hombres, así ocupan menos del $40 \%$ de los puestos académicos de las universidades más importantes de los países europeos y a nivel general las mujeres ocupan sólo el $18 \%$ de los puestos catedráticos. Con respecto a cargos más altos, las mujeres ocupaban el $15,5 \%$ de las posiciones de "Vice Chancellor".

En España, al igual que con el sector público, se extrajeron las estadísticas proporcionadas por un organismo objetivo, para este caso, el Instituto Nacional de Estadística, en adelante INE $^{112}$. En lo referente a la educación superior, según el informe del INE la última ${ }^{113}$ información y datos estadísticos por cursos académicos que se encontraba disponible a fecha de cierre de la investigación, era hasta 2010-2011, sobre la Enseñanza

112 El Instituto Nacional de Estadística es un organismo autónomo de carácter administrativo, juega un papel destacado en la actividad estadística pública pues se le encomienda expresamente la realización de las operaciones estadísticas de gran envergadura. Para este apartado, las estadísticas base fueron extraídas del grupo Mercado Laboral, para mayor información al respecto véase la URL: http://www.ine.es/dyngs/INEbase/es/categoria.htm?c=Estadistica_P\&cid=1254735976594

113 En España, los cursos académicos de los que se pueden extraer y analizar información son desde 1998/1999 hasta 2010-2011, incluso a 2017 no se ha actualizado la información de los cursos académicos posteriores. Confróntese en el link a continuación: http://www.ine.es/dyngs/INEbase/es/operacion.htm?c=Estadistica_C\&cid=1254736176744 \&menu=resultados\&idp $=1254735573113$ 
Universitaria en España (INE, 2012) con lo cual, a partir de ello, se tomó como base ese periodo y se trasladó a gráficos.

Así, se puede observar de acuerdo con el Gráfico 17, de izquierda a derecha que el $38,20 \%$ del profesorado eran mujeres en los centros propios de las universidades públicas; de un $42,55 \%$ en las universidades privadas y, de un $47,06 \%$ en los centros adscritos a universidades públicas; lo que equivale a una proporción total de mujeres de un $39,14 \%$.

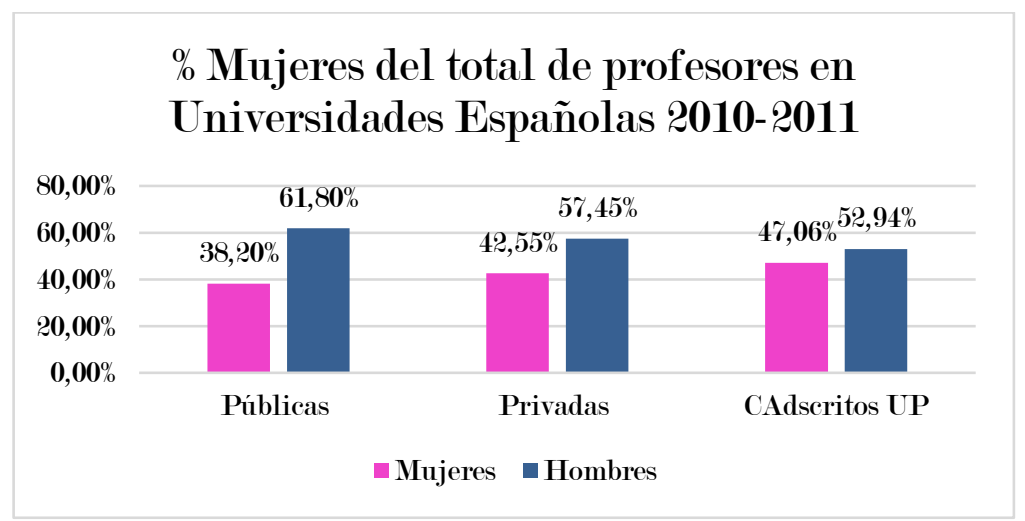

Gráfico 17. \%Mujeres del total de profesores. Fuente. INE. Elaboración propia

En las universidades públicas, en referencia a las dos escalas máximas de profesorado, los catedráticos y titulares, la proporción de mujeres resulta relativamente baja, lo cual confirma la teoría del techo de cristal para el acceso de la mujer a cargos superiores y para este ámbito en específico ${ }^{114}$.

114 Esta situación ocurre en general en varios países. Por ejemplo, según investigación de Catalyst (2015-e) se demostró que, en Australia en 2014, las mujeres australianas tenían $43,6 \%$ de los cargos de profesores y sólo $29,9 \%$ de los cargos de profesores superiores. Los hombres australianos poseían el $56,4 \%$ de los cargos de profesores y el $70,1 \%$ de los cargos 
Del total de catedráticos de universidad, las mujeres catedráticas representaban un 18\%; del total de catedráticos de escuela universitaria, la proporción de mujeres ascendía a un 29,83\% aproximadamente tal como se observa en el Gráfico 18.

De las 48 universidades públicas del estudio, la proporción más alta de catedráticas de universidad la tuvo la Universidad de la Rioja con un $27 \%$, seguida de la UNED con un $26 \%$ y la Universidad de Valencia con un $25 \%$. Mientras que las proporciones más bajas la obtuvieron la Universidad de Huelva con un $4 \%$ seguida de la Politécnica de Cataluña y Rey Juan Carlos con un $8 \%$ ambas.

Ahora bien, en número la Universidad que más mujeres catedráticas contratadas tiene en España en el periodo de la investigación es la Universidad Complutense de Madrid con 173 catedráticas seguida de la Universidad de Valencia con 130; a diferencia de las que menos tienen contratadas mujeres en número que nuevamente son la Universidad de Huelva y la Politécnica de Cartagena con 2 y 4 profesoras catedráticas respectivamente.

de profesores superiores. Además, revelaron una brecha salarial de género del 15\% para los académicos hombres y mujeres.

En Canadá, las profesoras ganan menos que los profesores en promedio, aproximadamente un $87,8 \%$. En Japón, en 2013, las mujeres representaban sólo el 12,7\% de los académicos de las universidades japonesas de mayor calificación. En Estados Unidos, mientras que las mujeres ocupaban casi la mitad $(48,4 \%)$ de todas las posiciones académicas en 2013 , ocupaban sólo el $37,5 \%$ de las posiciones permanentes. En general las mujeres ocuparon el $26,3 \%$ de los profesores titulares pero se reducía al 19,0\% cuando se refería a los profesores titulares específicamente en las escuelas de negocios. 


\section{\% Catedráticas Universidades \\ Públicas 2010-2011 España}

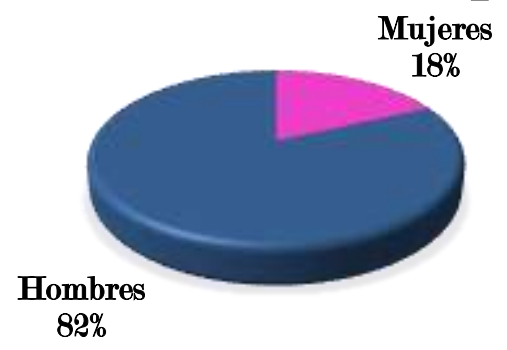

Gráfico 18. Catedráticas en Universidades Públicas. Fuente. INE. Elaboración propia

Del total de titulares de universidad, tal como se observa en el Gráfico 19 , las mujeres titulares representaban un $38,89 \%$, seguidamente del total de profesores titulares de escuelas universitaria, la proporción de mujeres ascendía a un $41,56 \%$ aproximadamente. De las 48 universidades públicas del estudio, la proporción más alta de profesoras titulares de universidad cambia considerablemente con respecto a las catedráticas, lidera la UNED con un $54 \%$, seguida de la Universidad de León con un $48 \%$, y la Rey Juan Carlos con un $47 \%$.

Mientras que las proporciones más bajas la obtuvieron las tres Politécnicas: de Cartagena, Cataluña y Madrid, con un $17 \%$, 24\% y $26 \%$ respectivamente. Ahora bien, en número, la Universidad que más mujeres titulares contratadas tiene en España es la Universidad Complutense de Madrid con 1028 catedráticas seguida de lejos por la Universidad de Barcelona con 590.

A diferencia de las que menos tienen contratadas mujeres en número que nuevamente son la Politécnica de Cartagena con 27 y la Pablo de Olavide con 40 profesoras titulares respectivamente. Hay que tener en cuenta que 
estas diferencias se deben al tamaño de las Universidades y los recursos que invierten en ellas las comunidades autónomas.

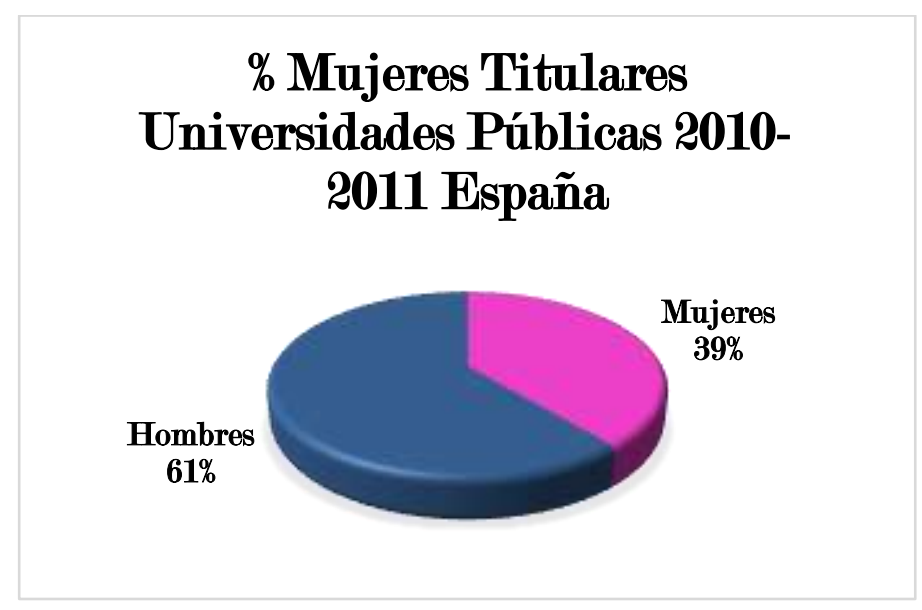

Gráfico 19. \% de Mujeres titulares Universidades Públicas. Fuente. INE. Elaboración propia

Este análisis de la evolución de la participación de las mujeres en la academia en España durante el periodo evaluado permite realizar una conclusión preliminar, combatir el techo de cristal en universidades más pequeñas es mucho más difícil que en las universidades de mayor tamaño. Además, en efecto la proporción más baja resultó de la mayor escala del profesorado, es decir, de las mujeres catedráticas. Es de resaltar, en este sentido, la labor de la Universidad Complutense de Madrid, al liderar una mayor proporción de profesoras contratadas en número no solo de catedráticas sino de titulares.

Ahora bien, es importante también analizar el profesorado de centros propios de Universidades Privadas y centros adscritos a Universidades Públicas, en los primeros, las profesoras doctoras equivalen a un $38,99 \%$ del total del profesorado doctor, y en los segundos, la proporción de profesoras doctoras sobre el total del profesorado doctor fue de un $36,66 \%$. Para un 
porcentaje total de mujeres doctoras en los dos centros de un $38,54 \%$, lo que dista mucho de las universidades públicas en cuanto a la máxima escala.

La situación es otra cuando se hace referencia al personal de administración y servicios en las universidades públicas españolas, pues del total de este personal las mujeres representan el 59\% tal como se observa en el Gráfico 20. En el desglose de ese porcentaje, un $66 \%$ son funcionarias; un 19\% están contratadas a término indefinido y un 15\% están contratadas a tiempo parcial.

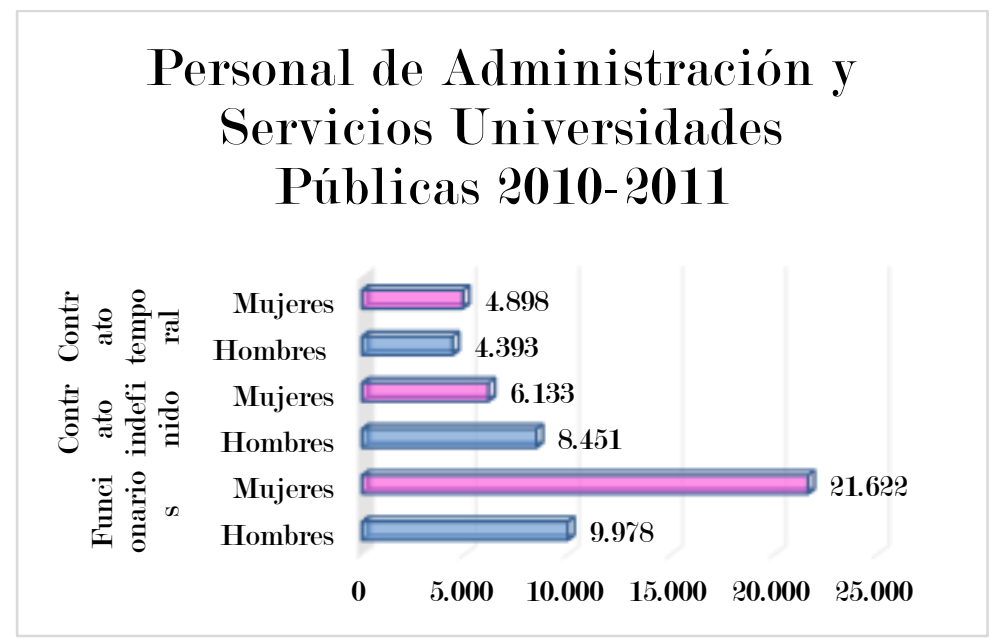

Gráfico 20. Personal de Administración y Servicios. Fuente.

INE. Elaboración propia

En cuanto a la participación de las mujeres en la investigación y el desarrollo, un informe en 2010 sobre la educación superior en lberoamérica, mostró que la situación de las mujeres es mucho mejor comparada con Europa, la proporción se encuentra alrededor del $40 \%$, a diferencia de los países europeos cuya proporción es globalmente de un 30\% lo que difiere notablemente del sector en el cual se encuentre, por ejemplo, el $23 \%$ en empresas privadas y un $45 \%$ en entidades de educación superior. 
Uno de los obstáculos que enfrentan las mujeres en el campo académico y científico, que se detectó durante una investigación de Izquierdo (2009, p. 62) es que "se perciben más fuertemente al momento de interactuar con sus pares, particularmente con los masculinos (compañeros, profesores), quienes en algunos casos cuestionaron su «capacidad» para los estudios aun cuando la realidad demostraba que ellas eran brillantes en su desempeño"

Se considera al igual que Callejo, Gómez, \& Casado (2013, p. 15), la situación contradictoria en la cual está sumergida la academia, cómo es posible que una institución encargada de promover la igualdad de género en el conjunto de la sociedad "....se muestra atravesada en su organización por aquella diferencia que intenta combatir...".

Se ha constatado nuevamente que en los cargos ${ }^{115}$ con mayor rango la proporción de mujeres en ellos disminuye. En este sentido, la universidad como agente social, debería ir más allá de producción de conocimiento y de investigación, es su responsabilidad, la formación de los estudiantes como futuros profesionales en cultura igualitaria, sin contar con que la igualdad debe formar parte intrínseca de su misión, pues es vital para erradicar todas las desigualdades planteadas, y en definitiva su intervención debe ser más activa ${ }^{116}$ que pasiva.

\footnotetext{
115 La investigación de Díez et al. (2003, p. 12) determinó que "el cargo del equipo directivo que la mujer más habitualmente ha desempeñado con anterioridad es el de secretaria (42\%) frente a un $36 \%$ de directores que habían sido secretarios. Parece que se mantiene esa correlación tradicional de "subordinación" de las mujeres en el campo organizativo, ligado a cargos de secretaria más que al ejercicio de la jefatura de estudios."
}

116 No obstante, hay que resaltar que en la academia es desde donde se han liderado las investigaciones más representativas que parten desde distintas disciplinas y han repercutido en los estudios de género. Para complementar esta información diríjase a la investigación de Cáceres et al. (2002) quien recopila los estudios e investigaciones sobre la mujer en la dirección de enseñanzas universitarias. 
Todos los resultados estadísticos, también son sustentados por la investigación previa de Alonso (2002, p. 468) quien mostró el "carácter altamente desigual de la Universidad como ámbito profesional. (...) la imagen de la estructura del profesorado universitario como una pirámide con una base amplia (constituida por los profesores no numerarios: asociados y ayudantes), un nivel intermedio (compuesto por los profesores titulares) y una mínima cúpula (ocupada por las cátedras). Pero lo verdaderamente subrayable es la diferencial presencia femenina en cada uno de los escalones de esta pirámide."

Los factores externos que contribuyen a perpetuar este fenómeno y los cuales se han ido detectando en investigaciones diversas como las de Cáceres y otros. (2012, pp. 72-73) siguen reflejando aspectos como: (i) la costumbre social, (ii) la dificultad de compatibilizar la vida familiar y la profesional, (iii) la definición masculina del poder, (iv) las expectativas proyectadas sobre la mujer, (v) las «redes invisibles» de los hombres, (vi) rituales de exclusión, (vii) pocos modelos femeninos de identificación y la (viii) inconsciencia e invisibilidad de la discriminación.

Aunque hoy en día se refleja que muchas mujeres se están formando mayormente, es evidente que, en algún momento de ese camino están dejando de lado la ciencia y la docencia universitaria, esta "grieta en el sistema" tal como lo denomina Escarrer et al. (2007, p. 3) muestra como "el paso del tiempo y la presencia de las mujeres en los estudios universitarios

\footnotetext{
Una primera conclusión es que "aún se requiere mayor trabajo para que el género se consolide como área de conocimiento o para la entrada de las mujeres en el sector; o incluso para mejorar las intervenciones de política pública para la igualdad en la ciencia, la tecnología y la innovación. Resulta indispensable entender más sobre el género como herramienta teórica interdisciplinar. Ello requiere reconocer los estudios de género como un campo de estudio, y su intersección con la ciencia como una agenda de investigación interdisciplinar fructífera y con gran valor social." (CINDA, 2015, p. 356)
} 
por sí mismos no son una garantía de mayor presencia femenina entre el profesorado universitario" lo cual genera una alerta en este sentido, por lo que desde dentro de las mismas instituciones se debería investigar más a fondo sobre las razones por las cuales sucede esto, y si es necesario la implementación de programas desde la gestión del talento humano para prevenir que siga sucediendo este fenómeno.

Es decir, las políticas internas propias deberían ir encaminadas a preocuparse por los aspectos laborales: desde el acceso al trabajo, el ingreso, los tipos de contrato, así como la permanencia y la promoción profesional ya sea en los centros de investigación 0 instituciones universitarias públicas y privadas de todo el país. Asimismo, valdría la pena evaluar más a fondo estos factores, lo que en efecto permitiría tener mayores elementos para gestionarlos.

Por último, uno de los retos en la academia según Gonzáles (2002, p.172) consistirá en identificar aquellas prácticas, formas encubiertas y "particularmente solapadas", que promuevan la discriminación en el trabajo, lo cual implica un razonamiento que requiere de un análisis exhaustivo y de una mayor perspicacia.

Además, en palabras de Figueruelo, del Pozo \& León "la presencia equilibrada de mujeres y hombres en todas las actividades y en la toma de decisiones dentro de la institución, representa un valor añadido, reforzando la calidad y la gobernanza en la Universidad, en un contexto de cambios y de integración de los sistemas educativos." (2012, p. 104). 


\subsection{El fenómeno de la discriminación múltiple}

Este fenómeno es importante que se coloque en las agendas de los organismos públicos pues, es uno de los escenarios que más pasa desapercibido y en el cual aún requiere de mayor estudio, investigación y visibilidad por parte de los académicos pues como lo sostiene Rey \& Giménez (2010, p. 36) "el concepto es más doctrinal y político que normativo y judicial" Se ha puesto de manifiesto, que a pesar que a nivel global dentro de los aspectos positivos para el desarrollo jurídico en materia de igualdad en los países, es que se ha avanzado en la inclusión de factores como la edad y la discapacidad, aspectos como la raza y el sexo siguen siendo los dos motivos de discriminación expresamente incluidos en casi todas las legislaciones a favor de la igualdad (OIT, 2011) mientras que sigue pendiente la mención explícita de otros factores como la ascendencia nacional, el origen social, la orientación sexual ${ }^{117}$ entre otros.

\footnotetext{
117 De acuerdo con Alventosa (2008, p. 27) "la discriminación por identidad de género se ha considerado como una forma de discriminación por motivos de sexo" lo cual no debería ser así teniendo en cuenta que "afectan a sujetos distintos y presentan problemáticas diferentes"
}

Y es que "las diferencias de trato basadas en la orientación sexual de las personas se deben, fundamentalmente, a los prejuicios sociales contra el comportamiento sexual o afectivo de los colectivos homosexuales, bisexuales y transexuales, hasta el punto de que en numerosos países la homosexualidad todavía se considera delito." (Chacartegui, 2001, p. 23)

En las relaciones laborales, se pueden encontrar ejemplos de muchos prejuicios morales que se dan con respecto a las personas con una orientación sexual determinada, "se presume la falta de aptitud para determinados puestos de trabajo" (Chacartegui, 2001, p. 99) lo cual ocasiona que, por ejemplo, no lo tengan tan fácil en el acceso al empleo, en las condiciones de trabajo, principalmente en los casos de acoso sexual o de las distintas formas de violencia en el trabajo, así como en los despidos y extinciones discriminatorias. 
De hecho, uno de los aspectos a tener en cuenta, dentro de las discriminaciones por razón de sexo contempladas en la LOIMH de acuerdo con Albiol et al. es el estado civil "cualquier tipo de diferencia de trato con origen en el estado civil -matrimonios versus uniones de hecho, beneficios de las personas casadas frente a las solteras, etc." (2007, p. 33). La crítica del autor se refiere a que dicha ley "sólo ofrece cobertura a aquellas situaciones en las que el estado civil de una persona dé lugar a una diferencia desfavorable para uno de los sexos."

Por su parte, grupos como las personas desempleadas mayores de 45 años se enfrentan a una barrera, la edad ${ }^{118}$, muy difícil de franquear a la hora de acceder a un empleo. Estas dificultades se acentúan en el caso de las mujeres. Al respecto, Mercader evidenció que a este colectivo se les suele "abalanzar un importante número de prejuicios sociales y laborales no siempre coincidentes con la realidad que afecta a este colectivo y los separa del de los trabajadores jóvenes. La mayor predisposición al conocimiento de estos últimos, su mayor receptividad a los cambios tecnológicos, su mejor

\footnotetext{
Según Chacartegui (2001, p. 100) "En muchos casos, la discriminación se manifiesta de forma directa, a través de cuestionarios que, de un modo directo en algunos casos o encubierto en otros, pretenden indagar sobre la orientación sexual del trabajador." De forma indirecta, según "uno de los ámbitos donde más claramente se pueden manifestar las discriminaciones indirectas por razón de orientación sexual es en las empresas ideológicas o de tendencia, pues la línea fronteriza entre la libertad de contratación del empresario y la vulneración de determinados derechos constitucionales resulta ciertamente difusa"
}

118 Sumado a lo anterior, es cierto que la discriminación salarial de las mujeres aumenta con la edad, de acuerdo con de Cabo \& Rodríguez (2014, p. 81) "Las mujeres trabajadoras de 50 o más años son las que perciben un peor salario respecto a los hombres, mientras que las mujeres de 16 a 24 se encuentran en la posición más ventajosa. Las mujeres de edades intermedias, por su parte, muestran diferencias muy sutiles en sus salarios respecto a los masculinos." 
capacidad de adaptación a los cambios y su mayor productividad resultan estereotipos más que discutibles. Trabajadores jóvenes y maduros aportan valores distintos y complementarios." (2009, p. 1)

Esto es un ejemplo de pérdida de eficacia por mala gestión de la diversidad, los procesos indiscriminados de prejubilación en base a la edad. Como ha ocurrido en muchas grandes empresas españolas, Pin, García \& Gallifa (2007, p. 10) estos procesos producen la salida de la empresa de enormes cantidades de experiencia y conocimientos.

Si a eso, se duplican dos o más factores, se aumentan las dificultades, es el caso, de Estados Unidos, donde las mujeres de color todavía mantienen sólo el $3 \%$ de los cargos en juntas directivas corporativas, es decir, la posibilidad de acceder a cargos de responsabilidad en igualdad de oportunidades, según investigaciones de Catalyst (2011).

De hecho, una investigación de Shelby et al. (2016, p. 12) concluyó que el tema de la discriminación múltiple y en especial en las mujeres en cargos de decisiones importa porque tienen percepciones y consecuencias distintas de acuerdo a los factores que se evalúen. Por ejemplo, "las mujeres negras son percibidas como dominantes, pero no competentes. Las mujeres estadounidenses son percibidas como competentes pero pasivas. Las mujeres blancas son percibidas como principalmente comunales."

Por otro lado, según Amnistía Internacional (2009, p. 18) "las mujeres son objeto de discriminación múltiple: las discriminan y les niegan sus derechos por ser mujeres y por pertenecer a un grupo marginado. Las mujeres que viven en la pobreza también se enfrentan a discriminación simplemente por su pobreza". Lo cual, expone a las mujeres y a las niñas a ser objeto de potenciales abusos y formas inimaginables de violencia, lo cual se convierte en un círculo vicioso sin fin. 
Es decir, es evidente la existencia de un conjunto de factores (véase tabla 5) que pudiesen ser objeto de discriminación que, sumados al sexo ${ }^{119}$, se pueden convertir en verdaderos dolores de cabeza. De hecho, Lombardo \& Verloo (2010) insisten en el cambio de rumbo que deberían tener las políticas de igualdad de género en la Unión Europea, pues es objeto de discusión la evolución de un enfoque "unitario" de las desigualdades (solo contempla y evalúa un factor de manera independiente) a un enfoque "múltiple".

\begin{tabular}{|c|}
\hline Tipos y/o factores de discriminación \\
\hline Sexo \\
\hline Estado Civil \\
\hline Religión \\
\hline Ideas políticas \\
\hline Estado serológico \\
\hline Discapacidad \\
\hline Edad \\
\hline Orientación sexual \\
Estilo de vida \\
\hline Negociación colectiva
\end{tabular}

\footnotetext{
119 Un ejemplo positivo a destacar es el caso de Jóhanna Sigurdardóttir, quien se desempeñó como primera ministra en Islandia, en el periodo comprendido entre 2009 y 2013. Ella fue reconocida como la primera jefa de gobierno LGBT del mundo, en este sentido, han influido dos factores que han hecho duro su camino, no solo el ser mujer en un cargo masculinizado históricamente, sino que además su orientación sexual, que ya por si solo es un factor discriminatorio. Con lo cual es evidente una situación en donde se interrelacionan dos factores, pero que aun así se logró derrumbar el techo de cristal.
} 
Tabla 9. Tipos o Factores de discriminación en el trabajo. Fuente. ONU. Elaboración propia.

\subsubsection{Personas con discapacidad}

En un escenario en donde el quehacer profesional es parte fundamental en la vida de las personas, y de manera especial en quienes padecen una discapacidad, diversos sectores han buscado a través de la Responsabilidad Social generar cambios positivos en esta dimensión social. Por una parte, el estado como garante de los derechos de la población, por otra parte, las empresas y organizaciones sociales a través de sus preocupaciones éticas con sus grupos de interés prioritarios, uno de ellos los empleados.

Al respecto, Hatcher (2002) y Carroll (2000) consideraron que ésta es una preocupación legítima, toda vez que atiende de una parte a un estándar de derechos morales con los grupos de interés prioritario, y de la otra a sus expectativas. Por tanto, se sitúa la necesidad de inclusión de personas con discapacidad en el mercado laboral, en tanto además de ser un grupo de interés social, son una colectividad en riesgo de exclusión en diversos ámbitos.

Además, hay que considerar que, en el mundo más de mil millones de personas, el $15 \%$ de la población mundial, viven con algún tipo de discapacidad reconocida y las cifras van al alza Ministerio de Sanidad, Política Social e Igualdad (2011, p. 16). Pues son un grupo que con facilidad está sujeto a situaciones de discriminación ${ }^{120}$, en este sentido, al extraer la información disponible del Instituto de la Mujer y el Instituto Nacional de

\footnotetext{
120 De hecho, tal como lo planteó Ruiz (2010, p. 85) “El acceso al empleo de los trabajadores con discapacidad es algo más que un aspecto del mercado de trabajo con funcionamiento anómalo o deficitario que hay que resolver."
} 
Estadística sobre este colectivo en el mercado de trabajo, en España las mujeres discapacitadas también se enfrentan al fenómeno de la discriminación múltiple. Es notable observar la brecha existente entre mujeres y hombres con discapacidad, las cifras muestran que además de una baja proporción en cuanto las tasas de actividad en España como grupo social durante los últimos años, también lo son las mujeres por el hecho de ser mujer.

Así pues, se observa que, con respecto a la tasa de empleo, la proporción de hombres es mucho mayor que la de las mujeres en los últimos años de acuerdo con el Gráfico 21, brecha que por ejemplo fue mucho mayor en 2009 cuando la tasa de los varones se situó en un 32\% mientras que la de las mujeres en un $23,80 \%$.

Es notable además ver como ambas proporciones han disminuido por efecto de la crisis lo que refuerza la teoría de que estos grupos son más vulnerables en épocas en donde no hay crecimiento económico, pero en este aspecto no profundizaremos pues no es el objetivo, sino demostrar que en efecto las mujeres, en este caso con discapacidad se enfrentan al fenómeno de la discriminación múltiple, habría que analizar a fondo a que se deben esas brechas y si corresponde al grado y tipo de discapacidad en específico.

En contraste, en lo referente a la tasa de paro de acuerdo con el Gráfico 22, de las personas con discapacidad esa brecha entre mujeres y hombres se ha ido disminuyendo en los últimos años situándose a 2013 en un porcentaje similar en torno al $35 \%$. Las mujeres ligeramente superan a los hombres en esta tasa. Hay que tener en cuenta que el aumento de la proporción en la última década también es debido a la entrada en vigor de la LISMI, o ley de integración social del minusválido ley 13/1982 de 7 de abril, que establece para las empresas públicas y privadas, con una plantilla superior a 50 trabajadores, la obligación de contratar a un número de trabajadores con discapacidad no inferior al $2 \%$. 


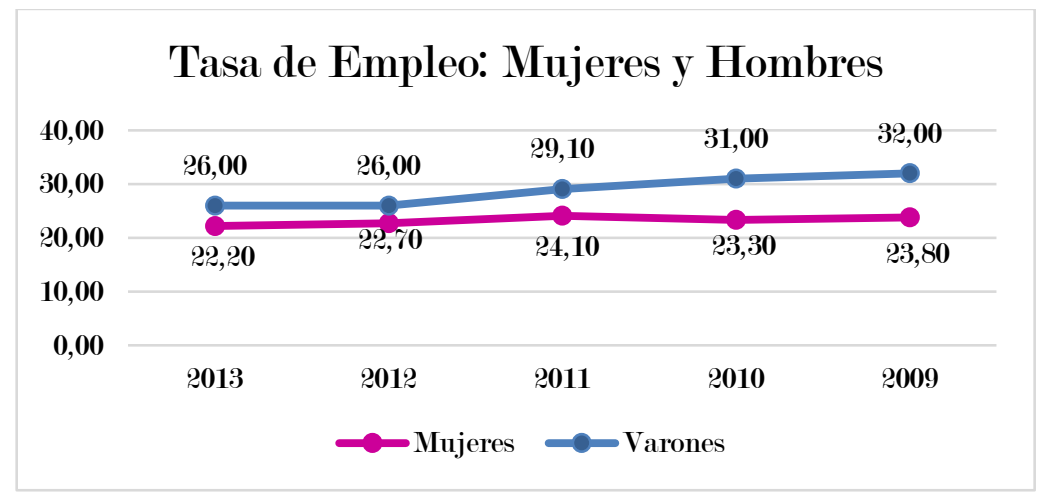

Gráfico 21. Tasa de Empleo Discapacitados Mujeres y Hombres 2009-2013. Fuente: IM e INE. Elaboración propia

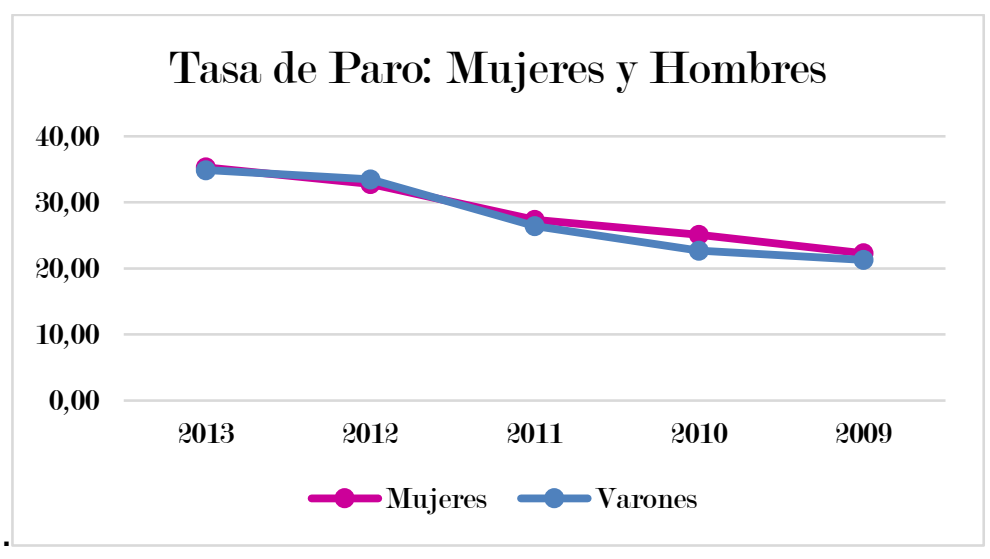

Gráfico 22. Tasa de Paro Discapacitados Mujeres y Hombres 20092013. Fuente: IM e INE. Elaboración propia

Una contribución española, a partir de la responsabilidad social empresarial, se observa en algunas empresas del IBEX 35, por ejemplo, la iniciativa for\&from, proyecto para la integración laboral de personas con discapacidad, a partir de la creación de una red de tiendas, en colaboración con entidades sociales, bajo el modelo de franquicia de Inditex. El modelo parte del suministro de ropa de campañas anteriores que es puesta a la venta 
a precios reducidos por parte de estas organizaciones. De esta forma, a partir de una donación inicial por parte de Inditex para la construcción de la tienda, el modelo se hace auto sostenible y aporta beneficios estables a las organizaciones sociales a través de la venta del producto.

La tienda, que está gestionada por personas con diversos tipos de discapacidad severa, convierte un espacio comercial en un centro de referencia para la inclusión, la accesibilidad y la eliminación de barreras. Actualmente, el programa cuenta con siete establecimientos comerciales en España que proporcionan empleo estable a más de 50 personas con discapacidad (Grupo Inditex, 2014).

\subsubsection{Discriminación racial}

Históricamente, se ha constatado la concepción de sistemas y mecanismos culturales, sociales e incluso institucionales de dominación a través de los cuales se impide el acceso equitativo de grupos sociales a los frutos del desarrollo económico. Las razones se remontan a épocas del colonialismo o el régimen de conquista, en donde se constituyeron las ideas sobre las diferencias raciales (Bello \& Rangel, 2000), de la superioridad entre grupos situación que se ha reforzado en múltiples lapsos históricos.

En el mercado de trabajo, se ha consolidado la discriminación y segregación étnica y racial, desde el uso de mano de obra en condiciones de esclavitud hasta la concentración de diversos grupos en empleos mal remunerados con evidencia mínima de prestaciones en seguridad social y sin ninguna formación. En este sentido, un gran porcentaje de los conflictos étnicos y problemas de xenofobia a escala global tienen su origen en las migraciones (Rengifo \& Oporto, 2005). 
En España, según Ford (2001, p. 38) entre las comunidades que "padecen actitudes de racismo y xenofobia figuran los trabajadores portugueses y marroquíes, que efectúan trabajos estacionales 0 permanentes, pero siempre mal remunerados y considerados, y la comunidad judía". A nivel general, los migrantes obtienen salarios y puestos laborales de menor calidad que el resto de la población en los países receptores, cumpliendo jornadas de trabajo con muchas más horas que la legal e incluso con salarios menores al mínimo legal.

Al hablar de discriminación racial, sin duda se erigen dos términos básicos, la raza y las etnias; si bien la raza se asocia a distinciones biológicas atribuidas a genotipos y fenotipos, especialmente con relación al color de la piel o los rasgos faciales dominantes; las etnias se vinculan a factores de orden cultural (Hopenhayn \& Bello, 2001, p. 7). Lo que permite que los integrantes sean identificados entre sí por diversas características como sus tradiciones, su idioma, su organización social, su cosmovisión de acuerdo con su naturaleza.

El racismo es un paso superior en la segregación de personas y grupos. No solo unifica al grupo en un conjunto extraño y peligroso, sino que considera imposible que adapte su actitud y comportamiento respecto a nuestra sociedad, y antinatural que nosotros cambiemos para adaptarnos en una convivencia con ellos. Tanto si se atribuye esta inmovilidad a causas genéticas como culturales, el racismo considera que estas características negativas se heredan sin posibilidad de evolución ni mejora. Incluso apunta que puede existir una conspiración por parte de ellos para acabar con lo «nuestro».

El perfil ocupacional de grupos étnicos como, por ejemplo, los indígenas en Latinoamérica tienen un componente de género importante (Hopenhayn \& Bello, 2001, pág. 18), si bien los hombres se incorporan a 
trabajos que les permiten una mayor movilidad laboral, las mujeres en varios países de la región acceden al trabajo doméstico en la ciudad.

La conjunción de variables de género y raza muestra la condición particular ocupada por la mujer en distintos mercados laborales. Este grupo ocupa los estratos sociales inferiores con menores ingresos y bajo retorno de las inversiones en educación.

Las barreras principales que impiden su integración al mercado laboral tienen que ver con la educación y la experiencia, por lo que se produce en condiciones de precariedad e informalización. Asimismo, se ha demostrado que muchos de estos grupos en riesgo de exclusión sufren con mayor fuerza que el resto de la población económicamente activa nacional, el desempleo, los bajos salarios y la falta de acceso a cargos de jefatura.

También ha faltado la participación y representación política de los grupos étnicos, lo que en efecto ha contribuido a excluirlos de los procesos de desarrollo, en este sentido, es necesario que los poderes públicos realicen profundas reformas en este ámbito para que estos grupos sean reconocidos como elementos claves de la ciudadanía, la integración y la cohesión social, la gobernabilidad y la estabilidad democráticas de los países.

En España, la situación ilegal de muchos inmigrantes norafricanos y latinoamericanos facilita que se contrate a parte de estos trabajadores con sueldos menores a los prescritos como mínimo, sin protección social ni seguridad sanitaria. El servicio doméstico es, con la agricultura, el sector donde trabajan más inmigrantes, la mayoría mujeres marroquíes y sudamericanas, empleadas en condiciones laborales deplorables. Distintas organizaciones de traficantes ingresan mujeres latinoamericanas y caribeñas a España y las fuerzan a prostituirse. 
De hecho, en el caso de las trabajadoras de servicio doméstico en su modalidad interna ${ }^{121}$, de acuerdo con Marcu (2009, p. 474) se constituye como "un ejemplo claro de explotación, a través del cual, se produce una transferencia de los resultados del trabajo de un grupo en beneficio de otro, lo que comporta distribuciones desiguales de recursos y de riqueza". Pues generalmente, en el caso de la inmigrante, la motivación se sustenta en la disponibilidad de estar en un lugar seguro si por ejemplo se encuentra indocumentada; en el caso de la familia, por la necesidad inmediata que una persona que realice los oficios del hogar y del cuidado familiar, lo que finalmente trae como consecuencia un empleo informal sin necesidad de un contrato laboral.

\subsection{La brecha existente entre los salarios de mujeres y hombres}

La diferencia salarial que existe entre los hombres y las mujeres en los distintos sectores económicos es una situación del mercado de trabajo que ha ido adquiriendo relevancia a lo largo de los años, analizado como fenómeno global, numerosos estudios han confirmado que el salario medio de los varones es superior, en media, al que perciben las féminas.

Así, en España con la publicación del informe "Determinantes de la Brecha Salarial de Género en España" (de Lucio, del Valle, \& Valero, 2014) se concluyó que "las mujeres cobran menos que los hombres en cualquier

\footnotetext{
121 Cuando se labora en régimen de interna estas mujeres pierden "espacio y tiempo necesario para mantener una vida privada al margen del trabajo, al menos durante los días laborales. La permanencia obligada en el lugar de trabajo, así como la convivencia continua con la familia, son las condiciones laborales más difíciles de asumir para las trabajadoras en esta modalidad" (Marcu, 2009, p. 475)
} 
circunstancia o característica personal, laboral, geográfica o empresarial". Aunque hay que entender primeramente que el origen de las diferencias salariales ${ }^{122}$ que "son resultado de la distinta estructura salarial, esto es, del diferente reparto de complementos salariales, pagos extraordinarios y otros componentes de la retribución entre hombres y mujeres. Además, tienen peso en la explicación de la brecha salarial otras variables relacionadas con las condiciones laborales como el tipo de jornada y la duración del contrato" (de Cabo \& Rodríguez, 2014, p. 13)

Se ha puesto de manifiesto en una investigación de Bodelón et al., (2014, p. 45) que en algunas organizaciones "se sigue negando la discriminación salarial y/o simplemente no se pretende abordar. La falta de transparencia de las empresas en este ámbito es criticada por muchas entrevistadas, afirmando que en los diagnósticos ni se habla de ello y/o se niega dicha desigualdad salarial entre mujeres y hombres. Se considera un tema "tabú" y/o la gerencia de la empresa se niega en rotundo a abordar esta cuestión."

El derecho a la igualdad salarial y a la no discriminación retributiva entre mujeres y hombres es un derecho reconocido expresamente en varias referencias normativas, principalmente en el artículo 23.2 de la Declaración

122 Sumado a esto, también se destaca como factores relevantes "la disponibilidad para viajar y para realizar horas extraordinarias, que son valoradas positivamente por las empresas y suelen traducirse en salarios más elevados". Así como también la antigüedad en el puesto de trabajo "es explicativa del salario y la diferencia salarial entre mujeres y hombres. De hecho, existen complementos salariales de antigüedad indicativos de esta relación" (de Cabo \& Rodríguez, 2014, p. 13)

Según los mismos autores "complementariamente, se observa que el salario tiende a aumentar cuando lo hace el nivel de esfuerzo físico o el nivel de estrés asociados al puesto de trabajo" (p. 14). 
Universal de los Derechos Humanos en el cual se proclamó que toda persona tiene derecho, sin discriminación alguna, a igual salario por trabajo igual. En la carta magna, el artículo 35.1 de la CE establece el derecho de todos los españoles a una remuneración suficiente en el trabajo "...sin que en ningún caso pueda hacerse discriminación por razón de sexo".

Por su parte, entendida como condiciones de trabajo retributivas y asumida como una tarea aún pendiente se encuentra reflejado el derecho en el artículo 5 de la Ley Orgánica 3/2007, de 22 de marzo, asimismo en el artículo 28 del Estatuto de los Trabajadores se promulga la obligación del empresario "... a pagar por la prestación de un trabajo de igual valor la misma retribución, satisfecha directa o indirectamente, y cualquiera que sea la naturaleza de la misma, salarial o extra salarial, sin que pueda producirse discriminación alguna por razón de sexo en ninguno de los elementos o condiciones de aquélla."

En España, según la investigación de Cabo \& Rodríguez (2014, p. 81) lograron concluir que "la discriminación salarial de las mujeres españolas es mayor que la de las extranjeras. Las trabajadoras españolas perciben un salario peor, con respecto a los hombres, que las que tienen nacionalidad de la UE, América Latina, y, especialmente, del resto del mundo."

Una de las razones propuestas por Romero (2006, p. 54) se debe a que al empresario no se le impone la igualdad retributiva para todos, en este supuesto admite el tratamiento desigual ante hechos que son diferentes, lo que no se admite es que las desigualdades se fundamenten en supuestos que estén prohibidos por la norma, aquellas desprovistas de justificación objetiva y razonable.

Con la adhesión y posterior ratificación de España en 1967 al Convenio número 100, instrumento internacional pionero en este ámbito, que establece 
el derecho a la remuneración igual para mujeres y hombres por un trabajo de igual valor, como estado miembro adquiere la obligación de promover y asegurar la aplicación para todos los trabajadores indistintamente del sexo del principio de igualdad de remuneración para por un trabajo de igual valor, en este sentido, según Oelz, Olney, \& Tomei (2013, p. 29) requiere un medio de medir y comparar trabajos diferentes sobre la base de criterios ${ }^{123}$ objetivos como competencias, condiciones de trabajo, responsabilidades y esfuerzo sin ningún tipo de prejuicio ${ }^{124}$ por motivo de género.

A partir de lo anterior, se puede afirmar que existe discriminación salarial por razón de sexo, cuando la mujer percibe una retribución distinta a la del hombre por la realización de un trabajo idéntico o de valor equivalente, o en otras palabras, cuando las trabajadoras reciben una remuneración menor que la de los trabajadores por el desempeño de un puesto de trabajo con las mismas tareas, funciones y responsabilidades, bajo las mismas condiciones laborales y en una empresa de similares características. Por lo que la diferencia salarial consistirá en la brecha existente entre lo que cobran, en media, hombres y mujeres.

\footnotetext{
123 Sobre los criterios razonables, González et al. (2010, p. 112) acertadamente enumera las exigencias sobre el trabajo de las empresas en la erradicación de las brechas de género, con lo cual, enfatizaron que "los criterios deberán ser neutros, basados en atributos igualmente predicables de ambos géneros, evitando el uso de criterios sexualmente caracterizados (con especial atención al criterio del esfuerzo físico, sobre el que pesa el prejuicio de ser característico de los hombres)."
}

${ }^{124}$ Con respecto a los prejuicios inconscientes Catalyst (2015-d) creó una infografía para los líderes y poder combatir este tipo de barreras que se presentan en la mayoría de las organizaciones, con una serie de 9 pasos así: comience por usted mismo, sea verbal, aprenda más, conozca a su gente, empodere a su gente, rompa el ciclo, arriésguese por otros, encuentre aliados y permanezca comprometido. Para más detalle véase Anexo 4. 
Hay que aclarar que el trabajo de igual valor también se refiere a la situación en la que desempeñan trabajos diferentes. Cuando los trabajadores independientemente del sexo llevan a cabo un trabajo de contenido diferente, que requiere de diferentes cualificaciones y que se desempeña en condiciones diferentes, pero que en general es de igual valor, según el convenio deberían recibir una remuneración igual.

Así, se entiende por retribución o remuneración, el salario o sueldo normal de base o mínimo y cualquier otra gratificación percibida, directa o indirectamente, en dinero o en especie, por la persona trabajadora en razón de la relación de trabajo.

Con respecto a la definición de remuneración el convenio deja claro que los pagos en cuestión son los que se producen a raíz del empleo del trabajador, sin embargo, estos pueden incluir además algunos de los siguientes elementos y complementos salariales: sueldo básico, sueldo mínimo, sueldo ordinario, horas extraordinarias, prima por productividad y rendimiento, incremento por antigüedad, asignación familiar por hijos o por dependencia, gratificaciones, lavado y secado pagado o asignación de gastos de viaje, coche de empresa, alojamiento pagado o asignación, uniforme pagado o asignación, comisiones, seguro de vida, seguro social del empleador o de la industria, acciones o beneficios de la empresa, comida pagada o asignación entre otros.

Hay que tener presente que la trayectoria en el ámbito laboral de los trabajadores por sexo no siguen los mismos patrones (García, 2012, p. 32) esto se debe primero al acceso de unos y otros a diferentes sectores y puestos de trabajo, además las jornadas a tiempo parcial que son más 
habituales para el género femenino ${ }^{125}$, sin contar que son ellas las que acceden mayormente a los permisos, reducciones de jornada lo que hace más difícil la promoción profesional e incremente las diferencias salariales.

Ahora bien, de acuerdo con de Cabo \& Garzón (2007, p. 30) existen dos teorías principales en lo que respecta a establecer y determinar el porqué de la diferencia salarial entre géneros: la teoría del capital humano y la teoría de la discriminación de la mujer. La primera, consiste en asociar los salarios con la productividad, en este sentido las mujeres ganan menos porque son menos productivas, la razón se debe a una menor inversión en capital humano, sobre todo en formación específica y experiencia para un determinado puesto de trabajo.

A estos efectos, la productividad es entendida como la relación entre los resultados obtenidos y los recursos utilizados para obtenerlos. Desde el punto de vista laboral, la productividad hace referencia al valor de la producción obtenida con un determinado volumen de trabajo. Así, se observa una relación directa entre los costes laborales y el valor de la producción.

No obstante, de acuerdo con Goldin (2014) no es justificable dichas razones para la existencia de una brecha salarial de género que se expanden tan enormemente con la edad y de la misma manera el por qué las mujeres sin hijos generalmente tienen ingresos más altos que las mujeres con hijos. En este sentido, argumenta que la mayor parte de la diferencia se reduce a

\footnotetext{
125 De hecho, una investigación de Villar et al. (2010, p. 78) colocó de manifiesto las características del empleo a tiempo parcial en España, "al igual que en la mayoría de países industrializados, este tipo de empleo está concentrado principalmente entre la población femenina, en ramas muy concretas del sector servicios (trabajo doméstico, comercio, hostelería, educación) y en ocupaciones elementales o poco cualificadas."
} 
factores que no tienen nada que ver con el sexismo: el número de horas que una persona trabaja y el grado de flexibilidad laboral.

Los principales estudios para determinar las diferencias salariales se han centrado en cinco aspectos principales: coste de la vida, productividad del trabajo, desempleo, tipo de convenio y tamaño de empresa (Cfr. Aláes, Longas, \& Ullibarri, 2003), en este sentido, han concluido que la presencia relativa de los individuos mejor dotados de capital humano es mayor en las empresas más grandes, así como en los sectores y regiones más productivos y con mayor importancia el convenio de empresa.

La segunda, tiene que ver con estereotipos meramente discriminatorios, no está asociado a temas de productividad sino porque los prejuicios permiten afirmar que pueden estar siendo objeto de discriminación en el mercado de trabajo y en las oportunidades laborales. Estos prejuicios discriminatorios pueden ser originados e impulsados por los empleadores, los trabajadores y directivos, e incluso los consumidores.

De hecho, no son los únicos factores que pueden justificar las diferencias salariales, ambas teorías pueden estar interrelacionadas, así Tenjo, Ribero, \& Bernat (2005, p. 4) clasificaron otras diferencias asociadas a la productividad surgidas de prácticas discriminatorias en otros niveles de la sociedad, como en el acceso a la educación o a la existencia de sistemas educativos de diferentes calidad para hombres y mujeres, así como las diferencias originadas por la oferta laboral, las compensatorias, y las de preferencias.

Sobre las diferencias compensatorias, están asociadas a algunas características de los trabajos en particular, por nombrar un ejemplo, si hay trabajos que implican inseguridad o condiciones laborales no tan preferentes tales como el trabajo por turnos, los viajes frecuentes o un mayor riesgo de 
accidentes o peores entornos ambientales es posible que la remuneración en dichos trabajos incluya un premio para compensar a los trabajadores pues les está generando dichas condiciones de trabajo.

De hecho, Goldin (2014) brinda una explicación simple de la existencia de las brechas salariales, pues lo asocia a las horas de trabajo que en muchas ocupaciones valen más cuando se administra en momentos particulares y cuando el horario es más continúo. Esto significa, que en diversos sectores se maneja un horario flexible que a menudo tiene un precio alto, sobre todo en los mundos corporativos, financieros y legales

Con respecto a las diferencias por preferencias, la teoría está basada en el enfoque de Becker (Cfr. Becker, 2010), los gustos y preferencias se refieren a la idea de personas a quienes les desagrada compartir espacios de trabajo con personas del grupo minoritario y están dispuestas a pagar para no hacerlo. Hay empleadores que están dispuestos a pagar mayores salarios a los hombres que a las mujeres, aunque sus productividades sean iguales, es un tema sociológico. Los empleadores que discriminan tendrán costos mayores que los que no discriminan.

Con una perspectiva ligeramente parecida, se encuentra la teoría de Milton Friedman al considerar las leyes de igual salario por igual trabajo como una fuerte de apartheid, el autor justificó esta afirmación al decir que las mujeres que piden igual salario por igual trabajo están siendo antifeministas, para él no tienen la intención de serlo pero es el precio de su creencia, porque si hay alguna actividad en la cual por cualquier razón un hombre es preferido por alguna mujer o viceversa, la única arma que el sexo menos productivo tiene es la de ofrecer trabajar por menos.

En este sentido, Friedman sostiene que el efecto de requerir igual salario por igual trabajo será el de perjudicar a las mujeres, ya que, si sus 
habilidades son más altas que la de los hombres en un trabajo en particular y se le reconoce como tales, la ley positiva no hace ningún bien. Por lo que, si sus habilidades son inferiores por cualquier razón, hay quienes dirían que la única forma de contratarlas es pagándoles el mismo salario, entonces para el autor se les negaría la única arma que tienen para ser competitivas.

Insiste, en que, si la falta de voluntad para contratarlas es por la existencia de estereotipos discriminatorios, se está buscando que sea costoso el ejercer su prejuicio. Al establecer que se le debe pagar lo mismo a mujeres y hombres se está impulsando aún más la discriminación pues finalmente, al empresario le dará igual contratar hombres o mujeres, y en dicho caso lo hará por preferencia, contratará más hombres.

Mientras que, si las mujeres son libres para competir, es decir, trabajar por menos, entonces el empresario contratará más mujeres en vez de hombres a menos que quiera asumir ese costo de más que le generaría, para Friedman si las mujeres son tan buenas como los hombres entonces está pagando un precio por discriminar. En conclusión, el autor no es un defensor de las medidas positivas, es decir, cuando se promueven leyes de igual trabajo, igual salario pues con ellas, el objetivo es reducir a cero el costo impuesto a las personas que discriminan por razones irrelevantes.

Ahora bien, si se observa datos estadísticos reales, el último informe global sobre salarios de la OIT (2014) pone de manifiesto y confirma que en casi todos los países de la muestra hay brechas salariales entre las mujeres y los hombres, además coloca en evidencia la situación salarial entre los trabajadores nacionales y los trabajadores migrantes, lo que se había planteado como discriminación múltiple.

Según el informe, las causas de dichas brechas son múltiples y complejos, por lo que difieren entre países y varían de un punto a otro en la 
distribución salarial. Tales brechas pueden dividirse en una parte explicada a través de características observables que definen el capital humano de cada individuo y sus características dentro del mercado laboral, y una parte no explicada que refleja la discriminación salarial y engloba características específicas que en principio no debieran incidir en los salarios.

El informe manifiesta que, si se suprimiera la penalización no explicada, es decir, la parte no explicada por las características laborales, la brecha media entre mujeres y hombres se reduciría, Además, "si dicha parte no explicada se suprimiera, la brecha salarial entre hombres y mujeres desaparecería casi por completo en alrededor de la mitad de los países de economías desarrolladas representados en la muestra".

El informe también da cuenta de una brecha salarial entre los trabajadores de la economía formal y la economía informal; ello queda de manifiesto en las diferencias salariales entre trabajadores de la economía formal e informal en países seleccionados. Tal como ocurre con las disparidades salariales entre mujeres y hombres y las disparidades de que son objeto los migrantes, la disparidad salarial de los trabajadores de la economía informal suele ser más reducida, y va aumentando en función del incremento en la escala salarial.

Por otra parte, frente a las de los trabajadores de la economía formal, las características observables de mercado laboral de los trabajadores de la economía informal difieren en todos los puntos de la distribución salarial y en todos los países (es decir, hay una disparidad explicada en la totalidad de la distribución). No obstante, esto no quita peso a que la parte no explicada de la brecha salarial entre trabajadores formales e informales sigue siendo sustancial. 
La situación de España indica que, según los datos disponibles de la Encuesta Anual de Estructura Salarial proporcionados por el INE a fecha de cierre de investigación son a fecha de 2013 (Cfr. INE, 2015), y en donde el salario medio anual de las mujeres fue de 19.515 euros mientras que el de los hombres fue de 25.675 euros.

El salario medio anual femenino representó aproximadamente el 76\% del masculino, en este sentido, en lo que respecta a la distribución salarial, la desigualdad entre sexos es apreciable, puesto que tal como se evidenció, en todas las actividades económicas, en todas las ocupaciones y en todas las comunidades autónomas, las mujeres tuvieron un salario inferior al de los hombres. Según el INE esta desigualdad se explica, en parte, por las diferencias en el tipo de jornada y de contrato.

En este sentido, el salario por hora se convierte en la variable más relevante, al momento de demostrar que existen las desigualdades por sexo (Oelz, Olney, \& Tomei, 2013), así la ganancia por hora de los trabajadores a tiempo parcial fue inferior a la ganancia media por hora, tanto para el total de los trabajadores como para cada sexo. En el caso de las mujeres, llegó a ser un $29 \%$ más baja. Por su parte, la ganancia por hora de los hombres a tiempo completo estuvo un 10,1\% por encima de la media, mientras que la de las mujeres fue un $5 \%$ inferior (INE, 2015, p. 5).

De acuerdo con el tipo de contrato por sexo, los hombres con contrato de duración indefinida tuvieron un salario superior un 22,3\% al medio y los de duración fija un $28,4 \%$ inferior a la media. En las mujeres, el salario fue inferior al medio independientemente del tipo de contrato, del 9,1\% para los contratos indefinidos y del 35,8\% para los de duración fija (INE, 2015, p. 6)

La mayoría de las mujeres termina obteniendo salarios menores que los hombres porque se las juzga a partir de los comportamientos promedio 
de la sociedad. Las desigualdades salariales son más perceptibles, cuando se muestra la evolución histórica del salario medio anual por sexo en España, así es evidente la existencia de la brecha salarial que existe entre mujeres y hombres tal como se observa en los gráficos comparativos (Gráfico 23 y 24) en donde las féminas no han logrado traspasar la barrera de los 20.000 euros anuales de media desde el año 2002, situándose el promedio anual en un $75 \%$ de salario de lo que cobran los hombres, los incrementos porcentuales por año para ellas han sido muy mínimos.

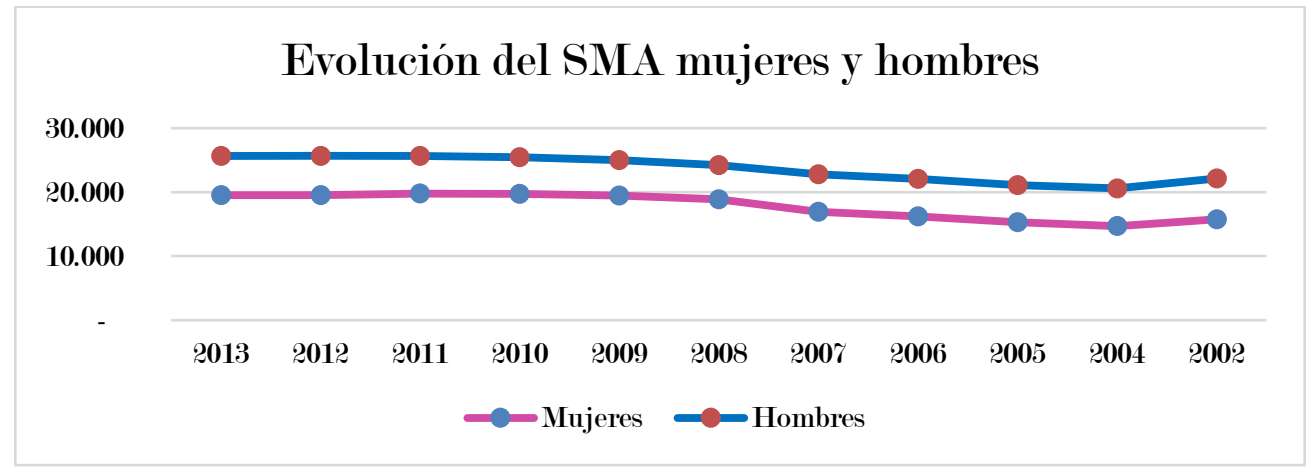

Gráfico 23. Evolución por año del SMA de las mujeres versus hombres. Fuente: INE.

Elaboración propia

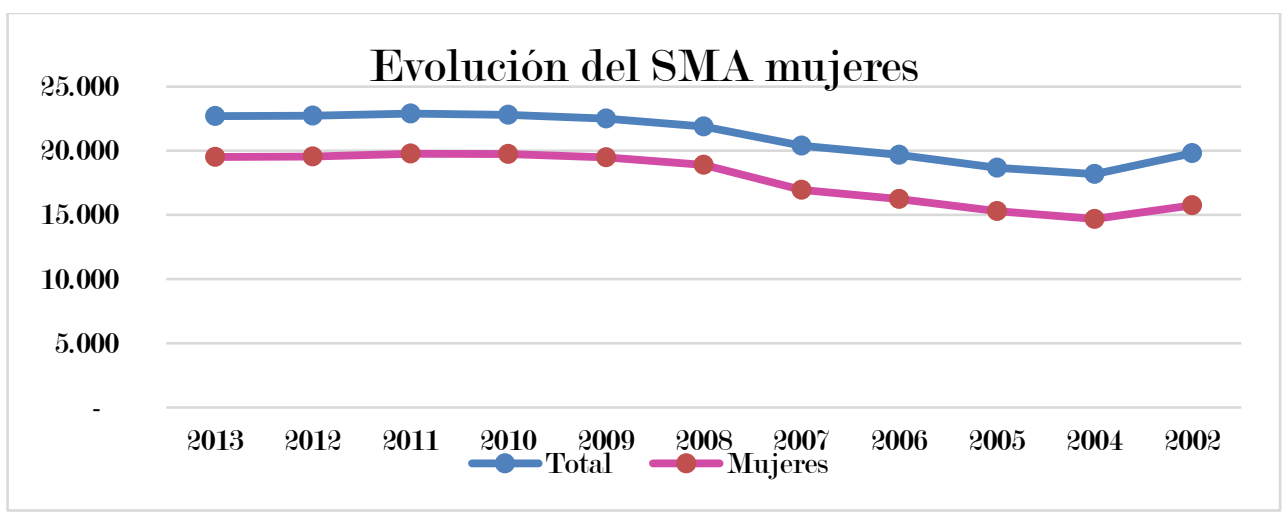

Gráfico 24. Evolución por año del SMA de las mujeres versus el total. Fuente: INE.

Elaboración propia. 
Toda esta información es puesta de manifiesto en un informe por parte de la organización sindical española Unión General de Trabajadores (2015) el cual alertó que la brecha salarial entre mujeres y hombres sigue aumentado durante los últimos años hasta situarse en casi un 24\% a 2012 , ésta brecha equivale a la diferencia en la ganancia media bruta anual de las mujeres respecto de los hombres, en este sentido su análisis reveló que "para percibir las mismas retribuciones por trabajos de igual valor los hombres necesitan trabajar doce meses y las mujeres dieciséis".

Según el informe, con respecto al análisis de los países europeos, en el conjunto de los sectores de actividad, las mujeres europeas ganan de media un $16,5 \%$ menos por hora que los hombres, esta diferencia se eleva para las mujeres españolas que ganan un 19,3\% menos por hora. El informe también muestra la preocupación por las mujeres que trabajan en jornada parcial, en España con un 33,7 \% de brecha salarial, lo cual situa al país en cabeza por el número de mujeres afectadas que son aproximadamente el 25 $\%$ de las trabajadoras españolas, y evidencia como por ejemplo en otros países como Dinamarca no se establecen diferencias salariales para esta modalidad de contratación.

Por otro lado, independiente de la formación adquirida para aumentar las competencias en dirección, las brechas salariales continúan, esto se ve reflejado en un estudio reciente en Estados Unidos realizado por Kitroeff \& Rodkin (2015) el cual mostró la preocupación por dicha diferenciación salarial que existe entre los jóvenes norteamericanos que se gradúan de un programa de posgrado -específicamente de un MBA- y se incorporan al mercado laboral.

En este sentido, las diferencias son concluyentes entre sexos: "las mujeres con MBA ganan salarios más bajos, manejan menos personas, y son menos satisfechas con su progreso que los hombres con el mismo grado". 
Sin contar con que las brechas aumentan y las desigualdades son especialmente marcadas entre los graduados de algunos de los programas más elitistas.

Una explicación de la brecha de género por parte de los autores puede ser que "las mujeres tienen menos probabilidades de ser jefes" y además que éstas pueden estar optando a sectores, industrias y profesiones menos remuneradas. Así, se evidenció en el estudio que, dentro de los graduados, el $43 \%$ de los hombres trabajaban en las cinco industrias más lucrativas, frente a $32 \%$ de las mujeres. Pero incluso, se les pagaba menos cuando las mujeres entraron en campos bien remunerados y la brecha persistió sin importar el trabajo que llevasen a cabo.

Un aspecto demostrado que fortalece la brecha salarial de género es la contratación temporal la cual "contribuye a elevar la discriminación salarial. Si bien la diferencia es moderada, las mujeres con contrato temporal están relativamente peor tratadas, con relación a los hombres, que las que tienen contrato indefinido." (de Cabo \& Rodríguez, 2014, p. 82). Además, complementado al fenómeno del techo de cristal "la discriminación salarial aumenta cuando las mujeres trabajadoras asumen responsabilidades organizativas y de supervisión. La posición salarial de las trabajadoras con responsabilidades en su organización es comparativamente peor, con respecto a la de los hombres, que la de las que no las tienen."

Para García (2012, p. 46) los poderes públicos tienen la obligación de actuar $^{126}$ contra las diferencias salariales, ampliando el control de la

\footnotetext{
${ }^{126}$ En este punto, es importante traer a colación la investigación de de Cabo \& Rodríguez, 2014, p. 19) quienes brindan una herramienta para examinar las diferencias salariales entre mujeres y hombres, en este sentido, proponen un Indicador Sintético de Brecha Salarial el cual "permite resumir una realidad tan compleja como la desigualdad salarial entre hombres
} 
inspección de trabajo sobre las partes interesadas, actualización continua del marco jurídico y doctrinal contra las discriminaciones, incentivando las buenas prácticas de empresas en este ámbito e implementar acciones positivas cuando se requiera.

Para los empleadores estos elementos introducen un factor de riesgo e incertidumbre en las decisiones que tienen que ver con la contratación de mujeres y la promoción profesional, por lo que al final terminan penalizándolas con menores salarios (Tenjo, Ribero, \& Bernat, 2005)

En este sentido, los poderes públicos y las partes interesadas deberán cerciorarse de que las labores realizadas por mujeres y hombres en el mercado de trabajo, sean estimados y valorados apropiadamente ${ }^{127}$, pues tal

y mujeres, teniendo en cuenta todos los factores que la originan, y ofreciendo información sobre la importancia de cada uno de ellos. Pretende constituirse, así como una herramienta que facilite la toma de decisiones acerca de las políticas más adecuadas que podrían llevarse a cabo en la lucha contra la brecha salarial de género y permita realizar un seguimiento de su evolución a lo largo del tiempo, así como comparaciones entre distintos países y regiones."

127 Sin alejarnos del tema en cuestión, pero igual de relevante hay que traer colación una investigación, teniendo en cuanta las críticas que se erigen sobre sectores económicos como el textil, de acuerdo con Laliena (2010, p. 46) "las mujeres han encajado, por la construcción cultural de su género, en este esquema de producción que las utiliza como mano de obra apropiada para beneficio de los intereses del capital."

De hecho, esto es evidenciable puesto que "las empresas transnacionales de los sectores de confección, textil, calzado y/o juguetería, entre ellas empresas españolas, desplazan parte de sus procesos manufactureros a países de la periferia económica, donde existen menores índices de protección social, condiciones laborales menos avanzadas que en sus países de origen, salarios menores, escasa exigencia en la conservación del entorno..., logrando con esto precios de producción más bajos y mayores tasas de competitividad en el mercado internacional." (Laliena, 2010, p. 47) 
y como lo sostienen Oelz, Olney, \& Tomei (2013) el objetivo de buscar prevenir y erradicar la discriminación salarial, se convierte en esencial para poder alcanzar la igualdad de género y el trabajo decente.

No se puede esperar ninguna mejora duradera en la situación económica de las mujeres mientras su tiempo y talento se valore menos que el de los hombres, por esta razón es importante ayudar a cambiar estereotipos sobre las aspiraciones, preferencias, capacidades y la idoneidad de las mujeres para determinados empleos.

Si bien reducir las brechas salariales ${ }^{128}$ existentes puede acarrear un conjunto de costos al empleador, los beneficios que puede traer consigo son mucho mayores, como ya se sabe el capital humano es básico en toda organización por lo que estimula una mejores prácticas de gestión del personal y un entorno de trabajo basado en el compromiso, pues no hay que olvidar que aquellos trabajadores cuyos empleos no se han evaluado o mejorado pueden manifestar descontentos traducidos a mediano y largo plazo en una disminución de la motivación y de la productividad.

Por lo que a nivel general es un gana y gana, por un lado, las mujeres se favorecen de un sistema más justo de reconocimiento y remuneración por lo que su economía familiar mejora económicamente, por otro lado, las

\footnotetext{
128 Hay consciencia que combatir las brechas salarial que tienen su origen en factores discriminatorios no es tarea fácil , pues según Forética \& Secretaria de Estado de Igualdad (2010, p. 46) requiere "no sólo una revisión cuidadosa de la estructura de la retribución (normalmente incluida en convenios de empresa y exenta de discriminación), sino también una valoración de puestos de trabajo que permita identificar tareas, funciones y competencias por familias de puestos y su vinculación a empleados/as con lo que algunas diferencias detectadas a igualdad de tareas, funciones y competencias podrían ser discriminatorias."
} 
organizaciones garantizan el contar con las personas adecuadas con las capacidades idóneas por lo que incrementaran su eficiencia empresarial y por último, en la sociedad irá en el camino de la justicia social y de la sostenibilidad.

No obstante, Goldin (2014) creen que la solución para combatir las desigualdades en el trabajo, no necesariamente, tiene por qué implicar la intervención de la administración pública y no tiene por qué hacer a los hombres más responsables en el hogar. Pero debe involucrar los cambios en el mercado laboral, sobre todo, cómo se estructuran los trabajos y la remuneración para mejorar la flexibilidad temporal, en este sentido, la brecha de género en los salarios se reduciría considerablemente y podrían desaparecer por completo si las empresas no tienen un incentivo para recompensar desproporcionadamente a las personas que trabajaban largas horas; según la autora dichos cambios han tenido "tanto éxito en diversos sectores, como la tecnología, la ciencia y la salud, pero es menos evidente en el corporativo, financiero y legal".

Lo que, si es cierto, es que al final "las mujeres cobran menos que los hombres $y$, por tanto, el sexo influye en la remuneración que perciben los trabajadores y las trabajadoras (...) la mayor parte de la diferencia salarial total entre sexos, el $89 \%$, viene dada por la parte discriminatoria por razón de sexo o discriminación salarial directa de las mujeres" (de Cabo \& Rodríguez, 2014 , p. 80). Por último, "uno de los campos de acción identificados por la Comisión Europea para tratar de resolver la brecha salarial entre mujeres y hombres es precisamente promover la igualdad salarial en trabajos de igual valor a través de la RSE" (Forética \& Secretaria de Estado de Igualdad, 2010, p. 46). 


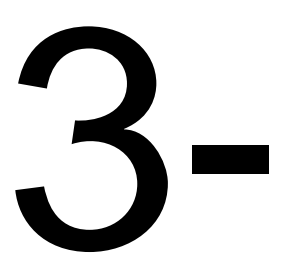

Capítulo Tres. El acceso de la mujer a cargos de toma de decisiones en el ámbito privado: empresas cotizadas. 


\subsection{Planteamiento introductorio}

A pesar de los progresos en cuanto a la participación en el mercado de trabajo de las mujeres en el último siglo, tal y como se ha venido planteando la incorporación de la mujer a puestos de toma de decisiones y de responsabilidad no sigue al mismo ritmo, situación que se ve reflejada en los sectores privado y público. En el primer caso, observando quiénes son las cabezas visibles de las grandes empresas y ocupan los cargos de alta dirección, o, cuáles son los miembros de las juntas directivas o consejos de administración de empresas cotizadas; en el segundo caso, la proporción de funcionarios pertenecientes a las tres ramas del poder público, principalmente en el ejecutivo o en cargos de elección democrática.

Ahora bien, no se puede desconocer el vínculo existente que tiene esta situación con la formación educativa, conforme a ello, hoy en día es notable ver una mayor accesibilidad de la mujer en los diferentes niveles educativos,

principalmente en lo referente a la educación superior, lo cual debería vaticinar una mayor participación de la mujer no solo en el ámbito laboral, sino también a futuro en otros aspectos sociales tales como el acceso a la salud, a la educación, a la política entre otras.

No hay que olvidar el carácter histórico de esta situación, pues en el pasado, los hombres eran quienes accedían a los estudios de educación superior como parte de su integración exitosa a la esfera pública y al reconocimiento social, mientras que las mujeres eran relegadas y asignadas a las tareas propias del hogar. No obstante, en las últimas décadas, se ha conseguido cambiar estos procesos históricos de exclusión en la formación académica al incrementarse la participación de la mujer en el ámbito educativo. 
Este componente histórico tenía sentido en el pasado, los hombres lideraban el mundo puesto que la fuerza física era indispensable para decidir quién mandaba y guiaba a los grupos sociales, pero en la época actual cuando ya no prima la fortaleza física, es más relevante a la hora de dirigir en las distintas esferas sociales que la persona disponga de otro tipo de habilidades como la creatividad, la inteligencia o la innovación, lo cual no tiene nada que ver con el sexo puesto que no depende de esta característica, la disponibilidad puede tener dichas competencias. Sin embargo, los últimos informes siguen demostrando que "las mujeres con educación avanzada tienen tasas de desempleo mayores que los hombres con niveles de educación similar" (ONU, 2015, p. 8).

Al tenor de lo anterior, es preciso destacar el interés creciente por parte de la sociedad en general sobre la participación de las mujeres en la alta dirección, en los consejos de administración y en las demás posiciones de liderazgo empresarial (Gabaldón, 2013) no sólo desde la perspectiva ética y moral sino también desde la perspectiva de la eficiencia empresarial. Ciertamente, las altas posiciones juegan un papel fundamental en las decisiones empresariales, es por ello que como garantía de este objetivo, se demande hoy en día y se considere un aspecto tan importante como lo es la diversidad en el gobierno corporativo, asociada en la mayoría de los casos a aspectos relacionados con la igualdad de género en el trabajo.

Es un hecho, que la diversidad se ha trasladado a las esferas organizacionales ${ }^{129}$, en la Unión Europea "el interés por la diversidad en la

\footnotetext{
129 Es cierto, tal como lo planteó la Agencia Europea para la Seguridad y la Salud en el Trabajo, la evolución de las responsabilidades de las organizaciones en distintos ámbitos, "las actividades económicas necesitan mostrar una actuación responsable hacia las personas, el planeta y los beneficios... Los trabajadores en particular son fundamentales para llevar a cabo los cambios sociales y medioambientales en la compañía" (2005, p. 11)
} 
empresa, que inicialmente estuvo muy vinculado a las empresas multinacionales de origen estadounidense, ha ganado peso en las agendas económicas y empresariales por los cambios sociodemográficos: la incorporación masiva de las mujeres al mercado laboral, la generalización de procesos migratorios, o el envejecimiento poblacional tiene ya y tendrá en el futuro un reflejo claro en las plantillas de las empresas" (Abay Analistas Económicos y Sociales, 2011, p. 7).

La justificación principal de esta creciente demanda radica en un entorno económico fluctuante con un constante aumento de exigencias por diversos grupos de interés por lo que las personas pasan a convertirse en el valor diferencial de las compañías.

Cabe por ello, la realización de un diagnóstico sobre la presencia femenina en los altos cargos empresariales por lo que será necesario evidenciar a partir de datos cuantitativos cual es la proporción actual de mujeres en los consejos de administración y/o juntas directivas. Para ello, se realizará inicialmente una revisión teórica del fenómeno del techo de cristal en el ámbito empresarial en específico, para posteriormente tal como se ha hecho previamente en las esfera pública y académica analizar la evolución de la proporción de mujeres en altos cargos.

Es importante, insistir en involucrar a los diferentes actores sociales para trabajar permanentemente en el logro de igualdad de oportunidades, por lo que es justo en primera medida, incentivar el desarrollo de un aspecto en el que ya han comenzado a trabajar las organizaciones e incluso los gobiernos a nivel internacional, se trata de la RSE.

En este sentido, Martín (2012) sostiene que para conseguir el objetivo de la igualdad efectiva de hombres y mujeres en las relaciones de trabajo además de la normativa y políticas comunitarias se necesita la conquista de otros dos propósitos adicionales de primordial relevancia, uno de ellos la RSE. Al respecto, dicha responsabilidad debe suponer según el Instituto 
Ethos de Empresas e Responsabilidade Social (2013, p. 3) “...prácticas de diálogo y compromiso de la compañía con todos los públicos a ella ligados, a partir de una relación ética y transparente" por lo que conforme a esta acepción uno de esos públicos también llamados stakeholders son los trabajadores y los directivos.

Antes de continuar, es necesario colocar a disposición del lector un conjunto de términos usados en la doctrina que tiene relación directa con la barrera invisible que se ha hablado a lo largo del texto los cuales se observa el Gráfico 25 y que se detalla muy bien en la investigación de Cáceres et al. (2012).

\section{2. ¿Por qué es tan difícil el acceso de la mujer a cargos de mayor responsabilidad?}

Al realizar el análisis del rol de las mujeres en cargos de decisión resulta complejo, sobre todo porque es un fenómeno que se viene estudiando recientemente, se debe a que como se ha visto, la adquisición de derechos de las mujeres en la sociedad ha sido un proceso lento, variable y particular; además ha faltado una mayor dedicación e investigaciones en este ámbito.

Sobre esta última afirmación se le debe dar relevancia puesto que ha existido un anonimato de las mujeres en el trabajo lo cual repercute directamente en la situación que nos ocupa, en efecto la falta de representación cuantitativa y la poca divulgación del trabajo de ellas. 
1. Síndrome del desequilibrio en la cumbre
Conjunto de dificultades o limitaciones a las que se enfrenta la mujer que se encuentra en el poder para desarrollar experiencias personales y profesionales gratificantes, por razón de género.

\begin{tabular}{|c|c|}
\hline $\begin{array}{l}\text { 2. Síndrome de } \\
\text { la abeja reina }\end{array}$ & $\begin{array}{l}\text { Tendencia de algunas mujeres de atribuir su éxito } \\
\text { profesional a sus propios méritos y rechazar, por tanto, } \\
\text { las acciones de discriminación contra personas de su } \\
\text { mismo género. }\end{array}$ \\
\hline 3. Techo de cristal & $\begin{array}{l}\text { Se refiere a una serie de obstáculos internos a los } \\
\text { propios mecanismos de actuación de la sociedad } \\
\text { (valores, etc.) que encuentran las mujeres para aspirar } \\
\text { a algún tipo de promoción profesional y que no son } \\
\text { perceptibles directamente. }\end{array}$ \\
\hline $\begin{array}{l}\text { 4. Política de tierra } \\
\text { quemada }\end{array}$ & $\begin{array}{l}\text { Las mujeres van ocupando aquellos lugares que el } \\
\text { hombre va desechando, puestos que han perdido su } \\
\text { reconocimiento y prestigio social. }\end{array}$ \\
\hline $\begin{array}{l}\text { 5. El mito de } \\
\text { la excepción }\end{array}$ & $\begin{array}{l}\text { Está muy relacionado con el síndrome de la abeja } \\
\text { reina. Hace referencia al carácter meritocrático e } \\
\text { individual a través del cual se explica el posible éxito } \\
\text { de cualquier mujer y con ello se rechaza la presencia de } \\
\text { cualquier tipo de discriminación. }\end{array}$ \\
\hline $\begin{array}{l}\text { 6. Prolongación del } \\
\text { mito maternal }\end{array}$ & $\begin{array}{l}\text { La mujer ocupa mayoritariamente profesiones propias } \\
\text { del rol maternal asignado como constructo sociocultural } \\
\text { a su condición de mujer, como por cjemplo en la } \\
\text { enseńanza y más concretamente en Educación Infantil, } \\
\text { que puede decirse es una profesional feminizada } \\
\text { prácticamente al cien por cien. }\end{array}$ \\
\hline $\begin{array}{l}\text { 7. Síndrome de } \\
\text { la mala madre }\end{array}$ & $\begin{array}{l}\text { Presión psicosocial ejercida sobre la mujer y su } \\
\text { rol maternal que genera una gran inestabilidad } \\
\text { emocional en el caso de romper con las tareas que } \\
\text { tradicionalmente le han sido propias, por lo que } \\
\text { contribuye a mantener la persistencia de este sistema y } \\
\text { la anulación del acceso de esta a posiciones de mayor } \\
\text { poder y participación. }\end{array}$ \\
\hline
\end{tabular}

8. Think manager, think male

Expresión inglesa que representa la asociación tradicional existente entre la dirección y el gobierno de los centros con un perfil propiamente masculino que ha sido el imperante de la cultura organizacional.

9. Harén pedagógico Determinación de las relaciones de poder, en las que los hombres ocupan las posiciones de mayor prestigio y estatus profesional, mientras que las mujeres desarrollan cargos pertenecientes a un segundo plano de importancia.

10. Old's boy club Redes de apoyo interno entre los hombres para posibilitar directa o indirectamente el acceso de estos a la participación en el gobierno y gestión de la comunidad educativa en detrimento de la presencia femenina.

11. Regla de hierro Recoge la idea de que cuanto más poder y prestigio tiene una posición menos posibilidad existe de encontrar a una mujer en el cargo. 
Gráfico 25. Conceptos claves en los estudios de género. Fuente: (Cáceres et al. 2012, pp.

No obstante, aparte de demostrar que existe un escaso porcentaje y número de mujeres en las escalas de poder hace falta conocer cuáles son las causas que lo han originado, de hecho, sin alejarse de la realidad española un estudio mostró "que la gran mayoría de hombres (84\%) reconoce la existencia en España de barreras para el ascenso de la mujer directiva: sólo un $16 \%$ cree que no existen obstáculos" (Grant Thornton España, 2017, p. 14).

Aunque, Eagly \& Carli (2007) insisten en que esas barreras se pueden romper, en este sentido, para las mujeres que aspiran al liderazgo superior, las rutas existen, pero están llenas de giros, tanto inesperados como esperados. Por lo que insisten que los laberintos tienen una ruta viable al centro, es decir, el objetivo final es alcanzable.

Es un hecho que las mujeres han tenido muchas más dificultades y obstáculos para insertarse y permanecer en el mercado laboral, a través de percepciones y creencias, este fenómeno, según Martín (2012), se debe a dos razones principales, ambas vinculadas a los llamados estereotipos de género, los cuales son una serie de ideas impuestas simplificadas pero fuertemente asumidas sobre las características, aptitudes y actitudes de las mujeres y los hombres, en este sentido, logran convertirse en verdades indiscutibles en la sociedad.

En los estereotipos pueden diferenciarse dos dimensiones, a saber, la descriptiva y la prescriptiva (Navas \& Guerrero, 2017). La primera dimensión está formada por las creencias sobre las características diferenciadas que poseen los sexos (p.ej. las mujeres son por naturaleza sumisas, débiles y 
emocionales, mientras que los hombres son independientes, agresivos y autosuficientes). La segunda dimensión, se refiere a las creencias sobre las características deseables para los miembros de cada sexo (p.ej. mientras que dentro de las habilidades interpersonales deseables para las mujeres está el ser pasiva y comunitaria, para los hombres está el ser fuerte e instrumental).

En este sentido, las mujeres se encuentran en una clara desventaja puesto que dichos estereotipos no encajan con las cualidades necesarias ${ }^{130}$ para desempeñar eficazmente trabajos de alto nivel directivo, lo que implica que en muchos casos sus logros sean minusvalorados o que se atribuyan las causas de su éxito a factores diferentes a sus habilidades y capacidades.

Dicho lo anterior, la primera razón parte del rígido papel predeterminado que en la sociedad les ha sido asignado como madre, cuidadora y esposa; la segunda razón se refiere a los prejuicios aun mantenidos por los empresarios, al parecer se tiende a considerar a las mujeres menos productivas, y por tanto menos rentables para las empresas.

En este punto, cabe señalar que el término empresario ${ }^{131}$ corresponde al sector empresarial, y no solo serían aquellos del género masculino, sino

\footnotetext{
130 De acuerdo con Cáceres et al. (2002, p. 76) "tradicionalmente, la mujer ha estado apartada de todas aquellas posiciones estratégicas de toma de decisiones debido a la debilidad de su naturaleza (emociones, sensibilidad, inseguridad, etc.), que no se correspondía con el perfil de líder individual y autoritario (seguro, independiente, racional, etc.), rasgos atribuidos comúnmente al hombre."

131 Incluyendo las prácticas laborales que se realizan dentro de la organización, en este sentido, Barberá, Estellés \& Dema (2009, p. 136) identificaron que "La política de recursos humanos relativa a la selección de personal y de desarrollo de carrera de los miembros de la organización, que siguen sesgadas por el género. Fundamentalmente, el sesgo viene asociado con las creencias, generalmente erróneas en el sentido de que: las mujeres no se adecuan al perfil directivo demandado; que abandonarán el trabajo o supondrán un coste
} 
también del género femenino, puesto que el asunto de la discriminación en el trabajo es un fenómeno que se sostiene en parte por los estereotipos equivocados, en este sentido, se ha evolucionado como sociedad en diversos aspectos, sin embargo, las ideas y las concepciones erróneas sobre el género continúan intactas.

Cabe mencionar que uno de los tantos estereotipos está fundado desde una edad infantil en las mujeres, la sociedad las prepara para ser exitosas, pero no más que los hombres ya que pueden terminar convirtiéndose en una amenaza lo que acarrearía un problema para encontrar, por ejemplo, incluso una pareja estable teniendo en cuenta que las mujeres siguen siendo educadas para el matrimonio (González, 2008; Tobío, 2003)

Dentro de los principales estereotipos ligados al género identificados a lo largo de investigaciones recientes se encuentran: la menor autoridad que ejercen las mujeres, la menor disponibilidad para viajar con respecto a los hombres, que el género masculino es de por si más competente y genera influencia en posiciones de poder (Molero et al., 2009, pp. 15-16)

De hecho, el entorno de trabajo ha perpetuado comportamientos "sutiles" que promueven las discriminaciones, pues de acuerdo con Arranz (2004, p. 236) "las mujeres muestren en las interacciones con sus compañeros su aceptación o consentimiento hacia la práctica de actitudes paternalistas; el que adopten posiciones serviciales, a pesar de su superior o igual categoría profesional —tareas de cuidadoras, secretarias, relaciones

cuando tomen una baja por maternidad; que crean relaciones conflictivas con los compañeros y el resto de trabajadores; o que no son bien vistas en determinados trabajos y espacios típicamente masculinos." 
públicas - o el que incluso sean proclives a participar en el juego de la seducción sexual".

La cuestión en el fondo es que las mujeres terminan encontrándose con un muro denominado techo de cristal, que, según Mateos, Gimeno, \& Escot (2010, p. 133) consiste en una barrera ficticia difícil de traspasar que impide el avance en su carrera laboral y profesional, lo cual, se debe nuevamente a la presunción sobre la capacidad de las mujeres para desempeñar estos cargos, principalmente los de mayor responsabilidad, lo que conlleva a que éstas sean infravaloradas en muchos casos.

Asimismo, se puede encontrar la situación en la cual muchas mujeres no cumplan con el perfil ${ }^{132}$ requerido, desencadenante del escenario anterior, pues dentro de los exigencias se encuentra el demostrar una experiencia elevada, práctica que no es posible tener debido a los aspectos planteados y al vínculo más estrecho que las mujeres tienen con las responsabilidades familiares.

\footnotetext{
132 Al respecto, una investigación sobre la mujer directiva española en el contexto europeo (de Anca \& Aragón, 2007, p. 48) mostró que "El perfil de la directiva española corresponde a una mujer casada (64\%), entre 35 y 45 años (40\%), con dos hijos (36\%) y con una formación superior, mayoritariamente orientada a las ciencias empresariales y económicas. Dentro de estas un $13 \%$ ha cursado dos carreras universitarias y un $17 \%$ ha realizado además un MBA". Además, "la directiva española encuentra muchas similitudes con su homóloga europea" (2007, p. 49)

Por su parte, en el caso de la percepción acerca de su crecimiento profesional "La mujer española percibe su carrera profesional como una carrera homogénea con un reducido número de fases y raros cambios de trayectoria. La carrera profesional está articulada en torno a un hilo conductor vocacional más que de metas, valorando más el esfuerzo que el azar." (de Anca \& Aragón, 2007, p. 54)
} 
Una de las posibles explicaciones propuestas para dar cuenta de la menor presencia femenina en puestos directivos podría ser la falta de preparación de las mujeres, este supuesto planteado por (Molero et al., 2009) era cierto en el pasado, cuando las mujeres tampoco podían acceder a la educación, pero hoy en día, son ellas quienes tienen la mayor proporción en cuanto a nivel de estudios llegando incluso a superar a los hombres en ciertas profesiones y niveles de educación superior.

De hecho, las posibilidades de continuar la formación educativa son diferenciadas entre mujeres y hombres (Gonzales, 2002, p.177). Se supone que ante el interés de continuar su carrera profesional con estudios de postgrado (especializaciones, maestrías y doctorados) el profesional deba estar avalado por su familia y aunque en general debiera esto interpretarse como deseo de superación, y de una mejora futura de la posición económica y social. "En el caso de las mujeres tal situación no es tan obvia, ya que necesariamente debe convencer a su familia -sobre todo si tiene pareja e hijos- de que sus estudios no interferirán con el tiempo que les dedica. En general se aprecia su interés como una motivación personal y hasta egoísta, en detrimento de sus funciones de esposa y madre".

Además, en el caso del emprendimiento, la decisión de una mujer de transformarse en empresaria está influida por una serie de factores que la inducen a participar en los mercados laborales y otros que la atraen y que están vinculados con las expectativas de ingresos (Banco Mundial, 2010). Al respecto en el caso español, se determinó en un estudio que se "presenta el ratio mujer/hombre emprendedor más alto de Europa y la mujer española tiene un alto concepto sobre su propia efectividad a la hora de relacionarse." (Porto, Neira \& Vázquez, 2010, p. 171)

Por otro lado, una investigación de Agut \& Martín (2007) en el cual se concluyó que existen una serie de factores (externos e internos) que dificultan 
el acceso de las mujeres a puestos de responsabilidad, dentro de los primeros, o factores externos, tal como se ha venido hablando durante todo el texto, se encuentran los estereotipos de género, la misma segregación del mercado de trabajo, la discriminación laboral de las mujeres solo por el hecho de serlo, el acoso sexual en el trabajo, el acoso psicológico, las menores oportunidades de desarrollo de carrera en la organización, la ausencia de una política laboral con enfoque de género y las responsabilidades familiares. Dentro de los factores internos se encuentran: baja autoeficacia en cuestiones tradicionalmente masculinas y la formación en áreas tradicionalmente femeninas.

Además, otro contexto identificado se da, en que a pesar de que éstas cuenten con altos niveles de formación y sean fuentes potenciales para el crecimiento en la organización, deban renunciar a la promoción profesional debido entre otros motivos a una mayor exigencia de responsabilidades $y$, por consiguiente, una menor flexibilidad en los puestos de trabajo directivo, lo cual termina por ser incompatible. Y eso que en España se encuentra entre los cinco países con la media de edad más alta de las mujeres en el nacimiento del primer hijo, 30 años (World Economic Forum, 2014, p. 21)

Para las mujeres que tienen esta doble actividad, la incompatibilidad con las obligaciones familiares puede convertirse en un limitante importante para el trabajo remunerado y para los ascensos (Tenjo, Ribero, \& Bernat, 2005 , p. 42) debido a que les es más difícil aceptar trabajar horas extras, asistir a cursos de capacitación fuera de las horas de trabajo regulares, realizar viajes que impliquen ausencia del hogar por varios días entre otras.

Aunque es claro que esto no es aplicable para todas las mujeres, pues muchas mujeres hoy en día han optado por la realización profesional, por encima de la vida familiar; la cuestión en el fondo es que resulta un verdadero dilema para los empleadores que les es difícil predecir cuales son las mujeres 
que tienen mayores y menores restricciones en términos de la doble jornada $y$, como se va a ver reflejado esos riesgos a futuro.

Por su parte, Debeljuh, Idrovo \& Bernal (2015) pusieron de manifiesto que otro de los factores que también influye es que las mujeres que alcanzan altos cargos se desempeñan en ciertos tipos de funciones que se encuentran en los lados de la pirámide y difícilmente las pueden llevan a ascender a otras posiciones superiores como directores ejecutivos en las empresas.

Si bien se ha analizado aspectos muy generales que han podido justificar el por qué las mujeres les resulta mucho más dificil acceder a cargos superiores, hace falta traer a colación tres aspectos que según un estudio de Chinchilla, León, Torres, \& Canela se deben tener en cuenta al momento de analizar la trayectoria profesional de las mujeres directivas.

Los dos primeros señalados como frenos tienen que ver, por una parte, con el conflicto entre la familia y el trabajo, situación repetitiva como lo hemos observado en el presente texto, aunado al hecho que las mujeres suelen manifestar que compañeros de trabajo y jefes no son comprensivos con la prioridad dada a sus responsabilidades familiares, paralelamente la existencia de una doble jornada de trabajo, solo que esta vez es al llegar a su hogar.

La otra parte tiene que ver con los obstáculos que se encuentran a la hora de desarrollarse profesionalmente, principalmente resaltan la falta de apoyo ${ }^{133}$ por parte de los superiores y la confianza en sí mismas. El último y

\footnotetext{
${ }^{133}$ En este sentido, a falta de ese apoyo de acuerdo con Glass \& Cook (2016, p. 61) si las mujeres son promovidas a puestos de alto riesgo y carecen del apoyo o la autoridad para lograr sus objetivos de liderazgo, entonces es probable que sean cada vez más vulnerables al escrutinio y a presiones sobre su rendimiento. Como resultado, las mujeres líderes pueden experimentar períodos más cortos comparados con sus pares masculino.
} 
tercer aspecto denominado impulsores, puede favorecer al desarrollo profesional de las mujeres, dentro de los cuales se encuentran la formación y la personalidad.

Todo ello, se puede complementar con una investigación de Diehl (2014, p. 55) quien en sus resultados evidenció que las mujeres líderes evaluadas en su estudio se enfrentaban a historias de adversidad ${ }^{134}$ significativas y verdaderos desafíos en sus vidas personales y profesionales. Dentro de las adversidades se encuentran: las profesionales (por ej., discriminación, liderazgo no favorable); las personales (por ej., conflicto de relaciones, desafíos familiares, problemas de salud graves); las de tipo conflicto trabajo-familia y los siempre obstáculos derivados de su género.

Pero hay más, pues otro contexto a considerar se encuentra en la elección de futuros candidatos a cargos de toma de decisiones, en este supuesto, no se realiza por concurso de méritos, puesto que se escogen entre un grupo pequeño de candidatos, donde éstos se conocen o tienen cierto nivel de confianza, lo que termina incrementando la discriminación por razón de género, hecho que en todo caso puede ir en contra del logro de objetivos de la propia organización y por consiguiente, sea más difícil la integración de personas con mejores capacidades independientemente de su sexo.

\footnotetext{
${ }^{134}$ La autora de la investigación aclara varios puntos de discusión con respecto a los resultados: (i) que con la adversidad viene la oportunidad o el crecimiento si se sobrevive, (ii) que la perspectiva importa, en este sentido, cómo una persona ve una situación a menudo define lo que se hace, (iii) la privacidad en la adversidad es importante, (iv) encontrar un significado para la adversidad o concluir que no existe guarda una relación con la autoestima y el empoderamiento, y por último ( $v$ ) "los participantes en este estudio son supervivientes. Estas mujeres hicieron algo que relativamente pocas mujeres han hecho. Superaron la adversidad, atravesaron obstáculos y rompieron barreras para alcanzar posiciones de liderazgo." (Diehl, 2014, pp. 60-61)
} 
De hecho, Mateos, Gimeno \& Escot (2010) expusieron la problemática de la discriminación por preferencias asociada a la existencia de clichés sociales por parte de aquellos que están encargados del nombramiento de altos cargos, arguyendo que esto supone un claro costo económico para las compañías pues al incluir estos criterios de contratación, la empresa estaría renunciando a escoger los mejores preparados para un puesto, independientemente de su sexo.

En este punto los autores sugirieron que esta situación puede verse reducida, si se incentiva a las organizaciones al diseño de mejores prácticas de buen gobierno que en todo caso deben ser lideradas por los organismos reguladores no solo a nivel internacional sino también local (p. 136). Ahora bien, a pesar de que la promoción de la igualdad de género en el trabajo es un asunto de derechos humanos, se trata en el fondo de establecer una relación positiva entre la diversidad, a través de la influencia femenina en la alta dirección y, la creación de valor en las compañías;

No debe olvidarse que según lo planteó Sánchez-Apellániz (1997), se ha potencializado la marginalidad del trabajo de la mujer en el tiempo, situación que se debe por una parte a los procedimientos empleados para elaborar las estadisticas que reflejan numerosos sesgos en cuanto a la información brindada, lo cual provoca un subestimación de la actividad económica femenina y el creciente potencial y aporte a las economias. De otra parte, la poca participación de las mujeres en las teorias organizacionales, aquellas que buscan aparte de otros aspectos fundamentales para la administración de las organizaciones, emitir un concepto o perfil sobre lo que significa ser un directivo o lider eficiente, en este sentido, se obvia la existencia de la mujer llegando incluso a entenderse que mujer y dirección son dos aspectos contrapuestos. 
De hecho, los resultados de una investigación de Molero et al (2009, p. 56) demostró que la exigencia es mayor para una directiva mujer que para un directivo hombre. Una directiva mujer debe incorporar las características positivas en la interacción con los demás (propias del estereotipo de género) y además ser más inteligente que el hombre directivo. En efecto, esta mayor exigencia hacia las mujeres, probablemente basada en la percepción y no de lo que sucede en la realidad, puede dificultar el acceso de las mujeres a cargos de responsabilidad.

Las desigualdades en el trabajo y la discriminación de la mujer en el mercado de trabajo como problema social han sido ampliamente analizadas desde numerosas perspectivas, a través del tratamiento de diversas teorías que buscan explicar su origen. Ribas las denominó teorías explicativas de las desigualdades de género y las agrupó teniendo en cuenta la perspectiva histórica y según las zonas geográficas, puesto que muchas cirscunstancias han influido en la participación de las mujeres en el mercado de trabajo.

Es por ello que por una parte, se encuentran las teorías económicas de tipo neoclásico que clasificó en cuatro las cuales son: la teoria neoclásica del mercado de trabajo, la teoria del capital humano, la nueva economia de la familia y las teorias del mercado dual y de la segmentación del mercado de trabajo.

Según Ribas (2005, p. 25) la corriente neoclásica se ha visto incapaz de adecuar el núcleo central del análisis del mercado de trabajo al estudio del trabajo de la mujer abordando únicamente el lado de la oferta femenina, ignorando la demanda excepto en el caso de las teorías de la discriminación.

Por otro lado, a través de enfoques multidisciplinares Ribas buscó ofrecer diversas perspectivas puesto que la complejidad de las relaciones entre las personas en diferentes ambitos merecia planteamientos mas 
amplios que afrontaran la diversidad de las cuestiones que se tratan en la discriminación laboral por lo que las clasificó como paradigmas alternativos así: el debate sobre el trabajo reproductivo o doméstico, la concepción marxista del mercado de trabajo, teorías feministas y sociosexuales, teorias institucionalistas y la construcción social de las diferencias de género. Por lo tanto, más alla es necesario abordar la complejidad del fenómeno de la discriminación de género desde diversos campos profesionales como por ejemplo desde la sociología, la antropología, la historia, la psicología social, entre otros que ayuden a encontrar respuestas y combatir de un modo más preciso las fuentes que originan las desigualdades planteadas.

En resumen, según lo planteado por Cuadrado, Navas, \& Molero (2006) que mostró un mapa general sobre los posibles factores que inciden a reforzar el techo de cristal teniendo en cuenta las investigaciones realizadas durante las últimas decadas y que pone de manifiesto que la mayoria de las explicaciones propuestas tienen su raiz en los estereotipos de género, se encuentra resumido en la Tabla 10 a continuación.

\begin{tabular}{|l|l|}
\hline \multicolumn{2}{|c|}{$\begin{array}{l}\text { Causas principales del glass ceiling para las } \\
\text { mujeres }\end{array}$} \\
\hline 1. & $\begin{array}{l}\text { Presentan características y atributos propios que no se ajustan a los } \\
\text { rasgos y motivaciones necesarios para acceder y lograr éxito en } \\
\text { posiciones de responsabilidad }\end{array}$ \\
\hline 2. & $\begin{array}{l}\text { Las mujeres tienen menores oportunidades de desarrollo en el trabajo } \\
\text { que los hombres debido a las condiciones y los puestos de trabajo que } \\
\text { han ocupado, y la entrada tardía al mercado laboral. }\end{array}$ \\
\hline 3. & $\begin{array}{l}\text { La influencia que ejerce las responsabilidades familiares en su carrera } \\
\text { y desarrollo profesional: la doble jornada }\end{array}$ \\
\hline
\end{tabular}




\begin{tabular}{|l|l|}
\hline 4. & $\begin{array}{l}\text { Influencia de los grupos dominantes para mantener el statu quo, es } \\
\text { decir, el buen directivo es el que tiene cualidades masculinas. }\end{array}$ \\
\hline 5. & $\begin{array}{l}\text { La discriminación por razón de sexo a través de sesgos que perjudican } \\
\text { el ascenso laboral. }\end{array}$ \\
\hline 6. & $\begin{array}{l}\text { Las mujeres influyen en la organización con menor autoridad ante sus } \\
\text { subordinados, pues son menos competentes y menos creíbles que los } \\
\text { hombres. }\end{array}$ \\
\hline 7. & $\begin{array}{l}\text { Se atribuyen causas externas a la evaluación de la labor de las mujeres } \\
\text { como por ejemplo, la suerte y no las capacidades y el trabajo propio. }\end{array}$ \\
\hline
\end{tabular}

Tabla 10. Causas del glass ceiling. Fuente. Cuadrado, Navas, \& Molero (2006, pp. 8-9).

Elaboración propia

Es importante visibilizar un estudio reciente de la consultora Grant Thornton España (2017), en el cual expuso las principales barreras para el acceso de las mujeres a la dirección señaladas por directivos y directivas, como se ve en el Gráfico 26 a continuación, el aspecto más importante señalado por los mismos candidatos, e incluso segregado por sexo, es el cuidado de los hijos, aunque en una parecida proporción se encuentra la cultura empresarial predominantemente masculina. Estas barreras ya se han repetido a lo largo del texto pues son las que realmente han estado impidiendo un ascenso más rápido y efectivo de la mujer en puestos de alta responsabilidad. 


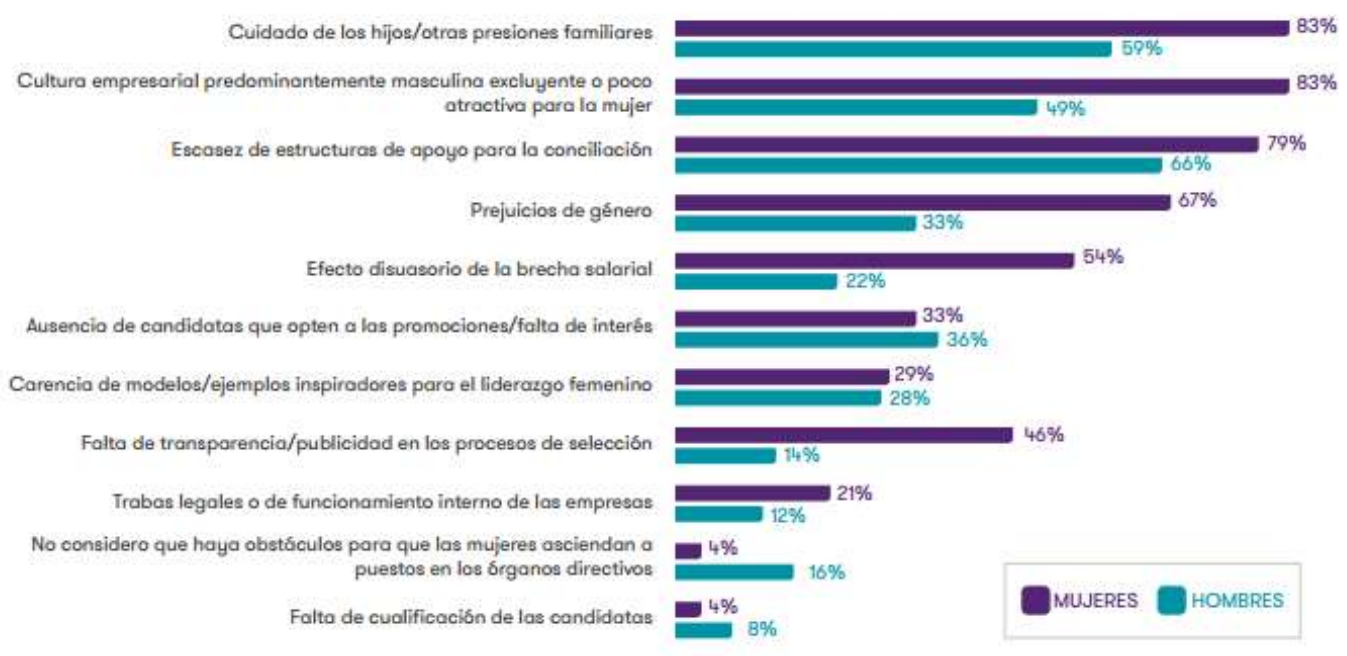

Gráfico 26. Barreras para el acceso de la mujer a cargos de dirección por sexo. Fuente:

Grant Thornton España (2017, p.13)

En este sentido, es importante que se tomen medidas al respecto, pues aún "hay resistencias en facilitar y fomentar la incorporación y el acceso de las mujeres en los puestos de dirección de las empresas y en revalorizar los puestos de trabajo feminizados. Esto evidencia el miedo a revisar las categorías profesionales para objetivar y hacer transparente el proceso de acceso y promoción en la empresa" (Bodelón et al., 2014, p. 52).

Es interesante, para finalizar, mostrar una investigación reciente de Chizema, Kamuriwo \& Shinozawa (2015) sobre los aceleradores y las barreras que inciden en participación de las mujeres en las juntas directivas en cuarenta y cinco países basandose en la evaluación de tres hipótesis: 1. El nivel de representación de las mujeres en la política tendrá un impacto positivo en la prevalencia de las mujeres en los consejos de directores de empresas; 2. El desarrollo institucional del entorno económico de un país tiene un impacto positivo en la prevalencia de mujeres en los consejos de 
administración de empresas; y 3 . El grado de religiosidad en una sociedad se relaciona negativamente con la proporción de directoras en los consejos.

En la primera hipótesis, se demostró que la correlación es positiva (2015, p. 1059) por lo tanto, se pudo comprobar que en la medida que aumente la participación en otros ámbitos decisorios se produce un efecto positivo para replicar ese tipo de prácticas en los demás ambitos sociales.

Los autores basan estos resultados en la teoría del papel social, la presencia de directoras en otras instituciones sociales clave ayuda a reducir los estereotipos tradicionales de género, llevando a la aceptación de las mujeres más allá. En la segunda hipótesis, los investigadores no encontraron resultados significativos para demostrarlo, por lo que no existe una relación positiva o negativa al respecto, es decir no existe una influencia directa, por lo que no es válida.

En la tercera hipotesis se concluyó que "el aumento de la religiosidad en un país dado conduciría a una disminución del número de directoras" por lo que existe una relación directa con las creencias religiosas de cada país en particular de manera negativa con la promoción de la participación de las mujeres en los puestos de toma de decisiones. Los autores concluyeron que "la religión juega un papel clave en la dinámica de la falta de representación de las mujeres en las juntas" (2015, p. 1060)

En conclusión, la investigación demostró que "en las construcciones sociales de los estereotipos y de los roles de género pueden ser mejor comprendidos mediante el examen de las instituciones sociales que potencialmente sostienen o minimizan esta percepción" (Chizema, Kamuriwo \& Shinozawa, 2015, p. 1061)

Por último, pero no menos importante, el apoyo familiar desde la corresponsabilidad es un aspecto transcendental en el momento de la 
promoción profesional de las mujeres, es decir, las parejas juegan un papel decisivo cuando se coloque en juego el ascenso, pues en ocasiones, se hace necesario por ejemplo, una mayor formación o experiencia profesional en el exterior; lo cual es diferente cuando a quienes hay que apoyar sea a los hombres.

En general, las mujeres estarían dispuestas a apoyar a sus parejas desde las responsabilidades familiares porque eso repercutirá positivamente en su economia familiar. No sucede lo mismo con los hombres pues tal como lo describió Gonzales (2002, p. 177) "en el caso de que una mujer desee salir del país para continuar estudiando, deberá en primer lugar convencer a su familia al respecto y no es usual que su pareja se adapte a una función de soporte. Más aún, la posibilidad de rechazo si el viaje pudiera interferir con el trabajo o carrera del esposo o compañero es muy alta".

\section{Conciliación de la vida familiar, personal y laboral}

El género femenino, es el que durante siglos se ha dedicado a las tareas domésticas, reproductora y de cuidado familiar, aunque se ha evidenciado en las últimas décadas cambios visibles en la distribución de estas cargas, resulta insuficiente, pues nada más en España los hombres dedican menos de 20 horas semanales mientras que las mujeres emplean entre 40 y 60 (Martínez, 2009, p. 18). De hecho, si las madres y las mujeres no han logrado la total equiparación en el mercado laboral, se debe tambien a esa desigualdad en los aspectos familiares.

Los cambios en los hábitos y costumbres entre mujeres y hombres, en relación a estas tareas, son valiosos, sin embargo, es importante conocer que el sistema laboral liderado por los empresarios castiga dichas acciones, ya 
sabemos que estos últimos lo hacen tomando en cuenta sus propios intereses, por lo tanto, la persona que lo realiza se convierte en un sujeto vulnerable, en definitiva, se trata de un problema cultural que corresponde a diversos sujetos sociales.

Es por ello, que para la compatibilización de estos asuntos la empresa tiene un rol significativo, de la implementación de medidas y programas, no hay que olvidar que este aspecto es desconocido en la mayoría de las organizaciones y que en general se encuentra este tipo de prácticas en empresas de mayor tamaño o multinacionales, en donde la legislación de origen ya ha dado un paso adelante. Para ello, no hay que olvidar, como lo sostiene Martínez (2009) el hecho de ser mujer o hombre, cuando se habla de la conciliación pues esto supone un sesgo en su comprensión y análisis, ya que anula un eje fundamental de interpretación de la realidad de las personas.

En este contexto, la asunción de todas estas tareas del hogar mayoritariamente por la mujer implica un serio obstáculo para su participación en el mercado de trabajo en igualdad de condiciones. De hecho, cuando se inserta laboralmente se somete a jornadas de trabajo laboral demoledoras pues debe compatibilizar su vida profesional y familiar, pues debe añadir a su jornada laboral, el trabajo doméstico que le impide disponer de tiempo libre, en cuanto que el cúmulo de tareas que está obligada a desempeñar para responder a las reglas de la organización social vigente absorbe su tiempo disponible.

La mayor concienciación por parte de ambos sexos sobre aspectos como la corresponsabilidad, constituye uno de los primeros pasos en esta materia, así, se debe asumir equitativamente las responsabilidades, los derechos, los deberes y las oportunidades asociados al ámbito de las tareas familiares. 
Para la conciliación de la vida familiar, laboral y personal es indispensable el desarrollo de una serie de aspectos que según Fundación MUJERES (2010, p. 4) comprende por un lado: el desarrollo de recursos y estructuras sociales que permitan el cuidado y la atención de las personas dependientes; por otro lado, la reorganización de los tiempos y espacios de trabajo incluyendo el establecimiento de medidas en las organizaciones laborales que posibiliten a las personas trabajadoras desarrollarse en las diferentes facetas de su vida. Por último, también requiere la modificación de los roles tradicionales de mujeres y hombres respecto a su implicación en la familia, hogar y el trabajo.

\subsubsection{La relación positiva entre la mujer y la dirección}

La principal justificación para contar con equipos de dirección equilibrados y diversos en una organización de cualquier tipo la sustentan Pin, García, \& Gallifa, su planteamiento tiene que ver con la aportación de puntos de vista y mecanismos de solución diferentes para afrontar los problemas. En este sentido, la importancia radica en que a partir de la diversidad se "descubren problemas y ven oportunidades que pasan inadvertidas" (2007, p. 9), por lo que se convierte en últimas en una mayor oportunidad para mejorar la competitividad organizacional.

Asimismo, Carrasco \& Laffarga defendieron que "la igualdad entre sexos aprovechará al máximo los recursos humanos disponibles en las empresas, así como las posibles ventajas que puede tener la existencia de participación femenina en los equipos de dirección, y además comprobar 
como la unión de las diferencias entre hombres y mujeres puede generar más poder que el que se pueda alcanzar por separado" (2007, p. 7).

No obstante, como se ha insistido desde la literatura todavía es posible encontrar detractores de la influencia positiva que tiene la presencia equilibrada de mujeres y hombres en cargos directivos y de responsabilidad, por lo que, para contrarrestar las diferentes teorías existentes sobre la capacidad de las mujeres para ejercer dichos puestos, analizaremos estudios que han demostrado la capacidad potencial de las mujeres en el desarrollo económico y su impacto positivo.

De hecho, un estudio de Del Brio \& Del Brio concluyó que una mayor presencia femenina en los cargos de toma de decisiones, ha traido como consecuencia el aumento de ventajas competitivas en cuanto a la reputación, la dirección estratégica y una visión mucho más global (2009, p. 104). Además, observó ciertas particularidades, que aquellas empresas más innovadoras y creativas (proyección al futuro) parecen estar más receptivas a la hora de nombrar mujeres en sus consejos.

Una investigación de Catalyst del porcentaje de mujeres en empresas de varios países en 2014, mostró que hay una correlación entre las expectativas relacionadas con un comportamiento responsable y los factores de gobernanza, así "tener un porcentaje más alto de directores de junta de mujeres se asoció positivamente con las calificaciones de las empresas en cuatro de seis dimensiones: comunidad, clientes, entorno y cadena de suministro" (2015-b, p. 1)

Asimismo, otro estudio, de Burgess \& Tharenou (2002, p. 45) evidenció que las mujeres aportan características diferenciales a los consejos de administración, pues dicha presencia aumenta el debate por diferencias de opinión, lo que se traduce en la toma de decisiones más beneficiosas para 
las empresas lo que además produce la atracción de otras mujeres por considerarse ejemplos a seguir dentro de la organización.

Carnicer et al. (2007, p. 38) defendieron que "la correlación entre el porcentaje de mujeres en los consejos de administración y los resultados de la empresa no es ninguna prueba de causalidad." En este sentido, se podría argumentar que las organizaciones con "mayor representación femenina en sus cuadros superiores tengan más éxito porque en ellas se promociona más a las personas en función de los méritos y capacidades".

No es de extrañar, que existan evidencias de esta relación positiva incluso con los resultados financieros, un estudio de Catalyst (2011) reveló que aquellas empresas con representación de mujeres en cargos directivos ofrecían a sus accionistas una rentabilidad total mayor que las empresas con menor representación de mujeres en dichos puestos, además que ellas estaban más propensas a desarrollar programas de responsabilidad social empresarial.

El estudio arrojó como resultado final al evaluar el desempeño corporativo y la representación de las mujeres en los consejos de empresas seleccionadas durante el periodo comprendido entre 2004 y 2008 que la diversidad de género se correlaciona con un mejor desempeño corporativo. "Las empresas con tres o más consejeros mujeres en cuatro de cinco años, en promedio, superaron a las empresas con cero directores mujeres en la junta directiva, las primeras tuvieron en promedio un $84 \%$ de retorno de las ventas, $60 \%$ de retorno sobre el capital invertido y $46 \%$ de retorno sobre el capital”135 (Catalyst, 2011, p.1)

135 Traducción libre del inglés al español por parte del autor (Cfr. Catalyst, 2011) 
En la misma línea, un estudio de la prestigiosa consultora McKinsey \& Company corroboró la relación existente entre los resultados económicos y el número de mujeres en cargos de toma de decisiones, solo que esta vez fueron empresas europeas que cotizaban en bolsa. La investigación determinó los beneficios de una mayor presencia femenina pues mientras más representación haya en los equipos de dirección, el rendimiento financiero será mayor (Desvaux, Devillard-Hoellinger \& Baum-Garten, 2007, p. 14) y, aunque reconocen que no existe un vínculo causal directo, es de resaltar que, en comparación con las empresas que no tenían dicha diversidad durante ese periodo el incremento en el precio de las acciones fue mayor, lo que proporciona un aliciente para destacar tal como se titula el informe que las mujeres importan y que la diversidad de género, puede ser un conductor del rendimiento corporativo.

Se demostró además la importancia de involucrar a las mujeres directivas en puestos de responsabilidad, pues existe una fuerte correlación entre el aumento de liderazgo de las mujeres y un mejor rendimiento del negocio. Las tres principales conclusiones del estudio fueron (i) las compañías con más mujeres en puestos de alta dirección, en promedio, superan a las que tienen menos; (ii) las compañías con más presencia femenina en los consejos de administración, son más propensas a tener más mujeres en cargos corporativos cinco años después, y (iii) las compañías con más mujeres en posiciones de liderazgo promueven mayormente la filantropía corporativa y probablemente también tienen iniciativas de Responsabilidad Social de mayor calidad.

Todo lo anterior no es porque sí. Justamente Gómez (2012, pp. 5354), analizando el estilo de liderazgo de las mujeres, basandose en estudios especializados y diversos informes de grandes consultoras, destacó que dichos resultados se deben a que las mujeres que ocupan altos cargos son 
más eficientes y prudentes, gestionan mejor el riesgo, hacen seguimientos más individualizados de los empleados, establecen cauces de comunicación más directos y eficientes y adoptan decisiones más democráticas.

En la investigación de Cabanas, Morales \& Molinero (2014, p. 9) tomando como base el Global Gender Gap se mostró que "existe una fuerte correlación entre los países con menores diferencias de género y los más competitivos económicamente. También indica que las empresas con mayor porcentaje de mujeres, particularmente en su consejo, tienen un $34 \%$ de mejora en sus retornos financieros."

Y no resulta para nada extraño que, por ejemplo, la revista Forbes ${ }^{136}$ publique cada año las 100 mujeres más poderosas del mundo, las cuales son elegidas porque representan características como el liderazgo y el poder, así han podido dirigir una nación o desempeñan un rol importante en el ámbito político, empresarial o económico lo cual se ve reflejado en la influencia que generan sobre un público amplio y el control sobre negocios que representan miles de millones de dólares. En este sentido, la mujer más influyente es la canciller alemana Angela Merkel la cual desempeña ese cargo desde 2005. En España, la representación solo corre por cuenta Ana Patricia Botín quien se desempeña en la actualidad como presidenta del Banco Santander y ocupa una privilegiada posición número 10 de las 100 mujeres más poderosas del mundo en 2016 de la revista es cuestión (Forbes, 2017-a)

De hecho, si se mira la Tabla a continuación con quienes lideran ese listado, se puede observar que estas mujeres se encuentran en los más altos

\footnotetext{
136 Para ampliar esta información véase: https://www.forbes.com/billionaires/list/ https://www.forbes.com.mx/las-100-mujeres-mas-poderosas-del-mundo-2016/
} 
cargos de los ámbitos público (políticos), privado y de la economía social, lo cual refleja una fuerte inherencia de ellas en sus países y a nivel global.

\begin{tabular}{|c|c|c|}
\hline Rank & Nombre & Cargo / País de origen \\
\hline 1 & Angela Merkel & Canciller/Alemania \\
\hline 2 & Hillary Clinton & Candidata presidencial/EU \\
\hline 3 & Janet Yellen & Presidenta/Reserva Federal/EU \\
\hline 4 & Melinda Gates & Copresidenta/Bill \& Melinda Gates Foundation/EU \\
\hline 5 & Mary Barra & CEO/General Motors/EU \\
\hline 6 & Christine Lagarde & Directora gerente/FMI/Francia \\
\hline 7 & Sheryl Sandberg & COO/Facebook/EU \\
\hline 8 & Susan Wojcicki & CEO/YouTube/EU \\
\hline 9 & Meg Whitman & CEO/HP/EU \\
\hline 10 & Ana Patricia Botín & Presidenta/Banco Santander/España \\
\hline
\end{tabular}

Tabla 11. Las 10 mujeres más poderosas del mundo según Forbes (2016). Elaboración

propia.

Y si se contrasta esta información, por ejemplo, con otro listado, el de los más ricos del mundo en 2017 según la publicación en la revista Forbes ${ }^{137}$, según este medio la representatividad femenina, aunque está en su máximo histórico, del listado total representan aproximadamente solo un $12 \%$, es decir, 227 mujeres de un total de 2,043 multimillonarios. Sin restarle méritos $^{138}$, en la publicación se afirmó que la mayoría de ellas heredaron su

137 https://www.forbes.com.mx/las-mujeres-en-la-lista-forbes-de-los-mas-ricos-del-mundoen-2017/

${ }^{138} \mathrm{Al}$ respecto, se resaltó las habilidades gerenciales y profesionales de Gina Rinehart, pues su patrimonio neto "pasó de 6.200 millones a 15,000 millones, convirtiéndola en la persona más rica de su país y en la multimillonaria número 69 del mundo, un gran salto desde el sitio 127 que se adjudicó en 2016. A diferencia de todas las otras mujeres ubicadas antes que 
fortuna, Liliane Bettencourt, de origen francés y una de las principales accionistas de la multinacional de cosméticos L'Oréal, es la mujer más rica del mundo con una fortuna estimada en 39,500 millones de dólares y quien ocupa el puesto número 14 del listado en cuestión (Wang, 2017).

En representación de España, muy lejos se encuentra Sandra Ortega Mera, del grupo Inditex, que ocupa el puesto 209 del listado general, pero que es la segunda persona más rica del país después de su padre Amancio Ortega.

\begin{tabular}{|r|r|l|l|}
\hline Rank & $\begin{array}{c}\text { Posición } \\
\text { Forbes }\end{array}$ & \multicolumn{1}{|c|}{ Nombre } & \multicolumn{1}{|c|}{ Compañía } \\
\hline 1 & 14 & Liliane Bettencourt & L'Oréal/Francia \\
\hline 2 & 17 & Alice Walton & Wal-Mart/EU \\
\hline 3 & 26 & Jacqueline Mars & Mars Inc/Reino Unido \\
\hline 4 & 29 & Maria Franca Fissolo & Ferrero Group/ltalia \\
\hline 5 & 38 & Sussanne Klatten & BMW/Alemania \\
\hline 6 & 40 & Laurene Powell Jobs & Emerson Collective/EU \\
\hline 7 & 69 & Gina Riheart & Hancock Prospecting/Australia \\
\hline 8 & 75 & Abigail Johnson & Fidelity Investments/EU \\
\hline 9 & 84 & Iris Balbina Fontbona & Antofagasta plc/Chile \\
\hline 10 & 95 & Charlene de Carvalho & Heineken/Paises bajos \\
\hline
\end{tabular}

Tabla 12. Las 10 mujeres más ricas del mundo según Forbes (2017). Elaboración propia.

ella, Rinehart puede jactarse de que sí construyó activamente su fortuna. Rinehart tomó la compañía en bancarrota de su difunto padre y la convirtió en algo mucho más grande. Su proyecto de Roy Hill, una mina de hierro de clase mundial en Australia Occidental, envió 30 millones de toneladas de mineral de hierro en sus primeros 14 meses de producción". (Wang, 2017) 
A manera de conclusión preliminar, es preciso afirmar que ya no se puede evadir el hecho de que la presencia femenina en la dirección estratégica resulta de vital importancia para la sostenibilidad ${ }^{139}$ de las organizaciones, y es que en definitiva tal y como lo señaló la ONU (2013, p. 33-35) "las decisiones tomadas en empresas privadas, así como las estrategias pueden tener impactos en las oportunidades de empleo y ascenso laboral de las mujeres.

\subsubsection{Informe de la OIT y la perspectiva internacional}

Con la publicación a comienzos de 2015 del informe mundial La mujer en la gestión empresarial, cobrando impulso, el principal objetivo de la OIT radicó en exponer los distintos beneficios que pueden obtener las empresas que no sólo reconocen, sino que a la vez promueven y aprovechan el talento y las competencias de las mujeres específicamente en el ámbito laboral, teniendo en cuenta que aparte de considerarse justa la decisión en definitiva es sabia.

A pesar de la superación de diferentes obstáculos por parte de las mujeres durante las últimas décadas, la OIT destacó que para desempeñar el más alto cargo directivo o ser parte de los consejos de administración, hay un considerable camino por recorrer además de ser una situación compleja. Sin embargo, indicó que "las mujeres que son nombradas en los cargos más altos atraen la atención de los medios de comunicación y aparecen así nuevos arquetipos".

\footnotetext{
139 De hecho, un estudio de Arredondo, Velásquez \& de la Garza (2013) concluyó que "la mujer, por sus características de género, es quien impulsa políticas internas de RSE vinculadas a la diversidad ya la flexibilidad laboral. En ella reside una importante fuerza motora para detonar estas prácticas de RSE interna"
} 
El informe además enumeró como uno de los grandes retos el aumento de la proporción de mujeres, en las grandes y medianas empresas principalmente nacionales puesto que multinacionales ya lo tienen dentro de sus requerimientos. En este sentido, subrayó que se necesita de un mayor acompañamiento por parte de diversas entidades, es decir, una mayor participación e integración que vaya en la búsqueda de herramientas reales para poder promover la igualdad efectiva y como consecuencia una mayor competitividad de estas organizaciones.

Justamente, Chinchilla et al. (2006, p. 11) en la misma línea afirmaron que como resultado de un estudio realizado, las mujeres accedían con más facilidad a la dirección general en las empresas pequeñas que en las grandes.

Otro de los retos radica en una mayor investigación en este ámbito puesto que dentro de las barreras encontradas en la elaboración del informe fue que en algunos países "prácticamente no había datos sobre la mujer en la gestión empresarial del sector privado", de lo que aquí se trata es de confirmar la colaboración conjunta entre empresa, universidad y administración pública, primero para la obtención de los datos que sean uniformes, veraces y en constante actualización; para de esta manera a partir de los resultados logrados trabajar simultáneamente en mecanismos para el aumento de la participación de la mujer en las grandes decisiones económicas.

Pero hay más, pues la OIT estableció una relación directa existente entre el tamaño de las empresas y la obtención de un alto cargo, pues determinó que cuanto más grande sean, "más complicado será para una mujer ocupar el cargo de ejecutiva máxima".

De hecho, si se observa a nivel internacional, actualmente, de las mujeres que ocupan el cargo de CEO de las mayores empresas que hacen 
parte de la Lista Fortune en Estados Unidos ${ }^{140}$, corresponden a un $5,2 \%$ de la Lista Fortune 500 y el 5,4\% de la Lista Fortune 1000 (Catalyst, 2014)

Y es que las cifras siguen avalando esta teoría pues el informe logró demostrar que en promedio menos del $5 \%$ de los directivos de las principales empresas del mundo son mujeres, esta información se puede corroborar en la tabla número 4 que contiene la proporción ordenada de mayor a menor de las directoras generales en las empresas cotizadas de catorce bolsas de valores a nivel mundial.

\begin{tabular}{|c|c|}
\hline Bolsa & Porcentaje \\
\hline China & 5,6 \\
\hline NZSX 100 Nueva Zelanda & 5,0 \\
\hline US Fortune 500 & 4,8 \\
\hline SGX Singapur & 4,6 \\
\hline OCDE & $<5,0$ \\
\hline
\end{tabular}

140 Según la pirámide actualizada de la representación de las mujeres en los cargos de las empresas S\&P 500, de abajo para arriba, las mujeres son el $45 \%$ de la fuerza laboral, representan el $36,8 \%$ de mandos medios, el $25,1 \%$ de mandos ejecutivos, el $19,2 \%$ de miembros en consejos de administración y son un 4\% de CEOs (Catalyst, 2016-b). Esto corresponde a una visión general a escala de la proporción de mujeres en los distintos cargos de la jerarquía organizacional para mostrar evidencia del fenómeno del techo de cristal en Estados Unidos.

Hay que tener en cuenta que el S\&P 500, mantenido por los índices S\&P Dow Jones, comprende las acciones comunes emitidas por 500 compañías de grandes capitalizaciones y cotizadas en bolsas de valores estadounidenses, y cubre aproximadamente el 80 por ciento del mercado de capitales estadounidense por capitalización. 


\begin{tabular}{|c|c|}
\hline BSE 100 India y FTSE 100 Reino Unido & 4,0 \\
\hline JSE Sudáfrica & 3,6 \\
\hline México Expansión 100 y ASX 200 Australia & 3,0 \\
\hline Unión Europea & 2,8 \\
\hline Latin 500 & 1,8 \\
\hline CAC 40 Francia y DAX 30 Alemania & 0,0 \\
\hline
\end{tabular}

Tabla 13. \% de directoras generales en las bolsas de valores a nivel mundial. Fuente: OIT 2015. Elaboración propia

Es interesante observar que, en dicha tabla, las bolsas asiáticas sean quienes lideren el listado, no es de extrañar que a ello se suma el notable crecimiento de dichas economías en los últimos años, contrariamente otras economías con una percepción histórica más social y de fuerte respeto por derechos fundamentales como, por ejemplo, la francesa no disponga de mujeres en el mayor cargo de toma de decisiones.

Es bien sabido, tal como se ha visto, que en la doctrina hay infinidad de argumentos que buscan favorecer una mayor participación de la mujer en la gestión empresarial. Sólo por rescatar alguno, la incidencia en los resultados operacionales de las compañías, pero, aunque se han hecho importantes investigaciones sobre este efecto, relacionado con el equilibrio de género que debe existir en los principales cargos directivos de la empresa, el informe aclaró que "sigue siendo un problema establecer relaciones de causa a efecto". 
El informe además destacó el esfuerzo realizado por varios países en fomentar la participación de las mujeres en los más altos cargos de tomas de decisiones, principalmente en las juntas directivas; precisamente destacan países europeos como Suecia, Noruega, Reino Unido y Finlandia cuya presencia obtenida fue en promedio mayor a un $20 \%$ según un informe publicado en 2014 por Catalyst.

Ahora bien, a estas alturas conviene explorar de igual manera si las mujeres que acceden a estos cargos puedan dirigir la junta directiva, es decir, la presidan, en este sentido, el informe concluyó al constatar varias fuentes que existe un número muy reducido, sin embargo, según su propia encuesta de empresas solo el $13 \%$ de las juntas directivas eran liderados por una mujer.

Otro aspecto importante citado por el informe y que requiere un análisis más profundo consiste en la concentración de las mujeres en determinados tipos de actividades de gestión empresarial lo que es bien llamado segregación por género en las ocupaciones empresariales. En realidad, según la OIT la tendencia muestra que las funciones gerenciales desempeñadas por las mujeres se encuentran principalmente en áreas como recursos humanos, relaciones públicas, comunicaciones, finanzas y administración por lo que concluye que debido a esto "solo puedan ascender hasta un cierto punto en la jerarquía organizacional" por lo que aquí juega un papel crucial la experiencia.

Sin embargo, a pesar de todo lo anterior la OIT afirmó que el número de mujeres en cargos directivos está aumentando gradualmente, aunque con ciertas disparidades y diferencias entre regiones. El informe indicó que es necesario la presencia de un número mayor de mujeres en cargos anteriores como por ejemplo directivos medios para que se conviertan en posibles 
candidatas para los cargos de presidente o director general de una compañía y de esta manera derrumbar los techos de cristal.

Eso sí a nivel educativo y sobre todo en títulos de educación superior, según el informe las mujeres sobrepasan significativamente a los hombres principalmente en los estudios de pregrado, lo que no sucede de igual manera nuevamente con los más altos niveles educativos tales como doctorado y posdoctorado, por ejemplo, en la mayoría de los países los hombres cuentan con casi "el $55 \%$ del total de diplomas de doctorado y el $71 \%$ son investigadores".

A modo de conclusión, es un hecho que uno de los factores que ha ayudado a incrementar la presencia femenina durante los últimos años en el gobierno corporativo, según Del Brío \& Del Brío "no parece ser un gesto voluntario... ha surgido como una adaptación a las nuevas recomendaciones que llegan desde los organismos supervisores de los mercados" (2009, p. 115), precisamente una de ellas, como se ha insistido el aumento de las llamadas cuotas y acciones positivas en varios países (ONU Mujeres, 2013, p. 35)

En este sentido, hay que tener presente que según el informe muchas mujeres no desean un trato especial, o la imposición obligatoria a las empresas de cupos; en definitiva, buscan soluciones flexibles para la conciliación de la vida laboral, familiar y personal, entendiendo que de esta manera puedan acceder a cargos superiores y unas mejores condiciones, todo ello a través de diversas medidas implementadas por las empresas. 


\subsection{Situación de las empresas cotizadas: El caso de España}

A continuación, se analizará la evolución del porcentaje de participación de mujeres en los consejos de administración, órgano jerárquicamente superior en las empresas y se tomó como base las empresas del IBEX 35, teniendo en cuenta la información pública disponible de los últimos años y hasta la fecha de cierre de la investigación 2013-2014, en este sentido, según cifras proporcionadas por el Instituto de la Mujer y la Comisión Nacional del Mercado de Valores.

Tal como se observa en el Gráfico 27, desde 2004 se ha logrado un aumento en la tendencia positiva en cuanto a proporción de mujeres en los consejos de administración de las empresas del IBEX 35, a excepción del año 2011 cuando bajó 3 puntos porcentuales, situación que coincide justamente con la crisis económica pasando de un $2.58 \%$ en 2004 a un máximo de 15,59\% máximo en 2013.

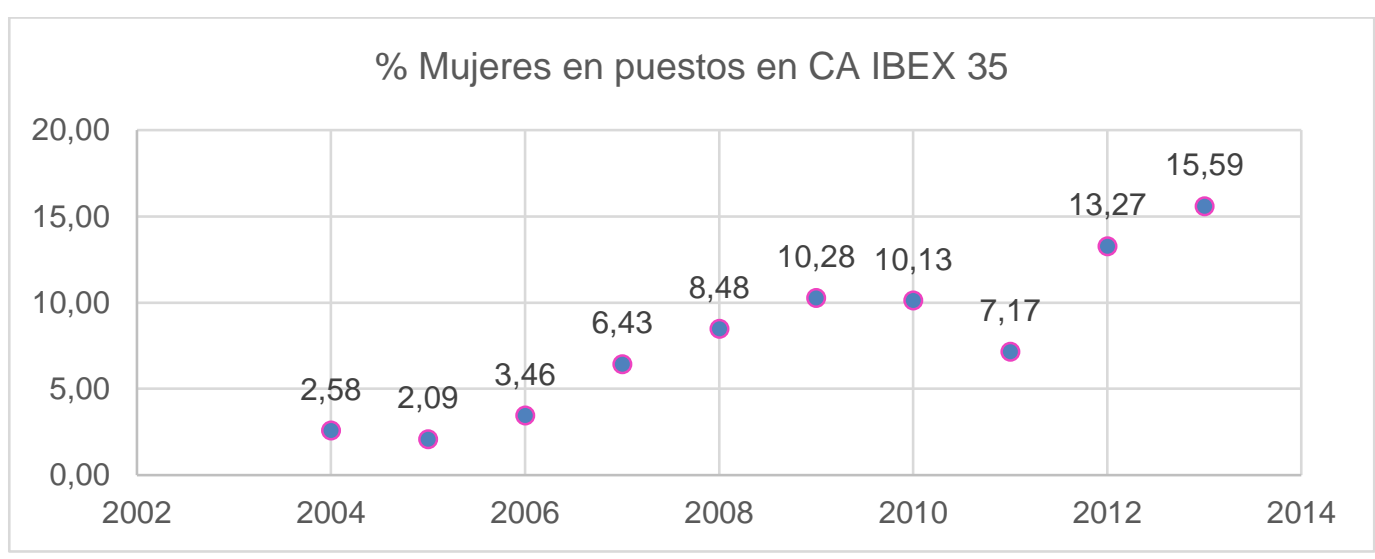

Gráfico 27. \% Mujeres en puestos en CA IBEX 35. Fuente. IM. Elaboración propia 
Sin embargo, la situación es otra cuando se evalúa la posición máxima, la presidencia ${ }^{141}$ de los Consejos. Desde 2004, hasta 2013 no parece haber variado mucho esta proporción, pues no ha logrado superar el $6 \%$. Aunque durante estos años sí que ha tenido fluctuaciones llegando incluso a un $0 \%$ en 2005 y 2010. Lo que, si indica, es que, en efecto, existe reticencias en depositar la confianza en una mujer para el mayor cargo de responsabilidad en una empresa tal y como se observa en el Gráfico 28.

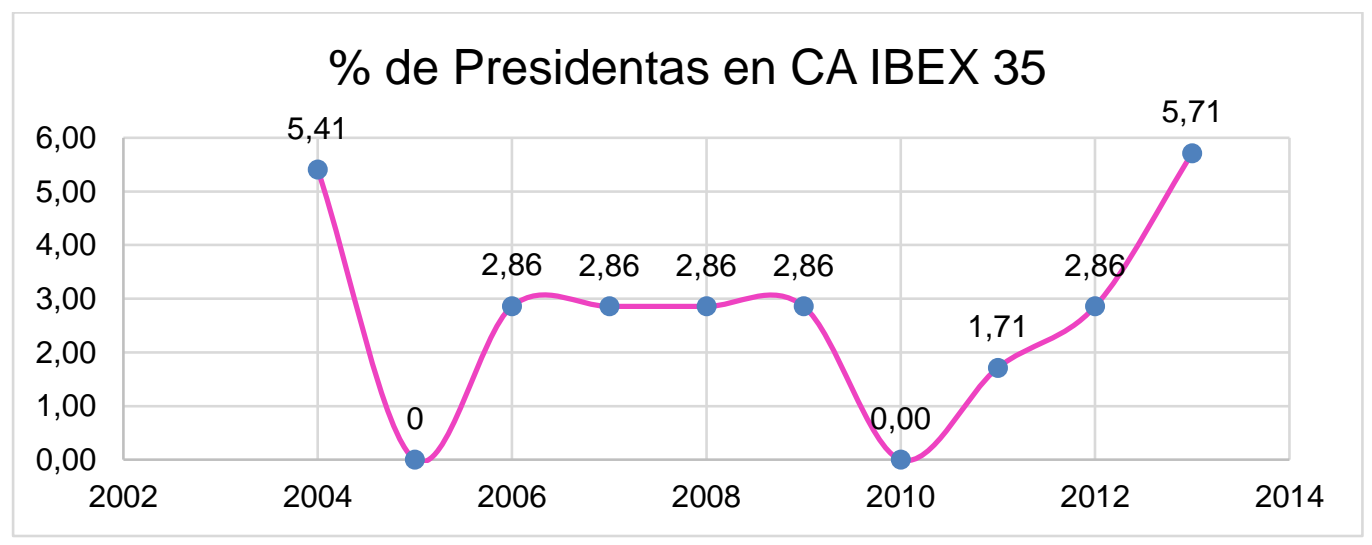

Gráfico 28. \% de presidentas CA IBEX 35. Fuente. IM. Elaboración propia

Ahora bien, ese $15,59 \%$ de participación de mujeres en los consejos de administración de las empresas del IBEX 35 en 2013, equivale aproximadamente a 75 mujeres sobre un total de 485 miembros que lo componen, las cuales se pueden ver representadas en la distribución de cargos en la Tabla 14 a continuación.

\footnotetext{
${ }^{141}$ A estos efectos nos referimos al presidente de la junta directiva de una empresa. En esta función, el presidente actúa como representante de alto nivel de los accionistas y es responsable de defender sus intereses.
} 


\begin{tabular}{|l|r|}
\hline Total & 75 \\
\hline Presidentas & 2 \\
\hline Vicepresidentas & 4 \\
\hline Consejeras & 69 \\
\hline Consejeras secretarias & 0 \\
\hline
\end{tabular}

Tabla 14. \# Mujeres en cargos CA IBEX 35 2013. Fuente. IM

En lo referente a los cargos en la alta dirección de las empresas del IBEX 35, es decir, el máximo cargo de presidente ejecutivo ${ }^{142}$, las cifras no son muy alentadoras. En vez de aumentar, durante los últimos cuatro años se ha mantenido constante, los hombres son quienes han obtenido este cargo y ninguna mujer ha podido escalar hasta ahí (Gráfico 29).

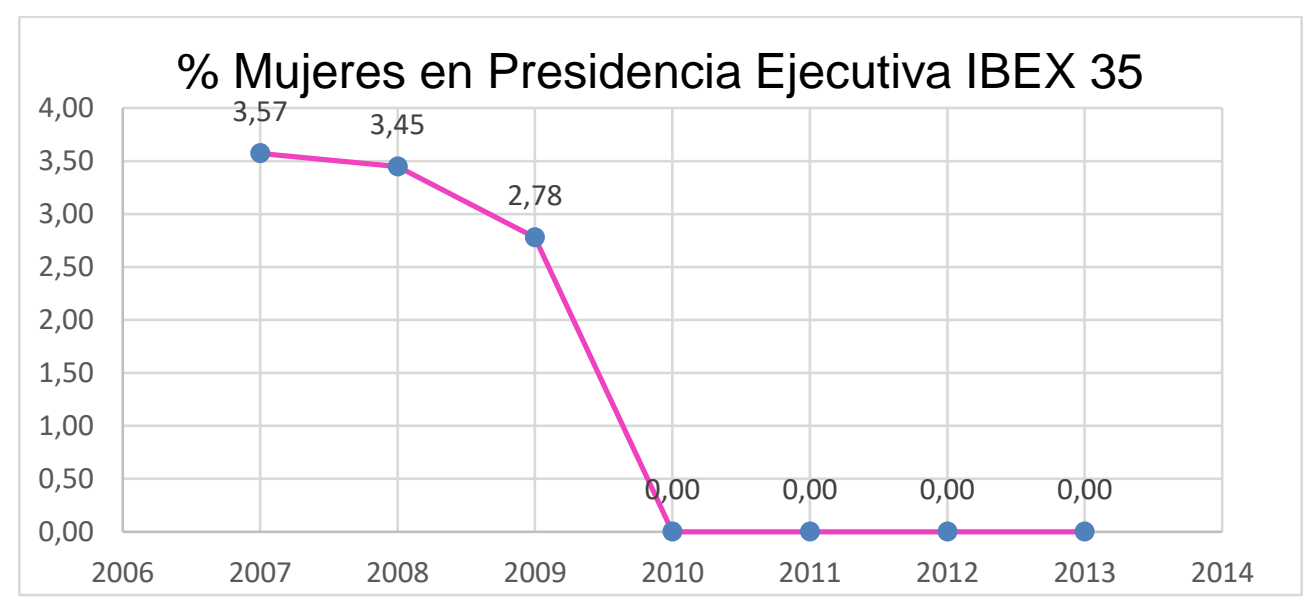

Gráfico 29. \% de Presidentas Ejecutivas IBEX 35. Fuente. IM. Elaboración propia.

\footnotetext{
142 El papel del director ejecutivo (chief executive officer o CEO por sus siglas en inglés) es el de quien toma las decisiones de alto nivel. En la mayoría de los casos se trata de supervisar a los jefes de departamento (y puede desautorizarlos, cuando siente que es necesario), al encargarse personalmente de las principales decisiones estratégicas tales como identificar y dirigirse a diferentes públicos, cambiar las estrategias de marketing o incluso hacerse cargo de otras empresas. Por lo general es visto como la persona de mayor rango dentro de la empresa.
} 


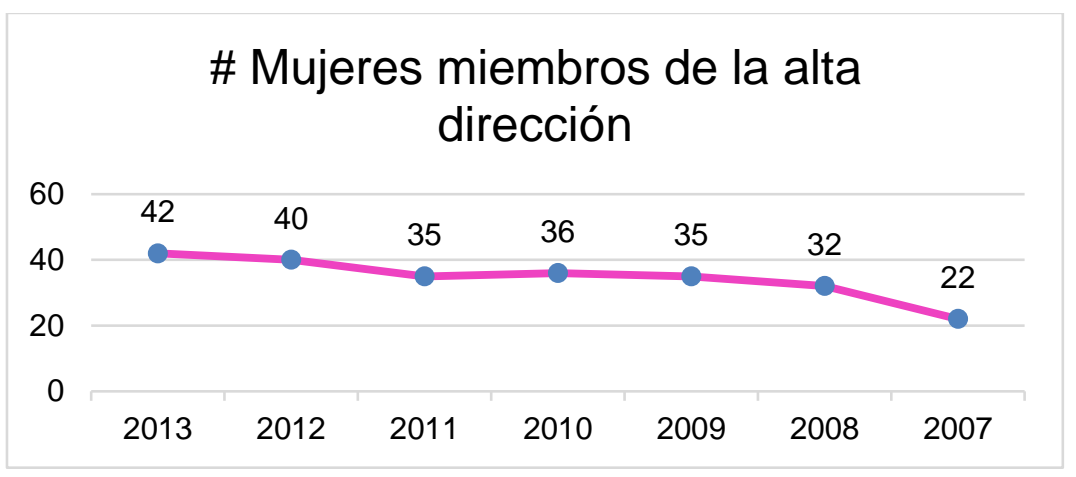

Gráfico 30. \# Mujeres miembros alta dirección IBEX 35. Fuente. IM. Elaboración propia

En cuanto a las mujeres que ocupan los cargos de la alta dirección ${ }^{143}$ de dichas empresas desde 2007 la tendencia ha sido positiva, duplicándose el número de mujeres que llegan a estos puestos por sus méritos tal como se observa en el Gráfico 30. Lo que nos da en la actualidad una proporción de aproximadamente un $10 \%$ de mujeres sobre el total de cargos, valor que resulta significativamente bajo aun, puesto que de 423 puestos que corresponde a la suma total de cargos disponibles en la alta dirección de las empresas del IBEX 35, solo 42 mujeres han logrado acceder a ellos.

Es interesante, también ver en el informe del ejercicio de 2014 de Gobierno Corporativo de las entidades emisoras de valores admitidos a negociación en mercados secundarios oficiales en España, proporcionado por la Comisión Nacional del Mercado de Valores. Esta entidad realiza un análisis de la representación femenina en las posiciones de gobierno corporativo, destina un espacio del informe denominado diversidad de género. Muestra de ello, el gráfico a continuación en la que se entrevé la

\footnotetext{
143 En estos datos no se incluyen a los que ocupan la Presidencia Ejecutiva, ni la Vicepresidencia Ejecutiva, ni el Consejero Delegado y la Secretaría General/Secretaria Técnica.
} 
incorporación y aumento lento de ellas en estos cargos, tal como se observa en las empresas del IBEX 35.

\begin{tabular}{|c|c|c|c|c|c|c|c|c|c|c|c|c|c|c|c|c|}
\hline \multicolumn{13}{|c|}{ Presencia de mujeres en los consejos } & \multirow{2}{*}{\multicolumn{4}{|c|}{ CUADRO 15}} \\
\hline & \multicolumn{4}{|c|}{$N^{0}$ de consejeras } & \multicolumn{4}{|c|}{$\%$ sobre el total } & \multicolumn{4}{|c|}{$\begin{array}{l}\text { No de sociedades } \\
\text { con mujeres }\end{array}$} & & & & \\
\hline & 2011 & 2012 & 2013 & 2014 & 2011 & 2012 & 2013 & 2014 & 2011 & 2012 & 2013 & 2014 & 2011 & 2012 & 2013 & 2014 \\
\hline lbex35 & 60 & 66 & 75 & 78 & 11,9 & 13,5 & 15,6 & 16,7 & 31 & 31 & 32 & 32 & 88,6 & 88,6 & 91,4 & 91,4 \\
\hline Más de 500 M.e & 30 & 23 & 23 & 32 & 10,8 & 9,6 & 8.5 & 11,6 & 17 & 14 & 14 & 19 & 68,0 & 66,7 & 58,3 & 73,1 \\
\hline Menos de $500 \mathrm{M} \in \mathrm{\epsilon}$ & 72 & 66 & 71 & 71 & 9,3 & 8,7 & 10,8 & 11,8 & 51 & 46 & 48 & 47 & 57,3 & 51,1 & 57,8 & 58,8 \\
\hline TOTAL & 162 & 155 & 169 & 181 & 10,4 & 10,4 & 12,0 & 13,5 & 99 & 91 & 94 & 98 & 66,4 & 62,3 & 66,2 & 69,5 \\
\hline
\end{tabular}

Gráfico 31. Presencia de las mujeres en los consejos. Fuente: (CNMV, 2015-a, p. 47)

De hecho, la CNMV (2015-b, p. 12) visibiliza esta situación en el código de buen gobierno de las sociedades cotizadas "dada la insuficiente presencia de mujeres en los consejos de administración, se recomienda que se incluyan objetivos concretos que la favorezcan". Asimismo, "recomienda que las sociedades en las que exista escasa presencia de mujeres en su consejo, hagan un esfuerzo deliberado por buscar posibles candidatas cada vez que deba cubrirse alguna vacante." (CNMV, 2015-a, p. 47)

Según el informe titulado La Mujer Directiva en España 2012 elaborado por PricewaterhouseCoopers e ISOTES, en lo que a cifras se refiere, las mujeres no alcanzan a ser ni un $10 \%$ en los altos cargos directivos de las principales compañías. Este informe enumeró las barreras de entrada con la que se encuentran las mujeres a la hora de poder acceder a puestos directivos, como lo son por ejemplo la dificultad para conciliar familia y trabajo; los patrones masculinos presentes en algunas empresas; los sistemas de promoción; los conflictos personales para el tema de la movilidad geográfica entre otros. 
Por ello, dicho informe recomienda a las empresas valerse de herramientas como la meritocracia para la progresión profesional, derribando aquellas barreras culturales que dificultan el camino a las mujeres mediante el establecimiento de objetivos concretos y planes de acción.

Por otro lado, y con ánimo de contrastar la información de España a nivel europeo, un estudio de Catalyst (2015-a) mostró en una comparativa de países europeos el porcentaje de mujeres en puestos de consejos de administración con fecha de cierre 2014, nuevamente quienes lideran son Noruega y Finlandia con el 36\% y el 30\% respectivamente, véase Gráfico 32 a continuación. España se encuentra en los últimos cinco puestos.

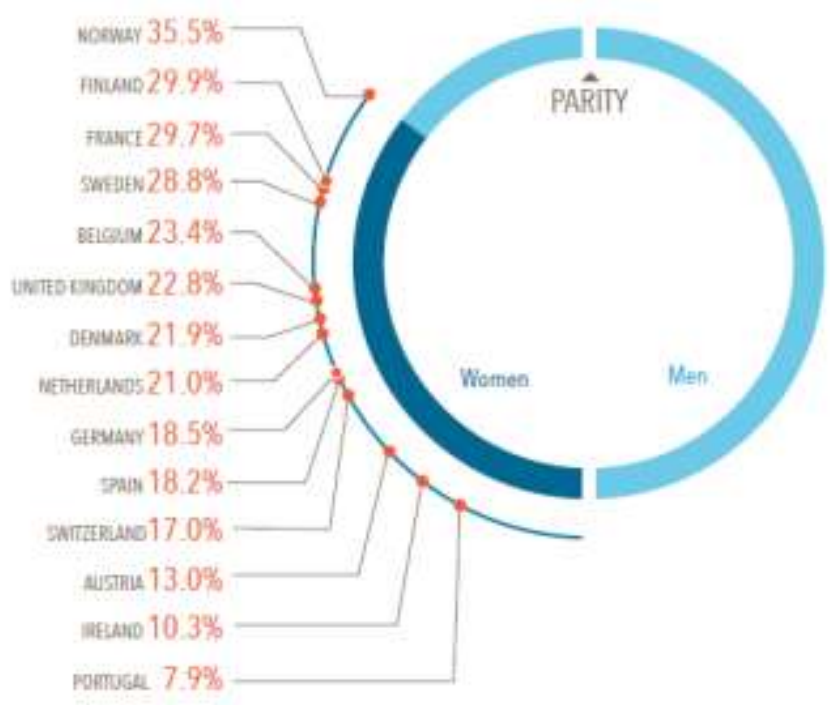

Gráfico 32. Women's share of board seats at european stock index companies. Fuente: (Catalyst 2015-a, p. 2)

Como se puede observar, los resultados siguen avalando la teoría que las mujeres ocupan un porcentaje muy bajo en la alta dirección, sin contar con el hecho de que las mujeres se ven enfrentadas a diversas situaciones de discriminación durante su vida laboral, para ello, hace falta la ejecución de 
medidas principalmente en las compañías para contrarrestar los diferentes obstáculos y prevenir a futuro este tipo de situaciones, por lo que en capítulos posteriores y durante todo el texto se ha propuesto un conjunto de acciones mínimas que las organizaciones deberían implementar para promover la igualdad de género en el trabajo y de esta manera las mujeres a futuro puedan romper el techo de cristal y acceder a cargos superiores.

De hecho, un pequeño avance, teniendo en cuenta las generaciones venideras, según Catalyst (2015-f) para aquellas organizaciones que buscan reclutar mejor, avanzar y retener millenials, de acuerdo con una investigación de este grupo en particular "las mujeres y los hombres tienen diferentes creencias acerca de lo que se está haciendo para abordar el sesgo de género" se concluyó en este sentido, que se debería fomentar la colaboración entre los géneros y ayudar a las mujeres y hombres a trabajar juntos para promover la inclusión. Esto solo se logrará si se asegura que los hombres jueguen un papel fundamental, alentando a los gestores para crear equipos grupos de trabajo diversos y programas que preparan a los empleados para convertirse en agentes de cambio e inclusión dentro de su organización.

Por último, es importante trabajar en la motivación de las mujeres que ya alcanzan posiciones de poder, pues de acuerdo con una investigación reciente "las mujeres CEOs son más propensas a retirarse o moverse fuera del ámbito corporativo después de su mandato, mientras que los hombres son más propensos a continuar en posiciones de liderazgo corporativo." (Glass \& Cook, 2016, p. 61). Por lo que uno de los retos consistirá en no solo aumentar el número de consejeras, sino también asegurar que su rol se desempeñe en términos de igualdad y no de responsabilidades secundarias, de igual manera con respecto al tema salarial, se trata en definitiva que exista una participación significativa para hacerle frente a escenarios discriminatorios. 


\subsection{Teorías y estilos de dirección: liderazgo en las organizaciones}

Una organización, independientemente del sector en el que se desenvuelva, precisa de personas para la realización de actividades de dirección de equipos de trabajo, lo cual implica que posean ciertas destrezas, capacidades, actitudes y habilidades que faciliten a los trabajadores desempeñarse de la mejor manera en el entorno laboral, a través de la generación en ellos del compromiso para la obtención de los objetivos empresariales.

Es común asociar los resultados empresariales al desempeño de las posiciones directivas (Marchant, 2005), ya que, al encontrarse estas personas en la parte superior de la estructura organizacional, se vean impuestos a la toma decisiones estratégicas y continuas que pueden afectar positiva o negativamente la gestión y pueden influir en la supervivencia del negocio. Por lo que estas posiciones son importantes en cualquier organización, ya que pueden lograr eficiencia y que los empleados bajo su responsabilidad se conviertan en capital humano productivo ${ }^{144}$.

Como se ha insistido, hoy en día todavía existen teorías y creencias, que las mujeres no lideran ni dirigen tan bien como los hombres, afirmación que se ha manejado como justificación para que las mujeres no acceden tan fácilmente a los niveles más altos de la jerarquía organizacional. Entonces, es clave persuadir a través de las investigaciones académicas en

\footnotetext{
144 En este sentido, se valora el aspecto de la inclusión y la innovación a través del entendimiento de la singularidad de las personas. Es decir, al reconocer los talentos ocasiona un efecto directo sobre la innovación. Con lo cual se denominarán líderes inclusivos aquellos que reconocen la importancia de valorar múltiples aspectos de la singularidad de sus colaboradores (Prime \& Salib, 2015, p. 6).
} 
colaboración con las empresas que la gestión de la diversidad ${ }^{145}$ puede convertirse en una poderosa herramienta que contribuye de manera positiva a la dirección estratégica de empresas.

Ahora bien, antes de ello hay que enfocarse en las habilidades directivas, para entender el origen de las creencias erróneas o no sobre la forma positiva o negativa de dirigir entre mujeres ${ }^{146} \mathrm{y}$ hombres. Por lo que se parte del planteamiento de Marchant que afirma que "El gerenciar requiere un cúmulo de competencias particulares que, en la actualidad, no forman parte de los programas curriculares de la educación formal" (2005, p. 64).

De acuerdo con López (2011), la característica principal que debe tener un directivo, o una persona que tenga la responsabilidad tomar decisiones en la organización es la habilidad de ser un líder, en este sentido, el liderazgo consistirá en la adquisición de un conjunto de competencias, sustentadas en valores éticos, que cualquier persona independiente del sexo

145 De acuerdo con Abay Analistas Económicos y Sociales (2011, p. 13) "Se entiende por diversidad los perfiles que diferencian a las personas y que tienen un impacto en el comportamiento grupal".

Asimismo, el principio de diversidad "se sustenta en el reconocimiento y valoración de la variabilidad, tanto individual como intergrupal. Este mismo principio se puede aplicar al mundo laboral considerando que no hay un único modo de trabajar sino muchas formas y que esta pluralidad laboral puede ser ventajosa para la organización, ya que favorece la innovación y la complementariedad de perspectivas." (Barberá, 2004, p. 43)

${ }^{146}$ En este punto, es acertado traer a colación el planteamiento de autores como Barberá, Sarrió \& Ramos, así "no a cualquier mujer, por el simple hecho de serlo, hay que suponerle el desarrollo de los rasgos que configuran la feminidad, ni hay que dar por sentado que puede llegar a ser una buena directiva" lo cual es completamente aplicable también al caso de los hombres. (2000-b, p. 55). 
puede aprender y desarrollar si une su voluntad con la formación adecuada (p. 16).

Bajo este concepto, dichas competencias son características y rasgos esenciales de las personas, que exteriorizan formas de pensamiento y de comportamiento, como se puede observar en el gráfico están representadas en tres grupos, las cuales pueden ser fácilmente perceptibles o encontrarse muy dentro del individuo.

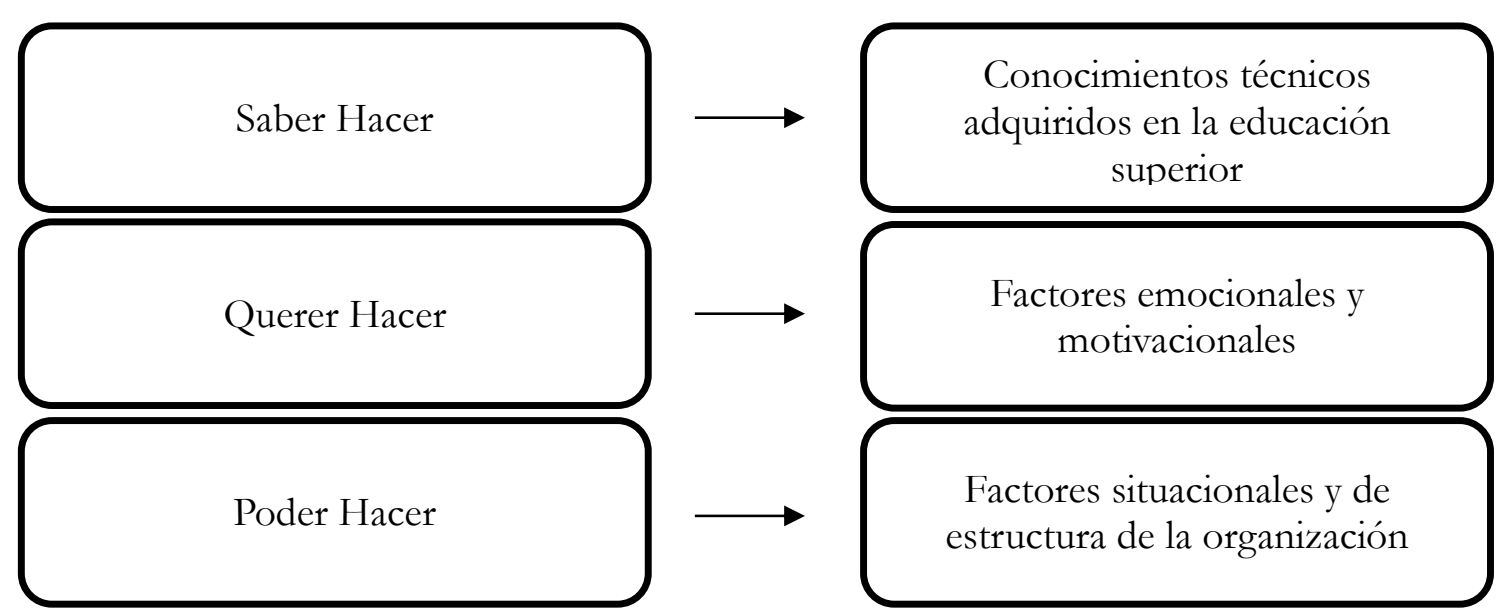

Gráfico 33. Componentes de las Competencias. Fuente: (Marchant, 2005). Elaboración

propia.

El alto rendimiento de las personas ${ }^{147}$ pasa por consiguiente por los conocimientos, pero también por una serie de creencias, actitudes y

${ }^{147}$ Al respecto, una investigación de Prime \& Salib (2014, p. 2) en seis países (Australia, China (Shanghái), Alemania, India, México y Estados Unidos) determinó que las personas en el trabajo se sentían más incluidos cuando percibieron que sus gerentes: (i) les dieron poder para tener éxito, (ii) mantuvieron la responsabilidad de hacer un buen trabajo, (iii) con valentía tomaron riesgos y, (iv) fueron lo suficientemente humildes como para admitir y 
conductas, que es preciso identificar en cada organización. A menudo surgen reservas sobre la posibilidad de desarrollar algunas de las competencias en personas que no parecen poseerlas; sin embargo, la formación básica de cada gerente debería ser reforzada a través de una formación continua que requiera de un contenido práctico, de experiencias en situaciones de trabajo.

\begin{tabular}{|c|c|}
\hline \multicolumn{2}{|c|}{ PRINCIPALES COMPETENCIAS GERENCIALES } \\
\hline $\begin{array}{c}\text { Gerenciamiento de la } \\
\text { Motivación del Personal }\end{array}$ & $\begin{array}{c}\text { Capacidad de mantener un equipo de trabajo } \\
\text { comprometido y enfocado en la consecución de los } \\
\text { objetivos }\end{array}$ \\
\hline $\begin{array}{c}\text { Conducción de Grupos de } \\
\text { Trabajo }\end{array}$ & $\begin{array}{c}\text { Capacidad de trabajo con personas diversas, de la } \\
\text { posibilidad de delegar actividades y controlarlas. }\end{array}$ \\
\hline Liderazgo & $\begin{array}{c}\text { Habilidad para orientar e inspirar a las personas y } \\
\text { colaboradores. }\end{array}$ \\
\hline Comunicación Eficaz & $\begin{array}{c}\text { Capacidad para establecer una comunicación activa. } \\
\text { Dirección de Personas }\end{array}$ \\
$\begin{array}{c}\text { Gestión del Cambio y } \\
\text { Desarrollo de la Organización }\end{array}$ & $\begin{array}{c}\text { Habilidad para enfrentarse a situaciones cambiantes y } \\
\text { tomar decisiones para gestionar los conflictos de } \\
\text { manera eficaz. }\end{array}$ \\
\hline
\end{tabular}

Tabla 15. Principales Competencias Gerenciales. Fuente: (Marchant, 2005).

Elaboración propia

aprender de los errores. Así los empleados aportaron a mejorar el rendimiento en el lugar de trabajo. 
De hecho, en las organizaciones existen expectativas estereotipadas sobre los diferentes estilos de liderazgo ejercidos por mujeres y por hombres $^{148}$, en este sentido según el trabajo de Eagly \& Johnson (1990) en cuanto a la tendencia a dirigir democrática o autocráticamente, las mujeres tendían a adoptar un estilo más participativo, en consecuencia, democrático mientras que los hombres, un estilo directivo más autocrático.

Un liderazgo eficiente es la capacidad de integrar con éxito y aprovechar al máximo los recursos disponibles para la consecución de los objetivos que la organización o la sociedad pretende alcanzar. Dentro de esos recursos se encuentra el capital humano, que se refiere a las personas y que no tiene nada que ver con el hecho de ser hombre o mujer.

Es por ello que en esta línea sobre el desarrollo de un liderazgo con resultados e intentando responder a la pregunta si son las mujeres mejores que los hombres ${ }^{149}$, una investigación de Zenger \& Folkman (2012) logró apilar 16 competencias principales que deben tener todos los lideres ejemplares, y las trasladaron a su estudio para ver si existian diferencias entre sexos.

\footnotetext{
148 Hay que tener en cuenta, que incursionar en el territorio de las diferencias de género resulta complejo, cuando se habla de estilos masculinos y femeninos generalmente se refiere a tendencias, no cuestiones absolutas (Benko \& Pelster, 2013, p. 5) por tanto no hay que caer en generalizaciones.

149 Por ejemplo, un estudio de Shelby, Mueller \& David (2015) determinó que los líderes masculinos sufrirían mayores costos de competencia que las mujeres cuando buscan ayuda, mostró que "en un campo lleno de problemas y con la oportunidad de un posible fracaso, los líderes masculinos que buscaban ayuda eran percibidos como menos competentes que los líderes masculinos que no buscaron ayuda." independientemente de la manera en que se ejercía el liderazgo.
} 


\begin{tabular}{|l|}
\hline \multicolumn{1}{|c|}{ COMPETENCIAS DE UN LIDER } \\
\hline Iniciativa propia \\
\hline Impulsa el auto-desarrollo \\
\hline Alta integridad y honestidad \\
\hline Dirigir hacia los resultados \\
\hline Desarrolla a otros \\
\hline Inspira y motiva a los demás \\
\hline Construye relaciones \\
\hline Colabora y trabaja en equipo \\
\hline Establece objetivos ambiciosos \\
\hline Campeones de cambio \\
\hline Resuelve problemas y analiza cuestiones \\
\hline Comunica poderosamente y prolíficamente \\
\hline Conecta el grupo con el mundo exterior \\
\hline Innovación \\
\hline Experiencia técnica o profesional \\
\hline Perspectiva estratégica \\
\hline
\end{tabular}

Tabla 16. Dieciséis competencias de los principales líderes según Zenger \& Folkman (2012). Elaboración propia 
No obstante, según Ibarra, Ely, \& Kolb (2013) el convertirse en un líder, implica mucho más que obtener el cargo de liderazgo, supone la adquisición de nuevas habilidades, la adaptación al propio estilo y a las exigencias de ese papel, se trata en definitiva de un cambio fundamental de identidad.

En la doctrina, se encuentra requisitos ineludibles para el liderazgo en los equipos de trabajo: aspectos como la coherencia y ejemplaridad de la alta dirección. En este sentido, todo directivo o gestor de personas es clave en la generación de actitudes de aquellos bajo su mando o influencia. Equipos en los que las personas que los integran se sientan motivadas y satisfechas, y contribuyan entre todas a alcanzar los objetivos que han sido establecidos $y$ son compartidos.

De hecho, una investigación de Molero et al. (2009) mostró que no se encontraron diferencias entre hombres y mujeres, en un gran número de características que corresponden a estereotipos masculinos o femeninos, dentro de ellas (i) ser sensible a las necesidades de los compañeros, (ii) capacidad de tomar decisiones, (iii) tratar de imponer sus ideas, (iv) ser eficaces, entre otros.

La mayoría de rasgos con estereotipos femeninos que impactan positivamente tienen que ver con aspectos relacionados con la sociabilidad y el establecimiento de buenas relaciones, mientras que dentro de los rasgos con estereotipos masculinos que pueden incidir negativamente en el trabajo se encuentran la imposición de ideas, el individualismo y la ambición. Por lo que el autor concluye que "... a la vista de estos resultados se observa un debilitamiento del estereotipo "think manager - think male" ya que, si bien algunas de las características del directivo/a con éxito son estereotípicamente masculinas, hay también características femeninas y otras no relacionadas con el género". 
Por su parte, un estudio de Barsh, Cranston \& Craske (2008, p. 36) identificó algunas características en particular de las mujeres frente a sus homólogos masculinos en el lugar de trabajo. En primer lugar, su doble carga -la maternidad y la gestión - las hace afrontar sus retos con una energía de una manera particularmente desafiante. En segundo lugar, ellas tienden a experimentar altibajos emocionales con más frecuencia y más intensidad que la mayoría de los hombres, estas emociones podrían convertirse en potencialmente negativas.

No obstante, en ese mismo estudio se identificaron cinco dimensiones que tiene el liderazgo, basándose en las mujeres directivas exitosas: el significado que mueve, participación, gestión de los niveles de energía, positivismo, redes y mentorías fuertes, obsérvese el Gráfico 34.

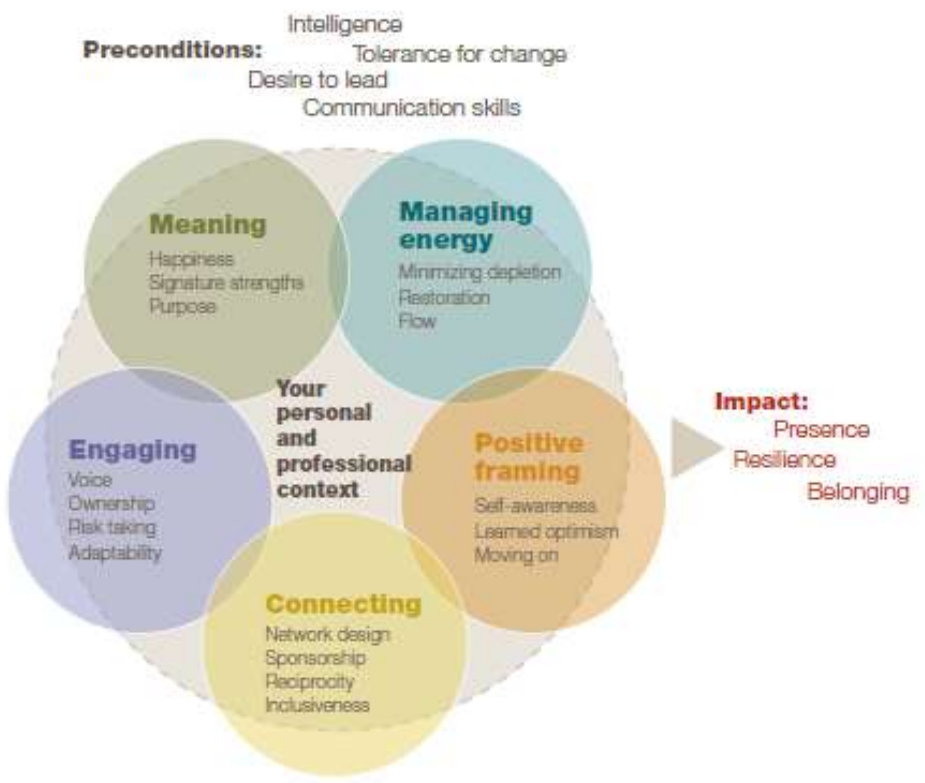

Gráfico 34. Cinco dimensiones del liderazgo. Fuente: (Barsh, Cranston \& Craske, 2008, p. 
Asimismo, una investigación de Prime \& Salib (2015, pp. 8-10) en líderes de empresas australianas que buscaba conocer el secreto de la inclusión en el lugar de trabajo a través del liderazgo de sus directivos, mostró un conjunto de estrategias para lograr la construcción de equipos innovadores: (i) Proveer Air Cover, que consiste en brindar protección y apoyo a sus colaboradores cuando encuentran dificultades o desafíos; (ii) Crear una Cultura de Coaching, lo cual implica en una práctica regular en la cual los miembros de los equipos de trabajo deben recibir y brindar entrenamiento, apoyo y asesoramiento entre sí, (iii) Compartir luchas, siendo transparentes en la resolución de los problemas y; (iv) Liderar con el corazón, pues se debe evitar el miedo a ser vulnerables para así lograr conexiones auténticas con sus colaboradores.

Al final, lo que se busca es que los líderes del futuro (hombres o mujeres) sean inclusivos en todo el sentido de la palabra, lo cual implica disponer de cuatro cualidades: empoderamiento, responsabilidad, humildad y coraje (Catalyst, 2015-c). Lo cual implica también crear una cultura inclusiva $^{150}$ para las organizaciones, en la cual los empleados puedan contribuir al éxito de la compañía siendo auténticos, mientras que la organización respeta y aprovecha sus talentos a través de una conexión con sentido y el fortalecimiento de equipos heterogéneos, aunque requiera de mayor tiempo la toma de decisiones (Groysberg \& Connolly, 2013)

\footnotetext{
150 Esto solo se logra con aquellas prácticas que hacen la diferencia así: midiendo la diversidad y la inclusión; manteniendo a los gerentes responsables en las organizaciones; apoyando las diferentes formas flexibles de trabajo; reclutando y promoviendo candidatos diversos; proporcionando educación en liderazgo para los colaboradores; patrocinando a grupos de empleados con potencial a través de programas de tutoría; ofreciendo modelos de calidad haciendo que la posición de directivo con enfoque diverso cuente, y por último; pero no menos importante, predicando con el ejemplo (Groysberg \& Connolly, 2013)
} 


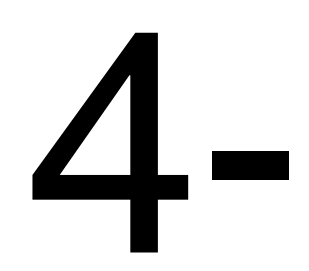

Capítulo Cuatro. El papel de la Responsabilidad Social en las organizaciones. 


\subsection{Evolución del concepto}

Al hablar de Responsabilidad Social de las organizaciones, no es un concepto rígido, pues va evolucionando a medida que pasa el tiempo, además plantea una interesante combinación de objetivos empresariales. Por esta razón, para saber sobre este término, es necesario adentrarnos un poco en la historia de la concepción de empresa y los cambios ${ }^{151}$ que han surgido en su relación con la sociedad.

Al respecto, diversos autores (Casado, Viñuales \& Jáuregui, 2006; Polo, 2011; Moreno, Uriarte, \& Topa, 2010) enlazan esta noción con el inicio de la revolución industrial desde finales del siglo XVIIII, y, de un grupo pionero de empresas que empezaban a establecer responsabilidades a su gestión; paralelamente con las ideas de Adam Smith, al considerar que los negocios no podían operar al margen de la moralidad.

A lo largo del siglo $\mathrm{XIX}$ y principios del siglo $\mathrm{XX}$, empresarios asumieron responsabilidades mas allá de las comerciales, en consecuencia se evidenciaron las primeras acciones filantrópicas, que consistia por ejemplo en destinar parte de sus beneficios economicos a fondos sociales y de caridad por tal motivo, es cierto afirmar que una idea inicial de responsabilidad social de las empresas fue asociada al mecenazgo.

La RSE no siempre tuvo adeptos precisamente, uno de ellos Friedman (2007) prevalece solo la función económica de la organización, con su artículo

\footnotetext{
151 De hecho, Carneiro (2009, p. 61) planteó que "para entender cómo son y cómo funcionan las organizaciones y, en concreto, las empresas, resulta preciso avanzar más allá de la mera miopía economicista para adentrarse, con la ayuda de otras disciplinas como la sociología, la psicología o la antropología entre otras, en el basto campo de relaciones que mantienen las empresas con el entorno."
} 
the social responsibility of business is to increase its profits, sentó unas premisas básicas, al respecto, las empresas contribuyen con la sociedad generando utilidades, por lo que el funcionamiento normal de una empresa desde ya supone un beneficio social suficiente al promover la creación de empleos, pagar impuestos y realizar compras. Asimismo, esta visión mostró que la responsabilidad social es individual, por lo que la única obligación de la empresa y de sus directivos en con sus dueños, es decir, la búsqueda de la maximización de beneficios, igualmente dejó clara la función pública versus la privada, a saber, las entidades públicas y las corporaciones, la primera con una clara orientación social, por lo que a la segunda no se le debería trasladar esa responsabilidad; justamente la sustentación de todas estas razones es la defensa de la libertad de empresa.

Por su parte, Satorras (2008, p. 27) sostuvo que la RSE nació a finales de los años 50 y principios de los 60 en los Estados Unidos, como consecuencia de un movimiento ideológico asociado a los acontecimientos del momento. En este sentido, se vinculaba el trabajo de algunas empresas y la compra de sus bienes y servicios con la colaboración de determinados regímenes que iban en contra de los derechos humanos. Así pues, se crea en ese entonces una necesidad de pedir explicaciones sobre aspectos éticos a las empresas y la exigencia de compromisos con los problemas sociales existentes.

Justamente, en la mitad del siglo XX la sociedad en su conjunto empieza a darse cuenta de las repercusiones que generaban las grandes industrias a nivel ambiental, por lo que nace la conciencia de la empresa por mitigar los impactos negativos externos, a través de la integración de dicha conciencia en las diferentes operaciones realizadas por la organización, para su prevención surgen los mapas de riesgos ajustados con una gestión 
apropiada de los recursos y la incorporación de un nuevo concepto: el de la sostenibilidad.

En este sentido, el eje de una empresa sostenible no es el crecimiento económico sino más bien el desarrollo que permita evolucionar modelos de negocio, que funcionen financieramente a la vez que son social, ambiental y éticamente correctos. A estos efectos, tomando como fuente el Informe Brundtland presentado en 1987 por la Comisión Mundial sobre el Medio Ambiente y el Desarrollo (CMMAD) se promueve el desarrollo sostenible cuando se "satisface las necesidades del presente sin comprometer la capacidad de las generaciones futuras de suplir sus propias necesidades".

Por otro lado, la idea de que ya la empresa no se encuentra sola, sino que hace parte de un entorno toma forma con Freeman (1984) quien con un enfoque hacia los stakeholders o grupos de interés, la empresa ya no se dirige pensando en el beneficio de unos pocos, sino en el beneficio de públicos amplios, diversos $\mathrm{y}$, a veces, con intereses contradictorios, distinguiéndoles entre primarios y secundarios, en este sentido, se hace ineludible la responsabilidad de establecer un dialogo activo y una comunicación permanente con los mismos.

Igualmente, como efecto de una mayor vigilancia a las empresas debido a sus impactos y la entrada en la era del conocimiento y de las nuevas tecnologías, las empresas comienzan a preocuparse por su imagen ante la sociedad, por lo que la reputación se convierte en un aspecto fundamental a la hora de gestionar sus responsabilidades y de informar a sus grupos de interés

Es cuando, la RSE resurge con fuerza, como respuesta entre otras cosas a la desconfianza generada fruto de escándalos de gran repercusión en el sector económico -el más conocido, el caso de la corporación Enron-. 
Por lo que, comienzan a aparecer los primeros rankings y herramientas para el análisis de la reputación, situación que aprovechan las empresas para mejorar la percepción externa e interna que se tiene sobre ellas, todo ello a través del desarrollo de la comunicación corporativa, pues resultaba evidente, los beneficios intangibles que genera, en lo que nos atañe comienza a confundirse el concepto de RSE con un término denominado marketing con causa.

Este último, también denominado marketing social o corporativo, según Silva \& Cañadillas (2003) es considerado una herramienta estratégica en aras de posicionar una empresa, en donde se identifica y contribuye con una causa social de interés logrando el beneficio mutuo.

Por su parte, Carroll (1991) planteó una serie de responsabilidades que debe tener una empresa socialmente responsable, representadas en una piramide, en cuya base se encuentran las responsabilidades económicas, en este sentido, las empresas deben ser rentables, le siguen las legales, que consisten en cumplir con dichas, mas arriba se encuentran las responsabilidades éticas, concerniente a obrar correcta y justamente evitando en lo posible daños a terceros. En la punta de la piramide se encuentran las filantrópicas que radica en la ciudadania corporativa

Sen por ejemplo, retomó el tema de la filosofía moral y la economía del bienestar planteando que una de las debilidades de la economía moderna supone un grave distanciamiento entre la economía y la ética de los negocios, por lo que planteó complejos desafíos como el hambre, la pobreza, la justicia social y su relación con la economía. En este sentido, defendió que un contacto más íntimo entre la ética y la economía puede ser beneficioso para ambas. 
Con Porter \& Kramer referentes en cuanto a estrategia empresarial, con su doctrina acerca de cómo reinventar el capitalismo, resultado de la desconfianza creada durante años en la sociedad por parte de las corporaciones, marcó unas bases sólidas que hacen parte intrínseca de la RSE, pues su mensaje bandera consistió en la creación de valor compartido, como parte de la legitimación social, esto significa que se puede crear valor económico y valor social a la vez, lo que proporciona una visión mucho más integrada de las responsabilidades empresariales.

Según Porter (1985), la cadena de valor es una poderosa herramienta de analisis para la planeación estrategica de los negocios, facilitando la identificación de las ventajas competitivas en el seno de la organización, en este sentido, toda organización puede analizarse en virtud de la contribución de valor que genera cada una de sus actividades (primarias y de apoyo), así como el que emerge de las interrelaciones entre ellas.

A estos efectos, incluye el concepto de cadena de valor, en la cual se debería evaluar la incidencia positiva y negativa en la sociedad que conlleva todos los procesos empresariales. Ahora bien, para el logro de estos objetivos sostienen que es necesario una decisión estratégica interna y su correspondiente alineación previamente indicada en toda la cadena de valor, todo ello, a través de la competencia lograda mediante aspectos clave como la redefinición de la productividad en sus procesos o de los productos y mercados, y la interacción con el entorno y las comunidades locales; por lo que la creación de valor compartido, en este sentido, sí es viable pues al combinar una estrategia de valor económico y social puede repercutir positivamente.

En definitiva, lograr el valor compartido en una organización implica prácticas operacionales que mejoran la competitividad de una empresa a la vez que ayudan a mejorar las condiciones económicas y sociales en las 
comunidades donde opera, todo ello mediante la identificación y la expansión de las conexiones entre lo social y lo económico. (Porter \& Kramer, 2011)

Por lo que se refiere a Prahalad \& Hart vemos que, partiendo de los desafíos y problemas sociales, éstos se deben observar a través de una óptica empresarial y no filantrópica, a partir de ello pueden suponer nuevas oportunidades empresariales como, por ejemplo, el descubrimiento de mercados no atendidos. Esta doctrina, vuelve a teorías pasadas en donde el foco principal de una organización debía ser el cliente, y en donde otros grupos de interés logran ser incorporados en la cadena de valor de la organización.

Así pues, se puede materializar esta larga trayectoria en el siguiente gráfico, la forma como se ha forjado ${ }^{152}$ el concepto que hoy en día se tiene sobre la responsabilidad social de las empresas, El perfil que va tomando a medida que pasa el tiempo, se encontrará determinada por la presión que ejerce la sociedad, las entidades públicas y el propio mercado.

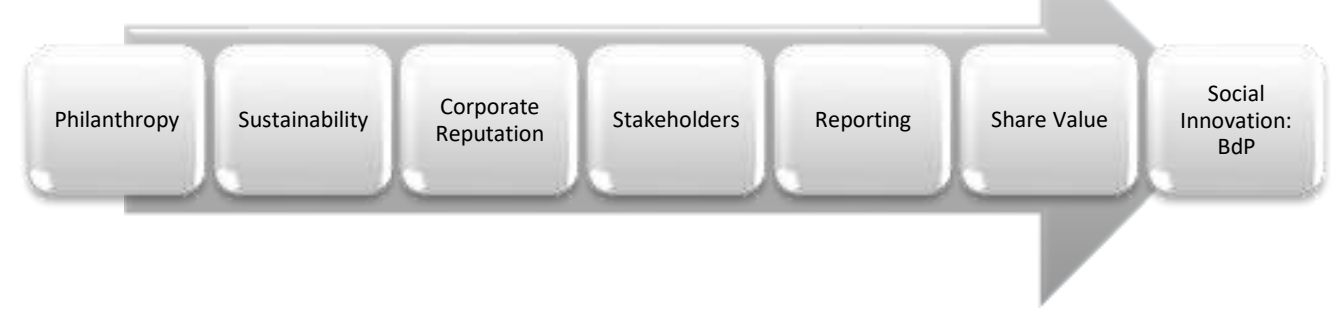

Gráfico 35. Evolución en el tiempo de la Responsabilidad Social.

Fuente: Elaboración propia

\footnotetext{
152 De hecho, el propio sector privado es quien ha participado en la "elaboración de regímenes voluntarios de conducta por los cuales se compromete a cumplir las normas internacionales de derechos fundamentales como parte de su política de Responsabilidad Social Empresarial" (Giner, 2008, p. 70)
} 
A pesar de la evolución histórica que ha tenido la RS en el tiempo, no existe aún una definición consensuada cuando se habla de este término, principalmente porque los puntos de vista desde los cuales se puede abordar son muy variados y además que es interdisciplinaria tal como lo hemos visto. Por lo que es muy común escuchar hablar de RSE o de RSC para representar este concepto, sin embargo, muchas entidades reconocidas se han preocupado por ilustrar el contexto en el cual se mueven las organizaciones actuales.

La definición más actual se encuentra en Europa, precisamente la Comisión Europea en su Estrategia renovada de la UE para 2011-2014 sobre la responsabilidad social de las empresas, marcó las bases actuales sobre este concepto, pues se tiene claro que las empresas como parte activa de la sociedad, pueden contribuir de manera significativa a la consecución de los objetivos, específicamente del Tratado de la Unión Europea, en este caso, la igualdad, el desarrollo sostenible y una economía social de mercado que sea competitiva, obviamente esto será posible si existe una preocupación por promover la responsabilidad social en las organizaciones.

Dicho esto, la interpretación por parte de la Comisión Europea está limitada a una sola frase, a saber, «la responsabilidad de las empresas por su impacto en la sociedad», pero no queda ahí, pues es requisito previo el respeto de la legislación aplicable y de la relación con sus grupos de interés incluyendo los convenios colectivos. Sin dejar de lado que la RS será real si existe una integración en la estrategia y en las operaciones empresariales de las preocupaciones sociales, medioambientales y éticas, primando el respeto por los derechos humanos y creando valor compartido con los stakeholders.

Por otra parte, algunas entidades enfocan la RSE ligada a la estrategia empresarial, es el caso del Instituto Ethos de Empresas e Responsabilidade Social quien concibe la RSE como una forma de gestión, esto a través de una 
relación ética y transparente de la organización con todos los públicos con los cuales se relaciona, asimismo, sus objetivos empresariales deben ser compatibles con el desarrollo sostenible.

Por otra parte, Forética define la RSE como "el fenómeno voluntario que busca conciliar el crecimiento y la competitividad, integrando al mismo tiempo el compromiso con el desarrollo social y la mejora del medio ambiente" (Saldaña \& Llàtser, 2007). A la par, la Organización Internacional del Trabajo (OIT, 2006, p. 1) define la RSE como algo espontaneo, es decir, la forma en que las empresas dan importancia de los impactos que generan en la sociedad, $y$, en donde salen a relucir los principios éticos y su relación con los demás actores". En este sentido, prima la voluntariedad y la realización de prácticas que exceden el cumplimiento de la legislación, sin reemplazar los papeles propios de los demás actores sociales.

A partir de todas estas definiciones, es justo enfocar la responsabilidad social en los ámbitos económico, social y ambiental, complementada con la dimensión ética asociada al Gobierno Corporativo, todas ellas deberían estar alineadas con los derechos humanos y las preocupaciones por los distintos grupos de interés: los trabajadores, el medio ambiente, los proveedores, los consumidores, los clientes, la comunidad local, la administración pública, las entidades no lucrativas, entre otros.

Al respecto, sobre estas dimensiones de la RSE mencionadas, Savitz sostiene que la primera persona en proponer el concepto Triple Bottom Line (TBL) fue el experto en sostenibilidad John Elkington, sustentando que los negocios necesitaban evaluarse no solo con el tradicional rendimiento financiero -expresado generalmente con indicadores como las utilidades económicas, el retorno de la inversión o el valor patrimonial- sino también con la evaluación de sus impactos en la economía, el medio ambiente y las sociedades en las cuales operan. 
Las organizaciones que han deseado incurrir en prácticas de responsabilidad social, se han guiado de un conjunto de iniciativas ${ }^{153}$ aceptadas internacionalmente, a estos efectos, hemos estimado organizarlas de acuerdo a sus características específicas, en este sentido, estas herramientas son divididas así: principios y directrices por una parte; en modelos de normalización por otra parte; las de reporting y por último, otras iniciativas no clasificadas pero igual de relevantes, por lo que a continuación las describiremos en ese orden.

Como consecuencia del aumento de la relación de la empresa con diferentes grupos de interés, se ha hecho necesario avanzar en la forma como se realiza la divulgación de la información empresarial, en este sentido, no solo del ámbito económico sino también del social, ambiental y del buen gobierno, por lo que cuando nos referimos a reporting, entendemos la forma de divulgar la información relevante acerca de la estrategia, gestión, resultados y perspectivas de una organización integrando los aspectos ya mencionados, en definitiva se trata de emitir información útil que sirva para establecer un dialogo activo con los actores sociales.

No obstante, es preciso saber que la organización independiente que ejecuten acciones en los contextos planteados. Dicha actuación no implica que sean socialmente responsables, muestra de ello se encuentran prácticas como el greenwashing en la cual organizaciones recurren a tácticas para

\footnotetext{
${ }^{153}$ Muy acertadamente, la Agencia Europea para la Seguridad y la Salud en el Trabajo (2005, p. 10) destacó que las iniciativas están enmarcadas bajo los siguientes parámetros: "1) Mayor sensibilización, galardones e iniciativas éticas. 2) Intercambio de conocimientos: prácticas idóneas, redes, proyectos piloto y directrices. 3) Normalización y certificación. 4) Elaboración de informes (destinados a terceros) y comunicación. 5) Asociaciones innovadoras, ONG públicas y privadas. 6) Iniciativas comerciales éticas («comercio justo»). 7) Participación del sector financiero/incentivos financieros."
} 
inducir a error a sus potenciales consumidores respecto a sus prácticas ambientales o, incluso los beneficios sociales de un producto o servicio, en este sentido, los beneficios potenciales de la comunicación de la RSE (Parguel, Benoît-Moreau, \& Larceneux, 2011) para la evaluación de marca corporativa pueden ser cuestionable, incluso para las empresas verdaderamente responsables.

Hay que tener presente, que la manera de ser responsable no implica dejar de obtener beneficios económicos, es una percepción errónea, justamente se trata de mejorar la forma de hacer empresa, sin dejar de lado su objeto social, puesto que muchas empresas en esa búsqueda se desvían del propósito inicial, en el fondo, insistimos que se trata de explotar la función social de las organizaciones mediante la innovación constante y la mejora continua de sus procesos empresariales.

Uno de los objetivos de las organizaciones y seguidamente de sus directivos, está en la maximización de los beneficios económicos, pero en esta instancia, el enfoque ético comienza con incorporar prácticas responsables y no dañinas para los diferentes grupos interesados dentro de lo que cabe, justamente Goñi (2011, pág. 22) sostiene que este enfoque ético debe ir vinculado a los objetivos de la organización, sin engaños ni trampas.

\subsection{La relación con el principio de igualdad y no discriminación}

De acuerdo con la Agencia Europea para la Seguridad y la Salud en el Trabajo (2005) dentro de los principales aspectos a evaluar en su dimensión social relacionados con la RSE se encuentran: (i) la seguridad de producto y 
la seguridad y salud en el trabajo de la población activa, (ii) reglamentación laboral y condiciones de trabajo, (ii) derechos humanos y, (iv) la igualdad de oportunidades y acceso al empleo. Es decir, como se puede observar la RSE está relacionada con el principio de igualdad y no discriminación, y no solamente en sus aspectos laborales.

En este contexto "la RSE se configura como un marco idóneo para la promoción de la igualdad entre mujeres y hombres, ya que aborda en sus definiciones y en los sistemas de seguimiento la igualdad de oportunidades en la empresa y ésta se constituye como un ámbito de actuación del desempeño social de la RSE." (Forética \& Secretaria de Estado de Igualdad, 2010, p. 12).

De hecho, en la publicación del Departamento de trabajo (2010, p. 27) se propone como uno de los indicadores en la adopción por parte de la dirección de una gestión organizativa que tiene en cuenta la igualdad de oportunidades, un indicador avanzado denominado "criterios de responsabilidad social en materia de igualdad de oportunidades en la contratación a empresas proveedoras y/o colaboradoras." Todo ello, para la realización de los planes de igualdad en las empresas españolas.

Por otro lado, si se entra a detallar las diversas iniciativas que existen sobre el tema, diversas organizaciones internacionales reconocidas las han liderado, así pues, por una parte, el Pacto Mundial o Global Compact, que en su principio número 6 estipula que las empresas deben apoyar la abolición de las prácticas de discriminación en el empleo y ocupación, en este sentido, mediante la firma o adhesión por parte de las empresas a esta iniciativa, será evidente el compromiso para combatir este problema, y no queda ahí pues será necesario en la publicación anual de resultados de cada empresa, informar sobre qué medidas se están implementando para el cumplimiento de dichos principios. 
Sin duda, el referente mundial más importante con respecto al tema de Responsabilidad Social es este pacto como iniciativa voluntaria internacional promovida por la ONU, en el que las empresas, organizaciones y gobiernos se comprometen a alinear sus estrategias y operaciones con diez principios universalmente aceptados en cuatro áreas temáticas a saber, derechos humanos, estándares laborales, medio ambiente y anti-corrupción. A manera de información y con ánimo de saber la representación empresarial, la Red Pacto Mundial de España ${ }^{154}$, dentro de sus socios figura un $74 \%$ de las entidades del lbex35 y más de 250 organizaciones de todos los sectores y tamaños.

Por otra parte, la Organización para la Cooperación y Desarrollo Económico (OCDE) propuso un conjunto de recomendaciones dirigidas conjuntamente por los gobiernos a las empresas multinacionales para el desarrollo de una conducta empresarial responsable en el contexto global las llamó las líneas directrices.

El objetivo de las directrices es garantizar que las actividades de dichas empresas, se desarrollen en armonía con las políticas públicas, del mismo modo, fortalecer la base de confianza mutua entre las empresas y las sociedades en las que desarrollan su actividad, asimismo, contribuir a mejorar el clima para la inversión extranjera y potenciar la contribución de las empresas multinacionales al desarrollo sostenible.

Las directrices forman parte de la Declaración de la OCDE sobre Inversión Internacional y Empresas Multinacionales, por lo que los países que se adhieren a las Directrices contraen el compromiso vinculante de implementarlas de acuerdo con la Decisión del Consejo relativa a las Líneas Directrices de la OCDE para Empresas Multinacionales, no obstante, el

154 Cfr. http://www.pactomundial.org/ 
cumplimiento de las Directrices por parte de las empresas es voluntario y no es jurídicamente vinculante.

En la última revisión realizada en 2011, se encuentran 15 principios generales reconocidos como deber de las empresas que incluyen diversas áreas relacionadas con los impactos de las mismas, de igual manera, se enumeran recomendaciones y comentarios específicos en materia de divulgación de la información, derechos humanos, empleo y relaciones laborales, medioambiente, lucha contra la corrupción, intereses de los consumidores, ciencia y tecnología, competencia, y cuestiones tributarias, además del procedimiento para la implementación de las líneas directrices.

En este sentido, también se contempla aspectos que tienen que ver con el respeto por la igualdad en el trabajo, específicamente en lo concerniente a los derechos humanos, el empleo y relaciones laborales. EI documento, invita a dichas empresas a inspirarse para sus actividades, en el principio de igualdad de oportunidades y trato en el trabajo mediante la no discriminación de sus trabajadores por cualquier motivo o circunstancia en la asignación de puestos de trabajo, despido, remuneración, otros beneficios, ascensos, traslados, cese o desvinculación, capacitación y jubilación.

Por su parte, la Organización Internacional para la Estandarización (ISO) creó una guía no certificable que aporta conceptos y líneas de acción en materia de responsabilidad social: la ISO 26000 sobre Responsabilidad Social, dentro de las acciones propuestas en materia de prácticas laborales (aspecto 6.4) establece que se debe asegurar la igualdad de oportunidades para todos los trabajadores y no discriminar, ya sea directa o indirectamente.

De igual manera, existen además sistemas de gestión certificables como el Modelo Internacional SA8000, que dentro de sus requisitos de responsabilidad social se encuentra el tema de la Discriminación, así pues la 
empresa no debe practicar o apoyar la discriminación en la contratación, remuneración, acceso a la capacitación, promoción, despido o jubilación basado en el género o cualquier otra condición que pueda dar origen a la discriminación, igualmente no debe permitir ningún comportamiento que sea amenazador, abusivo, explotador o sexualmente coercitivo, incluyendo gestos, lenguaje, y contacto físico en el lugar de trabajo y, donde sea aplicable, en residencias y otras instalaciones para el uso de los empleados ofrecidas por la empresa.

El estándar SAI 8000, una norma enteramente creada a impulsar condiciones de trabajo digno, creada por la organización Social Accountability International, y que mediante un sistema de verificación por terceras partes, establece los requisitos voluntarios a ser cumplidos por los empleadores en el lugar de trabajo, incluyendo los derechos de los trabajadores, las condiciones en el centro de trabajo y los sistemas de gestión, lo que puede suponer que sea la más relacionada con el principio de igualdad a nivel laboral.

Es de suponer que la existencia de todas estas iniciativas que tienen como eje central la responsabilidad social, ha llevado a las empresas a ser más transparentes de lo que eran en el siglo pasado, a través de la publicación de informes anuales sobre su situación actual con respecto las múltiples dimensiones de la RSE, basta con dirigirnos a las páginas web de variadas empresas principalmente las multinacionales y comprobar dicha afirmación.

Por lo que se nota que al implementar prácticas de Responsabilidad Social también existe una concienciación con respecto a los problemas que existen en estas organizaciones, para nuestro caso el tema de la discriminación en el empleo en la ocupación y específicamente la igualdad de género. Por ello, la existencia de mecanismos para la realización de dichos 
informes anuales, o, también denominados memorias de sostenibilidad, incluyen además un conjunto de indicadores de desempeño en diferentes ámbitos, información que por sí sola cualquier empresa no estuviera dispuesta a brindar lo que ha permitido que cualquier público pueda enterarse de diversos aspectos y prácticas que realiza una organización.

De interés están los relacionados con el tema en cuestión, por ejemplo los informes que siguen los lineamientos del Global Reporting Initiative (GRI), y que deben contener una gestión de la dimensión social, específicamente los relacionados con las prácticas laborales, trabajo digno y derechos humanos, muestran indicadores de desempeño tales como: la relación entre salario base de los hombres con respecto al de las mujeres, desglosado por categoría profesional así como el número total de incidentes de discriminación y medidas correctivas adoptadas.

Precisamente, en la evaluación del desempeño social, específicamente en dos sub-categorías (prácticas laborales y derechos humanos), se valoran los siguientes aspectos: el primero relacionado con la diversidad y la igualdad de oportunidades, en el mismo se debe incluir la composición de los órganos de gobierno y el desglose de la plantilla por categoría profesional, sexo, edad, pertenencia a minorías y otros indicadores de diversidad (G4-LA12).

El segundo, relacionado con la igualdad de retribución entre hombres y mujeres, que mide la relación entre el salario base de los hombres con respecto al de las mujeres, desglosada por categoría profesional y por ubicaciones significativas de actividad (G4-LA13). El tercero, relacionado con la no discriminación, busca calcular el número de casos de discriminación y las medidas correctivas adoptadas en la organización (G4-HR3) 
Global Reporting Initiative (GRI), organización cuyo fin es impulsar la elaboración de memorias de sostenibilidad en todo tipo de organizaciones, produce un completo marco para la elaboración de Memorias de Sostenibilidad, cuyo uso está muy extendido en todo el mundo. El marco incluye la Guía para la elaboración de memorias que establece los principios e indicadores que las organizaciones pueden utilizar para medir y dar a conocer su desempeño económico, ambiental y social

Ahora bien, que las empresas sigan estos lineamientos no quiere decir que tienen buenas prácticas con respecto al tema de la igualdad, pues, aunque en principio, hay transparencia en la comunicación de dichos datos, no es suficiente dicha información para determinar si en efecto existe o no desigualdades y discriminación en el trabajo por razón de sexo. Lo que supone para las organizaciones y los académicos un desafío, trabajar a futuro en la creación de otros indicadores que representen la realidad misma de la situación en las empresas.

En este sentido, se sugiere la utilización de la propuesta de indicadores del Departamento del trabajo (2010) que corresponde a un marco completo no solo para realizar el diagnostico empresarial a nivel básico, sino que va más allá a un nivel avanzado, que busca evaluar en diferentes ámbitos lo que está haciendo y lo que debería hacer la organización en materia de igualdad de oportunidades de manera integral y transversal (Véase Anexo 5)

A partir de todo lo anterior, es evidenciable como las empresas como parte fundamental de nuestra sociedad influyen en el sistema económico y social, por lo que se convierten en parte activa para la resolución de las situaciones de desigualdad laboral que se dan entre mujeres y hombres, debido a ello, la Responsabilidad Social supone también una alternativa para la consecución de la igualdad efectiva y real, lo que significa ofrecer condiciones de trabajo igualitarias no solo en el sistema de selección sino 
también en la promoción, las retribuciones, la formación y ante todo en la conciliación de la vida profesional y personal

Puesto que a pesar que existe una mayor legislación, que busca la igualdad de oportunidades entre hombres y mujeres, es insuficiente, pues la discriminación salarial, el mayor desempleo femenino entre otras situaciones mostradas en el texto, demuestran que la igualdad plena, efectiva y real, es hoy un asunto pendiente que precisa de nuevos instrumentos jurídicos o no, es por ello nuestra defensa ante este tipo de movimientos como la RSE que se alza como un apoyo ante nuestros sistemas jurídicos para apoyar la consecución de la igualdad.

No hay que olvidar que también es necesario una mayor concienciación de los derechos y no solamente a nivel educativo, sino también en la empresa pues de esa manera ayudará en gran medida a que no solo las mujeres lo conozcan y luchen, sino también la sociedad en su conjunto, también responsable que hoy en día aun exista el fenómeno de las desigualdades en el trabajo, en efecto también contribuirá a producir un rechazo colectivo en el caso que se presencie este tipo de situaciones.

Tampoco se puede olvidar el rol de los gobiernos, a través de los incentivos a las empresas y otros actores sociales, para destacar y resaltar las buenas prácticas en la materia y asegurar la replicabilidad en otros ámbitos. Un ejemplo claro de esto es, el distintivo Igualdad en la Empresa creado por el Ministerio de Igualdad en 2009, como una marca de excelencia en igualdad que busca servir de estímulo y reconocimiento a aquellas organizaciones de cualquier tipo comprometidas con la igualdad a través de la creación de políticas de igualdad de trato y de oportunidades en las condiciones de trabajo, en los modelos de organización y en su responsabilidad social. 
Promover la responsabilidad social de las empresas, ya hace parte de las estrategias de la Comisión Europea, pues de esta manera se contribuye al logro de los objetivos de la Estrategia Europa 2020 para un crecimiento inteligente, sostenible e integrador. No es de extrañar entonces, que muchas iniciativas asociadas a la RSE ya hayan incluido la igualdad de género en sus aspectos a evaluar, lo que en principio daría a entender que si las empresas se involucraran en prácticas de RSE se contribuiría al logro de este objetivo, por lo que analizaremos de qué forma está abarcado este tema en las herramientas disponibles y más conocidas para las empresas en este ámbito.

A nivel país, en Brasil una herramienta de gestión denominada Indicadores Ethos para Negócios Sustentáveis e Responsáveis, promovida por el Instituto Ethos la cual a través de indicadores busca medir el desempeño de las organizaciones que acceden mediante una encuesta, en este sentido, vemos en la evaluación del público interno, un aspecto como lo es el respeto al individuo que está asociado a la valoración de la diversidad; el compromiso con la no discriminación y, la promoción de la equidad racial y de género.

En estas categorías, principalmente se busca valorar no solo las políticas internas sino también de manera porcentual la proporción de colectivos como los discapacitados, minorías étnicas y las mujeres, sobre el total de empleados de la organización, dependiendo del tipo de cargo y edad, asimismo, el salario promedio mensual durante tres periodos anuales.

A simple vista, después de hacer un recorrido por las distintas herramientas en materia de RSE se podría suponer que al implementar estrategias de sostenibilidad empresarial es mayor el compromiso de las empresas en temas de promoción de igualdad en el trabajo, sin embargo, el adecuarse a una de las iniciativas, implica en primera medida que las organizaciones comunicasen que están haciendo en este ámbito para acabar 
con las desigualdades en materia laboral. No obstante, sólo están divulgando información puntual, los requeridos por las diversas herramientas como por ejemplo ¿cuál es la proporción de un grupo sobre el total de los empleados?

Es de resaltar en este punto, que las diferentes iniciativas incluyan dentro de sus requisitos la evaluación de este aspecto social, por lo que hoy en día es posible encontrar mayor información voluntaria al respecto y con enfoque de género, situación que se debe además a un mayor interés de las empresas en este ámbito reforzada por los avances de los últimos años en temas de RSE.

Ahora bien, un porcentaje no dice si realmente en la empresa haya igualdad de oportunidades, se puede afirmar entonces que en una empresa se cumple el principio ¿a partir de cuánto? ¿Si la proporción es mayor que un $50 \%$ del total de los empleados?, ¿cómo se mide si hay igualdad real?

Se puede estudiar un caso hipotético en el cual se evalúa a una empresa de productos de belleza, en su informe de sostenibilidad afirman que "se encuentran fuertemente comprometidos con la promoción de la igualdad de género pues un $70 \%$ de su plantilla está conformada por mujeres" ¿podemos decir entonces que hay igualdad de género?

En principio sí, aunque en teoría existe un fenómeno denominado segregación horizontal en el cual, los géneros se concentran en determinados sectores de producción y empleos específicos, entonces ¿éste no sería el caso? ¿No sería mucho más relevante esta cifra si fuese una empresa metalmecánica conformada históricamente por hombres?

Continuando con el caso hipotético, de los cargos directivos solo un $10 \%$ es ocupado por mujeres, con respecto a los salarios, los hombres ganan un $20 \%$ más que las mujeres, pero esta empresa por asuntos de estrategia prefiere no divulgarlo, es entonces, cuando cambia la situación, pues ya no 
se ve tan claro que esta sea una empresa líder en temas de equidad de género, pues esta situación corresponde a un fenómeno llamado segregación vertical, que ocurre cuando se produce esta concentración en determinados grados y niveles de responsabilidad.

Se puede concluir entonces, que las cifras por si solas no determinan que exista igualdad de oportunidades, específicamente la promoción de la igualdad de género, pues en primera medida, las empresas no siempre están dispuestas a divulgar voluntariamente toda la información requerida, no obstante, si es evidente un aumento de la transparencia a nivel de información por parte de las empresas a los diferentes públicos y eso es gracias a la RSE.

Se evidencia, además, que las iniciativas no pasan de ser meras declaraciones de intenciones, es decir, se basan en la transcripción de derechos fundamentales y de los convenios fundamentales de la OIT (para nuestro caso, la eliminación de la discriminación en materia de empleo y ocupación que incluye el convenio sobre igualdad de remuneración núm. 100 y el convenio sobre la discriminación en empleo y ocupación núm. 111), pero no van más allá de cómo conseguir el logro de una igualdad efectiva, ni de brindar herramientas reales que ayuden a las empresas a prevenir estos escenarios, por lo que en definitiva no proponen cuestiones diferentes a lo que se encuentra en la legislación.

Al respecto, sobre las herramientas reales se sugiere utilizar el conjunto de indicadores proporcionados en el Anexo 5 y que tienen como base la propuesta de (Departamento del trabajo, 2010)

Asimismo, según el análisis de Giner sobre la relación entre los derechos humanos y las empresas trasnacionales a través de asunción de códigos voluntarios de conducta, este jurista especializado en derechos 
humanos los reprocha sistemáticamente, su discrepancia se origina en dos sustentos: "el (i) no contribuir significativamente a las mejoras sociales imprescindibles, ya que no miden objetivamente lo que las empresas hacen en el terreno -y no están designados para ello-; y (ii) el no contar con los mecanismos de control, seguimiento y supervisión adecuados que permitan condenar a las empresas que contravienen estos códigos y reforzar la implementación de sus disposiciones" (2008, p.77).

Por lo que al implementar una iniciativa de RSE, se debe evaluar no sólo el proceso de gestión sino también los resultados, e incluir la igualdad de oportunidades dentro de los criterios de gestión, con la exigencia específica de fomentarla y garantizarla, teniéndola en cuenta en los planes, estrategias y valorando, en los resultados cualitativos y cuantitativos, las repercusiones y consecuencias de estas políticas. Adicionalmente, evaluar la calidad de la información sobre aspectos de RSE proporcionada en la documentación y en las memorias públicas accesibles de diversas organizaciones.

\subsection{Acciones concretas de las empresas españolas en Igualdad de Género}

En este apartado se busca identificar y resaltar las prácticas con respecto a la igualdad de género en algunas empresas del IBEX35 ${ }^{155}$ desde una visión crítica, se toma como referencia estas empresas por estar en el punto de mira de la población española, su visibilidad y además por la disponibilidad de información voluntaria que proporcionan. A nivel muy

155 Véase Listado de empresas del IBEX 35 en el apéndice. 
general, son destacadas por ser líderes en términos de sostenibilidad empresarial.

Para ello, se validó con la información proporcionada por las mismas empresas, sin entrar de lleno en el uso que las empresas hacen de las memorias de responsabilidad social e informes de gestión -puramente informativo o como herramienta fundamental para la rendición de cuentas o la gestión y control interno de las estrategias de la compañía-, se escogió de manera aleatoria las experiencias y prácticas que están llevando a cabo en materia de igualdad de género, por lo que recurrimos a esos informes de consulta pública, pues en el fondo se busca que otras empresas u organizaciones puedan replicar o mejorar dichas prácticas en la medida en las que les sea posible, o tomarlas como punto de origen para desarrollarse en este sentido.

En el pasado era impensable que las empresas proporcionaran tanta información con respecto a sus prácticas laborales e internas, hoy en día debido a la alta exigencia de los grupos de interés y la incorporación de los programas de responsabilidad social independientemente de cuál es su propósito final ya sea la mejora de la reputación corporativa o el desarrollo de la parte ética de las organizaciones es más fácil encontrar una mayor transparencia en cuanto a datos se refiere, por ejemplo, aquellas empresas que utilizan como guía el estándar GRI publican el indicador G4-HR3 concerniente a los "Incidentes de discriminación".

De hecho, esto además es una consecuencia del artículo 45.1 de la Ley Orgánica 3/2007, de 22 de marzo, para la igualdad efectiva entre mujeres y hombres, en el cual se establece que "las empresas están obligadas a respetar la igualdad de trato y de oportunidades en el ámbito laboral y, con esta finalidad, deberán adoptar medidas dirigidas a evitar cualquier tipo de discriminación laboral entre mujeres y hombres, medidas que deberán 
negociar, y en su caso acordar, con los representantes legales de los trabajadores y trabajadoras en la forma que se determine en la legislación laboral".

De igual manera, la LOIMH en su Título VII da la oportunidad de realizar de manera "voluntaria de acciones de responsabilidad social por las empresas en materia de igualdad, que pueden ser también objeto de concierto con la representación de los trabajadores y trabajadoras, las organizaciones de consumidores, las asociaciones de defensa de la igualdad o los organismos de igualdad. Específicamente, se regula el uso de estas acciones con fines publicitarios."

A continuación, detallaremos las experiencias de estas compañías, antes de eso es importante rescatar un conjunto de medidas a tomar para favorecer el acceso de la mujer a cargos directivos que proporciona la consultora Grant Thornton España (2017) a partir de las soluciones que conjuntamente proporcionan los directivos, como se evidenciará mas adelante, muchas de las iniciativas de algunas de las empresas españolas se acercan a estas medidas.

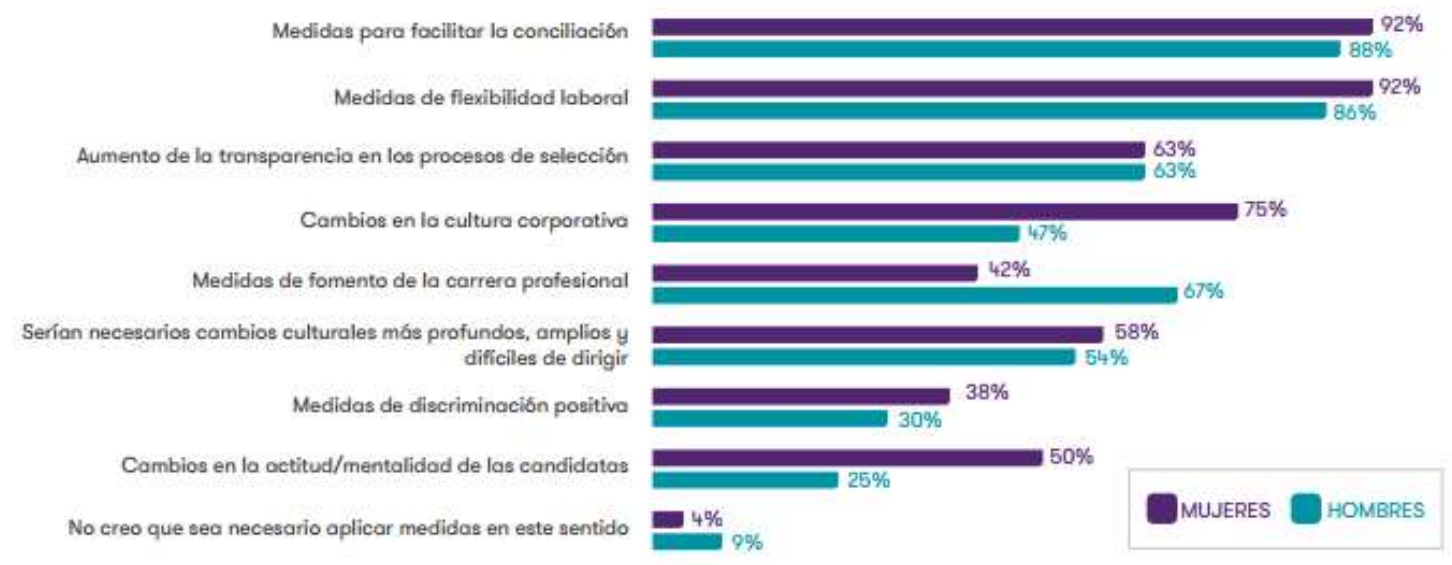

Gráfico 36. Soluciones conjuntas entre hombres y mujeres en España. Fuente: Grant Thornton España (2017, p. 14) 


\subsubsection{Análisis de caso: Banco BBVA ${ }^{156}$}

\section{La diversidad de género es uno de los temas cruciales en BBVA para mejorar} la calidad laboral, por lo tanto, disponen de un Plan Global de Diversidad de Género, sus principales actuaciones son en:

- Maternidad ${ }^{157}$, en la que se ha puesto en marcha la elaboración de un archivo que recoge medidas de apoyo para los padres en el cuidado de los hijos. El objetivo principal en este aspecto consiste en eliminar

156 La mayoría de la información fue extraída del informe de responsabilidad social "BBVA en 2014: Trabajamos por un futuro mejor para las personas" y la traducción al español del informe de ONU Mujeres sobre compañías que lideran los principios del empoderamiento de las mujeres, se encuentra disponibles en las URL:

https://accionistaseinversores.bbva.com/TLBB/micros/bbvain2014/images/BBVAen2014 ca st marcadores.pdf

http://library.pcw.gov.ph/sites/default/files/Companies Leading the Way.pdf

http://bancaresponsable.com/informacion-de-responsabilidad-corporativa-2011/banca-

responsable/recursos-humanos/

http://bancaresponsable.com/los-premios-wlmt-reconocen-a-bbva-por-su-innovacion-en-lagestion-de-la-diversidad/30/10/14 noticia

157 Para las madres, en una primera etapa, la licencia de maternidad está cubierta por una persona con calificaciones similares con el fin de impedir que las mujeres sentir ningún tipo de presión o de culpa debido a su embarazo. Las mujeres se van sabiendo que sus colegas no serán sobrecargados por su trabajo, y que BBVA les garantiza su mismo puesto de trabajo después de terminar su licencia de maternidad. Cuando vuelve a trabajar, se proporciona soporte para un par de semanas por un tutor personal, que puede ser su propio jefe. El objetivo del profesor es hacer más fácil el retorno, explicando las noticias y los cambios que puedan haber ocurrido en el lugar de trabajo en su ausencia, y guiándola a través de ellos. Además, después de un período de aproximadamente un año, una entrevista de seguimiento se lleva a cabo con la madre con el fin de obtener un conocimiento en profundidad de su experiencia y detectar posibles áreas de mejora. 
todos los impedimentos para el desarrollo profesional de las mujeres en el grupo. A través de medidas para mejorar el equilibrio entre maternidad y una carrera profesional las cuales son tres: (i) baja por maternidad de larga duración cubierta, (ii) sala de teletrabajo y (iii) tutoría después salir de la maternidad).

- Promoción, uno de los proyectos el Plan Equilibra, para establecer planes de carrera y sucesión para el colectivo de mujeres, así como la elaboración de un índice, el índice de velocidad, que mida el grado de diversidad por área o país.

- Sensibilización, creación de talleres específicos sobre diversidad y flexibilidad, la comunicación de historias de éxito sobre mujeres y el fomento de encuentros de desarrollo profesional entre mujeres profesionales que destacan en su función y los responsables de las áreas de negocio.

- Programas de coaching y mentoring se han centrado en el talento femenino para potenciar su desarrollo profesional e incrementar la figura femenina en puestos de relevancia. Además, tutorización y apoyo a las mujeres que se reincorporan a su puesto tras una baja maternal.

La compañía BBVA fue galardonada en los Premios Women Leadership Management \& Talent WLMT, que concede la consultora Intrama en colaboración con la Comunidad de Madrid y el Ministerio de Sanidad, Servicios Sociales e Igualdad, su iniciativa genera! es una web de diversidad de género. Esta web es considerada un vehículo para sensibilizar a las más de 100.000 personas de BBVA en todo el mundo sobre la importancia que tiene la igualdad de oportunidades. Con la puesta en marcha de iniciativas corporativas, locales, y proyectos a partir de las ideas planteadas a través de 
esta plataforma de networking, en distintos países en los que la organización está presente.

La compañía además mantiene un marco de colaboración con el Ministerio de Sanidad, Servicios Sociales e Igualdad "Empresas por una sociedad libre de violencia de género". También ha firmado su compromiso expreso con Los Principios para el Empoderamiento de las Mujeres de la ONU, del Charter europeo de la diversidad, como entidad adherida a la red de promoción de la diversidad e inclusión Catalyst ${ }^{158}$ y, en España, como entidad colaboradora de la Red Concilia del Ayuntamiento de Madrid.

En cuanto a la acción social, en la educación y en el apoyo a los emprendedores, especialmente a la figura de la mujer emprendedora, con la realización del programa Women Entrepreneur Executive School.

\footnotetext{
158 Las investigaciones de Catalyst han sido mencionadas durante todo el texto. Fundada en 1962 es la principal organización sin fines de lucro que amplía las oportunidades para mujeres y empresas (Prime \& Salib, 2015). En la actualidad, son una buena fuente para el conocimiento sobre género y liderazgo inclusivo en el negocio. A través de sus investigaciones se ha logrado conocer la realidad de la igualdad de género en el trabajo, principalmente en cuatro aspectos: (i) Equidad en el liderazgo empresarial: entendiendo el contexto y la representación en la sociedad en el lugar de trabajo, (ii) Caminos de carrera: saber por qué persisten ciertas barreras para alcanzar la igualdad en los lugares de trabajo alrededor del mundo, (iii) Aumentar la efectividad de los líderes: identificando cómo los líderes individuales pueden cerrar brechas y mitigar las barreras dentro del lugar de trabajo, (iv) Práctica corporativa: mostrar cómo las organizaciones pueden cerrar las brechas de género y mitigar las barreras dentro del lugar de trabajo. Cfr. http://www.catalyst.org/whatwe-do
} 


\subsubsection{Análisis de caso: Banco Santander}

Lo primero que hay que resaltar de esta compañía es que su presidenta Ana Botín, es una mujer. En su informe de responsabilidad social la mayoría de los datos en cuanto a los empleados están segregados por género, lo cual implica una mayor transparencia por parte del Banco. No disponen de una política específica de igualdad, lo cual no implica que la empresa no se encuentre comprometida con estos asuntos, pues estas políticas pueden hacer parte de un código general de actuación lo que implica la transversalidad en toda la organización, que es mucho mejor, no se dice que este sea el caso.

Banco Santander cuenta iniciativas dirigidas a promover la equidad y también el desarrollo del talento femenino, como Sumando Talento o Take the Lead, dirigidos a mujeres en posiciones directivas o predirectivas de todos los países para impulsar el desarrollo del talento y el liderazgo femenino.

Asimismo, son patrocinadores del programa Women 50 (W50), impartido por la UCLA conjuntamente con la Anderson Business School y patrocinado por Santander Universidades. Este programa está dirigido a mujeres de entre 35 y 40 años, con alto potencial de desarrollo y con las habilidades y la experiencia requerida para convertirse en futuras líderes. En 2014, al igual que en ediciones anteriores, contó con la participación de directivas de Banco Santander de distintos países

En cuanto a iniciativas de acción social ${ }^{159}$ van encaminadas a fortalecer el emprendimiento femenino en países de Latinoamérica como por

\footnotetext{
159 La acción social, es una parte del desarrollo de la Responsabilidad Social de las empresas (no son equiparables los dos términos) corresponde a un aspecto de la dimensión interna o social en la gestión de las compañías. Según Fernández (2007, p. 16) "Se entiende por
} 
ejemplo en Brasil Parceiras em Ação, en donde se reconoce la labor de empresas que tienen de emprendimiento en comunidades desfavorecidas como objetivo promover la inclusión social, fomentar y para mujeres con rentas bajas.

Santander Microcréditos en Brasil, es un modelo de negocio inclusivo y cerca del $70 \%$ están destinados a mujeres empresarias, en grupos solidarios de 5-6 personas. El importe medio es de 700 euros sin necesidad de garantías adicionales. Y el plazo medio de 8,7 meses. (p. 69). En Chile, patrocinan el Premio Nacional Mujer Emprendedora en donde se reconoce el esfuerzo y la capacidad emprendedora de las mujeres de Chile. En su $13^{\mathrm{a}}$ edición se premió a seis.

\subsubsection{Análisis de caso: Iberdrola}

Iberdrola dispone de una "política de igualdad de oportunidades y conciliación" en la cual promueve diversas medidas enfocadas a fomentar el acceso al empleo, la formación, la promoción profesional y las condiciones de trabajo. Para los altos cargos, "Política de retribuciones de los altos

Acción Social Empresarial todo lo que la empresa hace para contribuir a eliminar las carencias que pueda haber en la sociedad en la que está implantada". Es decir, son acciones puntuales que tienen un alto impacto en la comunidad como grupo de interés, lo cual requiere de programas desinteresados y en ocasiones filantrópicos, aunque en el fondo tenga repercusiones positivas en la reputación de las compañías, para lo cual este aspecto puede ser considerado clave en algunas de sus estrategias. En el texto, es interesante visualizar estas acciones porque generan una huella en la sociedad si se busca desde el ámbito privado contribuir a la erradicación de las desigualdades. 
directivos" y un "Código ético". En materia de igualdad es firmante del Charter de la Diversidad desde 2009, cuyo compromiso se ha renovado en 2015.

El plan de igualdad de Iberdrola incluye medidas de protección para las personas víctimas de la violencia de género, en la cual además de difundir campaña del Ministerio de Sanidad, Servicios Sociales e Igualdad "Hay salida a la Violencia de Género", se ha creado un programa especial que incluye medidas de protección y apoyo a empleadas, para informar, acompañar y proteger a las víctimas de violencia de género.

Estas medidas están recogidas en el Plan de Igualdad de la Empresa, actualizadas en el VI Convenio Colectivo y cubren diversos aspectos del ámbito personal, económico y laboral de las personas afectadas. Entre las medidas más importantes, se pueden destacar ( $($ ) el apoyo económico frente a alquileres y gastos escolares derivados de traslados, (ii) permisos laborales y posibilidad de obtener una suspensión temporal de contrato, (iii) posibilidad de traslado a otros centros de trabajo, (iv) permiso de un mes sin sueldo sin alegar causa, $(v)$ flexibilidad de horarios, concesión de préstamos o anticipos personales, (vi) asesoramiento psicológico, médico y jurídico.

Además, esta empresa se encuentra orgullosa de ser "la primera empresa del IBEX-35 en implantar la jornada continua en España, como medida para fomentar la conciliación entre vida familiar y laboral"

No obstante, es interesante ver el contraste de sus resultados con las estadísticas propias, por ejemplo, en cuanto al indicador "Diversidad hombres/mujeres"160 a 2015 fue de un $77 \%$ para los hombres versus un $23 \%$ de mujeres. Los directores corporativos y de negocio eran 14 de los cuales el $100 \%$ eran hombres, en el caso de otros directores los cuales eran 6 , solo uno era mujer y los corporativos en otros países todos eran hombres. Lo que,

\footnotetext{
160 Esta información puede ser contrastada en la URL: http://www.iberdrola.es/sala-prensa/galeria/grupo-iberdrola/directores-corporativos/
} 
en principio, nos daría una primera alerta para la inclusión de las mujeres en estos altos cargos y demuestra la tesis que, aunque es aparentemente visible que existe un compromiso en esta empresa, es necesario hacer más pues las cifras demuestran todo lo contrario.

Sin embargo, hay que resaltar que los principios de no discriminación e igualdad de oportunidades aplicados en el Grupo Iberdrola se extienden a los países donde operan y están recogidos tanto en el Código ético como en diferentes convenios, políticas y procedimientos aprobados y puestos en práctica, como es el caso de: El VI Convenio colectivo y la Política de reclutamiento y selección, aplicados en España. El Convenio colectivo y las políticas de igualdad de oportunidades, de no discriminación por edad, de personas con discapacidad, de igualdad salarial, de acoso, y de flexibilidad en el trabajo, aplicados en el Reino Unido. El Convenio colectivo y las políticas sobre acoso sexual, sobre igualdad de oportunidades en el empleo, y sobre acoso y discriminación, de aplicación en los Estados Unidos.

Por último, las acciones del Grupo Iberdrola en materia de igualdad de género en el trabajo se han centrado principalmente en:

El fomento de la conciliación de la vida laboral y familiar de los empleados, que incluye medidas para hacer compatible la experiencia positiva de la maternidad y paternidad con una carrera profesional de éxito.

El desarrollo de relaciones laborales basadas en la igualdad de oportunidades, la no discriminación y el respeto a la diversidad.

El fomento de la diversidad y la inclusión social de colectivos vulnerables, a través del programa de voluntariado corporativo. 


\subsubsection{Análisis de caso: Inditex ${ }^{161}$}

Inditex dispone de un "Código de Conducta y Prácticas Responsables" y un procedimiento del Canal de Denuncias. Con respecto a la diversidad de la plantilla, ellos se sienten orgullosos pues la multiculturalidad es parte esencial, pues los más de 140.000 empleados del Grupo suman más de 83 nacionalidades y 45 idiomas, que se debe a su presencia internacional. Con respecto a las estadísticas, la alta dirección, lo conformaban 21 miembros de los cuales 4 eran mujeres (p. 149).

Uno de los pilares de su modelo de recursos humanos, es la gestión de un capital humano global: "hombres, mujeres, personas de diferentes edades y orígenes diversos pero que forman un equipo único". Inditex tiene un compromiso explícito con la igualdad y la no discriminación a través de la ratificación del proyecto Equal Diversidad Activa, en 2006 cofinanciado por la Comisión Europea.

Sus acciones de responsabilidad social están dirigidas por la Coordinadora Española del Lobby Europeo de Mujeres y la Fundación Carolina. Buscan impulsar la implantación de medidas que tiendan a reducir los desequilibrios entre hombres y mujeres en las empresas. Se trabaja con las comisiones de seguimiento en impulsar los acuerdos que afectan a todas las áreas (selección y contratación, conciliación, desarrollo) y en acordar

\footnotetext{
${ }^{161}$ La mayoría de la información de Inditex fue extraída de la información pública disponible en:

http://www.inditex.com/es/sustainability/employees/equality_conciliation

http://www.inditex.com/documents/10279/13717/Inditex_+Memoria_Anual_2014_web.pdf/5

bef1508-9aa7-49df-80d5-5b46f4295ac6

http://www.inditex.com/documents/10279/88163/Codigo-de-conducta-y-practicas-

responsables.pdf/79fc6e30-b94e-435a-957c-4e5b20f7f65d
} 
nuevas medidas que reafirmen el compromiso (protocolos de actuación en casos de acoso sexual y por razón de sexo, violencia de género, sensibilización) (p. 102)

Por otra parte, Inditex tiene un protocolo de actuación frente a eventuales discriminaciones por razón de sexo y frente al acoso sexual, en el que, ante la denuncia de cualquier empleado, se pone en marcha una investigación interna con la finalidad de averiguar los hechos y depurar eventuales responsabilidades.

El Grupo ha desarrollado planes de igualdad que incluyen medidas para favorecer la conciliación de la vida familiar y laboral como facilidades para la incorporación de la mujer tras su baja por maternidad o medidas de corresponsabilidad con la paternidad, facilidades para ajustar su jornada laboral al calendario escolar, o ayudas sociales, entre otras. Para el seguimiento de los planes de igualdad se ha creado una comisión que analiza su aplicación y resultados.

Una de las iniciativas a nivel internacional es la participación en Tamil Nadu Multi Stakeholder Initiative para un trabajo conjunto en la erradicación de formas de empleo abusivas en el sur de India a partir de programas dirigidos a las comunidades, mediante la implantación de medidas directamente en las hilaturas y apoyo a los cambios en políticas para una mayor protección de las mujeres (p. 63)

Otro programa consiste en la formación a mujeres en India a través del proyecto Shaki, conscientes de que la presencia mayoritaria de mujeres en el sector textil es una realidad presente en muchos de los países de la cadena de suministro de Inditex busca establecer sensibilización y prácticas de igualdad de género en las fábricas a partir de formación tanto a trabajadores 
como a supervisores y gerencia y así evitar y prevenir cualquier tipo de privación de los derechos de estas mujeres por cuestión de género.

A través de la alianza público-privada, y con la colaboración de la ONG india especializada en salud Swasti, 68 proveedores y 11 fábricas de este país recibieron durante 2014 formación sobre sensibilidad de género y la importancia de contar con mecanismos de prevención de discriminación o acoso sexual, incluyendo la creación de un comité de género en la fábrica. La formación se ha impartido a 195 participantes, entre trabajadores, supervisores y equipos gerenciales de las fábricas.

Con respecto a la parte de acción social, en 2014 sus programas fueron encaminados a la población bangladesí, en colaboración con ONGs a través de herramientas de empoderamiento de las mujeres rurales, en este sentido, 225 mujeres recibieron apoyo financiero para establecer negocios ( $p$. 122)

A pesar que existe aparentemente una promoción de la igualdad de género a nivel de plantilla en España, se nota que al especificar el tipo de contratación o de jornada, varia considerablemente. Por ejemplo, teniendo en cuenta la distribución de la plantilla por tipo de jornada a tiempo parcial, las mujeres son un $63 \%$ versus los hombres con un $28 \%$, mientras que a tiempo completo, los hombres son un $72 \%$ versus un $37 \%$ de las mujeres. (Grupo Inditex, 2014, pág. 91) 


\subsubsection{Análisis de caso: Telefónica ${ }^{162}$}

Dentro de los doce principales asuntos materiales ${ }^{163}$ para Telefónica, justo en el número 12 se encuentra la diversidad y no discriminación, que fue identificada en su matriz de asuntos sociales. Las mujeres representan un $38 \%$ de la plantilla y un $21 \%$ son directivas. En 2014 , Telefónica ha vuelto a ocupar puestos destacados en las listas de mejores lugares para trabajar en diferentes países y regiones donde opera la compañía, que elabora el instituto Great Place to Work ${ }^{\circledR}$, referente internacional en el análisis de las prácticas y políticas de gestión de personas y de las compañías.

Las acciones que en materia de conciliación de la vida familiar y laboral desarrolla Telefónica se encuentran:

- A nivel corporativo, en materia de jornada y horarios un amplio porcentaje de la plantilla disfruta de jornada continuada anual y de jornada continuada en verano para los meses de julio y agosto, fomentando las nuevas formas de trabajo flexible que permiten las nuevas tecnologías.

162 La mayoría de la información fue extraída del informe de sostenibilidad 2014 de Telefónica "Conecta con el futuro" que se encuentra disponibles en la URL:

http://informeanual2014.telefonica.com/sites/default/files/documentos/informesostenibilidad.pdf

163 La materialidad, es un análisis que debe realizar toda organización que se disponga a poner en marcha la responsabilidad social dentro de su estrategia global, es decir, "supone que la organización debe tener en cuenta las necesidades y expectativas de las partes interesadas en la toma de decisiones, afrontando todas las dimensiones de la RSC, así como todas sus actividades e impactos, directos e indirectos" Moneva (2005, p. 45), para ello debe priorizar los aspectos en los cuales va a ir enfocada sus acciones de manera periódica, lo que es relevante para la entidad. 
- Los empleados gozan de flexibilidad para escoger sus vacaciones, pudiendo compaginarlas con las vacaciones escolares.

- Dentro de los beneficios laborales, los empleados gozan de bonos guardería. En el Distrito Telefónica (España), sede de la Compañía con más de 10.000 empleados, existe también un servicio de guardería para empleados.

- En Alemania, los empleados disponen de un servicio para las familias. Se trata de un portal que les facilita aumentar su capacidad de flexibilidad laboral, ayuda con el cuidado de los niños, cuidado de mayores, etc.

Asimismo, otras medidas concretas:

Creación de espacios de divulgación, como el 'site' igualdad. A través de la Intranet, todos los empleados pueden acceder a un espacio de divulgación y comunicación con acceso directo a los Planes de Igualdad, protocolos de acoso y los compromisos suscritos con la dirección y representantes de los trabajadores en esta materia. En este site también se puede encontrar información puntual y actualizada de los trabajos que se van realizando en materia de igualdad.

El programa Women in Leadership que empezó en 2012 el cual pone en contacto a mujeres directivas de Global y CCDO. El objetivo de esta iniciativa es fortalecer las capacidades de las mujeres, su confianza y sus dotes de superación personal, y establecer una sólida red de mujeres directivas en Telefónica y aumentar su visibilidad. Se pretende también crear un entorno en el que puedan compartir experiencias relacionadas con la cultura organizativa, y buscar consejeros y patrocinadores que puedan apoyarlas. 
Una alianza entre el área de Sostenibilidad junto con el área de Recursos Humanos, organizan ciclos de entrevistas bajo el epígrafe 'La mujer en la empresa'. El objetivo es aportar desde la compañía al debate sobre el futuro de la mujer en el trabajo, la conciliación y su papel en la economía digital, en un contexto en el que se estima que hay más de 900.000 vacantes en empleos digitales en Europa a futuro.

Otro punto, a resaltar es que el grupo tiene desagregada las cifras por género, cargos ejecutivos y ámbito geográfico, lo que permite enfatizar en las mujeres directivas y mostrar una visión más amplia de como la mujer está representada en la compañía pues es una de las pocas empresas que lo proporciona, tal como lo vemos en el siguiente Gráfico:

Presencia de la mujer en el Grupo Telefónica por ámbito geográfico

$\%$ en plantilla $\quad \%$ directivas

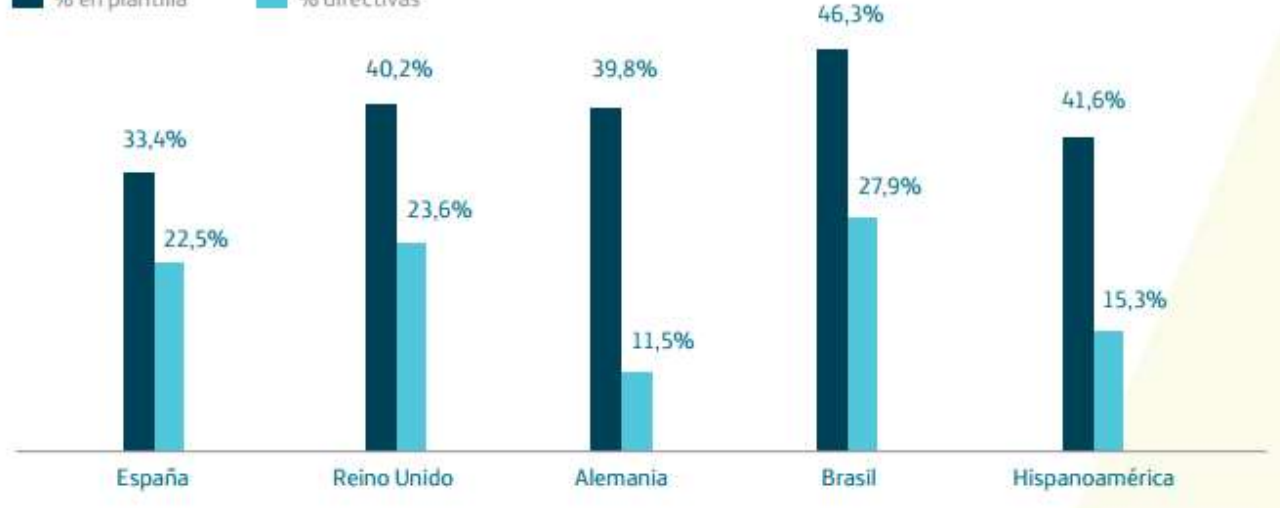

Gráfico 37. Presencia de la mujer en Telefónica. Fuente: Telefónica (2015, p. 71) 


\subsubsection{Análisis de caso: Renfe ${ }^{164}$}

Del total de la plantilla en 2014,1470 son mujeres lo que equivale a un $10,2 \%$. De 16 miembros del consejo de administración 3 son mujeres lo que equivale a un $18,75 \%$. En la estructura de dirección representan aproximadamente un $19 \%$, es decir, hay 156 mujeres versus 668 hombres. Un aspecto a resaltar en su informe de sostenibilidad es que todos sus datos laborales aparecen segregados por sexo, además su estructura de dirección se refleja detallado por edades y sexo, así como otras variables como los salarios y el tipo de contratación.

En general, comunican los objetivos o intenciones de su plan de igualdad y del convenio colectivo, pero no aparecen reflejadas unas medidas concretas o iniciativas realizadas para que se cumplan. Renfe se ha adhirió a la Red de Empresas por una Sociedad Libre de Violencia de Género. En 2014, se emitió en sus trenes de cercanías spot de la campaña 'Hay salida' contra la violencia de género y se colocaron vinilos con información para las víctimas de la violencia de género.

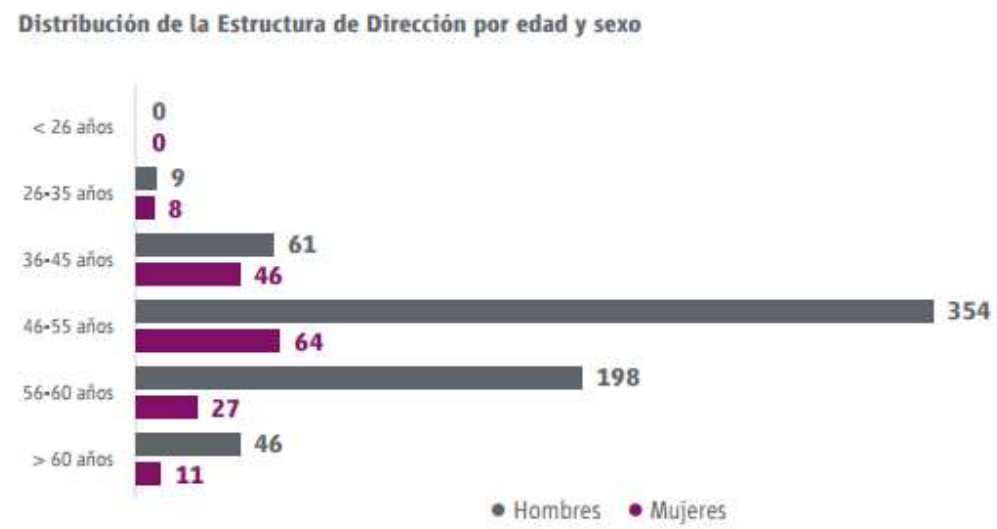

\footnotetext{
164 La mayoría de la información fue extraída del informe anual de responsabilidad social empresarial 2014 de Renfe que se encuentra disponible en la URL:

http://www.renfe.com/docs/renfe-informe-rse-2014-accesible.pdf
} 
Gráfico 38. Presencia de la mujer en la Dirección Renfe. Fuente: Renfe (2015, p. 72)

\subsubsection{Conclusiones preliminares}

Una primera conclusión al respecto es que si no existieran los informes o memorias de sostenibilidad sería mucho más difícil saber que están haciendo las empresas de acuerdo con sus objetivos sociales y ambientales, en el fondo, existe un fuerte vínculo entre las actividades que realizan las compañías en torno a la igualdad de género y a su responsabilidad social empresarial, lo cual permite reflexionar sobre la relación existente entre las mismas. No se puede hablar de igualdad de género en las organizaciones sin meterse de lleno en su responsabilidad social.

Se ha notado, que en el análisis de casos de empresas del IBEX35 y en otras empresas, están desarrollando su responsabilidad social empresarial, lo cual ha implicado que la mayoría se haya adherido voluntariamente a los siguientes estándares relacionados con contenidos y sistemas de gestión de RSC, razón por la cual existe una mayor preocupación y concienciación en aspectos sociales y ambientales: uno de ellos la igualdad de oportunidades en el empleo y la ocupación. Esos estándares son principalmente: 


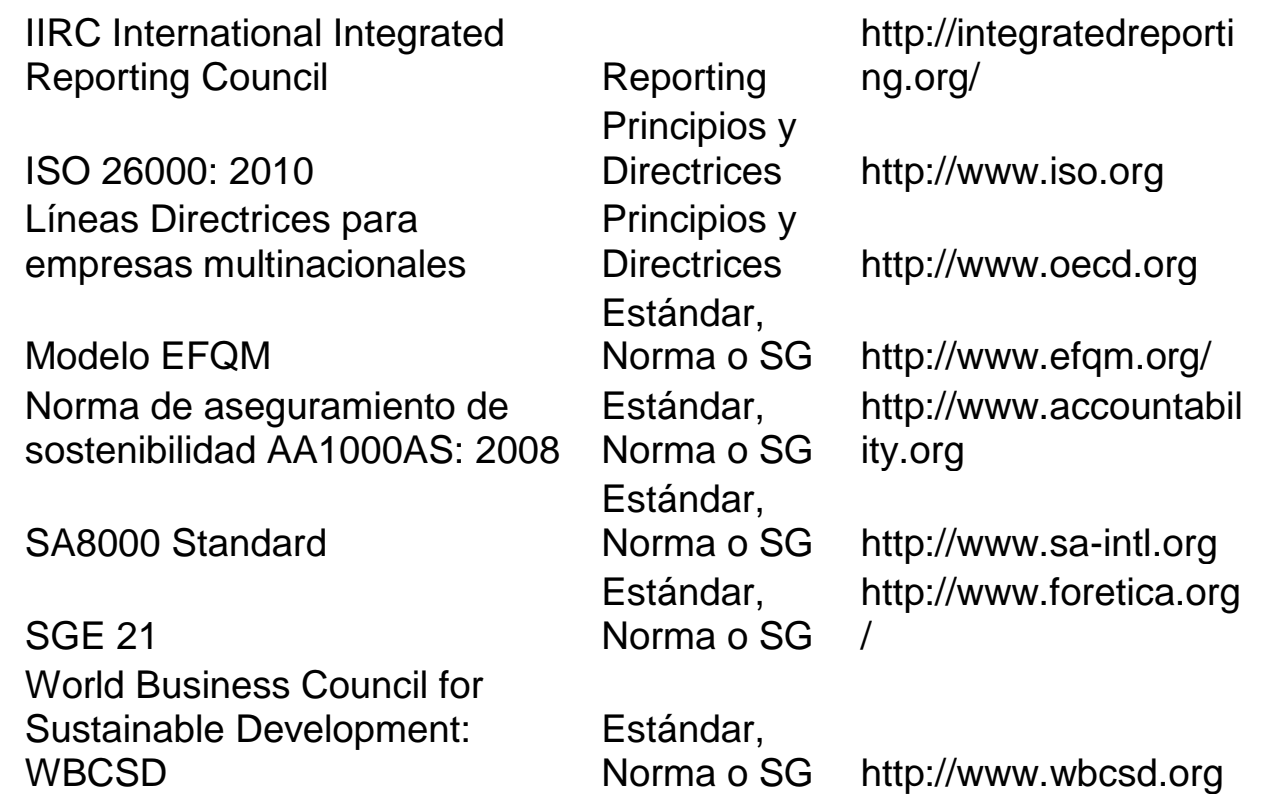

La incorporación del compromiso con la igualdad de oportunidades se ve reflejada en la evaluación de su dimensión social o interna: a través de un aspecto denominado gestión de la diversidad en las prácticas laborales que tiene que ver, por una parte, con los recursos humanos e integra otros factores que pudieran ser objeto de discriminación como la raza, la orientación sexual o la discapacidad. Por otra parte, también se encuentra en el gobierno corporativo, con la valoración del acceso de las mujeres a la junta directiva y cargos de responsabilidad. Así como a la protección de la maternidad para que no impida el desarrollo profesional de las mujeres.

El primer paso es identificar si las empresas tienen una política de diversidad, se promueve la diversidad, por ejemplo, a través de la creación de comités de diversidad, o de un plan de igualdad, si disponen de un protocolo de actuación frente a eventuales discriminaciones por razón de sexo y frente al acoso sexual y como está la situación actual en este ámbito con respecto a los datos aportados. 
Existe una variedad de políticas que incluyen el factor del género como aquellas políticas de reclutamiento y selección ${ }^{165}$, política de conciliación de la vida personal y laboral e igualdad de oportunidades, política de prevención de riesgos laborales, política de gestión del conocimiento. En este sentido, a nivel general "las políticas empresariales, por tanto, habrán de ir dirigidas a potenciar la autoestima y crear confianza entre sus trabaajdores como la más eficaz vacuna frente al miedo y los riesgos que le son inherentes." (Luelmo, 2012, p. 21)

Con respecto a la política de prevención de riesgos laborales, al observar los riesgos de la mujer trabajadora "resulta imprescindible incorporar un enfoque de género ya que existe una forma distinta de enfermar y accidentarse entre mujeres y hombres ya sea, bien como consecuencia de las propias diferencias biológicas, como por la definición u organización social del trabajo, que adjudica a las mujeres el desempeño de profesiones específicas, con sus factores de riesgo determinados." (Forética \& Secretaria de Estado de Igualdad, 2010, p. 75)

165 En este punto, es importante rescatar el estudio de Bodelón et al. (2014, p. 106) quien realiza una crítica interesante sobre la incorporación del enfoque de género en los procesos de selección, teniendo en cuenta que "son el primer escalón en el cual se construye la desigualdad de género en las empresas".

Resultado de la investigación en este sentido mostró que en la evaluación de una muestra de los planes de igualdad en empresas seleccionadas "en el $82 \%$ de los planes de igualdad no contienen datos en el diagnóstico sobre esta cuestión. Se debe destacar que únicamente en un $5 \%$ de los planes se afirma que las empresas disponen ya de un procedimiento para evitar la discriminación en el proceso de selección. En un $84 \%$ de los casos se contempla la creación de un procedimiento o se modifica el ya existente para prevenir la discriminación, aunque en el $69 \%$ de los planes no se detallan cuáles deben ser las medidas concretas para evitar la discriminación en el procedimiento de selección." 
Dentro de las conclusiones preliminares, empresas como Grifols muestra su responsabilidad social como algo aislado lo ven como la realización de acciones sociales. Por lo tanto la disponibilidad de información para diagnosticar que programas realiza en cuanto al ámbito de la igualdad resulta engorroso, incluso para conocer los datos de la relación porcentual entre mujeres y hombres hay que recurrir a otro tipo de informes como el de gobierno corporativo.

En algunas empresas, la brecha salarial entre hombres y mujeres son consecuencia de la evolución de la estructura de la plantilla, no como resultado de una política discriminatoria, dado que en cada categoría profesional se encuentran agrupados: Distintos niveles profesionales con diferente proporción entre hombres y mujeres, y colectivos que pertenecen a distintas áreas geográficas, en distintas monedas y bandas salariales.

Se tiene claro que con la ley de igualdad y su novedad de los planes de igualdad se está garantizando que las empresas mayores de 250 empleados busquen la promoción de la igualdad en la organización. Pero esto no llega a la sociedad en su conjunto pues hay que tener en cuenta que se deja de lado a las pequeñas y medianas empresas, en España según el DIRCE, a 1 de enero del año 2014 hay en España 3.114.361 empresas, de las cuales $3.110 .522(99,88 \%)$ son PYME (entre 0 y 249 asalariados).

Se evidencia que las compañías, divulgan como una de las medidas para el desarrollo de la igualdad en las organizaciones los planes de igualdad, cuando es su obligación pues está exigido en la ley de igualdad. La idea desde la Responsabilidad Social es que las acciones, programas e iniciativas de las empresas puedan ir más allá de lo exigido legalmente.

Por último, hay que resaltar la importancia actual de la Responsabilidad Social de la Empresa pues según Molina (2006, p.20) en 
sus prácticas "tiene especial cabida la cuestión de la conciliación. En esta dirección convergen diferentes estrategias ya recogidas. Por un lado, la búsqueda de un desarrollo económico socialmente sostenible implica no sólo la incorporación de la mujer al mercado de trabajo, sino un diferente reparto, más equitativo, de los tiempos de trabajo."

\subsection{Hacia un modelo de RSE con enfoque de género}

Cuando las empresas $u$ organizaciones de distinto tipo tienen de manera intrínseca su compromiso con la igualdad de género ${ }^{166}$, es indiscutible una evolución en el rol de las mismas, pues sin contar con que ya tienen desarrollada una política interna que desarrolle estos temas, esto lo podemos ver reflejado e integrado en todos sus procesos de gestión ${ }^{167}$ lo cual repercute en la eliminación de las desigualdades en el mercado de trabajo.

${ }^{166}$ Lo que se busca en el fondo es que en el ámbito privado se desarrolle un rol activo en lo concerniente a los derechos humanos, para evitar una situación que en la doctrina se denomina complicidad silenciosa se basa en la "aceptación creciente de que la influencia de las empresas en los gobiernos trasciende el ámbito comercial y económico y que existe culpabilidad en no ejercer influencia en estas circunstancias. Por ejemplo, la inacción o la actitud de tolerancia por las empresas ante situaciones de discriminación sistemática en el empleo de ciertos grupos por motivos de origen étnico o de género" (Giner, 2008, p.83).

${ }^{167}$ Las prácticas para promover la igualdad de género comienzan con una serie de acciones que abordan la forma de gestionar una organización. Las medidas que se evalúan en este sentido empiezan por (i) Facilidades de elección de horarios de trabajo/existencia de fórmulas de trabajo flexible, (ii) Facilidades para la obtención de permisos especiales. (iii) Política de igualdad de oportunidades en la contratación, (iv) Política de igualdad de oportunidades para acceder a oportunidades laborales, (v) Existencia de un presupuesto en 
Ya Barberá (2004) proporcionó un marco (véase Gráfico) para identificar los obstáculos que pueden estar provocando la ausencia de mujeres en cargos de responsabilidad en cualquier tipo de organización, lo cual puede servir para hacer una primera aproximación, análisis y evaluación de las barreras que están provocando esta situación de desigualdad en las compañías de cualquier sector para después implementar propuestas específicas de acción.

En este sentido, las principales áreas de actuación en materia de igualdad vinculadas a criterios de RSE se enmarcan en aspectos como: la conciliación y corresponsabilidad ${ }^{168}$; la diversificación profesional; la inclusión social y violencia de género; la representación en puestos de alta dirección y promoción profesional y; la prevención de riesgos laborales con enfoque de género (Forética \& Secretaria de Estado de Igualdad, 2010, p. 22)

No se ha querido centrar en la razón por la cual existe esta responsabilidad en las empresas $u$ organizaciones, se podría decir que se realiza por la misma imposición del mercado de trabajo o, de manera natural como parte de su conciencia social, no obstante, sí hay que resaltar que el impacto social que genera es positivo, pues forja la replicabilidad en el resto

la empresa destinado a apoyar la flexibilidad y la diversidad (Arredondo, Velásquez \& de la Garza, 2013).

${ }^{168}$ En este sentido, son de importante aplicación las medidas de flexibilización de la relación laboral, de los tiempos de trabajo, de flexibilización del lugar de trabajo, las prestaciones sociales de las empresas relacionadas con la conciliación de la vida laboral, personal y familiar, la cultura y políticas de Recursos Humanos y abordar el seguimiento de unos indicadores. (Forética \& Secretaria de Estado de Igualdad, 2010, p. 25) 
de compañías que quieren emprender en el camino de una responsabilidad social de género RSG ${ }^{169}$.

De hecho, según (Gala, 2010, p. 109) "la RSE es una nueva forma de fomentar y avanzar en la puesta en práctica de las políticas de igualdad y no discriminación" cuestión que se ve reflejada en la puesta en práctica por parte de algunas Comunidades Autónomas (Galicia, Cataluña y Andalucía), que están adoptando medidas concretas en este ámbito.Aclarando que esta responsabilidad social implica siempre ir más allá de lo que resulta obligatorio por ley o convenio colectivo y que, en consecuencia, el mero cumplimiento de lo previsto en aquéllos no constituye un comportamiento socialmente responsable en sentido propio sino el simple cumplimiento de la legalidad vigente.

De acuerdo con Maxfield, Cárdenas \& Heller (2008) cuyo enfoque se basa en las mejores prácticas del ambiente latinoamericano con respecto a la presencia directiva femenina concluyen que (i) es mejor, las intervenciones orientadas a la cultura organizacional pues estas pueden tener un éxito mayor en comparación con aquellas intervenciones que se basan en la imposición de reglas, (ii) es importante la estimulación de las mujeres con potencial de crecimiento y (iii) su desarrollo a través de programas de mentorías eficaces y eficientes, (iv) promover las redes de apoyo para las mujeres que no vienen de familias de negocios, en este sentido, las mujeres que disponen de una procedencia marcada en el ámbito empresarial debido a sus familiares y

\footnotetext{
169 Este término se ha venido utilizando en la doctrina, por Kahale (2013) quien, a partir de un trabajo sobre Responsabilidad Social de Género, desde la perspectiva del derecho del trabajo fue ganador del V Premio Forética-MSD a la investigación en ética empresarial.
} 
conocidos tendrán mucha más ventaja y deberán aprovecharla para posicionarse como líderes.

De acuerdo con Cabanas, Morales \& Molinero (2014, p. 45) es preciso poner en práctica una serie de medidas y que se mantengan en el tiempo, las cuales empiezan por un "1. Fuerte apoyo visible por parte de la Alta Dirección, expresado como prioridad estratégica y progresivamente monitorizado y evaluado. 2. Programas de formación, de coaching y mentoring para el desarrollo del liderazgo para las mujeres. 3. Incluir políticas de recursos humanos que aseguren que haya mujeres tanto en los procesos de reclutamiento como de promoción. 4. Asegurar que las políticas de evaluación de rendimiento, liderazgo y retribución son diversas y neutrales con respecto al género."

\begin{tabular}{|c|c|c|}
\hline \multicolumn{2}{|c|}{$\begin{array}{l}\text { Condicionantes } \\
\text { externos-organizacionales }\end{array}$} & \multirow{2}{*}{$\begin{array}{c}\begin{array}{c}\text { Condicionantes } \\
\text { internos-personales }\end{array} \\
\text { Condicionantes personales }\end{array}$} \\
\hline Cultura organizacional & Politicas organizacionales & \\
\hline Valores y normas & Pollicas de salección & Metas protesionales \\
\hline Redes y grupos de poder & Polliticas de evaluación y promoción & Mothación de logro \\
\hline Estio y orientacion de dirección & Politicas de horatios, viajes y traslados & Intereses prolesionales \\
\hline Poder de decision y lbertad de actuación & Politica salarial & Satisfacción con la cultura y politicas \\
\hline $\begin{array}{l}\text { Valía y aportacion prolesiónal } \\
\text { Clima y relaciones }\end{array}$ & Politica de formación & $\begin{array}{l}\text { Satistacción con el desarrolo de } \\
\text { carrera }\end{array}$ \\
\hline $\begin{array}{l}\text { Acthudes y omportamiantos de respeto } \\
\text { Comunicación } \\
\text { Instalaciones, entomo de trabajo y servicios } \\
\text { OSarta educativa (solo en universidades) }\end{array}$ & Polticas de igualdad de oportunidades & $\begin{array}{l}\text { Satisfacción con el reconocimiento } \\
\text { de la valia }\end{array}$ \\
\hline
\end{tabular}

Gráfico 39. Categorías de indicadores en el Análisis de Barreras. Fuente: (Barberá, 2004, p. 47)

No obstante, también resulta de vital importancia la implicación de la dirección de la empresa en la implantación y/o desarrollo de las políticas y/o planes de igualdad, en este sentido, se ha comprobado que "cuando la 
dirección de la empresa apuesta claramente por conseguir la igualdad efectiva a través de un plan de igualdad, lo impulsa y cree en ello, el proceso tiene más posibilidades de ser satisfactorio" (Bodelón et al., 2014, p. 53)

Aunque desde las corporaciones se han estado realizando esfuerzos, según Carter \& Silva (2010) la última década era una oportunidad para el desarrollo de las mujeres, como se ha constatado las desigualdades continúan. En este sentido, es importante aumentar la consciencia de las empresas, aprender por qué no han tenido éxito al respecto, y llegar a mejores programas para ayudar a las mujeres que tienen talento a avanzar.

\subsubsection{Iniciativas que buscan la promoción de la igualdad de género en el lugar de trabajo}

En diversos países del mundo, las organizaciones con un destacado compromiso por la igualdad de género tienen la posibilidad de recibir un reconocimiento a su esfuerzo, todo ello, a través de la puesta en marcha de medidas legislativas y no legislativas que pueden verse representadas en programas de reconocimiento ${ }^{170}$. En este sentido dicho reconocimiento que suele darse a través de -un certificado, una mención o una etiqueta- no debe

\footnotetext{
170 Por ejemplo, el caso de Women and Opportunity de la empresa textil estadounidense Gap Inc. quien fue la iniciativa ganadora en 2016 de Catalyst Award Winner, notablemente como resultado de una estrategia alineada, entre 2010 y 2015 la representación de mujeres en su consejo de administración se incrementó de un 10\% a un 36\%. En este sentido, la compañía y su estrategia global se centró principalmente en cuatro aspectos: disponen de un consejo de diversidad e inclusión; tienen programas estructurados de reclutamiento, desarrollo del talento y capacitación; así como de vida laboral y flexibilidad; y promueven el contacto con sus grupos de interés a través de la Responsabilidad Social Corporativa (Catalyst, 2016-a)
} 
ser considerado como un fin, sino como una señal de que la compañía está en constante renovación de su cultura hacia la mejora de la igualdad de género.

Las empresas multinacionales adoptan sus estrategias y enfoques de acuerdo con el entorno legislativo y cultural del país están operando. Por lo tanto, las medidas específicas pueden variar de un país a otro. También, mientras algunas de las iniciativas de la empresa tienen un fondo en lugar específico de la industria, otros parecen ser más general y puede ser fácilmente transferido a través de industrias. Según un estudio de Austrian Institute for SME Research (2010) en la Unión Europea reveló que los principales ámbitos de intervención de las empresas en materia de igualdad de género se concentran en: la contratación, la reconciliación, la retención, las oportunidades de carrera, formación, creación de redes y la comunicación.

Por lo que una buena práctica, en los aspectos mencionados consiste en una "iniciativa, actuación, manera de proceder, metodología y herramienta de carácter innovador que, siendo impulsada o ejecutada por la Administración Local (Ayuntamientos, Diputaciones, Cabildos, Consejos insulares y Mancomunidades) o por una empresa o entidad privada del entorno local, ha demostrado su eficacia en la consecución del objetivo de favorecer la conciliación personal, familiar y profesional de los ciudadanos y ciudadanas y, además, es susceptible de ser transferida a otros contextos" (Instituto de la Mujer et al, 2010).

En este sentido, se presentará un conjunto de iniciativas que se están desarrollando en la materia y que se hace necesario mostrarlas no solo por su objetivo loable, sino para que más compañías u organizaciones se embarquen en los temas de igualdad de género en el trabajo. 


\section{Más Mujeres mejores empresas}

En materia de promoción profesional, desde el Ministerio de Sanidad, Servicios Sociales e Igualdad en España, uno de los proyectos que tiene por objetivo el fomento la participación equilibrada y derribar el techo de cristal se denomina Más Mujeres mejores empresas ${ }^{171}$, una iniciativa flexible, integral y novedosa a la que ya se han adherido empresas españolas en la cual se comprometen a incrementar, en un plazo de 4 años, el número de mujeres que ocupan en sus compañías los puestos predirectivos, directivos, comités de dirección y consejos de administración.

La adhesión se formaliza mediante la firma de un Convenio de Colaboración mediante el compromiso de:

1. Promover activamente que la igualdad, el mérito y la capacidad de las mujeres sean valorados adecuadamente en los procesos de formación interna, selección y promoción de personal.

2. Establecer medidas de organización y flexibilización del tiempo de trabajo que faciliten la conciliación de la vida laboral, personal y familiar y promuevan su utilización tanto por hombres como por mujeres.

3. Prestar especial atención para que, en todos los procesos de formación interna, selección y promoción de personal, sin menoscabo de los principios de mérito y capacidad, exista una presencia más equilibrada de mujeres y hombres.

171 Para mayor información véase:

https://www.msssi.gob.es/ssi/igualdadOportunidades/iEmpleo/promocionprofesionalfoto.htm 
4. Avanzar hacia una participación más equilibrada cuando se produzca una vacante en un puesto predirectivo, directivo, o en la renovación de un miembro del Comité de Dirección o del Consejo de Administración.

El seguimiento se realiza a través de una comisión de seguimiento la cual analiza y evalúa los informes de gestión o de sostenibilidad presentado por las empresas en el cual se recoge los objetivos en la materia, los avances y el impacto de los programas. En la actualidad, según la iniciativa ya son 86 empresas las que se han adherido (Véase Anexo 3).

\section{Certificación EDGE}

La certificación EDGE ${ }^{172}$ (cuyas siglas representan las palabras "dividendo económico de igualdad de género" en inglés), utiliza una rigurosa metodología ${ }^{173}$ para evaluar cómo se desempeñan las organizaciones en términos de igualdad en diversos aspectos (véase gráfico a continuación) como el pago por trabajo equivalente, contratación y promociones, desarrollo de liderazgo, capacitación y mentoría, flexibilidad de horarios de trabajo y cultura corporativa.

\footnotetext{
172 http://www.edge-cert.org/

http://www.edge-cert.org/wp-content/uploads/2016/04/EDGE-Brochure-2016.pdf
}

173 "El estándar EDGE garantiza que las empresas certificadas cuentan con un enfoque estructurado y sistemático para medir, controlar y eliminar la brecha de género en el trabajo mediante indicadores de rendimiento cualitativos y cuantitativos. La metodología tiene un enfoque de negocio en vez de un enfoque teórico, e incorpora al procedimiento la comparativa de mercado, la métrica y la contabilidad" http://www.flocert.net/es/flocert-recibe-la-aprobacion-edge-para-certificar-la-igualdad-degenero-en-el-ambito-laboral/ 
Su meta es ayudar a las organizaciones a crear lugares de trabajo óptimos tanto para las mujeres como para los hombres. En este sentido, toma en cuenta no solo las intenciones de la empresa, sino también la realidad. Después de la evaluación, clasifica las empresas en niveles de acuerdo con su compromiso con la igualdad de género (i) EDGE Assess, (ii) EDGE Move y (iii) EDGE Lead, el tiempo en el cual dura la certificación es de 2 años.

Para realizar la medición de las empresas, EDGE utiliza tres fuentes de información: (i) las estadísticas, (ii) la infraestructura y (iii) la experiencia. Es decir, por una parte, examina los datos relevantes en materia de igualdad de género, como, por ejemplo, la participación femenina en los consejos de administración; por otra parte, evalúa el impacto de la implementación de las políticas, prácticas y programas que promueven la igualdad de género en la compañía y; por último, realiza una encuesta a los empleados para medir cual es la percepción de la igualdad de género en el lugar de trabajo. En general, es una iniciativa muy completa, a diferencia de la mayoría de iniciativas de responsabilidad social que solo mide estadísticas.

\section{KEY ASSESSMENT AREAS}

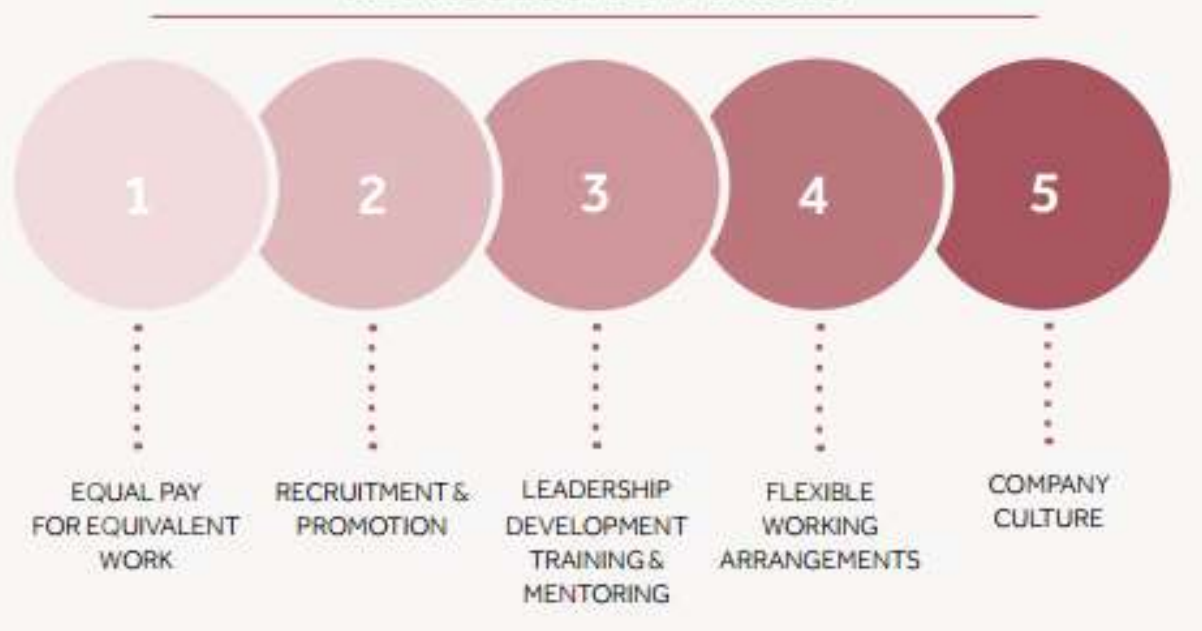

Gráfico 40. Áreas de actuación Certificación Edge. Fuente: Edge (2016, p. 5) 


\section{Acciones desde el Pacto Mundial Red Española}

En la web del Pacto Mundial capítulo España, se trabaja partiendo desde el Objetivo de Desarrollo Sostenible \#5 que consiste en "Lograr la igualdad entre los géneros y empoderar a todas las mujeres y las niñas". En este sentido, promueven una serie de medidas 0 acciones prácticas ${ }^{174}$ para las organizaciones que desde el sector privado quieran realizar un liderazgo social ${ }^{175}$ y contribuir a la erradicación de estas desigualdades. Estas acciones son principalmente:

- La elaboración de un plan formativo en la empresa en materia de género, que incluya temáticas como los derechos humanos y la no discriminación, debería transmitirse a todos los departamentos y cargos de la empresa.

- El establecimiento de políticas salariales que aseguren una igual retribución por igual trabajo, independientemente del género del empleado.

- La implementación de un sistema de contratación y protección del empleo que integre la perspectiva de género lo cual requiere la especialización del departamento de recursos humanos en estos temas.

\footnotetext{
174 Para complementar esta información véase http://www.pactomundial.org/2016/05/sectorprivado-ante-el-ods5/

175 Según Carreras, Leaverton \& Sureda (2009, p. 14) "el concepto de liderazgo social está asociado a la trayectoria de personas impulsoras de organizaciones de la sociedad civil que actúan con una vocación de transformación social. Hay que reconocer de entrada que es un concepto en fase de construcción. Se define básicamente por el sector en el que se desarrolla y no tanto por sus características propias y sus elementos diferenciales."
} 
- El fomento y la promoción del nombramiento de mujeres en puestos directivos y de responsabilidad, así como en el seno del consejo de administración.

- El respeto de la dignidad de las mujeres y niñas en todos los productos y servicios de la empresa, así como en la cadena de valor, incluyendo las campañas de marketing u otros.

- La formando de los grupos de interés en materia de igualdad de género $y$ de los negocios inclusivos.

\subsubsection{El empoderamiento de la mujer}

No es posible hablar sobre el acceso de las mujeres a cargos de responsabilidad sin mencionar el término empoderamiento, de acuerdo con León (2000), los usos de este concepto varían de acuerdo con las diferentes disciplinas que lo utilizan, así pues, lo vemos en áreas como la antropología, la educación, la psicología, la ciencia política, el derecho, la economía entre otras.

Aunque ha sido sin lugar a dudas, los estudios de la mujer y el género, y en especial los asociados al desarrollo los que han utilizado el término como uno de los ejes de su discurso, es un hecho que no es discutible que la mujer como grupo social sea excluida y no participe en la toma de decisiones del futuro en los diferentes ámbitos.

Históricamente, se hizo un acercamiento al término en la Resolución de la IV Conferencia Mundial de las Mujeres en Beijing (inciso 13) al describir la importancia de la potenciación del papel de la mujer como participe de los procesos de adopción de decisiones y el acceso al poder. En este sentido, el rol que la mujer debe desempeñar en la economía, en el ejercicio del poder y 
la adopción de decisiones es considerado un objetivo estratégico y por tal motivo se defiende la capacidad de las mujeres para ejercer liderazgo e influencia en muchas instituciones clave; para ello se siguen proponiendo adoptar una serie de medidas por parte de todas las partes interesadas como los partidos políticos, los gobiernos, el sector privado, y otras instituciones para el cumplimiento de este objetivo.

Ahora bien, al referirse al concepto en sí, puede definirse como un proceso por el cual una persona o grupo de personas fortalecen sus capacidades y aprovechan todo su potencial, lo que aumenta su confianza, y permiten el cumplimiento de su rol como grupo social para impulsar cambios positivos de las situaciones que viven, en este sentido, es posible afirmar que es aplicable a todos los grupos vulnerables o marginados, para nuestro caso a las mujeres.

Por lo tanto, implica tanto como el cambio individual, así como la acción colectiva, y por consiguiente la alteración radical de los procesos y estructuras que reproducen la posición subordinada de las mujeres como género. También supone mejorar el acceso a las diferentes esferas sociales, así como a las estructuras políticas, con el fin de poder participar en la toma de decisiones económicas y políticas.

Por su parte, el empowerment que defiende Hall (2013) supone un proceso social que neutraliza la opresión de las mujeres, para ello, se deben tomar medidas decisivas en su propio nombre, de lo contrario, su victimización continuará automáticamente a través de su subordinación tradicional. Todo ello, mediante el activismo político que se derive en la facultad de otorgar poder a las mujeres en la toma de decisiones, por lo que se deben crear nuevos patrones que les permita desarrollar su potencial y asumir roles más amplios en las actividades sociales, principalmente en el 
trabajo, lo que en definitiva sería sinónimo de la consecución de la equidad y la igualdad.

Para Silvestre, Royo \& Escudero (2014, p. 13) el empoderamiento social implica lograr autonomía para las mujeres, es preciso un aumento de la visibilidad y el reconocimiento de sus logros que busque la construcción de referentes sociales. Para ello es necesario la participación en las diferentes esferas de poder y en los distintos ambitos de toma de decisiones por lo que "...hace falta el conocimiento, la información, la participación, el reconocimiento, la captación y la presencia...".

De hecho, la ONU respalda todas estas premisas, está de acuerdo en el papel que juegan las mujeres en la creación de unas economías más fuertes, y como ya se había señalado anteriormente en los objetivos de desarrollo y sostenibilidad que se han trazado internacionalmente. Coincidimos en el rol que deben jugar todos los actores sociales en este cambio, y principalmente los diversos sectores como agentes clave en los esfuerzos de promoción de la igualdad de género y del empoderamiento de la mujer.

Por ello, con la creación del Índice de Potenciación de Género publicado hasta 2009 y sustituido en la actualidad por el Índice de Desigualdad de Género, el PNUD busca medir las desigualdades de género en tres dimensiones, para nuestro caso, el empoderamiento se mide por medio de dos indicadores: la proporción de escaños parlamentarios ocupados por sexo, y la proporción de población segregados por sexo con al menos educación secundaria completa. 
Para ello, con la publicación de los principios para el empoderamiento de las mujeres ${ }^{176}$, elaborados por ONU Mujeres y el Pacto Mundial de las Naciones Unidas, se ha buscado brindar orientaciones prácticas sobre cómo empoderar a las mujeres en los puestos de trabajo, en las economías y en la comunidad en general, convirtiendo a éstas en un agente activo de cambio.

En resumen, estos siete principios residen en:

Promover la igualdad de género desde la dirección al más alto nivel: implica el apoyo desde los niveles más altos de la dirección (accionistas, miembros del consejo de administración y administradores) en la implementación de políticas y cultura organizacional basada en la igualdad de género.

"N"T Tratar a todos los hombres y mujeres de forma equitativa en el trabajo, básicamente respetar y defender los derechos humanos dentro de ellos la no discriminación: implica el garantizar que se efectúe la integración y la igualdad de género en todos los procesos administrativos y verificar su cumplimiento.

Velar por la salud, la seguridad y el bienestar de todos los trabajadores y trabajadoras: implica procurar unas condiciones de trabajo dignas, libres de violencia y conforme a los riesgos laborales que tienen mujeres y hombres.

Promover la educación, la formación y el desarrollo profesional de las mujeres: implica la elaboración de programas que permitan el

\footnotetext{
176 Estos principios, que se presentaron en 2010 en conmemoración al Día Internacional de la Mujer, constituyen una adaptación de los Calvert Women's Principles, publicados en 2004 como el primer código de conducta empresarial mundial centrado exclusivamente en el empoderamiento, el progreso y la inversión en las mujeres de todo el mundo. A febrero de 2016, 1152 compañías a nivel mundial son firmantes, en España 100 empresas. http://www.weprinciples.org/Site/Companies/1
} 
conocimiento por parte de todo el personal y demás partes interesadas en pro de la igualdad entre mujeres y hombres.

Llevar a cabo prácticas de desarrollo empresarial, cadena de suministro y marketing a favor del empoderamiento de las mujeres: implica integrar la perspectiva de género y la promoción en todos los aspectos empresariales.

Promover la igualdad mediante iniciativas comunitarias y el liderazgo: implica ser un agente activo en la promoción del empoderamiento de la mujer y la igualdad de género en la sociedad.

:०" Evaluar y difundir los progresos realizados a favor de la igualdad de género: implica la comunicación, la transparencia de las políticas internas a través de los programas aplicados para gestionar la diversidad y el empoderamiento de las mujeres mediante la rendición de cuentas.

Con la declaración de apoyo de los CEO de las empresas firmantes a estos principios, se asumió un compromiso público de alinear las políticas de las compañías que hacen parte para avanzar en el camino hacia la igualdad entre los géneros. Así, se mostró la intención de integrar e implementarlos desde los consejos directivos hasta el mercado laboral, pasando por la cadena de abastecimiento y las comunidades.

No hay que olvidar, que no basta con la adhesión, el compromiso por parte de las organizaciones debe ir más allá y realizar una medición frecuente que permita determinar las oportunidades de mejora en este ámbito, las entidades con frecuencia olvidan divulgar toda la información concerniente a todos sus grupos de interés, en especial, sus propios trabajadores y se privan de cambios reales y sustanciales en la cultura organizacional indispensable para una mentalidad defensora de la igualdad. 


\section{Apartado especial, una visión de Colombia ${ }^{177}$.}

Teniendo en cuenta mi procedencia, quise hacer un estudio para saber cómo es la realidad de las mujeres en mi país Colombia, por lo tanto, era preciso abordar lo más básico, es decir, comenzar por conocer los datos generales de género en el mercado de trabajo por lo que en concordancia con la investigación, según el Departamento Administrativo Nacional de Estadística (2014-a) las mujeres representaban en el último trimestre de 2013 un 50,7 \% de la población total en Colombia; con respecto al mercado de trabajo por sexo, de la población que se encontraba ocupada en ese mismo periodo, un $58,4 \%$ correspondía a los hombres mientras que un $41,6 \%$ a las mujeres.

De la población que se encontraba en situación de desempleo, un 41,4\% correspondía a las mujeres y el $58,6 \%$ restante a los hombres. Del total de la población económicamente activa [PEA] -aquellas personas en edad de trabajar, que trabajan o están buscando empleo-, del género femenino, un $25,8 \%$ contaba con un título de educación superior mientras que del género masculino solo un 16,7\% (Departamento Administrativo Nacional de Estadística, 2014-b).

Un primer análisis que se puede extraer de los resultados de dichos indicadores, es que, aunque las mujeres son más en nuestro país, los hombres tienen una mayor tasa de ocupación mientras que las mujeres, de desempleo. En cuanto a la educación superior, hay una mayor proporción de

\footnotetext{
177 Este apartado fue publicado como una parte de los resultados de esta tesis doctoral en la revista Entramado. Véase. MARRUGO-SALAS, L. (2016). El acceso de la mujer a cargos de toma de decisiones en las empresas colombianas que cotizan en bolsa. Entramado, 12 (1), p. 108-120 disponible en http://dx.doi.org/10.18041/entramado.2016v12n1.23104
} 
mujeres profesionales en comparación con los hombres, situación que llama la atención pues evidentemente no se traslada a las cifras de empleabilidad.

\section{2013 (en miles de personas)}

\begin{tabular}{|lll|}
\hline Población total PT = (45.970) & $50,7 \%$ & $49,3 \%$ \\
\hline Población ocupada O = (21.758) & $41,6 \%$ & $58,4 \%$ \\
Población desocupada D = (1952) & $41,4 \%$ & $58,6 \%$ \\
PEA / Educación Superior = (23.710) & $25,8 \%$ & $16,7 \%$
\end{tabular}

Tabla 1. Datos estadísticos de género en Colombia. Fuente: DANE. Elaboración propia.

También era preciso conocer el comportamiento de la presencia femenina en lo más alto de la cúspide empresarial, es decir, en la junta directiva de las empresas colombianas más representativas. A estos efectos, se debía establecer cuál era el porcentaje de mujeres del total de los miembros de este órgano, lo cual como ya se ha planteado corresponde al objeto de la investigación, por lo cual se toma como referencia, dos estudios realizados previamente [Véase Tabla 2] que sirviese para contrastar los resultados de la investigación. Entonces, realizando un primer acercamiento para conocer dicho comportamiento, en Colombia solo un $9 \%$ de los miembros de las juntas directivas de las empresas eran mujeres (Idrovo, 2012). 


\begin{tabular}{|c|c|c|c|}
\hline Estudio & Base de Empresas & $\begin{array}{c}\% \\
\text { Mujere }\end{array}$ & Año \\
\hline $\begin{array}{c}\text { Centro de } \\
\text { Investigación } \\
\text { INALDE BS }\end{array}$ & $\begin{array}{l}100 \text { más grandes del país } \\
\text { según Revista Semana }\end{array}$ & $9 \%$ & 2012 \\
\hline $\begin{array}{c}\text { McKinsey \& } \\
\text { Unilever }\end{array}$ & 30 empresas & $9 \%$ & 2013 \\
\hline
\end{tabular}

Tabla 2. Estudios del \% de mujeres en junta directiva. Fuente: Elaboración propia

\section{Descripción, metodología y resultados del estudio}

A fecha de inicio de la investigación, la información pública disponible en las páginas web de las empresas seleccionadas [véase Anexo 1] y en sus informes de gestión 0 , de responsabilidad social corporativa estaba actualizada hasta el año 2013, por lo que este fue el año de evaluación. La investigación fue de carácter documental, orientada a la localización, registro, procesamiento, análisis e interpretación de información proveniente de fuentes secundarias (Galeano, 2004), pues se obtuvo los datos de un listado de 76 organizaciones emisoras en la Bolsa de Valores de Colombia procedentes de diversos sectores de la economía clasificadas según como aparece en la tabla 4. Asimismo, a efectos de conocer el género de los miembros de las juntas directivas de dichas empresas solo se tuvo en cuenta a los miembros principales, no se contó a los suplentes. 


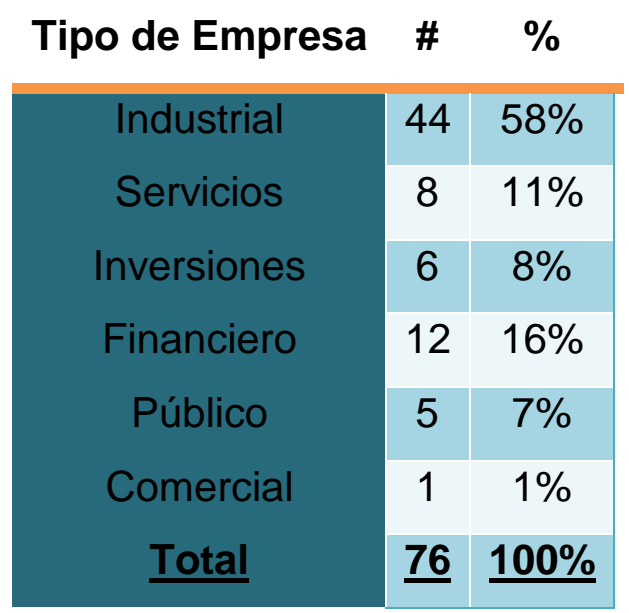

Tabla 3. Empresas que cotizan en la BVC por sector. Fuente: Elaboración propia

Los resultados obtenidos fueron los siguientes, como podemos observar en el gráfico 1, del total de los miembros de las juntas directivas de las 76 empresas evaluadas, sólo un $9 \%$ corresponde al género femenino, es decir, 45 mujeres a diferencia de un $91 \%$ que corresponde al género masculino, es decir, 446 hombres. Una primera conclusión al respecto es que evidentemente al igual que los resultados proporcionados por las investigaciones hechas unos años atrás (Idrovo, 2012) el porcentaje continua intacto.

De igual manera, conviene analizar también cuantas mujeres ocupan el más alto cargo ejecutivo en la empresa -llámese Presidente, Gerente General, CEO O Director- , como se puede observar en el gráfico 2, ocurre una situación muy similar a la anterior, de las 76 empresas evaluadas solo 8 mujeres ocupan este cargo, es decir, un $11 \%$ de las empresas analizadas tienen a una mujer dirigiendo la organización, a diferencia del $89 \%$ restante es decir, 68 hombres ocupan dicho cargo, lo que nos muestra que en principio, ese porcentaje de mujeres aunque bajo ha logrado derrumbar el 
techo de cristal y que esas compañías han depositado la confianza en ellas para llevar el timón de su barco.

A partir de estos últimos datos y entrando más en detalle, también era necesario analizar la participación de las mujeres por tipo de empresa para ver en cuales se encuentra mayores oportunidades para las mismas, para ello en el gráfico 3 , vemos como es dicha distribución.

Podemos concluir que de los seis sectores a los que pertenecen las empresas analizadas, tres de ellos no tienen a ninguna mujer en el más alto cargo ejecutivo, es decir que los sectores económicos -servicios, inversiones y comercialización- son liderados por el género masculino lo que significa que las mujeres les es más difícil derrumbar el techo de cristal en este tipo de empresas lo que debería generar una primera alerta para combatir la discriminación en dichos sectores.

A diferencia del sector industrial, en donde hay más inclusión femenina en el más alto cargo ejecutivo, es decir, un $11 \%$ de estas empresas son lideradas por mujeres, lo que pareciera en principio ser contradictorio, teniendo en cuenta que las carreras profesionales industriales son estudiadas mayoritariamente por hombres (OECD, 2012).

Aunque en el sector financiero y público se evidencia una proporción de mujeres en este cargo, no resulta ser significativo en el primero, puesto que de las doce empresas analizadas en este sector sólo una tiene en su más alto cargo a una mujer. En términos porcentuales solo un $8 \%$ del sector financiero es liderado por una mujer, mientras que, en las empresas públicas, las cuales de las cinco estudiadas, dos son lideradas por mujeres, lo que en términos porcentuales representa casi un $40 \%$. 
Con respecto, al número de mujeres en las juntas directivas, tal como lo vemos en el gráfico 1, de las 67 empresas analizadas el $54 \%$ que corresponde a 41 empresas no tiene ninguna mujer en la junta directiva. El $33 \%$ que equivale a 25 empresas tiene al menos una mujer y solo el $13 \%$, es decir, 10 empresas tienen dos. Se concluye entonces que un poco más de la mitad de las empresas objeto de nuestro estudio aún no le dan la oportunidad a una mujer para ser parte de su máximo órgano de gobierno, y aquellas en las que, si hay al menos una mujer, la representatividad no es suficiente.

A partir de lo anterior, es considerable la brecha existente en las empresas en cuanto a la designación del cargo de Presidencia, esto responde en parte a lo que se llama segregación del mercado laboral: horizontal, cuando hombres y mujeres se concentran en determinados sectores de producción y empleos específicos; y, vertical, cuando se produce esta concentración en determinados grados y niveles de responsabilidad.

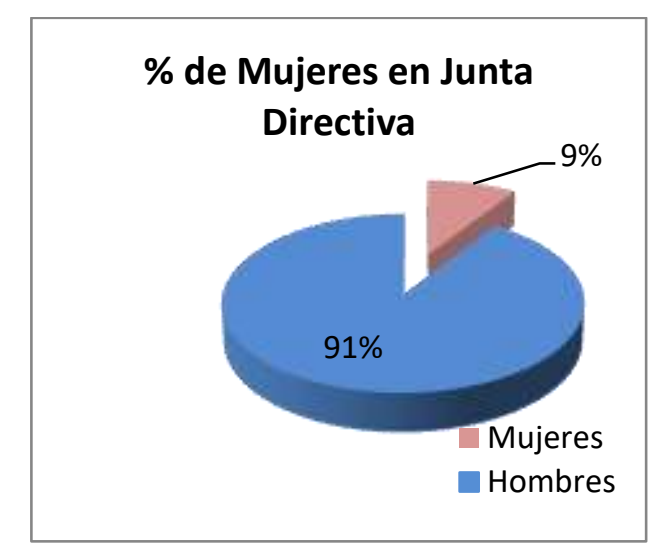

Gráfico 1. \% de mujeres en puestos de alta dirección. Fuente: Elaboración propia 


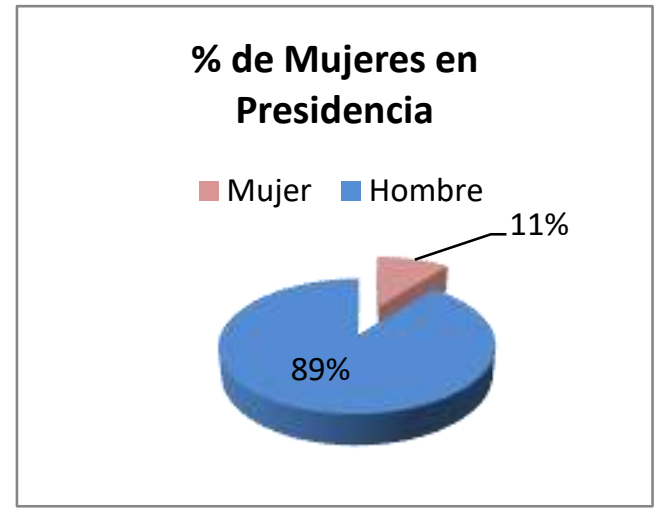

Gráfico 2. \% de mujeres en puestos de alta dirección. Fuente: Elaboración propia

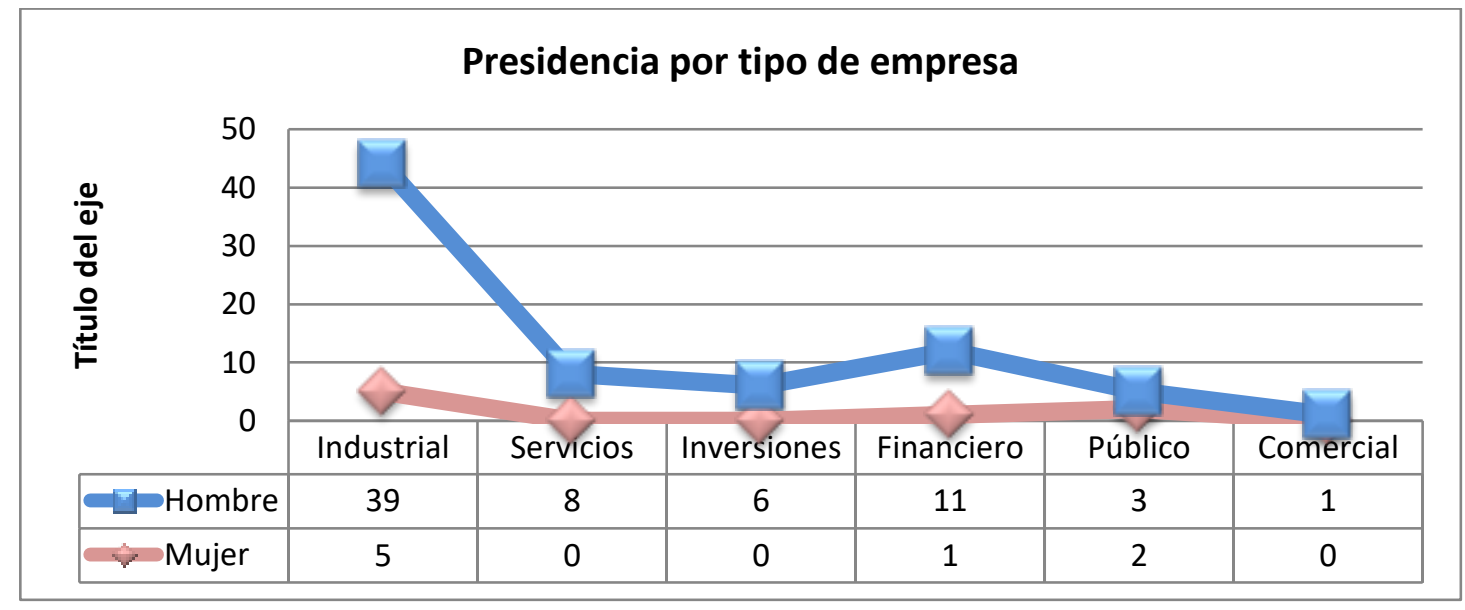

Gráfico 3. Comparativa por género en el cargo de presidente. Fuente: Elaboración propia 


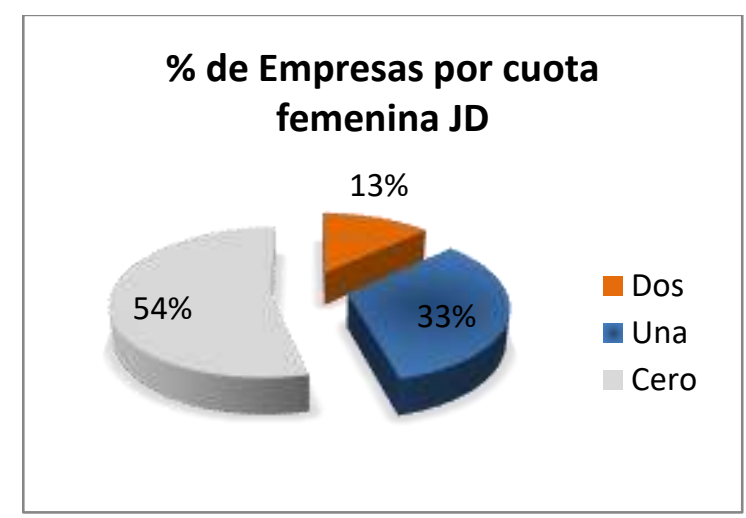

Gráfico 4. Empresas por su cuota femenina en la Junta Directiva. Fuente: Elaboración

propia

\section{¿Cómo se combate el problema?}

Como puede observarse, los resultados avalan la teoría que las mujeres ocupan un porcentaje muy bajo en la alta dirección, sin contar con el hecho de que las mujeres se ven enfrentadas a diversas situaciones de discriminación durante su vida laboral, para ello, hace falta la ejecución de medidas principalmente en las compañías para contrarrestar los diferentes obstáculos y prevenir a futuro este tipo de situaciones, por lo que a continuación en el cuadro se propone un conjunto de acciones mínimas que las organizaciones deberían implementar para intentar promover la igualdad de género en el trabajo y de esta manera las mujeres a futuro puedan traspasar el techo de cristal y acceder a cargos superiores.

\section{Acciones}

Descripción

Implementación de una política de La creación de una política integral igualdad de oportunidades en el que requiere la participación activa de todos los actores, en especial de 
trabajo y de prevención del acoso la alta dirección. Los resultados son sexual. los códigos de conducta y procedimientos de actuación y de evaluación continua. Deberá ponerse en conocimiento de todos los empleados incluso de los demás grupos de interés tales como contratistas entre otros. La empresa deberá dejar claro que el no cumplimiento de estas políticas tendrá consecuencias.

Modificar la gestión de los recursos El responsable de gestión humana humanos y actualización continua deberá transversalizar el enfoque de de procedimientos. género en todos los procesos de gestión humana tales como: selección, contratación, bienestar, formación, seguridad y salud en el trabajo. No olvidar que se deberá incluir también a los intermediarios tales como head hunters y bolsas de empleo quienes juegan a la vez un papel fundamental pues proveen futuros candidatos a la organización. La sensibilización jugará un papel primordial en el cambio de mentalidad

Creación de un mecanismo de Las empresas pueden crear un denuncia de posibles situaciones de canal en donde los empleados discriminación en el trabajo. puedan denunciar con las máximas 
garantías aquellas situaciones que vulneren el principio de igualdad en el trabajo, de tal manera que se tomen las correspondientes medidas a lugar y se rechace este tipo de actuaciones.

Identificación de mejores prácticas El objetivo de identificar estás de empresas en materia de igualdad prácticas es poder replicarlas en las y conciliación de la vida personal, organizaciones y si se pueden familiar y profesional mejorar sería ideal. Se puede involucrar directamente a las mujeres para que propongan alternativas de solución e incluso a los propios trabajadores.

Creación de planes de sucesión Identificar aquellas mujeres que por para aquellas mujeres con alto sus capacidades puedan ejercer en potencial. un futuro cargos de alta dirección, por lo que la empresa podrá crear planes de sucesión efectivos que motiven a las trabajadoras

Tabla 4. Acciones para combatir el techo de cristal. Fuente. Elaboración propia.

Asimismo, es preciso insistir que el papel de los departamentos de gestión humana en las organizaciones resulta de vital importancia, pues en la ejecución de sus funciones se pueden perpetuar todas estas desigualdades que hemos mencionado a lo largo del texto. Justamente, Grueso (2009) planteó que se debe tener cuidado en cinco prácticas de recursos humanos 
para evitar dichas discriminaciones: (i) en la provisión de personal, (ii) en la promoción del personal, (iii) en la formación y desarrollo de personal, (iv) en los criterios de evaluación del desempeño y por último (v) en la compensación del personal. 


\section{Consideraciones finales}

A continuación, se presentan las principales conclusiones resultantes de la investigación:

1. Después de este recorrido por la situación actual de las mujeres con respecto al empleo y la ocupación, si hay algo claro es que no se han eliminado del todo las desigualdades: las cifras hablan por sí mismas. Es cierto que es visible una regulación internacional en hay un avance importantísimo para la promoción de la igualdad de oportunidades, pero la realidad demuestra que esto no es suficiente por sí solo, es necesario el rol activo de otros actores sociales partiendo del lugar de origen de estas desigualdades como el mercado de trabajo (organizaciones y empresas) y las escuelas e instituciones de educación superior, además del control de la administración pública. En este sentido, se debe propiciar los espacios de trabajo en equipo por parte de todos los grupos interesados a través de alianzas públicoprivada.

2. Es evidente como la crisis económica ha aumentado las brechas entre mujeres y hombres en cuanto a salarios y el acceso a cargos directivos en todos los ámbitos. Con respecto a la brecha salarial de género, para las mujeres se amplía significativamente con la edad, a un cierto punto, y difiere con la ocupación. Aunque en el fondo hay que resaltar que la brecha es mucho menor de lo que había sido en la historia y el descenso ha sido en gran parte, a un aumento en el capital humano productivo de las mujeres respecto a los hombres.

3. La cultura arraigada en la sociedad es un componente prioritario que hace que se perpetúen en el tiempo los comportamientos claramente 
discriminatorios contra la mujer, se necesitará entonces atacar el problema de raíz desarrollando una política educativa que haga que en la escuela se forme desde pequeños en materia de igualdad. Por lo tanto, ahora más que nunca los gobiernos deben extender las medidas en materia de protección social dirigida a reducir la vulnerabilidad de las mujeres, las inversiones en competencias y educación, y a instaurar políticas públicas que favorezcan el acceso al empleo, que puede ser a través de las acciones positivas, pero siempre incorporando transversalmente la perspectiva de género.

4. Hay que tener en cuenta que las causas de esta situación son de carácter socio cultural pero también de tipo normativo. Aun reconociendo que la norma laboral no es la panacea que por sí misma (Pérez, 2006), está demostrado que puede constituir un instrumento de primer orden para conseguirlo. Pero tampoco es suficiente que la norma jurídica sea técnicamente buena; es necesario además que los operadores jurídicos la conozcan en todo su alcance, que asuman la voluntad y compromiso de aplicarla y controlar y garantizar su respeto y aplicación.

5. Una de las propuestas para mejorar la participación de la mujer en los cargos puede ser la creación de asociaciones civiles o headhunters especializados en la formación y el desarrollo de las competencias de las directivas mujeres con potencial para desempeñarse, que, en todo caso, la inscripción por parte de esas mujeres y su identificación pudiera ser mediante la postulación por parte de algunas empresas, organizaciones de todo tipo o universidades, posteriormente la visibilidad por parte de las directivas exitosas y puntos de encuentro para la retroalimentación a las mujeres que quieran seguir ese proceso. 
6. Una crítica a las iniciativas de RSE, es que requieren de un nivel de inversión alto para su adhesión y en muchos países no existe la suficiente difusión, en este sentido, para que las empresas puedan adherirse la contribución voluntaria no puede ser tan alta.

7. Hay que tener en cuenta que la presencia de mujeres en los órganos de poder y decisión no asegura la consecución de la igualdad de oportunidades de mujeres y hombres en nuestra sociedad, pero permite avanzar para que las luchas contra las discriminaciones de género ocupen un lugar central en la agenda política.

8. Una propuesta en el ámbito académico sería la creación de cátedras de emprendimiento y empoderamiento de las mujeres, en donde se le brinde herramientas prácticas para generar un cambio social y puedan abrirse nuevos campos laborales, así como desempeñarse a futuro como potenciales directivos.

9. Es importante la aplicación de un lenguaje e imágenes no sexistas, en las políticas de comunicación, información, acceso al empleo y la formación, tanto dentro como fuera de la empresa. En este sentido, habría que combatir que no se convierta en una medida no interiorizada (Bodelón et al., 2014, p. 42) aunque hay que admitir que representa un bajo coste económico para las organizaciones.

10. Se comprobó que las desigualdades aun presentes en el trabajo son: (i) la brecha salarial, (ii) que las mujeres se siguen concentrando en determinados puestos de trabajo, (iii) que existen dificultades importantes para que hombres y mujeres puedan conciliar la vida personal y laboral, (iv) que existen discriminaciones ocultas, (v) que es baja la proporción femenina en los cargos de poder y de responsabilidad y, que cuando las mujeres logran acceder a éstos 
puestos, (vi) se encuentran aun con muchas más barreras y diferencias en las condiciones laborales.

11. Los embajadores de organismos internacionales no reportaron mujeres, es decir, un $100 \%$ de estos cargos estaban ocupados por hombres, lo cual debe mostrar una primera alerta del porqué las mujeres no han podido acceder específicamente a este cargo en particular.

12. Después de hacer este recorrido del acceso de las mujeres al empleo público evaluando los distintos poderes públicos, es evidente como ha mejorado la situación para ellas en cuanto a la inclusión laboral, sin embargo, no en todos los cargos sucede de igual manera, en algunos la progresividad es más lenta mientras que en otros por lo menos se ha alcanzado la paridad. Se constata el hecho que en los cargos con mayor autoridad disminuye la proporción de las mismas.

13. En el caso de las universidades se comprobó que combatir el techo de cristal en universidades más pequeñas es mucho más difícil que en las universidades de mayor tamaño. Además, en efecto la proporción más baja resultó de la mayor escala del profesorado, es decir, de las mujeres catedráticas.

14. A pesar de que varios países han implementado políticas que incluyen el enfoque de género, e incluso medidas positivas para la inclusión de las mujeres en cargos como, por ejemplo, las juntas directivas en las empresas cotizadas, es necesaria, mayor investigación para comprender los beneficios de la diversidad en estos entornos de trabajo, lo cual precisa de la colaboración entre los tres sectores: privado, público y académico, además de la continuidad que requieren dichos estudios y el rigor. Al respecto (Adams, 2016) concluyó que los tres desafíos principales en este sentido son: las 
limitaciones de los datos, la selección de la muestra y la inferencia causal, con ello, se requiere la alineación y el perfeccionamiento de dichas investigaciones.

15. Es importante que a futuro se evalúe la funcionalidad de los planes de igualdad, en este sentido, que no se convierta en algo meramente testimonial. Pues como afirmó Bodelón et al. (2014, p. 133) estos en ocasiones "no mejoran o garantizan mejor los derechos establecidos por la legislación laboral y de igualdad de género. De esta manera, el plan se convierte en la mayoría de los casos en un acto burocrático, que no pretende profundizar el derecho a la igualdad efectiva"

16. Con respecto a los programas realizados para la promoción de la igualdad de género, requiere de un proceso de transformación y de cambio, con lo cual "las prácticas que mejoran la diversidad en la dirección requieren tiempo para hacer efecto, estar plenamente implementadas en toda la organización y sostenidas en el tiempo. Es decir, se convierten en inútiles si se aplican como una mera operación cosmética de marketing." (Cabanas, Morales \& Molinero, 2014, p. 15).

17. Los atributos que en un principio se asociaron a la mujer y que fueron la principal causa de su exclusión en los cargos de dirección "parecen estar desembocando en un estilo de liderazgo "femenino", que además coincide con las nuevas tendencias y corrientes dentro de la cultura organizacional que apuntan a la necesidad de un liderazgo compartido, participativo" lo cual implica la promoción de un conjunto de valores y competencias para generar un clima adecuado en el seno de las instituciones (Cáceres et al. 2012, p. 79)

18. Un desafío importante, es el rol de la negociación colectiva en estos aspectos pues se debería incentivar aún más la participación de 
las mujeres en sindicatos $\mathrm{o}$ asociaciones de trabajadoras, pues tal como se evidenció, en la actualidad, las mujeres se enfrentan a "esquemas de empleo cada vez más flexibles, su alta participación en el trabajo informal, la creciente subcontratación y división de funciones en empresas cada vez más pequeñas que no permiten la sindicalización." (CEPAL et al. 2013, p. 223).

19. Por último, la responsabilidad social empresarial ha favorecido la igualdad de oportunidades entre mujeres y hombres dentro de las organizaciones, lo cual se ve reflejado en una mayor transparencia de información y datos que están segregados por sexo, así como en la creación de programas que promuevan la diversidad y la inclusión laboral. No obstante, es necesario una revisión exhaustiva de las iniciativas internacionales vigentes, tal como se analizó en el texto, pues es necesario, pasar de las intenciones (declaración de compromisos y de voluntades) a las acciones reales, con lo cual se necesita herramientas prácticas que permitan medir el impacto que generan las actuaciones de las organizaciones en este ámbito y su posterior seguimiento y control. Hay muchas entidades con una fuerte experiencia, con lo cual se necesita una mayor visibilización de las mismas. 


\section{Listado de Tablas}

Tabla 1. Convenios complementarios de la OIT ratificados por España con base en la OIT.

Tabla 2. Listado de Directivas Europeas que promueven la igualdad de género a nivel laboral.

Tabla 3. Selección de acciones puntuales en materia de la igualdad de género en el Empleo y Ocupación de la UE.

Tabla 4. Legislación española complementaria de igualdad de género.

Tabla 5. Ranking Spain Gender Gap

Tabla 6. Presidentas y Jefes De Gobierno del Siglo XX Y XXI

Tabla 7. \% total mujeres senadoras por grupos parlamentarios 2011-2015 de mayor a menor.

Tabla 8. \% total mujeres diputadas en el congreso por grupos parlamentarios 2011-2015 de mayor a menor.

Tabla 9. Tipos o Factores de discriminación en el trabajo.

Tabla 10. Causas del glass ceiling.

Tabla 11. Las 10 mujeres más poderosas del mundo según Forbes (2016)

Tabla 12. Las 10 mujeres más ricas del mundo según Forbes (2017)

Tabla 13. \% de directoras generales en las bolsas de valores a nivel mundial Tabla 14. \# Mujeres en cargos CA IBEX 352013.

Tabla 15. Principales Competencias Gerenciales

Tabla 16. Dieciséis competencias de los principales líderes según Zenger \& Folkman (2012) 


\section{Listado de Gráficos}

Gráfico 1. Spain Position Global Gender Gap

Gráfico 2. ¿Cuántas mujeres presidentas están en el poder?

Gráfico 3. \% total mujeres presidentas en las consejerías autonómicas.

Gráfico 4. \% total mujeres consejeras en gobiernos autonómicos.

Gráfico 5. \% total mujeres consejeras por gobierno autonómico.

Gráfico 6. \% total mujeres alcaldesas en España.

Gráfico 7. \% total mujeres alcaldesas por gobierno autonómico.

Gráfico 8. \% total mujeres senadoras por periodos legislativos.

Gráfico 9. \% total mujeres diputadas por periodos legislativos.

Gráfico 10. Comparativo de partidos y evolución del \% total mujeres diputadas en el congreso.

Gráfico 11. Comparativo de partidos y evolución del \% total mujeres diputadas en el senado.

Gráfico 12. \% Mujeres ministras por año.

Gráfico 13. \% Mujeres en Secretarías de Estado por año.

Gráfico 14. \% Mujeres Magistradas en Tribunal Constitucional por año.

Gráfico 15. \% Mujeres Fiscales Poder Judicial por año.

Gráfico 16. \% Mujeres Fiscales por categoría Poder Judicial por año.

Gráfico 17. \% Mujeres del total de profesores.

Gráfico 18. \% Catedráticas en Universidades Públicas.

Gráfico 19. \% de Mujeres titulares Universidades Públicas.

Gráfico 20. Personal de Administración y Servicios.

Gráfico 21. Tasa de Empleo Discapacitados Mujeres y Hombres 2009-2013.

Gráfico 22. Tasa de Paro Discapacitados Mujeres y Hombres 2009-2013.

Gráfico 23. Evolución por año del SMA de las mujeres versus hombres.

Gráfico 24. Evolución por año del SMA de las mujeres versus el total.

Gráfico 25. Conceptos claves en los estudios de género

Gráfico 26. Barreras para el acceso de la mujer a cargos de dirección por sexo 
Gráfico 27. \% Mujeres en puestos en CA IBEX 35.

Gráfico 28. \% de presidentas CA IBEX 35.

Gráfico 29. \% de Presidentas Ejecutivas IBEX 35.

Gráfico 30. \# Mujeres miembros alta dirección IBEX 35.

Gráfico 31. Presencia de las mujeres en los consejos.

Gráfico 32. Women's share of board seats at european stock index companies.

Gráfico 33. Componentes de las Competencias

Gráfico 34. Cinco dimensiones del liderazgo

Gráfico 35. Evolución en el tiempo de la Responsabilidad Social.

Gráfico 36. Soluciones conjuntas entre hombres y mujeres en España.

Gráfico 37. Presencia de la mujer en Telefónica

Gráfico 38. Presencia de la mujer en la Dirección Renfe

Gráfico 39. Categorías de indicadores en el Análisis de Barreras.

Grafico 40. Áreas de actuación Certificación Edge 


\section{Anexos}

Anexo 1. Listado de empresas del IBEX 35

\begin{tabular}{|c|c|c|c|}
\hline 1 & ABENGOA CL.B & 19 & GRIFOLS \\
\hline 2 & ABERTIS & 20 & IAG (IBERIA) \\
\hline 3 & ACERINOX & 21 & IBERDROLA \\
\hline 4 & $\underline{\mathrm{ACS}}$ & 22 & INDITEX \\
\hline 5 & AENA & 23 & INDRA \\
\hline 6 & AMADEUS & 24 & JAZZTEL \\
\hline 7 & ARCELORMITTAL & 25 & MAPFRE \\
\hline 8 & BANKIA & 26 & MEDIASET \\
\hline 9 & BANKINTER & 27 & $\underline{\mathrm{OHL}}$ \\
\hline 10 & BBVA & 28 & POPULAR \\
\hline 11 & CAIXABANK & 29 & REE \\
\hline 12 & $\underline{\mathrm{DIA}}$ & 30 & REPSOL \\
\hline 13 & ENAGAS & 31 & SABADELL \\
\hline 14 & ENDESA & 32 & $\underline{\text { SACYR }}$ \\
\hline 15 & $\underline{\text { FCC }}$ & 33 & SANTANDER \\
\hline 16 & FERROVIAL & 34 & $\begin{array}{r}\text { TECNICAS } \\
\text { REUNIDAS }\end{array}$ \\
\hline 17 & GAMESA & 35 & TELEFONICA \\
\hline 18 & GAS NATURAL & & \\
\hline
\end{tabular}


Anexo 2. Listado de empresas españolas pertenecientes al pacto mundial.

\begin{tabular}{|r|l|l|}
\hline & Company & Sector \\
\hline 1 & 1 A Consultores, S. Coop & Support Services \\
\hline 2 & AC Servicios, E.I. & $\begin{array}{l}\text { Health Care Equipment } \\
\text { and Services }\end{array}$ \\
\hline 3 & Aceitunas Ochoa Doblado, S.L. & Food Producers \\
\hline 4 & Advocare, S.C.A. & Support Services \\
\hline 5 & Agbar & $\begin{array}{l}\text { Gas, Water and } \\
\text { Multiutilities }\end{array}$ \\
\hline 6 & Aguas Termales de Graena, S.A. & Travel and Leisure \\
\hline 7 & Alguas, S.L. & Support Services \\
\hline 8 & $\begin{array}{l}\text { Andaluza de Montajes Eléctricos y Telefónicos, } \\
\text { S.A. (Ametel, S.A.) }\end{array}$ & Electronic and Electrical \\
Equipment
\end{tabular}




\begin{tabular}{|l|l|l|}
\hline 20 & Caja Navarra & Financial Services \\
\hline 21 & CAJAMAR Caja Rural & Financial Services \\
\hline 22 & Carnicería Zacatín, S.L. & Food Producers \\
\hline 23 & Centros Comerciales Carrefour, S.A. & Food and Drug Retailers \\
\hline 24 & Cesurca CSA & Food Producers \\
\hline 25 & Cinde Soluciones S.L. & Support Services \\
\hline 26 & Clielsa Innovacion y Desarrollos Tecnológicos & Support Services \\
\hline 27 & Corporació de Salut del Maresme I La Selva & $\begin{array}{l}\text { Health Care Equipment } \\
\text { and Services }\end{array}$ \\
\hline 28 & COSAFRA Cooperativa San Francisco, S.C.A. & Food Producers \\
\hline 29 & Efectivamente Comunicación, S.L. & Media \\
\hline 30 & EGA MASTER S.A. & General Industrials \\
\hline 31 & El Castillo de Mi Bebe S.L.U. & General Retailers \\
\hline 32 & El Cortijo Bio S.L. & Food Producers \\
\hline 33 & El Roble, S.C.A. & Support Services \\
\hline 34 & El Ser Creativo S.L. & Media \\
\hline 35 & Embutidos García Lizana, S.L. & Food Producers \\
\hline 36 & Emturaxa S.L. & Travel and Leisure \\
\hline 37 & Endesa S.A. & Electricity \\
\hline 38 & ENUSA Industrias Avanzadad, S.A. & $\begin{array}{l}\text { Gas, Water and } \\
\text { Multiutilities }\end{array}$ \\
\hline 39 & Estratega Consulting & Financial Services \\
\hline 40 & Euskaltel, S.A. & Fixed Line \\
\hline 41 & FClecommunications \\
\hline 42 & Fomento de Construcciones y Contratas, S.A. & Construction and \\
\hline & Fraternidad Muprespa & Materials \\
\hline & Health Care Equipment \\
and Services
\end{tabular}




\begin{tabular}{|l|l|l|}
\hline 44 & Frunet S.L. & Food Producers \\
\hline 45 & Gamesa Corporación Tecnológica, S.A. & Alternative Energy \\
\hline 46 & García Narváez, S.L. & Food Producers \\
\hline 47 & Gesproenergía S.L. & $\begin{array}{l}\text { Gas, Water and } \\
\text { Multiutilities }\end{array}$ \\
\hline 48 & Gestion de Proyectos Ledesma y Franco, S.L. & Travel and Leisure \\
\hline 49 & Grupo Dabo Consulting Empresarial, S.L. & Support Services \\
\hline 50 & Grupo Gesor, S.L. & Support Services \\
\hline 51 & Grupo Hotelero Sierra, S.L. & Travel and Leisure \\
\hline 52 & Grupo Lacera & Financial Services \\
\hline 53 & Grupsa (Grupo Metal System, S.A.) & $\begin{array}{l}\text { Construction and } \\
\text { Materials }\end{array}$ \\
\hline 54 & Gutiérrez Rozos y Asociados & Support Services \\
\hline 55 & Hijos de Francisco Jiménez Tienda, S.L. & Food Producers \\
\hline 56 & Hospital Moncloa, S.A. & Health Care Equipment \\
and Services
\end{tabular}




\begin{tabular}{|c|c|c|}
\hline 68 & Las Palmeras, S.C.A. & Food Producers \\
\hline 69 & Legalitas Quality Assurances (L.Q.A.) & Food Producers \\
\hline 70 & Loewe & Personal Goods \\
\hline 71 & Los Gallombares, S.C.A. & Food Producers \\
\hline 72 & Macrosad SCA & $\begin{array}{l}\text { Health Care Equipment } \\
\text { and Services }\end{array}$ \\
\hline 73 & Mia / GyJ España & Media \\
\hline 74 & Microambiental, S.C.A & Support Services \\
\hline 75 & Ociomágina Servicios Educativos y de Ocio S.L. & Support Services \\
\hline 76 & Olea Cosméticos, S.L. & Personal Goods \\
\hline 77 & Olivar de Segura, S.C.A. & Food Producers \\
\hline 78 & Organismo Autónomo de Gestión Tributaria & Government \\
\hline 79 & Ostos y Sola & Support Services \\
\hline 80 & Perfumes Loewe S.A & Personal Goods \\
\hline 81 & Puentes y Calzadas Infraestructuras S.L.U. & $\begin{array}{l}\text { Construction and } \\
\text { Materials }\end{array}$ \\
\hline 82 & Quality Experts, S.A. & Support Services \\
\hline 83 & Raíces Serranas de Jabugo, S.L. & Food Producers \\
\hline 84 & Rancho Cortesano, S.C.A. & Food Producers \\
\hline 85 & $\begin{array}{l}\text { Residencia de Personas Mayores Ciudad de } \\
\text { Úbeda S.C.A }\end{array}$ & Travel and Leisure \\
\hline 86 & Restaurante Casa Salvi & Travel and Leisure \\
\hline 87 & Roadmap Excelencia y Responsibilidad & Support Services \\
\hline 88 & San Isidro de Loja, S.C.A. & Food Producers \\
\hline 89 & Santiago Apostol, S.C.A. & Food Producers \\
\hline 90 & SATEC & $\begin{array}{l}\text { Software and Computer } \\
\text { Services }\end{array}$ \\
\hline 91 & Schneider Electric España S.A. & $\begin{array}{l}\text { Electronic and Electrical } \\
\text { Equipment }\end{array}$ \\
\hline 92 & Sierra Nevada, S.C.A. & Support Services \\
\hline
\end{tabular}




\begin{tabular}{|r|l|l|}
\hline 93 & Sulayr Global Service, S.L. & Support Services \\
\hline 94 & $\begin{array}{l}\text { Suministros Eléctricos Industriales Antón- } \\
\text { Teixido, S.A. (SEITSA) }\end{array}$ & Support Services \\
\hline 95 & Taller USOA Lantegia, S.A.U. & Support Services \\
\hline & $\begin{array}{l}\text { Tejeda \& Encinas Hispano Portuguesa de } \\
\text { Abogados y Asociados, S.L. }\end{array}$ & Support Services \\
\hline 97 & Trops, SAT 2803 & Food Producers \\
\hline 98 & Turismo Rural Genatur, SCA & Travel and Leisure \\
\hline 99 & Unión de Mutuas & $\begin{array}{l}\text { Health Care Equipment } \\
\text { and Services }\end{array}$ \\
\hline 10 & & $\begin{array}{l}\text { Fixed Line } \\
\text { Telecommunications }\end{array}$ \\
\hline 0 & Unitronics &
\end{tabular}


Anexo 3. Listado de empresas españolas que se adhirieron al proyecto "Más Mujeres mejores empresas"

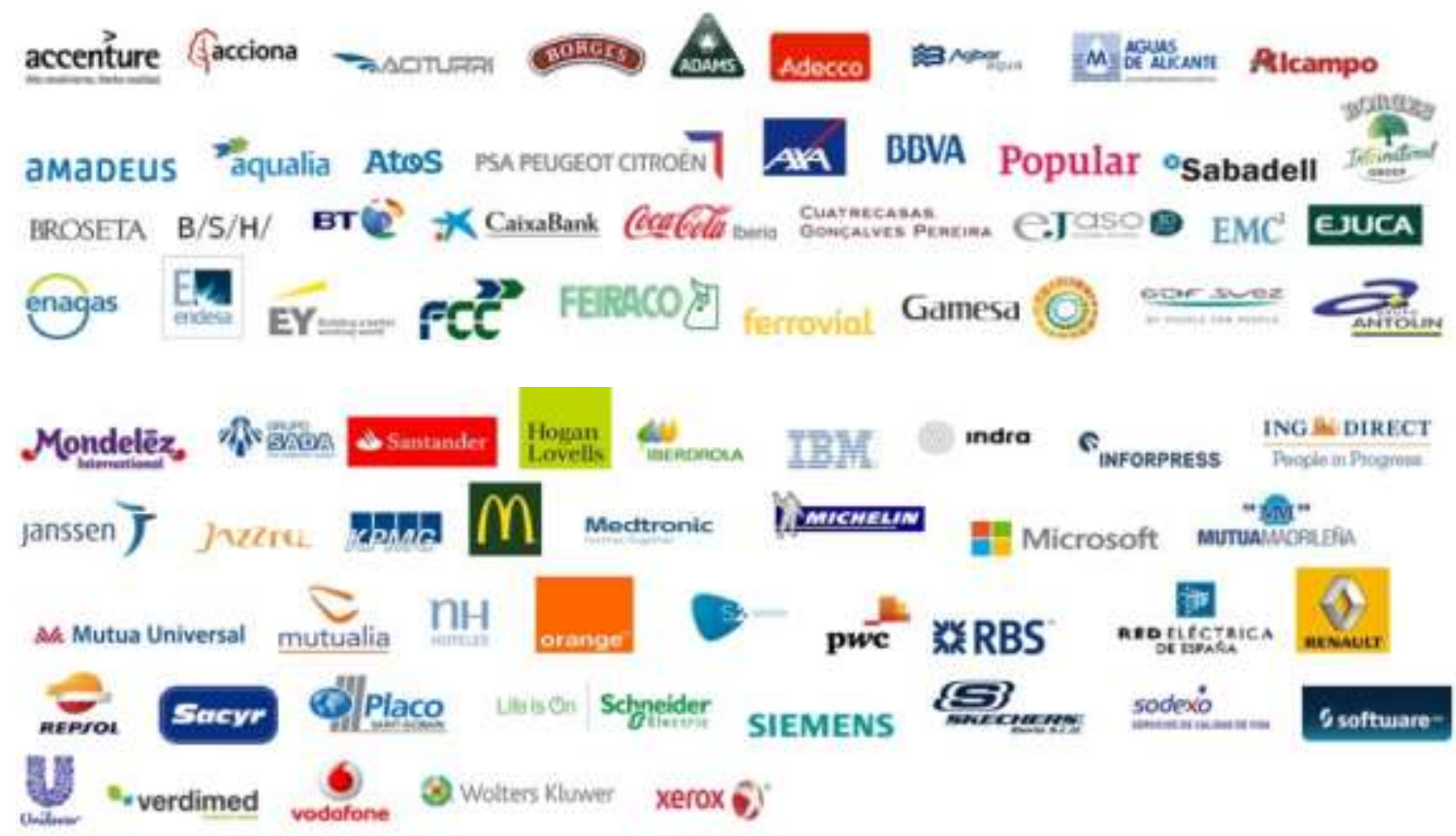




\section{Anexo 4. Pasos para combatir el prejuicio inconsciente (Catalyst- $d, 2015)$}

COMIENCE POR

USTED MISMO

SEA VERBAL

APRENDA MAS

CONOZCA

A SU GENTE

EMPODERE

A SU GENTE

ROMPA

EL CICLO

ARRIÉSGUESE

POR OTROS

\section{ENCUENTRE \\ ALIADOS}

Avóquese a la reflexión autocritica. Tome la responsabilidad de reconocer y hacer a un lado sus propic prejuicios antes de pedirles a los demás que lo hagan. Comparta sus propias historias de vulnerabilida aprendizaje y crecimiento. Sea el primero en descubrir y convertirse en un ejemplo de estas conductas para los demás.

Diga: "Soy un adalid de la diversidad. Reconozco que he tenido prejuicios y estoy esforzándome en identificarlos, entenderlos y manejarlos. "Los efectos de estos pequeños planteamientos se amplificarán en la medida que otros en la organización las repitan y las lleven a cabo.

Haga preguntas para comprender la causa raiz de los prejuicios. ¿Qué formas del prejuicio son las que están ocurriendo? ¿En que forma se están encubriendo? ¿Cómo lo afectan a usted, a sus colegas, a sus equipos, su lugar de trabajo y a su negocio?

Haga contactos personales y dedique tiempo a comprender la experiencia que tienen sus colaboradores en su lugar de trabajo. No asuma que sabe cuales son las ideas más efectivas y donde están. jPregunte!

Ayude a sus empleados a entender su papel en el cambio. Involucre a los interesados de muchas áreas para que las decisiones sean más inclusivas.

Todo mundo tiene prejuicios inconscientes. Haga que su personal recurra a la estructura para modificar sus prejuicios y conductas en vez de apoyarse en su voluntad.

Deles una oportunidad, principalmente a aquellos que son diferentes. Ábrase a aprender de ellos tanto como ellos esperan aprender de usted. Conviértase intencionalmente en mentor y patrocine a la gente que no es como usted.

Contacte a otras personas que tengan una trayectoria de logros comprobados y que abanderen la causa contra los prejuicios dentro y fuera de la organización. Encuentre a otros que compartan este compromiso y esta pasión para involucrarlos como socios.

PERMANEZCA

Todos tenemos prejuicios que cambian y evolucionan aủn cuando los confrontamos. Manténgase comprometido a sostener esta acción a través del tiempo. 


\section{Anexo 5. Indicadores para la evaluación de la igualdad de género} en las organizaciones (Departamento del trabajo, 2010, pp. 25-56)

\begin{tabular}{|c|c|c|}
\hline Ámbitos & $\#$ & Indicadores \\
\hline \multirow{18}{*}{$\begin{array}{l}\text { 1. Adopción } \\
\text { por parte } \\
\text { de la } \\
\text { dirección }\end{array}$} & 1 & Existencia en la empresa de un plan de igualdad. \\
\hline & 2 & \begin{tabular}{|l}
$\begin{array}{l}\text { Presupuesto específico asignado al diseño y a la } \\
\text { implementación de medidas de igualdad. }\end{array}$ \\
\end{tabular} \\
\hline & 3 & Existencia en la empresa de la figura de agente de igualdad. \\
\hline & 4 & $\begin{array}{l}\text { Horas de dedicación mensuales por parte del personal de la } \\
\text { plantilla a la promoción de la igualdad según categoría } \\
\text { profesional y sexo. }\end{array}$ \\
\hline & 5 & $\begin{array}{l}\text { Acciones desarrolladas para el fomento de una cultura } \\
\text { empresarial basada en la igualdad de oportunidades. }\end{array}$ \\
\hline & 6 & $\begin{array}{l}\text { Referencias a la igualdad de oportunidades en la documentación } \\
\text { corporativa de la empresa. }\end{array}$ \\
\hline & 7 & $\begin{array}{l}\text { Existencia de un plan de responsabilidad social que incorpora la } \\
\text { igualdad de oportunidades. }\end{array}$ \\
\hline & 8 & $\begin{array}{l}\text { Acciones implementadas de responsabilidad social en materia } \\
\text { de igualdad. }\end{array}$ \\
\hline & 9 & $\begin{array}{l}\text { Acciones publicitarias de las acciones de responsabilidad social } \\
\text { en materia de igualdad. }\end{array}$ \\
\hline & 10 & $\begin{array}{l}\text { Referencias a la igualdad de oportunidades en las líneas } \\
\text { estratégicas de la empresa. }\end{array}$ \\
\hline & 11 & $\begin{array}{l}\text { Medidas adoptadas por parte de la empresa que van más allá de } \\
\text { las que exige la normativa. }\end{array}$ \\
\hline & 12 & $\begin{array}{l}\text { Apoyo económico externo para el desarrollo de medidas de } \\
\text { igualdad según la organización impulsora. }\end{array}$ \\
\hline & 13 & $\begin{array}{l}\text { Apoyo metodológico o técnico externo para el desarrollo de } \\
\text { medidas de igualdad, según tipo de apoyo, organización de } \\
\text { apoyo y coste, si se tercia. }\end{array}$ \\
\hline & 14 & $\begin{array}{l}\text { Reconocimientos públicos en materia de igualdad de } \\
\text { oportunidades según tipo: premios, distinciones, } \\
\text { reconocimientos de buenas prácticas o de empresa experta en } \\
\text { igualdad. }\end{array}$ \\
\hline & 15 & $\begin{array}{l}\text { Participación como empresa que promueve la igualdad en } \\
\text { conferencias, jornadas o intercambio de experiencias en materia } \\
\text { de igualdad. }\end{array}$ \\
\hline & 16 & Acciones del plan de igualdad implementadas. \\
\hline & 17 & $\begin{array}{l}\text { Realización de una diagnosis de situación sobre la igualdad de } \\
\text { trato y oportunidades entre hombres } \\
\text { y mujeres en la empresa. }\end{array}$ \\
\hline & 18 & $\begin{array}{l}\text { Acciones correctoras de desigualdad para todos los puntos } \\
\text { débiles detectados en la diagnosis. }\end{array}$ \\
\hline
\end{tabular}




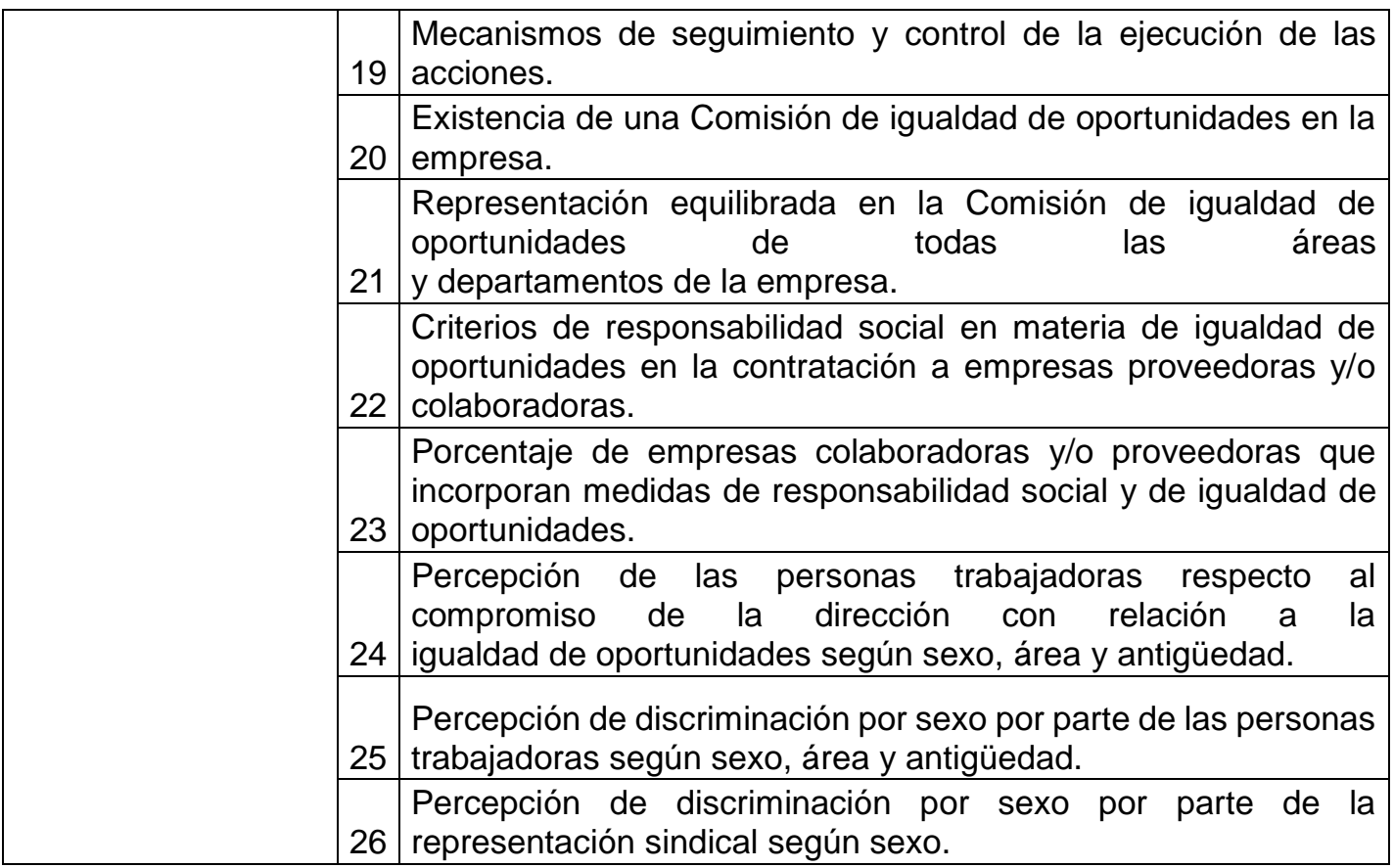




\begin{tabular}{|c|c|c|}
\hline Ámbitos & \# & Indicadores \\
\hline \multirow{18}{*}{$\begin{array}{l}\text { 2. Participación } \\
\text { e implicación } \\
\text { del personal } \\
\text { de la } \\
\text { empresa }\end{array}$} & 1 & $\begin{array}{l}\text { Perfil del agente para la igualdad con la formación específica } \\
\text { requerida. }\end{array}$ \\
\hline & 2 & $\begin{array}{l}\text { Mecanismos de participación de las personas trabajadoras en } \\
\text { la política de igualdad de oportunidades de la empresa. }\end{array}$ \\
\hline & 3 & $\begin{array}{l}\text { Mecanismos de participación de la representación sindical en } \\
\text { la política de igualdad de oportunidades de la empresa. }\end{array}$ \\
\hline & 4 & $\begin{array}{l}\text { Uso de los mecanismos de participación en la política de } \\
\text { igualdad de oportunidades en la empresa por parte de las } \\
\text { personas trabajadoras. }\end{array}$ \\
\hline & 5 & $\begin{array}{l}\text { Mecanismos para garantizar que toda la plantilla pueda } \\
\text { acceder a los canales de participación. }\end{array}$ \\
\hline & 6 & $\begin{array}{l}\text { Acciones informativas a la plantilla sobre la igualdad de } \\
\text { oportunidades en la empresa. }\end{array}$ \\
\hline & 7 & $\begin{array}{l}\text { Horas de las acciones informativas dirigidas a la plantilla } \\
\text { sobre la igualdad de oportunidades. }\end{array}$ \\
\hline & 8 & $\begin{array}{l}\text { Horas de las acciones informativas a la representación de las } \\
\text { personas trabajadoras. }\end{array}$ \\
\hline & 9 & $\begin{array}{l}\text { Mecanismos que garantizan que la información llega a toda } \\
\text { la organización. }\end{array}$ \\
\hline & 10 & $\begin{array}{l}\text { Acciones formativas en materia de igualdad de oportunidades } \\
\text { a las personas trabajadoras. }\end{array}$ \\
\hline & 11 & $\begin{array}{l}\text { Horas de formación en materia de igualdad de oportunidades } \\
\text { a las personas trabajadoras. }\end{array}$ \\
\hline & 12 & $\begin{array}{l}\text { Número de reuniones trimestrales de la Comisión de } \\
\text { igualdad. }\end{array}$ \\
\hline & 13 & $\begin{array}{l}\text { Participación de la representación de las personas } \\
\text { trabajadoras en la selección de los miembros de la Comisión } \\
\text { de igualdad. }\end{array}$ \\
\hline & 14 & $\begin{array}{l}\text { Acciones ejecutadas a partir de las propuestas realizadas por } \\
\text { la Comisión de igualdad de oportunidades. }\end{array}$ \\
\hline & 15 & $\begin{array}{l}\text { Acciones de información a la plantilla sobre el desarrollo y los } \\
\text { resultados del Plan de igualdad. }\end{array}$ \\
\hline & 16 & $\begin{array}{l}\text { Acciones de información a la representación de las personas } \\
\text { trabajadoras sobre el desarrollo y los } \\
\text { resultados del Plan de igualdad. }\end{array}$ \\
\hline & 17 & $\begin{array}{l}\text { Acciones ejecutadas a partir de las propuestas realizadas } \\
\text { para las personas trabajadoras en materia } \\
\text { de igualdad de oportunidades. }\end{array}$ \\
\hline & 18 & $\begin{array}{l}\text { Grado de conocimiento de las medidas de igualdad por parte } \\
\text { de las personas trabajadoras. }\end{array}$ \\
\hline
\end{tabular}




\begin{tabular}{|c|c|c|}
\hline Ámbitos & $\#$ & Indicadores \\
\hline \multirow{12}{*}{$\begin{array}{c}\text { 3. Uso no } \\
\text { discriminatorio } \\
\text { en el lenguaje } \\
\text { y la } \\
\text { comunicación } \\
\text { corporativa }\end{array}$} & 1 & $\begin{array}{l}\text { Existencia de un protocolo donde se establecen los criterios } \\
\text { para una comunicación escrita y oral no sexista. }\end{array}$ \\
\hline & 2 & $\begin{array}{l}\text { Existencia de un protocolo donde se establecen los criterios } \\
\text { para una imagen externa (logotipos } \\
\text { y publicidad) no sexista. }\end{array}$ \\
\hline & 3 & $\begin{array}{l}\text { Incorporación de los criterios para el uso de un lenguaje no } \\
\text { sexista en el Manual de estilo y/o planes } \\
\text { de comunicación de la empresa. }\end{array}$ \\
\hline & 4 & $\begin{array}{l}\text { Mecanismos que garantizan la comunicación escrita (interna } \\
\text { y externa) se utiliza de forma no sexista. }\end{array}$ \\
\hline & 5 & $\begin{array}{l}\text { Mecanismos que garantizan que la comunicación oral se } \\
\text { utiliza de forma no sexista. }\end{array}$ \\
\hline & 6 & $\begin{array}{l}\text { Mecanismos que garantizan una imagen corporativa y } \\
\text { publicidad no sexista. }\end{array}$ \\
\hline & 7 & $\begin{array}{l}\text { Existencia de un plan de comunicación o mecanismos de } \\
\text { difusión de las ofertas laborales que permitan una } \\
\text { representación equilibrada de mujeres y hombres que se } \\
\text { presentan a los procesos de selección de personal. }\end{array}$ \\
\hline & 8 & $\begin{array}{l}\text { Utilización no sexista del lenguaje oral y escrito en los } \\
\text { procesos de selección de personal y la descripción de los } \\
\text { puestos de trabajo. }\end{array}$ \\
\hline & 9 & $\begin{array}{l}\text { Visibilidad de las mujeres en los instrumentos de } \\
\text { comunicación de las empresas (web, intranet y } \\
\text { revista interna de la empresa). }\end{array}$ \\
\hline & 10 & $\begin{array}{l}\text { Los regalos y los artículos de promoción de la empresa son } \\
\text { adecuados para mujeres y hombres. }\end{array}$ \\
\hline & 11 & $\begin{array}{l}\text { Percepción de las personas trabajadoras del uso no sexista } \\
\text { en la comunicación interna y externa de la empresa. }\end{array}$ \\
\hline & 12 & $\begin{array}{l}\text { Conocimiento por parte de toda la plantilla de los criterios de } \\
\text { lenguaje y no comunicación no sexista. }\end{array}$ \\
\hline
\end{tabular}




\begin{tabular}{|c|c|c|}
\hline Ámbitos & \# & Indicadores \\
\hline \multirow{15}{*}{$\begin{array}{l}\text { 4. Participación } \\
\text { igualitaria de } \\
\text { mujeres y } \\
\text { hombres en } \\
\text { los lugares } \\
\text { de trabajo }\end{array}$} & 1 & $\begin{array}{l}\text { Mecanismos de recogida y sistematización de datos } \\
\text { segregados por sexo de la la plantilla } \\
\text { por categoría laboral, área o departamento de trabajo. }\end{array}$ \\
\hline & 2 & $\begin{array}{l}\text { Existencia de una definición de los puestos de trabajo según } \\
\text { las competencias técnicas, profesionales y formativas que } \\
\text { omiten otras características que no son imprescindibles para } \\
\text { el puesto de trabajo y que pueden inducir a algún tipo de } \\
\text { discriminación (disponibilidad horaria, posibilidad de viajar...). }\end{array}$ \\
\hline & 3 & $\begin{array}{l}\text { Existencia de una denominación neutra de cada puesto de } \\
\text { trabajo (que no tenga ninguna connotación } \\
\text { que los marque o predetermine como adecuados o dirigidos a } \\
\text { mujeres u hombres exclusivamente). }\end{array}$ \\
\hline & 4 & $\begin{array}{l}\text { Utilización de técnicas de selección neutras y que omitan la } \\
\text { información personal (estado civil, cargas familiares, etc.). }\end{array}$ \\
\hline & 5 & $\begin{array}{l}\text { Número de personas en la empresa según sexo y porcentaje } \\
\text { comparativo mujeres-hombres. }\end{array}$ \\
\hline & 6 & $\begin{array}{l}\text { Número de personas en cada categoría profesional, según } \\
\text { sexo y porcentaje comparativo mujeres-hombres }\end{array}$ \\
\hline & 7 & $\begin{array}{l}\text { Número de personas en cada área o departamento, por sexo } \\
\text { y porcentaje comparativo mujeres-hombres. }\end{array}$ \\
\hline & 8 & $\begin{array}{l}\text { Número de personas contratadas en el último año, por sexo y } \\
\text { porcentaje comparativo mujeres-hombres. }\end{array}$ \\
\hline & 9 & $\begin{array}{l}\text { Número de personas contratadas según categoría profesional, } \\
\text { por sexo y porcentaje comparativo } \\
\text { mujeres-hombres. }\end{array}$ \\
\hline & 10 & $\begin{array}{l}\text { Número de personas en la empresa que pertenecen a } \\
\text { colectivos con especiales dificultades de } \\
\text { inserción, según sexo y porcentaje comparativo mujeres- } \\
\text { hombres. }\end{array}$ \\
\hline & 11 & $\begin{array}{l}\text { Diferencia entre número de personas que se presentan al } \\
\text { proceso de selección y personas contratadas, según sexo, } \\
\text { categoría laboral y área o departamento de trabajo, y } \\
\text { porcentaje } \\
\text { comparativo mujeres-hombres. }\end{array}$ \\
\hline & 12 & $\begin{array}{l}\text { Mecanismos para garantizar la igualdad de oportunidades y la } \\
\text { no discriminación por razón de sexo en los procesos de } \\
\text { selección de personal. }\end{array}$ \\
\hline & 13 & $\begin{array}{l}\text { Acciones positivas para alcanzar una presencia equilibrada de } \\
\text { mujeres y hombres en las diferentes categorías laborales, } \\
\text { áreas o departamentos. }\end{array}$ \\
\hline & 14 & $\begin{array}{l}\text { Número de mujeres que se han beneficiado de las acciones } \\
\text { positivas para alcanzar una presencia } \\
\text { equilibrada en las diferentes áreas o departamentos de la } \\
\text { empresa. }\end{array}$ \\
\hline & 15 & $\begin{array}{l}\text { Existencia de un protocolo de selección del personal con } \\
\text { criterios claros, objetivos y transparentes que eviten la } \\
\text { discriminación por sexo. }\end{array}$ \\
\hline
\end{tabular}




\begin{tabular}{|l|r|l|}
\hline & & $\begin{array}{l}\text { Existencia de formularios de selección del personal con } \\
\text { criterios claros objetivos y transparentes que } \\
\text { eviten la discriminación por sexo. }\end{array}$ \\
\cline { 2 - 3 } 17 & Miembros del equipo de selección según sexo. \\
\hline & $\begin{array}{l}\text { Existencia de mecanismos que garanticen los conocimientos } \\
\text { y/o experiencia en técnicas de selección no discriminatoria por } \\
\text { parte del equipo de selección. }\end{array}$ \\
\cline { 2 - 3 } 18 & $\begin{array}{l}\text { Percepción de las personas trabajadoras de barreras de } \\
\text { acceso a determinadas áreas o departamentos. }\end{array}$ \\
\hline
\end{tabular}




\begin{tabular}{|c|c|c|}
\hline Ámbitos & $\#$ & Indicadores \\
\hline \multirow{18}{*}{$\begin{array}{l}\text { 5. Presencia de } \\
\text { mujeres en } \\
\text { cargos } \\
\text { directivos de } \\
\text { responsabilidad }\end{array}$} & 1 & $\begin{array}{l}\text { Mecanismos de recogida y sistematización de datos } \\
\text { segregados por sexo de la plantilla por cargos directivos. }\end{array}$ \\
\hline & 2 & $\begin{array}{l}\text { Cargos de responsabilidad de la empresa según nivel } \\
\text { directivo y sexo. Total y y porcentajes } \\
\text { comparativos mujeres-hombres. }\end{array}$ \\
\hline & 3 & $\begin{array}{l}\text { Cargos de responsabilidad según nivel directivo y } \\
\text { antigüedad por sexo. Total } \\
\text { comparativos mujeres-hombres. }\end{array}$ \\
\hline & 4 & $\begin{array}{l}\text { Cargos de responsabilidad según nivel de estudios por } \\
\text { sexo. Total y porcentajes comparativos mujeres-hombres }\end{array}$ \\
\hline & 5 & $\begin{array}{l}\text { Cargos directivos por nivel directivo según antigüedad en el } \\
\text { cargo por sexo. }\end{array}$ \\
\hline & 6 & $\begin{array}{l}\text { Porcentaje de mujeres y porcentaje de hombres con cargos } \\
\text { directivos respecto al total de la plantilla. }\end{array}$ \\
\hline & 7 & $\begin{array}{l}\text { Porcentaje de mujeres y porcentaje de hombres con cargos } \\
\text { directivos respecto al total de los cargos directivos. }\end{array}$ \\
\hline & 8 & $\begin{array}{l}\text { Porcentaje de mujeres con cargos directivos respecto al } \\
\text { total de mujeres de la plantilla. }\end{array}$ \\
\hline & 9 & $\begin{array}{l}\text { Porcentaje de hombres con cargos directivos respecto al } \\
\text { total de hombres de la plantilla. }\end{array}$ \\
\hline & 10 & $\begin{array}{l}\text { Acciones positivas para promover la presencia equilibrada } \\
\text { de mujeres y hombres en cargos directivos. }\end{array}$ \\
\hline & 11 & $\begin{array}{l}\text { Mecanismos de promoción profesional que garantizan la } \\
\text { igualdad de oportunidades y la la no } \\
\text { discriminación por sexo (formación, coaching, mentoring, } \\
\text { etc.). }\end{array}$ \\
\hline & 12 & $\begin{array}{l}\text { Número de personas que han solicitado permisos y ayudas } \\
\text { para participar en cursos de formación por sexos y } \\
\text { porcentaje comparativo mujeres-hombres. }\end{array}$ \\
\hline & 13 & $\begin{array}{l}\text { Número de personas al que se ha concedido permisos y } \\
\text { ayudas para participar en cursos de } \\
\text { formación por sexos y porcentaje comparativo mujeres- } \\
\text { hombres. }\end{array}$ \\
\hline & 14 & $\begin{array}{l}\text { Número de personas participantes en acciones para la } \\
\text { promoción profesional desglosado por sexo. }\end{array}$ \\
\hline & 15 & $\begin{array}{l}\text { Mecanismos que garantizan los conocimientos y/o } \\
\text { experiencia por parte de la dirección de sistemas de } \\
\text { promoción no discriminatorios. }\end{array}$ \\
\hline & 16 & $\begin{array}{l}\text { Número de personas contratadas para ocupar un cargo } \\
\text { directivo según sexo y porcentaje comparativo mujeres- } \\
\text { hombres. }\end{array}$ \\
\hline & 17 & $\begin{array}{l}\text { Número de personas que han participado en procesos de } \\
\text { selección para ocupar un r cargo } \\
\text { directivo por sexo y porcentaje. }\end{array}$ \\
\hline & 18 & $\begin{array}{l}\text { Número de personas que han sido promocionadas en el } \\
\text { último año según sexo. Totales y porcentajes } \\
\text { comparativos mujeres-hombres. }\end{array}$ \\
\hline
\end{tabular}




\begin{tabular}{|l|l|lr|}
\hline \multirow{2}{*}{19} & $\begin{array}{l}\text { Número de personas que han dejado un cargo directivo, } \\
\text { desglosado por causa, nivel de dirección y sexo. Totales y } \\
\text { porcentajes comparativos mujeres-hombres. }\end{array}$ \\
\hline & $\begin{array}{l}\text { Percepción de las personas trabajadoras respecto a la } \\
\text { igualdad de oportunidades en el acceso a } \\
\text { los cargos de responsabilidad. }\end{array}$ \\
\hline 21 & $\begin{array}{l}\text { Conocimiento de las vacantes en cargos de } \\
\text { responsabilidad por parte de toda la plantilla. }\end{array}$ \\
\hline
\end{tabular}




\begin{tabular}{|c|c|c|}
\hline Ámbitos & \# & Indicadores \\
\hline \multirow{20}{*}{$\begin{array}{l}\text { 6. Medidas } \\
\text { implantadas } \\
\text { para mejorar } \\
\text { la } \\
\text { compatibilidad } \\
\text { de la vida } \\
\text { personal y } \\
\text { laboral }\end{array}$} & 1 & Existencia en la empresa de un plan de conciliación. \\
\hline & 2 & $\begin{array}{l}\text { Medidas y servicios para facilitar la compatibilidad del tiempo } \\
\text { laboral y personal (jornada continuada, horario flexible, } \\
\text { reducción de la jornada, etc.). }\end{array}$ \\
\hline & 3 & $\begin{array}{l}\text { Medidas y servicios que amplíen el marco legislativo de } \\
\text { referencia para facilitar la compatibilidad o conciliación del } \\
\text { tiempo laboral y personal. }\end{array}$ \\
\hline & 4 & $\begin{array}{l}\text { Las medidas destinadas a facilitar la compatibilidad entre } \\
\text { tiempo laboral y personal van dirigidas a todo el personal: } \\
\text { mujeres y hombres de todos los niveles jerárquicos. }\end{array}$ \\
\hline & 5 & $\begin{array}{l}\text { Las medidas destinadas a compatibilizar el tiempo laboral y } \\
\text { personal son conocidas por toda la plantilla. }\end{array}$ \\
\hline & 6 & $\begin{array}{l}\text { Las medidas de gestión del tiempo establecidas por la } \\
\text { organización son utilizadas por ambos sexos. }\end{array}$ \\
\hline & 7 & $\begin{array}{l}\text { La conciliación de la vida personal y laboral forma parte de la } \\
\text { cultura organizativa de la empresa. }\end{array}$ \\
\hline & 8 & $\begin{array}{l}\text { La dirección de la empresa ha asumido la conciliación a nivel } \\
\text { personal y utiliza las medidas existentes actuando como } \\
\text { modelo para el resto de la plantilla. }\end{array}$ \\
\hline & 9 & $\begin{array}{l}\text { Personas con horario flexible y porcentaje comparativo entre } \\
\text { mujeres y hombres. }\end{array}$ \\
\hline & 10 & Existencia de bancos de horas a disposición de la plantilla. \\
\hline & 11 & $\begin{array}{l}\text { Número de personas que utilizan el banco de horas por sexo } \\
\text { y porcentaje comparativo entre mujeres y hombres. }\end{array}$ \\
\hline & 12 & Posibilidad de teletrabajo. \\
\hline & 13 & $\begin{array}{l}\text { Número de personas que utilizan el teletrabajo por sexo y } \\
\text { porcentaje comparativo entre mujeres y hombres. }\end{array}$ \\
\hline & 14 & $\begin{array}{l}\text { Existencia de servicios a las personas que faciliten la } \\
\text { compatibilización del tiempo laboral y personal (tickets } \\
\text { guardería, ticket restaurante, comedor de empresa, servicios } \\
\text { de salud, guardería de empresa, etc.). }\end{array}$ \\
\hline & 15 & Realización de reuniones dentro del horario laboral habitual \\
\hline & 16 & $\begin{array}{l}\text { Número de personas que se acogen a permisos por adopción } \\
\text { o nacimiento por sexo y porcentaje comparativo entre } \\
\text { mujeres y hombres. }\end{array}$ \\
\hline & 17 & $\begin{array}{l}\text { Número de mujeres y hombres que se han acogido a los } \\
\text { derechos de cuidado de hijos, hijas y } \\
\text { familiares dependientes. }\end{array}$ \\
\hline & 18 & $\begin{array}{l}\text { Porcentaje de mujeres y hombres por categorías y edad que } \\
\text { se han acogido a los derechos de cuidado de hijos, hijas y } \\
\text { familiares dependientes. }\end{array}$ \\
\hline & 19 & $\begin{array}{l}\text { Número de hombres que han hecho uso de la baja por } \\
\text { maternidad y porcentaje por departamentos y categorías. }\end{array}$ \\
\hline & 20 & $\begin{array}{l}\text { Número de hombres que se han acogido al permiso de } \\
\text { paternidad por departamentos y categorías. }\end{array}$ \\
\hline
\end{tabular}




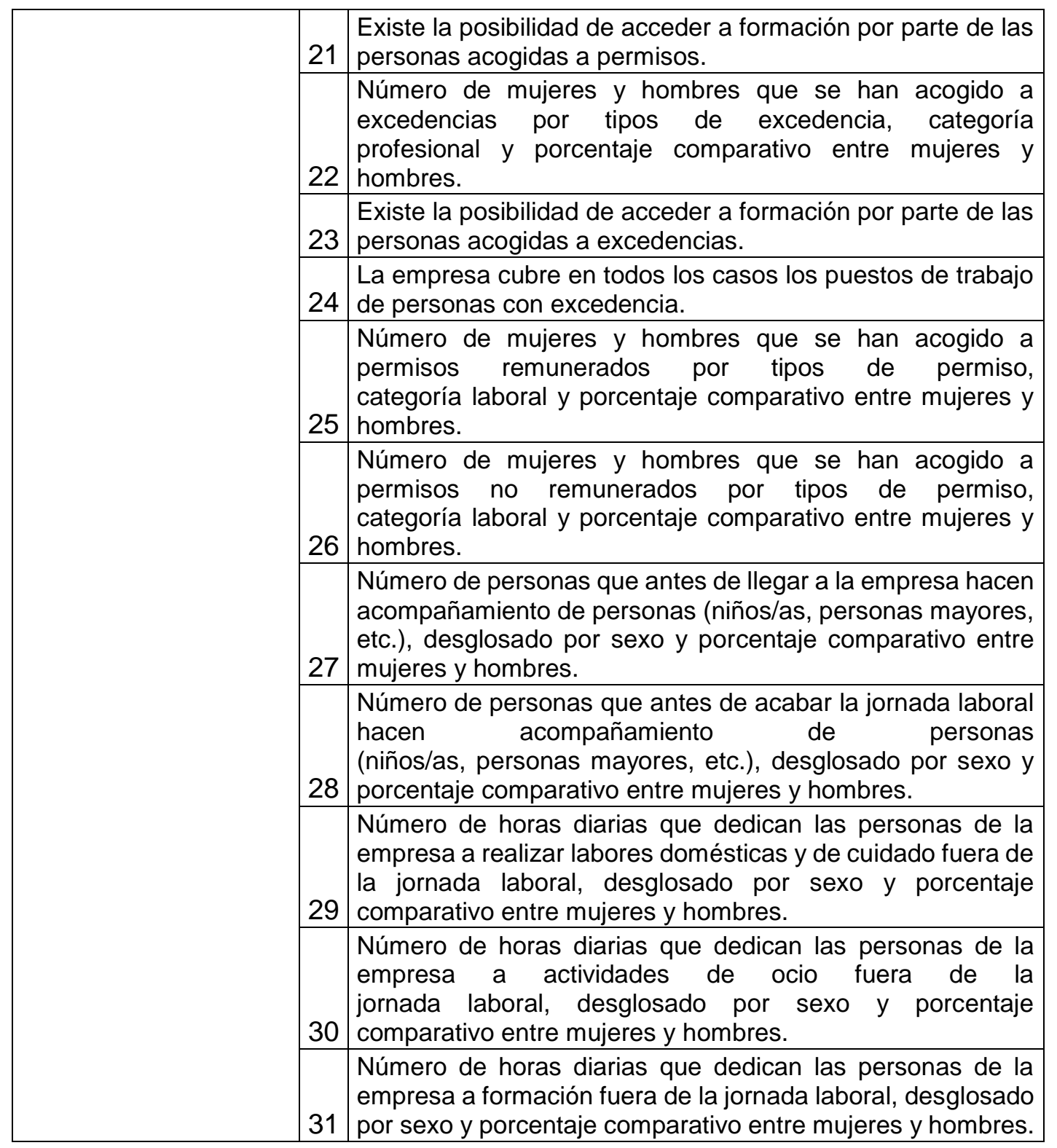




\begin{tabular}{|c|c|c|}
\hline Ámbitos & $\#$ & Indicadores \\
\hline \multirow{16}{*}{$\begin{array}{l}\text { 7. Adopción } \\
\text { de } \\
\text { medidas } \\
\text { de } \\
\text { prevención } \\
\text { de salud } \\
\text { y riesgos } \\
\text { laborales } \\
\text { con } \\
\text { perspectiva } \\
\text { de género }\end{array}$} & 1 & $\begin{array}{l}\text { Existen datos sobre salud laboral de la empresa desagregados } \\
\text { por sexo. }\end{array}$ \\
\hline & 2 & $\begin{array}{l}\text { Existe un plan de seguridad y salud laboral que tenga en cuenta } \\
\text { la especificidad de las mujeres y los } \\
\text { hombres en la definición, la prevención y la evaluación de los } \\
\text { riesgos laborales }\end{array}$ \\
\hline & 3 & $\begin{array}{l}\text { Se han adaptado las condiciones de trabajo teniendo en cuenta } \\
\text { que los riesgos pueden ser diferentes en función del sexo de las } \\
\text { personas. }\end{array}$ \\
\hline & 4 & $\begin{array}{l}\text { Número de accidentes que han tenido lugar dentro de la } \\
\text { empresa según la gravedad por sexo y porcentaje comparativo } \\
\text { entre mujeres y hombres. }\end{array}$ \\
\hline & 5 & $\begin{array}{l}\text { Número de accidentes que han tenido lugar dentro de la } \\
\text { empresa según tipología de riesgo (seguridad, higiene, } \\
\text { ergonomía y psicosociales) por sexo y porcentaje comparativo } \\
\text { entre mujeres y hombres. }\end{array}$ \\
\hline & 6 & $\begin{array}{l}\text { Se tiene en cuenta la influencia de la situación social y familiar } \\
\text { de las mujeres y de los hombres para } \\
\text { establecer las medidas de prevención de la salud y riesgos } \\
\text { laborales. }\end{array}$ \\
\hline & 7 & $\begin{array}{l}\text { En el caso de que la empresa tenga un comité de seguridad y } \\
\text { salud, hay una representación paritaria de hombres y mujeres. }\end{array}$ \\
\hline & 8 & $\begin{array}{l}\text { Existen medidas específicas para prevenir el acoso sexual y por } \\
\text { razón de sexo en la empresa (acciones formativas, códigos de } \\
\text { buenas prácticas y campañas de sensibilización). }\end{array}$ \\
\hline & 9 & $\begin{array}{l}\text { La empresa ha realizado una declaración institucional donde } \\
\text { explicita su compromiso para la parán } \\
\text { erradicación y prevención del acoso sexual y el acoso por razón } \\
\text { de sexo. }\end{array}$ \\
\hline & 10 & $\begin{array}{l}\text { Existe un protocolo para prevenir, detectar y actuar en casos de } \\
\text { acoso sexual y por razón de sexo en el trabajo. }\end{array}$ \\
\hline & 11 & $\begin{array}{l}\text { Existen canales para recoger denuncias o reclamaciones en } \\
\text { caso de conocer o ser víctima de acoso sexual y por razón de } \\
\text { sexo en el trabajo. }\end{array}$ \\
\hline & 12 & $\begin{array}{l}\text { Están perfectamente identificadas las personas responsables } \\
\text { de atender a las que formulen una una } \\
\text { queja o denuncia en el ámbito del acoso sexual y por razón de } \\
\text { sexo. }\end{array}$ \\
\hline & 13 & $\begin{array}{l}\text { Las personas que atienden las quejas están formadas para la } \\
\text { labor que cumplen. }\end{array}$ \\
\hline & 14 & $\begin{array}{l}\text { Se hace un tratamiento reservado de las denuncias de hecho } \\
\text { que puedan ser constitutivos de acoso } \\
\text { sexual y por razón de sexo. }\end{array}$ \\
\hline & 15 & $\begin{array}{l}\text { Dispone de un código de buenas prácticas para evitar el acoso } \\
\text { sexual y por razón de sexo. }\end{array}$ \\
\hline & 16 & $\begin{array}{l}\text { Se ha realizado difusión y campañas informativas de este código } \\
\text { de buenas prácticas. }\end{array}$ \\
\hline
\end{tabular}




\begin{tabular}{|l|l|l|}
\hline & $\begin{array}{l}\text { En cumplimiento de la normativa, en cuántas ocasiones ha } \\
\text { informado la representación sindical del personal a la dirección } \\
\text { de la empresa de las conductas o comportamientos de que } \\
\text { tengan conocimiento o que puedan propiciar el acoso sexual y } \\
\text { por razón de sexo. }\end{array}$ \\
\cline { 2 - 3 } 18 & $\begin{array}{l}\text { Número de casos de acoso sexual y por razón de sexo en el } \\
\text { último año. }\end{array}$ \\
\hline 19 & $\begin{array}{l}\text { Existencia de baños y vestuarios diferenciados para hombres y } \\
\text { mujeres. }\end{array}$ \\
\hline 20 & $\begin{array}{l}\text { Existen medidas específicas de prevención de riesgos laborales } \\
\text { en el caso de mujeres embarazadas } \\
\text { y en periodo de lactancia. }\end{array}$ \\
\hline 21 & $\begin{array}{l}\text { Se incluyen en la formación en materia preventiva las } \\
\text { situaciones de riesgo para el embarazo y la lactancia. }\end{array}$ \\
\hline & $\begin{array}{l}\text { Se incluyen en los planes y medidas de emergencias la } \\
\text { presencia de trabajadoras embarazadas o de mujeres con las } \\
\text { mismas condiciones ajenas a la empresa. }\end{array}$ \\
\hline
\end{tabular}




\begin{tabular}{|c|c|c|}
\hline Ámbitos & $\#$ & Indicadores \\
\hline \multirow{14}{*}{$\begin{array}{l}\text { 8. Igualdad } \\
\text { retributiva } \\
\text { entre } \\
\text { mujeres y } \\
\text { hombres }\end{array}$} & 1 & $\begin{array}{l}\text { Existencia de mesas retributivas que incluyen todos los puestos } \\
\text { de trabajo existentes en la empresa. }\end{array}$ \\
\hline & 2 & $\begin{array}{l}\text { Transparencia de la política retributiva de la empresa y de la } \\
\text { estructura salarial, incluyendo la definición } \\
\text { y las condiciones de todos los elementos, pluses o complementos } \\
\text { del sector o de la empresa. }\end{array}$ \\
\hline & 3 & $\begin{array}{l}\text { Existencia de una definición clara, objetiva y neutra de los } \\
\text { conceptos variables de las retribuciones. }\end{array}$ \\
\hline & 4 & $\begin{array}{l}\text { Existencia de una delimitación del porcentaje de retribución } \\
\text { variable sobre la retribución total. }\end{array}$ \\
\hline & 5 & $\begin{array}{l}\text { Retribución anual media de las mujeres y de los hombres, } \\
\text { desglosado por cada uno de los componentes salariales, así como } \\
\text { por categoría profesional, por colectivo y por tipo de jornada (para } \\
\text { comprobar que no se discrimina el personal a tiempo parcial se } \\
\text { puede analizar la retribución/hora). }\end{array}$ \\
\hline & 6 & $\begin{array}{l}\text { Retribución en especies y gratificaciones (coche de empresa, } \\
\text { regalos, etc.). }\end{array}$ \\
\hline & 7 & $\begin{array}{l}\text { Número de mujeres y de hombres y porcentajes por niveles } \\
\text { retributivos. }\end{array}$ \\
\hline & 8 & $\begin{array}{l}\text { Porcentaje de mujeres respecto al total de mujeres de la empresa } \\
\text { y porcentaje de hombres de respecto } \\
\text { al total de hombres de la empresa, por niveles retributivos. }\end{array}$ \\
\hline & 9 & $\begin{array}{l}\text { Existencia de una valoración de los puestos de trabajo en función } \\
\text { de las labores realizadas y el nivel de responsabilidad. }\end{array}$ \\
\hline & 10 & $\begin{array}{l}\text { Existencia de retribuciones asociadas a los resultados } \\
\text { individuales o al tiempo de presencia. }\end{array}$ \\
\hline & 11 & $\begin{array}{l}\text { Número de mujeres y de hombres entre las personas a las que se } \\
\text { les ha subido el salario en los últimos } \\
\text { dos años y porcentaje comparativo entre mujeres y hombres. }\end{array}$ \\
\hline & 12 & $\begin{array}{l}\text { Porcentaje de mujeres respecto al total de mujeres de la empresa } \\
\text { y porcentaje de hombres respecto al total de hombres de la } \\
\text { empresa a los que se les ha subido el salario en los últimos dos } \\
\text { años. }\end{array}$ \\
\hline & 13 & $\begin{array}{l}\text { Incremento salarial medio de las mujeres e incremento salarial } \\
\text { medio de los hombres. }\end{array}$ \\
\hline & 14 & $\begin{array}{l}\text { Nombre de mujeres y de hombres acogidos a los beneficios } \\
\text { sociales de la empresa: seguro médico, plan de pensiones, plan } \\
\text { de jubilaciones, coche de empresa y porcentaje comparativo entre } \\
\text { mujeres y hombres. }\end{array}$ \\
\hline
\end{tabular}




\begin{tabular}{|c|c|c|}
\hline Ámbitos & \# & Indicadores \\
\hline \multirow{20}{*}{$\begin{array}{l}\text { 9. Condiciones } \\
\text { laborales } \\
\text { igualitarias } \\
\text { para } \\
\text { mujeres y } \\
\text { hombres }\end{array}$} & 1 & $\begin{array}{l}\text { Existen datos desagregados por sexos y por categoría } \\
\text { profesional de las condiciones laborales: tipos de contrato, } \\
\text { jornada y horarios, niveles, grupos y categorías profesionales. }\end{array}$ \\
\hline & 2 & $\begin{array}{l}\text { Se hacen públicos datos desagregados por sexos y por } \\
\text { categoría laboral de las condiciones laborales: tipos } \\
\text { de contrato, jornada y horarios. }\end{array}$ \\
\hline & 3 & $\begin{array}{l}\text { Número de mujeres y hombres con contrato laboral indefinido } \\
\text { y porcentaje comparativo entre mujeres y hombres. }\end{array}$ \\
\hline & 4 & $\begin{array}{l}\text { Porcentaje de mujeres con contrato laboral indefinido respecto } \\
\text { al total de mujeres de la plantilla. }\end{array}$ \\
\hline & 5 & $\begin{array}{l}\text { Porcentaje de hombres con contrato laboral indefinido respecto } \\
\text { al total de hombres de la plantilla. }\end{array}$ \\
\hline & 6 & $\begin{array}{l}\text { Número de mujeres y hombres con contrato laboral temporal y } \\
\text { porcentaje comparativo entre mujeres y hombres. }\end{array}$ \\
\hline & 7 & $\begin{array}{l}\text { Porcentaje de mujeres con contrato laboral temporal respecto } \\
\text { al total de mujeres de la plantilla. }\end{array}$ \\
\hline & 8 & $\begin{array}{l}\text { Porcentaje de hombres con contrato laboral temporal respecto } \\
\text { al total de hombres de la plantilla. }\end{array}$ \\
\hline & 9 & $\begin{array}{l}\text { Número de mujeres y hombres con jornada completa y } \\
\text { porcentaje comparativo entre mujeres y hombres. }\end{array}$ \\
\hline & 10 & $\begin{array}{l}\text { Porcentaje de mujeres con jornada completa respecto al total } \\
\text { de mujeres de la plantilla. }\end{array}$ \\
\hline & 11 & $\begin{array}{l}\text { Porcentaje de hombres con jornada completa respecto al total } \\
\text { de hombres de la plantilla. }\end{array}$ \\
\hline & 12 & $\begin{array}{l}\text { Número de mujeres y hombres con jornada reducida y } \\
\text { porcentaje comparativo entre mujeres y hombres. }\end{array}$ \\
\hline & 13 & $\begin{array}{l}\text { Porcentaje de mujeres con jornada reducida respecto al total } \\
\text { de mujeres de la plantilla. }\end{array}$ \\
\hline & 14 & $\begin{array}{l}\text { Porcentaje de hombres con jornada reducida respecto al total } \\
\text { de hombres de la plantilla. }\end{array}$ \\
\hline & 15 & $\begin{array}{l}\text { Porcentaje de mujeres y hombres con jornada reducida con } \\
\text { familiares dependientes (personas mayores, } \\
\text { con discapacidad e hijos e hijas menores de } 12 \text { años). }\end{array}$ \\
\hline & 16 & $\begin{array}{l}\text { Porcentaje de mujeres y hombres con horario de noche, de } \\
\text { festivos o de fines de semana. }\end{array}$ \\
\hline & 17 & $\begin{array}{l}\text { Número medio de horas extra trabajadas por las mujeres y los } \\
\text { hombres en el último año y porcentaje comparativo } \\
\text { entre mujeres y hombres. }\end{array}$ \\
\hline & 18 & $\begin{array}{l}\text { Número de mujeres y hombres que deben viajar por motivo de } \\
\text { su trabajo y porcentaje comparativo entre mujeres y hombres }\end{array}$ \\
\hline & 19 & $\begin{array}{l}\text { Número medio de días que han viajado las mujeres y los } \\
\text { hombres en el último año. }\end{array}$ \\
\hline & 20 & $\begin{array}{l}\text { Número medio de noches que las mujeres pasan fuera de la } \\
\text { vivienda habitual por viaje y número medio de noches por } \\
\text { hombres. }\end{array}$ \\
\hline
\end{tabular}




\begin{tabular}{|l|l|l|}
\hline & $\begin{array}{l}\text { Mecanismos para la asignación de tipos de jornada y horarios, } \\
\text { o que favorezcan a las personas que tienen } \\
\text { a su cargo familiares dependientes (personas mayores, con } \\
\text { discapacidad e hijos e hijas menores de 12 años). }\end{array}$ \\
\hline 22 & $\begin{array}{l}\text { Medidas que incentiven que los hombres se acojan a la jornada } \\
\text { reducida para cuidar a personas. }\end{array}$ \\
\hline \multirow{2}{*}{23} & $\begin{array}{l}\text { Número de personas con baja voluntaria, desglosado por sexo } \\
\text { y categoría laboral y porcentaje comparativo entre mujeres y } \\
\text { hombres. }\end{array}$ \\
\hline \multirow{2}{*}{24} & $\begin{array}{l}\text { Número de personas despedidas, desglosado por sexo y } \\
\text { categoría laboral y porcentaje comparativo entre mujeres y } \\
\text { hombres. }\end{array}$ \\
\hline \multirow{2}{*}{25} & $\begin{array}{l}\text { Número de personas a las que se les ha ofrecido acogerse a la } \\
\text { jubilación anticipada, desglosado por sexo y categoría } \\
\text { profesional y porcentaje comparativo. }\end{array}$ \\
\hline \multirow{2}{*}{$\begin{array}{l}\text { La asignación de espacios para mujeres y hombres } \\
\text { (despachos, superficie, privacidad, tipo de iluminación, } \\
\text { ventanas, temperatura, ruido, etc.) se hace con las mismas } \\
\text { condiciones. }\end{array}$} \\
\hline \multirow{2}{*}{$\begin{array}{l}\text { Adecuación de lugar de trabajo y de los espacios (salas, } \\
\text { vestidores, lavabos, duchas, etc.) a las características y } \\
\text { necesidades de las mujeres y los hombres. }\end{array}$} \\
\hline 28 & $\begin{array}{l}\text { En el caso de que el personal lleve uniforme, se ha diseñado } \\
\text { especialmente para mujeres y para hombres teniendo en } \\
\text { cuenta las diferencias físicas. }\end{array}$ \\
\hline 29 & $\begin{array}{l}\text { En el caso de que el personal lleve uniforme, se da a escoger } \\
\text { a las mujeres la posibilidad de llevar falda y pantalón. }\end{array}$ \\
\hline \multirow{2}{*}{$\begin{array}{l}\text { Porcentaje de mujeres y de hombres que no han superado el } \\
\text { periodo de prueba (después de una nueva contratación) en el } \\
\text { último año. }\end{array}$} \\
\hline
\end{tabular}




\section{Bibliografía}

Abay Analistas Económicos y Sociales. (2011). Presencia de mujeres en puestos de responsabilidad y competitividad empresarial. Madrid: Consejo Superior de Cámaras de Comercio.

Abramo, L. (2006). Trabajo decente y equidad de género en América Latina. Santiago de Chile: Organización Internacional del Trabajo.

Adams, R. (2016). Women on boards: The superheroes of tomorrow?. The Leadership Quarterly.

Agencia Europea para la Seguridad y la Salud en el Trabajo. (2005). La responsabilidad social de las empresas y la seguridad y la salud en el trabajo. Luxemburgo: Oficina de Publicaciones Oficiales de las Comunidades Europeas.

Agut, S., \& Martín, P. (2007). Factores que dificultan el acceso de las mujeres a puestos de responsabilidad: una revisión teórica. Apuntes de psicología, 25(2), 201-214.

Aláez, R., Longas, J., \& Ullibarri, M. (2003). Diferencias salariales en España: un análisis sectorial/regional. Investigaciones Regionales, (3), 524.

Alba, A. (2000). La Riqueza de Las Familias: Mujer y Mercado de Trabajo en la España Democrática. Barcelona: Editorial Ariel.

Albiol, I., Alfonso, C., Blasco, J., Camps, L., García, M., \& Rodríguez, G. (2007). Los aspectos laborales de la ley de igualdad. Valencia: Tirat lo blanch.

Alonso, M. (2002). Las académicas: profesorado universitario y género. Revista de Educación, (328), pp. 465-475. 
Álvaro, C. (2013, 13 de noviembre). Latinoamérica: pocas ejecutivas, CEO y consejeras multilatinas. Capital Madrid. Edición Digital. Obtenido de: $\quad$ https://www.capitalmadrid.com/2013/11/13/31824/latinoamericapocas-ejecutivas-ceo-y-consejeras-en-las-multilatinas.html

Alventosa, J. (2008). Discriminación por orientación sexual e identidad de género en el derecho español. Madrid: Ministerio de Trabajo y Asuntos Sociales, Subdirección General de Información Administrativa y Publicaciones.

Amnistía Internacional. (2009). La trampa del género: mujeres, violencia y pobreza. Madrid: Amnistía Internacional.

Arranz, F. (2004). Las mujeres y la universidad española: estructuras de dominación y disposiciones feminizadas en el profesorado universitario. Política y sociedad, 41(2), 223-242.

Arredondo, F., Velásquez, L., de la Garza, J. (2013). Políticas de diversidad y flexibilidad laboral en el marco de la responsabilidad social empresarial. Un análisis desde la perspectiva de género. Estudios Gerenciales, 29(127), 161-166.

Austrian Institute for SME Research. (2010, marzo). Study on nonlegislative initiatives for companies to promote gender equality at the workplace - Contract VC/2008/0348. Viena: Austrian Institute for SME Research.

Ballester, M. (2006). Guía sobre el acoso moral en el trabajo. Sevilla: Consejo Andaluz de Relaciones Laborales.

Banco Mundial. (2010). Mujeres Empresarias: Barreras y oportunidades en el sector privado formal en América Latina. Washington: Banco Internacional de Reconstrucción y Fomento Banco Mundial.

Barberá, E. (2004). Diversidad de género, igualdad de oportunidades y entornos laborales. (La diversidad de género como estrategia 
favorecedora de la igualdad de oportunidades en los entornos laborales). Revista de Economía Pública, Social y Cooperativa, (50), 37-53.

Barberá, E., Sarrió, M., \& Ramos, A. (2000-a). Mujeres directivas: promoción profesional en España y en el Reino Unido. Valencia: Universitat de Valencia.

Barberá, E., Sarrió, M., \& Ramos, A. (2000-b). Mujeres y estilos de dirección: el valor de la diversidad. Psychosocial Intervention, 9(1), 49-62. Barberá, T., Estellés, S., \& Dema, C. (2009, septiembre). Obstáculos en la promoción profesional de las mujeres: El "techo de cristal". En 3rd International Conference on Industrial Engineering and Industrial Management, (pp. 133-142). Barcelona.

Barsh, J., Cranston, S., \& Craske, R. (2008). Centered leadership: How talented women thrive. A new approach to leadership can help women become more self-confident and effective business leaders. McKinsey Quarterly, (4), 35-48.

Bauer, S., Finnegan, G., \& Haspels, N. (2011). Género y Emprendimiento: Guía de formación para mujeres empresarias. Paquete de formación y herramientas. San José: Organización Internacional del Trabajo.

Becker, G. (2010). The Economics of Discrimination (2 ed.). Chicago: University of Chicago Press.

Benko, C., \& Pelster, B. (2013). How women decide. Harvard Business Review,

Birgin, H., Ackerman, M., Cortés, R., Golbert, L., Mercado, M., \& Pautassi, L. (2000). Ley, mercado y discriminación: el género del trabajo. Buenos aires: Editorial Biblos.

Bodelón, E., Igareda, N., Rodríguez, R., Barcons, M., \& Garrido, L. (2014).

El impacto de los planes de igualdad en las empresas. Barcelona: Universidad Autónoma de Barcelona. 
Boderías, C. (2007). Género y políticas del trabajo en la España contemporánea 1836-1936. Barcelona: Icaria Editorial.

Browne, K. (1999). Divided Labours: An evolutionary view of women at work. New Haven: Yale University Press.

Burgess, Z. \& Tharenou, P. (2002). Women Board Directors: Characteristics of the Few. Journal of Business Ethics, (37), 39-49.

Bustelo, M. (2004). La evaluación de las políticas de género en España. Madrid: Editorial Catarata.

Bustos, E. (2015, 13 de julio). Nuevas tecnologías: violencia de género, también en internet. $A B C$ edición digital: http://www.abc.es/toledo/20150713/abcp-nuevas-tecnologias-violenciagenero-20150713.html

Cabanas, C., Morales, E. \& Molinero, S. (2014). Mujeres en la Alta Dirección en España. Investigaciones y Publicaciones II, Centro de Gobierno Corporativo

Cáceres, M., Trujillo, J., Hinojo, F., Aznar, I., \& García, M. (2012). Tendencias actuales de género y el liderazgo de la dirección en los diferentes niveles educativos. Educar, 48(1), 69-89.

Callejo, J., Gómez, C., \& Casado, E. (2013). El techo de cristal en el sistema educativo español. Madrid: UNED Ediciones.

Carli, L (2001). Gender and social influence. Journal of Social Issues, 57 (4),725-741

Carneiro, M. (2009). Pido para ti una vejez tranquila, Más allá de la responsabilidad social empresarial: Deliberación sobre el beneficio que las empresas aportan al bienestar social. Oleiros: Netbiblo.

Carnicer, L., Martínez, A., Pérez, M., \& Vela, M. (2007). La diversidad de género en la alta dirección de las mayores empresas españolas. 
Investigaciones Europeas De Dirección De La Empresa (IEDEE), 13(2), 33-53.

Carrasco, A. \& Laffarga, J. (2007). La diversidad de género en el Código Unificado español y la práctica empresarial. Pecvnia, 4, 1-25

Carreras, I., Leaverton, A. \& Sureda, M. (2009). Líderes para el cambio social. Características y competencias del liderazgo en la ONG. Barcelona: Instituto de Innovación Social de Esade.

Carrillo, I. (2011). Desvelar las desigualdades: la educación como posibilidad. En I. Carrillo, I. Comins, A. Gómez, M. Sánchez, N. Santaner, A. Vega, \& P. Zaccaria, Mujeres, género y desarrollo: Saberes interdisciplinares (pp. 117-134). Vic: Servei de Publicacions de la Universitat de Vic.

Carroll, A. (2000). Corporate Social Responsibility Evolution of a Definitional Construct. Business Society, 38(3), 268-295.

Carter, N., \& Silva, C. (2010). Women in management: Delusions of progress. Harvard Business Review, 88(3), 19-21.

Casado, F., Viñuales, V., \& Jáuregui, R. (2006). La RSE ante el espejo: carencias, complejos y expectativas de la empresa responsable en el siglo XXI. Zaragoza: Prensas Universitarias de Zaragoza.

Castro, R. \& Casique, I. (2008). Estudios sobre cultura, género y violencia contra las mujeres. Cuernavaca: UNAM Centro Regional de Investigaciones Multidisciplinarias.

Castro \& Álvarez. (s.f.) La Igualdad en la Responsabilidad Social de las Empresas.

http://www.castello.es/web20/archivos/contenidos/61/D021_Igualdad_R SE.pdf 
Catalyst. (2011). Media Announcements: No News Is Bad News: Women's Leadership Still Stalled in Corporate America. New york: Catalyst.

Catalyst. (2015-a, January 13). 2014 Catalyst Census: Women Board Directors. New york: Catalyst.

Catalyst. (2015-b, January 13). Companies Behaving Responsibly: Gender Diversity on Boards. New york: Catalyst.

Catalyst. (2015-c, May 22). La inclusión es importante. New york: Catalyst.

Catalyst. (2015-d, June 4). Como combatir el prejuicio inconsciente. New york: Catalyst.

Catalyst. (2015-e, July 9). Quick Take: Women in Academia. New york: Catalyst.

Catalyst. (2015-f, October 6). Revealing the Real Millennials: Workplace Gender Bias. New york: Catalyst.

Catalyst. (2016-a, January 21). Gap Inc.-Women and opportunity. New york: Catalyst.

Catalyst. (2016-b, February 3). Pyramid: Women in S\&P 500 Companies. New york: Catalyst.

Catalyst. (2016-c, February 3). Quick Take: Women in Goverment. New york: Catalyst.

Catalyst, (2016-d, February 4). Quick Take: Women of Color in the United States. New york: Catalyst.

Cea, M. (2010). Metodología cuantitativa: estrategias y técnicas de investigación social. Madrid: Síntesis.

Centro Interuniversitario de Desarrollo (CINDA). (2010). El rol de las universidades en el desarrollo científico y tecnológico. Educación superior en Iberoamérica, Informe 2010. Santiago de Chile: RIL editores. 
Centro Interuniversitario de Desarrollo (CINDA). (2015). La transferencia de I+D, la innovación y el emprendimiento en las universidades: Educación superior en Iberoamérica Informe 2015. Santiago de Chile: RIL editores.

CEPAL, FAO, ONU Mujeres, PNUD \& OIT. (2013). Informe regional: Trabajo decente e igualdad de género. Políticas para mejorar el acceso y la calidad del empleo. Santiago: Organización Internacional del Trabajo. CEPC. (2010). Legislación sobre Igualdad de trato y no Discriminación. Madrid: Centro de Estudios Políticos y Constitucionales.

Chacartegui, C. (2001). Discriminación y orientación sexual del trabajador (1a. ed.). Valladolid: Lex Nova.

Charlo, M., \& Núñez, M. (2007). Introducción de la perspectiva de género en la investigación empírica en contabilidad desde un marco teórico sociológico-institucional. En J. Ayala, Conocimiento, innovación y emprendedores: Camino al futuro (p. 183). Logroño: Universidad de La Rioja.

Chinchilla, N., León, C., Torres, E., \& Canela, M. (2006, mayo). Frenos e impulsores en la trayectoria profesional de las mujeres directivas. Documento de Investigación DI No. 632, Navarra: IESE Business School. Chizema, A., Kamuriwo, D., \& Shinozawa, Y. (2015). Women on corporate boards around the world: Triggers and barriers. The Leadership Quarterly, 26 (6), 1051-1065.

CNMV. (2015-a). Informe de Gobierno Corporativo de las entidades emisoras de valores admitidos a negociación en mercados secundarios oficiales. Ejercicio 2014. Madrid: Comisión Nacional del Mercado de Valores.

CNMV. (2015-b). Código de buen gobierno de las sociedades cotizadas. Madrid: Comisión Nacional del Mercado de Valores. 
Colom, A. (2000). Desarrollo sostenible y educación para el desarrollo. Barcelona: Octaedro.

Comisión Europea. (2008). La legislación en materia de igualdad de género en la Unión Europea. Luxemburgo: Oficina de Publicaciones Oficiales de las Comunidades Europeas.

Comisión Europea. (2012). Propuesta de DIRECTIVA del Parlamento Europeo y del Consejo destinada a mejorar el equilibrio de género entre los administradores no ejecutivos de las empresas cotizadas y por la que se establecen medidas afines. Bruselas: Comisión Europea.

Contreras, F., Pedraza, J., \& Mejía, X. (2012). La mujer y el liderazgo empresarial. Diversitas - Perspectivas en Psicología, 8 (1), 183-194.

Corral, J. (2007). Dirección de personas: escuchar, influenciar y desarrollar a los colaboradores. Oleiros: Netbiblo.

Cuadrado, I., Navas, M., \& Molero, F. (2006). Mujeres y liderzgo: Claves psicosociales del techo de cristal. Madrid: Sanz y Torres.

de Anca, C., \& Aragón, S. (2007). La mujer directiva en España: catalizadores e inhibidores en las decisiones de trayectoria profesional. Academia, Revista Latinoamericana de Administración, (38), 45-63.

de Cabo, G., \& Garzón, M. (2007). Diferencia y discriminación salarial por razón de sexo. Madrid: Instituto de la mujer (MTAS).

de Cabo, G., \& Rodríguez, M. (2014, julio). Elaboración de un índice sintético de discriminación salarial. Madrid: Centro de Estudios Económicos Tomillo.

de Lucio, J., del Valle, M., \& Valero, M. (2012). Determinantes de la brecha salarial de género en España: Un análisis de la retribución en función de las características personales, empresariales y de la competitividad de la empresa. Madrid: Colección EME Ministerio de Sanidad, Servicios Sociales e Igualdad. 
de Miguel, A. (2003). El movimiento feminista y la construcción de marcos de interpretación. El caso de la violencia contra las mujeres. Revista Internacional de Sociología (RIS), 61(35), 127-150.

Debeljuh, P., Idrovo, S. \& Bernal, M. (2015). El lado femenino del poder. Buenos aires: LID Editorial Argentina.

Del Brío, E. \& Del Brío, I. (2009). Los consejos de administración en las sociedades cotizadas: avanzando en femenino. Revista de Estudios Empresariales Segunda época, (I), 102-118

Delgado, I., \& Jerez, M. (2008). Mujer y política en España: un análisis comparado de la presencia femenina en las asambleas legislativas (19772008). Revista Española de Ciencia Política, (19), 41-78.

Departamento del Trabajo. (2010). Propuesta de indicadores para la elaboración de planes de igualdad. Barcelona: Dirección General de Igualdad de Oportunidades en el Trabajo. Generalitat de Cataluña.

Desvaux, G., Devillard-Hoellinger, Sandrine \& Baum-Garten, P. (2007). Women Matter: Gender diversity a corporate performance driver. Paris: Mckinsey \& Company.

Diehl, A. (2014). Making Meaning of Barriers and Adversity: Experiences of Women Leaders in Higher Education. Advancing Women in Leadership, 34, 54-63

Díez, E., Valle, R., Terrón, E., \& Centeno, B. (2003). El liderazgo femenino y su ejercicio en las organizaciones educativas. Revista lberoamericana de Educación, (31), 1-18.

Dirección General del Servicio Jurídico del Estado. (1991-a). El principio de igualdad en la constitución española: XI jornadas de estudio, Volumen 1. Madrid: Ministerio de Justicia, Secretaría General Técnica, Centro de Publicaciones. 
Dirección General del Servicio Jurídico del Estado. (1991-b). El principio de igualdad en la constitución española: XI jornadas de estudio, Volumen 2. Madrid: Ministerio de Justicia, Secretaría General Técnica, Centro de Publicaciones.

Dueñas, D., Iglesias, C., \& Llorente, R. (2013). La segregación laboral en las regiones españolas durante el periodo 1996-2010. Investigaciones Regionales, (27), 91-113

Eagly, A., \& Carli, L. (2007). Women and the Labyrinth of Leadership. Harvard Business Review, 85(9), 62.

Eagly, A., \& Johnson, B. (1990). Gender and leadership style: A metaanalysis. Psychological Bulletin, 108(2), 233-256.

Engels, F. (2002). Manifiesto comunista. Madrid: Editorial El Viejo Topo Fernández, A. (2002). Estereotipos y roles de género en el refranero popular: charlatanas, mentirosas, malvadas y peligrosas: proveedores, maltratadores, machos y cornudos. Barcelona: Anthropos Editorial Fernández, E. (2003). Igualdad y derechos humanos. Madrid: Tecnos. Fernández, M. (2007). Motivar con la acción social: El voluntariado corporativo como herramienta de gestión de personas. Oleiros: Netbiblo. Figueruelo, Á., del Pozo, M., \& León, M. (2012). ¿Por qué no hemos alcanzado la igualdad?. Santiago de Compostela: Andavira.

Figueruelo, Á., del Pozo, M., León, M., \& Gallardo, A. (2012). Igualdad: Retos para el siglo XXI. Santiago de Compostela: Andavira.

Ford, G. (1991). Comisión de investigación sobre el racismo y la xenofobia: informe sobre las conclusiones. Luxemburgo: Oficina de Publicaciones Oficiales de las Comunidades Europeas.

Forética \& Secretaria de Estado de Igualdad. (2010). Igualdad y RSE: Guía para PYMES. Madrid: Centro de Publicaciones Ministerio de Sanidad, Política Social e Igualdad. 
Friedman, M. (2007). The Social Responsibility of Business Is to Increase Its Profits. En W. Zimmerli, Corporate Ethics and Corporate Governance. Berlin: Springer.

Friedman, M. (s.f.). The case against Equal Pay for Equal Work [Archivo de vídeo]. Recuperado de YouTube https://www.youtube.com/watch?v=OcsbMPAW83A

Fundación MUJERES. (2008). Orientaciones para Negociar Medidas y Planes de Igualdad de Oportunidades entre Mujeres y Hombres en las Empresas. Madrid: Instituto de la mujer.

Fundación MUJERES. (2010). Conciliación de la vida laboral, familiar y personal. Madrid: Ministerio de Igualdad.

Gabaldón, P. (2013). Mujeres en los Consejos de Administración y en la Alta Dirección en España. Investigaciones y Publicaciones del Centro de Gobierno Corporativo, (I), p. 1-50.

Gala, C. (2010). Nuevos contenidos de las Leyes de Igualdad: la responsabilidad social empresarial como nuevo instrumento de intervención. DERECHO, GÉNERO E IGUALDAD: CAMBIOS EN LAS ESTRUCTURAS JURÍDICAS ANDROCÉNTRICAS

Galindo, J. (2000). Conciliación de la vida familiar y laboral. Aequalitas: Revista jurídica de igualdad de oportunidades entre mujeres y hombres, (4), 32-40.

Gálvez, L., \& Rodríguez, P. (2012). La desigualdad de género en las crisis económicas. Investigaciones Feministas, 2, 113-132.

Goldberg, S. (1993). Why Men Rule: A theory of male domination. Chicago: Open Court

Grant Thornton. (2015). Mujeres directivas: en el camino hacia la alta dirección. Grant Thornton International Business Report 2015.Grant Thornton International 
Grant Thornton. (2017). Women in business: Visiones diversas, soluciones conjuntas. Grant Thornton International

Giner, A. (2008). Las empresas transnacionales y los Derechos Humanos. Lan Harremanak. Revista de Relaciones Laborales, (19), 6787

Glass, C. \& Cook, A. (2016). Leading at the top: Understanding women's challenges above the glass ceiling. The Leadership Quarterly, 27 (1), 51 63.

Godoy, L., \& Mladinic, A. (2009). Estereotipos y Roles de Género en la Evaluación Laboral y Personal de Hombres y Mujeres en Cargos de Dirección. Psykhe, 18(2), 51-64.

Goldin, C. (2014). A Grand Gender Convergence: Its Last Chapter. American Economic Review, 104(4), 1091-1119.

Gómez, H. (2012). Empresa internacionalizada y responsabilidad social: Un matrimonio convencido. Madrid: ICEX

Gómez, J. \& Sánchez, M. (2009). La participación de la mujer en los consejos de administración de empresas del lbex-35. Revista de Humanidades, 16, p. 105-140.

González, A., Fuster, M., Pérez, P., Montserrat, L., \& Tabernero, J. (2010). El plan de igualdad y la responsabilidad social de la empresa (1a. ed.). Valladolid: Lex Nova.

González, B. (1999). Los estereotipos como factor de socialización en el género. Comunicar, (12), 79-88.

González, M., \& Rodríguez, P. (2008). Límites y desigualdades en el empoderamiento de las mujeres en el PAN, PRI y PRD. Ciudad de México: UNAM.

González, P., Pérez, C., Pliego, P., \& Sánchez, M. (1992). El trabajo de las mujeres a través de la historia. Madrid: Instituto de la Mujer. 
González, T. (2008). El aprendizaje de la maternidad: discursos para la educación de las mujeres en España (siglo XX). Convergencia, 15(46), 91-117.

Gregorio, C., \& Ramírez, Á. (2000). ¿En España es diferente...? Mujeres inmigrantes. Papers, (60), 257-273.

Groysberg, B., \& Connolly, K. (2013). Great Leaders Who Make the Mix Work. Harvard Business Review, 91(9), 68-76.

Grueso, M. (2009). La discriminación de género en las prácticas de recursos humanos: un secreto a voces. Cuadernos de administración, 22 (39), 13-30

Hall, C. (2010). Women and Empowerment: Strategies For Increasing Autonomy. New york: Taylor \& Francis.

Hansen, M., Ibarra, H., \& Peyer, U. (2010). The Best-Performing CEOs in the World. Harvard Business Review, 88 (1), 104-113

Hansen, M., Ibarra, H., \& Peyer, U. (2013). The Best-Performing CEOs in the World. Harvard Business Review, 91(1), 81-95.

Hansen, M., Ibarra, H., \& Peyer, U. (2015). The Best-Performing CEOs in the World. Harvard Business Review.

Hatcher, T. (2000). Ethics and HRD: A New Approach To Leading Responsible Organizations (New Perspectives in Organization). Cambridge: Basic Books.

Hernández, M. (2008). Exclusión social y desigualdad. Murcia: Ediciones de la Universidad de Murcia.

Hopenhayn, M., \& Bello, A. (2001). Discriminación étnico-racial y xenofobia en América Latina y el Caribe. Santiago de Chile: CEPAL.

Ibarra, H., Ely, R., \& Kolb, D. (2013). Women Rising: The Unseen Barriers. Harvard Business Review, 91(9), 61-66 
ICSA. (2016, mayo 18). La recuperación económica no genera mayor igualdad entre géneros. http://www.icsarrhh.com/la-recuperacioneconomica-no-genera-mayor-igualdad-entre-generos/

INE. (2012). Nota de Prensa. Estadística de la Enseñanza Universitaria en España. Madrid: INE. Obtenido de

INE. (2004). Nota de Prensa. Encuesta Anual de Estructura Salarial 2002. Madrid: INE. Obtenido de http://www.ine.es/prensa/np347.pdf INE. (2006). Nota de Prensa. Encuesta Anual de Estructura Salarial 2004. Madrid: INE. Obtenido de http://www.ine.es/prensa/np441.pdf INE. (2007). Nota de Prensa. Encuesta Anual de Estructura Salarial 2005. Madrid: INE. Obtenido de http://www.ine.es/prensa/np916.pdf INE. (2008). Nota de Prensa. Encuesta Anual de Estructura Salarial 2006. Madrid: INE. Obtenido de http://www.ine.es/prensa/np525.pdf INE. (2009). Nota de Prensa. Encuesta Anual de Estructura Salarial 2007. Madrid: INE. Obtenido de http://www.ine.es/prensa/np568.pdf INE. (2010). Nota de Prensa. Encuesta Anual de Estructura Salarial 2008. Madrid: INE. Obtenido de http://www.ine.es/prensa/np601.pdf INE. (2011). Nota de Prensa. Encuesta Anual de Estructura Salarial 2009. Madrid: INE. Obtenido de http://www.ine.es/prensa/np658.pdf INE. (2012). Nota de Prensa. Encuesta Anual de Estructura Salarial 2010. Madrid: INE. Obtenido de http://www.ine.es/prensa/np741.pdf INE. (2012). Nota de Prensa. Estadística de la Enseñanza Universitaria en España. Madrid: INE.

INE. (2013). Nota de Prensa. Encuesta Anual de Estructura Salarial 2011. Madrid: INE. Obtenido de http://www.ine.es/prensa/np790.pdf INE. (2014). Nota de Prensa. Encuesta Anual de Estructura Salarial 2012. Madrid: INE. Obtenido de http://www.ine.es/prensa/np852.pdf 
INE. (2015). Nota de Prensa. Encuesta Anual de Estructura Salarial 2013. Madrid: INE. Obtenido de http://www.ine.es/prensa/np916.pdf Instituto de la Mujer, FEMP \& Asociación Noruega de Autoridades Locales y Regionales. (2010). Guía de buenas prácticas para promover la conciliación de la vida personal, familiar y profesional. Desde entidades locales de España y Noruega. Madrid: Instituto de la mujer Instituto de la Mujer. (2010). Poder y toma de decisiones. Obtenido de Mujeres en el gobierno: http://www.inmujer.gob.es/estadisticas/decisiones/poderEjecutivo/2010/ mujeresGob.xls Instituto de la Mujer. (2011). Poder y toma de decisiones. Obtenido de Concejalas/Concejales según Comunidad Autónoma: http://www.inmujer.gob.es/estadisticas/decisiones/administracionLocal/2 011/w81.xls

Instituto de la Mujer. (2013). Poder y toma de decisiones. Obtenido de Directiva de los sindicatos UGT, CCOO y USO: http://www.inmujer.gob.es/estadisticas/decisiones/partidosPoliticos/2013 M89.xls

Instituto de la Mujer. (2013). Poder y toma de decisiones. Obtenido de Participación de mujeres en cargos ejecutivos de los principales partidos políticos:

http://www.inmujer.gob.es/estadisticas/decisiones/partidosPoliticos/2013 W811.xls

Instituto de la Mujer. (2014). Poder y toma de decisiones. Obtenido de Alcaldesas/alcaldes según comunidad autónoma: http://www.inmujer.gob.es/estadisticas/decisiones/administracionLocal/2 014/W94.xls 
Instituto de la Mujer. (2014). Poder y toma de decisiones. Obtenido de Alcaldesas/alcaldes según partido político: http://www.inmujer.gob.es/estadisticas/decisiones/administracionLocal/2 014/W408.xls

Instituto de la Mujer. (2014). Poder y toma de decisiones. Obtenido de Concejalas/concejales según partido político: http://www.inmujer.gob.es/estadisticas/decisiones/administracionLocal/2 014/W575.xls

Instituto de la Mujer. (2014). Poder y toma de decisiones. Obtenido de Consejos de Administración de las empresas del lbex 35: http://www.inmujer.gob.es/estadisticas/decisiones/poderEconomico/201 4/W779.xls

Instituto de la Mujer. (2014). Poder y toma de decisiones. Obtenido de Embajadoras/es acreditadas/os ante Gobiernos de Estados extranjeros: http://www.inmujer.gob.es/estadisticas/decisiones/poderJudicial/2014/W 131.xls

Instituto de la Mujer. (2014). Poder y toma de decisiones. Obtenido de Organos de dirección de las empresas del lbex 35: http://www.inmujer.gob.es/estadisticas/decisiones/poderEconomico/201 4/W1064.xls

Instituto de la mujer. (2014). Poder y toma de decisiones. Obtenido de Órganos superiores y altos cargos de la Administración General del Estado:

http://www.inmujer.gob.es/estadisticas/decisiones/altosCargosAdmin/20 14/W98.xls

Instituto de la Mujer. (2014). Poder y toma de decisiones. Obtenido de Representación española en organismos internacionales: 
http://www.inmujer.gob.es/estadisticas/decisiones/poderJudicial/2014/W 785.xls

Instituto de la Mujer. (2014). Poder y toma de decisiones. Obtenido de Sistema Judicial: http://www.inmujer.gob.es/estadisticas/decisiones/poderJudicial/2014/W 99.xls

Instituto de la Mujer. (2014). Poder y toma de decisiones. Obtenido de Tribunal Constitucional: http://www.inmujer.gob.es/estadisticas/decisiones/poderJudicial/2014/W 806.xls

Instituto de la Mujer. (2015). Poder y toma de decisiones. Obtenido de Mujeres en el Congreso según partido político: http://www.inmujer.gob.es/estadisticas/decisiones/poderLegislativo/2015 M91.xls

Instituto de la Mujer. (2015). Poder y toma de decisiones. Obtenido de Mujeres en el Senado según partido político: http://www.inmujer.gob.es/estadisticas/decisiones/poderLegislativo/2015 W92.xls

Instituto de la Mujer. (2015). Poder y toma de decisiones. Obtenido de Mujeres en los gobiernos autonómicos: http://www.inmujer.gob.es/estadisticas/decisiones/poderEjecutivo/2015/ W95.xls

Instituto de la Mujer. (2015). Poder y toma de decisiones. Obtenido de Participación de mujeres en diversos órganos constitucionales: http://www.inmujer.gob.es/estadisticas/decisiones/poderJudicial/2015/W 776.xls

Instituto de la Mujer. (2015). Poder y toma de decisiones. Obtenido de Participación en los parlamentos autonómicos según Comunidad 
autónoma:

http://www.inmujer.gob.es/estadisticas/decisiones/poderLegislativo/2015 /w93.xls

Instituto de la Mujer. (2015). Poder y toma de decisiones. Obtenido de Representantes del gobierno en comunidades autónomas y provincias: http://www.inmujer.gob.es/estadisticas/decisiones/poderEjecutivo/2015/ W780.xls

Instituto Ethos de Empresas e Responsabilidade Social. (2013). Indicadores Ethos de Responsabilidad Social Empresarial.Sao Paulo: Instituto Ethos de Empresas e Responsabilidade Social Interpar

IOÉ. (1990). El servicio doméstico en España. Entre el trabajo invisible y la economía sumergida. Madrid: Juventud Obrera Cristiana de España. Izquierdo, I. (2008). Mujeres en la academia ¿cambio de oportunidades?. Revista Géneros, 51-65.

Jerez, M., \& Delgado, I. (2011). Mujeres y parlamentos entre dos siglos: el caso de España. Psicología Política, (42), 89-116.

Johns, M. (2013). Breaking the Glass Ceiling: Structural, Cultural, and Organizational Barriers Preventing Women from Achieving Senior and Executive Positions. Perspectives in health information management, (10), 1-11.

Kahale, D. (2013). La Responsabilidad Social de Género. Pamplona: Thomson Reuters.

Kanter, R. (1977). Men and Women of the Corporation. Nueva York: BasicBooks.

Kitroeff, N., \& Rodkin, J. (2015, 20 de octubre). The Real Payoff From an MBA Is Different for Men and Women. Bloomberg Businessweek. 
Obtenido de http://www.bloomberg.com/news/articles/2015-10-20/thereal-cost-of-an-mba-is-different-for-men-and-women

Kolhatkar, S. (2014). Why the Gender Pay Gap Persists-and How to Really End It. Bloomberg Businessweek. Obtenido de http://www.bloomberg.com/bw/articles/2014-03-04/the-gender-pay-gappersists-on-long-inflexible-work-hours Laliena, A. (2010). Perspectiva de género y enfoque de responsabilidad social en el estudio del sector textil: Aportaciones a la cooperación al desarrollo (1a.ed.). Zaragoza: Prensas Universitarias de Zaragoza.

León, M. (2000). Empoderamiento: Relaciones de la mujer con el poder. Estudos Feministas, 8(2). 191-206.

Lombardo, E., \& Verloo, M. (2010). La interseccionalidad del género con otras desigualdades en la política de la Unión Europea. Revista Española de Ciencia Política, 23, 11-30.

López, E., \& Santos, J. (2013). La mujer en el mercado laboral español. Economía española y Protección Social, (5), 145-167.

López, M. (2002). Gestión ética y responsabilidad social en las empresas. Comunicaciones en Propiedad Industrial y Derecho de la Competencia, (28), 131-136.

López, P. (2011). Habilidades directivas: 30 habilidades para el desarrollo de un liderazgo efectivo. Oleiros: Netbiblo.

Lousada, J. (2014). El derecho fundamental a la igualdad efectiva de mujeres y hombres. Valencia: Tirant lo blanch.

Luelmo, M. (2012). La responsabilidad social corporativa en el ámbito del derecho laboral: Un instrumento económico-jurídico para un humanismo del siglo XXI. Oleiros: Netbiblo.

Marchant, L. (2005). Actualizaciones para el Desarrollo Organizacional, Primer Seminario. Viña del Mar: Universidad de Viña del Mar 
Marcu, S. (2009). Inmigrantes rumanas en el servicio doméstico y de cuidados de la Comunidad de Madrid: Estudio cualitativo. Estudios Geográficos, Vol. LXX, 267, pp. 463-489.

Martín, M. (2012). Discriminación por razón de sexo en el acceso al empleo en la empresa privada. En N. Sanz, Políticas de empleo e igualdad especial referencia al ámbito universitario. Granada: Editorial Comares

Martínez, A. (2014). Las nodrizas y su papel en el desarrollo de la sociedad española: una visión transdisciplinar. Alicante: Tesis Doctorales Universidad de Alicante.

Martínez, C., Melero, R., Menéndez, P., Núñez-Cortés, P., Ridaura, M., \& Velasco, T. (2009). Nociones básicas sobre igualdad en las relaciones laborales: Guía para la empresa y las administraciones públicas. Madrid: Editorial Tecnos.

Martínez-Losa, J. F., \& Sarrate, J. (2014). Impacto socio-económico del estrés laboral y de los riesgos psicosociales. Seguridad y Salud en el Trabajo, 79, 36-52.

Martínez, M. (2009). Género y conciliación de la vida familiar y laboral: Un análisis psicosocial. Murcia: EDITUM.

Martínez, M., Guilló, N., Santero, R., \& Castro, R. (2011). Trayectorias laborales de las mujeres que ocupan puestos de alta cualificación. Madrid: Ministerio de Sanidad, Política Social e Igualdad Centro de Publicaciones.

Maruani, M. (2000). Las nuevas fronteras de la desigualdad: hombres y mujeres en el mercado de trabajo. Barcelona: Icaria Editorial.

Mateos, R., Iturrioz, J., \& Gimeno, R. (2009). La participación financiera y el papel de la mujer en la toma de decisiones de las sociedades 
cooperativas: los consejos de administración. Revista Europea de Dirección y Economía de la Empresa, 18(3), 65-82.

Mateos, R., Gimeno, R. \& Escot, L. (2010). Discriminación en consejos de administración: análisis e implicaciones económicas. Revista de Economía Aplicada, 18(53), 131-162.

Maxfiel S, Cárdenas, M. \& Heller, L. (2008). Mujeres y vida corporativa en Latinoamérica: Retos y dilemas. Bogotá: Universidad de los Andes.

Medina-Vincent, M. (2015). Role models, mentoring y redes de mujeres profesionales: educar en valores feministas para fomentar liderazgos éticos. Revista Iberoamericana de Producción Académica y Gestión Educativa, (Julio a Diciembre).

Mercader, J. (2009). Trabajadores maduros: Un análisis multidisciplinar de la repercusión de la edad en el ámbito social. Valladolid: Lex Nova.

Ministerio de Sanidad, Política Social e Igualdad. (2011). Estrategia Española sobre Discapacidad 2012-2020. Madrid: Centro Español de Documentación sobre Discapacidad (CEDD).

Molero, A., Cuadrado, I., García, C., Recio, P., \& Rueda, B. (2009). Mujer y liderazgo en el siglo XXI: una aproximación psicosocial a los factores que dificultan el acceso de la mujer a los puestos de alta responsabilidad. Madrid: Instituto de la Mujer.

Moneva, J. (2005). Información sobre responsabilidad social corporativa: Situación y tendencias. RAE: Revista Asturiana de Economía, (34), 4367.

Monroy, J (2013). Mujeres de poder. Disponible para consulta pública en URL http://monroy.eu/mujeres-en-el-poder.pdf Mora, F. (2002). Mujer y representación política. Praxis Sociológica, 6, 83-103. 
Morales, J. \& Cuadrado, I. (2011). Perspectivas psicológicas sobre la implicación de la mujer en política. Psicología Política, (42), 29-44 Morán, M. (2011). La cultura política de las mujeres: Un campo de estudio todavia por explorar. Psicología Política, (42), 45-68.

Moreno, A., Uriarte, Luis., \& Topa, G. (2010). La responsabilidad social empresarial: Oportunidades estratégicas, organizativas y de recursos humanos. Madrid: Pirámide.

Nicolson, P. (1997). Poder, género y organizaciones: se valora a las mujeres en la empresa?. Madrid: Narcea Ediciones.

OCDE. (2012). Women in Business: Policies to Support Women's Entrepreneurship Development in the MENA Region. OCDE Publishing. Oelz, M., Olney, S., \& Tomei, M. (2013). Igualdad salarial: Guía introductoria. Turin: Organización Internacional del Trabajo.

OIT. (1951). C100 Convenio sobre igualdad de remuneración, 1951. Ginebra: Oficina Internacional del Trabajo.

OIT. (1998). Declaración de la OIT relativa a los principios y derechos fundamentales en el trabajo y su seguimiento. Ginebra: Oficina Internacional del Trabajo.

OIT. (2003). Los convenios fundamentales de la Organización Internacional del Trabajo. Ginebra: Oficina Internacional del Trabajo.

OIT. (2011). La igualdad en el trabajo: un objetivo que sigue pendiente de cumplirse. Ginebra: Oficina Internacional del Trabajo.

OIT. (2012). Global Employment Trends for Women 2012. Geneva: ILO OIT. (2014). Global Employment Trends for Women 2014. Geneva: ILO OIT. (2014). Resumen ejecutivo. Informe Mundial sobre Salarios 2014/2015. Salarios y desigualdad de ingresos. Ginebra: Oficina Internacional del Trabajo 
OIT. (2015). La mujer en la gestión empresarial. Cobrando impulso. Ginebra: Oficina Internacional del Trabajo.

ONU Mujeres. (2011). Principios para el empoderamiento de las mujeres: la igualdad es un buen negocio. Pacto Mundial de las Naciones Unidas. ONU Mujeres. (2014, 11 de marzo). Comunicado de prensa: Pese al progreso de las mujeres en la política, el techo de cristal permanece firme. ONU Mujeres. (2015). El progreso de las mujeres en el mundo: 20152016. Transformar las economías para realizar los derechos. Nueva york: ONU Mujeres.

ONU Mujeres. (2016, enero). Liderazgo y participación política.

ONU. (2013). Objetivos de Desarrollo del Milenio. Informe de 2013. Nueva york: ONU

ONU. (2015). Objetivos de Desarrollo del Milenio. Informe de 2015. Nueva york: ONU

Ortega, C., Torres, J. \& Trujillo, J. La igualdad efectiva entre mujeres y hombres: un estudio de las elecciones al congreso de los diputados de 2008. Psicología Política, (42), 117-139.

Osborne, R. (2011). Apuntes sobre violencia de género. RIS, 69 (1), 517 540.

Parlamento Europeo. (2011). Resolución del Parlamento Europeo, de 13 de marzo de 2012, sobre la representación de las mujeres en los procesos de toma de decisiones políticas: calidad e igualdad (2011/2295(INI)). Estrasburgo: Parlamento Europeo.

Perán, S. (2014). Derecho Social y Género: El camino hacia la igualdad efectiva en las relaciones sociolaborales. Pamplona: Thomson Reuters. Pérez, T. (2006). Igualdad y género en el empleo. Sevilla: Consejo Andaluz de Relaciones Laborales. 
Pérez, J., \& Nogareda, C. (2012). Factores psicosociales: metodología de evaluación. Madrid: INSHT.

Pin, J., García, P. \& Gallifa, A. (2007). Libro blanco sobre la gestión de la diversidad en las empresas españolas: retos, oportunidades y buenas prácticas. IESE Universidad de Navarra.

PNUD. (2014). Informe sobre desarrollo humano 2014. Sostener el Progreso Humano: Reducir vulnerabilidades y construir resiliencia. Nueva York: Programa de las Naciones Unidas para el Desarrollo.

PNUD. (2015). Panorama general. Informe sobre Desarrollo Humano 2015. Trabajo al servicio del desarrollo humano. Nueva York: Programa de las Naciones Unidas para el Desarrollo.

Polo, J. (2011). La RSC de las grandes empresas españolas con presencia en américa latina. Madrid: Editorial Fragua.

Porto, N., Neira, I., \& Vázquez, E. (2010). Perfil de la mujer directiva española. Revista universitaria de ciencias del trabajo, (11), 147-173.

Prime, J., \& Salib, E. (2014, May 7). Inclusive Leadership: The View From Six Countries. New york: Catalyst.

Prime, J., \& Salib, E. (2015, August 25). The Secret To Inclusion In Australian Workplaces: Psychological Safety. New york: Catalyst.

Rey, F. (2008). La discriminación múltiple, una realidad antigua, un concepto nuevo. Revista española de derecho constitucional, 28(84), 251-283.

Rey, F., \& Giménez, D. (2010). Por la diversidad, contra la discriminación la igualdad de trato en España: hechos, garantías y perspectivas. Madrid: Fundación IDEAS.

Ribas, M. (2005). Mujer y trabajo en la economía social (1a. ed.). Madrid: Consejo Económico y Social. 
Rivero, Á, Caunedo, P., \& Rodríguez, A. (2008). De la conciliación a la corresponsabilidad: buenas prácticas y recomendaciones. Madrid: Instituto de la Mujer (Ministerio de Igualdad)

Rodrigo, A. (2014). Mujeres para la historia: la España silenciada del siglo $X X$. Bélgica: Primento

Romero, A. (2006). Igualdad y retribución. Valencia: Tirant lo Blanch.

Ruiz, M. (2010). Igualdad y no discriminación: La proyección sobre el tratamiento laboral de la discapacidad (1a.ed.). Albacete: Bomarzo.

Saldaña, F., \& Llàtser, M. (2007). Guía para la gestión de la igualdad en las organizaciones. Madrid: Forética.

Sánchez-Apellániz, M. (1997). Mujeres, dirección y cultura organizacional. Madrid: Centro de Investigaciones Sociológicas.

Selva, C., Sahagún, M., \& Pallarès, S. (2011). Estudios sobre Trayectoria Profesional y Acceso de la Mujer a Cargos Directivos: un Análisis Bibliométrico. Revista de Psicología del Trabajo y de las Organizaciones, 27(3), 227-242.

Shelby, A., Mueller, J. \& David, R. (2015). Are male leaders penalized for seeking help? The influence of gender and asking behaviors on competence perceptions. The Leadership Quarterly, 26 (5), 749-762.

Shelby, A., Zhou, C., Ma, A \& Livingston, R. (2016). Race matters for women leaders: Intersectional effects on agentic deficiencies and penalties. The Leadership Quarterly.

Schiek, D. \& Lawson, A. (2011). European Union Non-discrimination Law and Intersectionality: Investigating the Triangle of Racial, Gender and Disability Discrimination. Farnham: Ashgate.

Schonard, M. (2017). La igualdad entre hombres y mujeres. Fichas técnicas sobre la Unión Europea en URL: http://www.europarl.europa.eu/ftu/pdf/es/FTU_5.10.8.pdf 
Silvestre, M., Royo, R., \& Escudero, R. (2014). El empoderamiento de las mujeres como estrategia de intervención social. Bilbao: Universidad de Deusto.

Suddath, C. (2014). Tech Startup Founder Says Women Are Like Men, Only Cheaper. Bloomberg Businessweek. Obtenido de http://www.bloomberg.com/bw/articles/2014-09-22/tech-start-up-foundersays-women-are-like-men-only-cheaper

Tenjo, J., Ribero, R., \& Bernat, L. (2005). Evolución de las diferencias salariales por sexo en seis paises de américa latina: un intento de interpretación. Documento CEDE, (18), 1-59.

The World Bank. (2011). World development report 2012: Gender equality and development. Washington: The World Bank.

Tobío, C. (2003). Cambio social y solidaridad entre generaciones de mujeres. Feminismo/s, (2), 153-166.

UGT. (2015). Trabajar igual cobrar igual. Madrid: Unión General de Trabajadores.

UN Women. (2014). The World Survey on the role of women in development 2014: Gender equality and sustainable development. New york: UN Women.

UNESCO. (2015). Informe de Seguimiento de la EPT en el mundo 2015. París: Organización de las Naciones Unidas para la Educación, la Ciencia y la Cultura.

Valdés, A. (2010). Responsabilidad social de la empresa y relaciones laborales: entre la ley y la negociación colectiva. Madrid: Editorial Reus. Varela, N. (2008). Feminismo para principiantes. Barcelona: Ediciones B, S. A.

Villar, A., de la Rica, S., Denia, A., Domínguez, M., Gálvez, L., Goerlich, F, Guilló, M. \& Rodríguez, P. (2010). Mujeres y mercado laboral en 
españa: Cuatro estudios sobre la discriminación salarial y la segregación laboral (1a. ed.). Bilbao: Fundación BBVA.

Vizcarra, I. (2005). Género y poder: diferentes experiencias, mismas preocupaciones. Toluca: CEDIMSA

World Economic Forum. (2013). The Global Gender Gap Report 2013. Geneva: World Economic Forum. Obtenido de http://www3.weforum.org/docs/WEF_GenderGap_Report_2013.pdf World Economic Forum. (2014). The Global Gender Gap Report 2014. Geneva: World Economic Forum. Obtenido de http://www3.weforum.org/docs/GGGR14/GGGR_CompleteReport_2014. pdf

World Economic Forum. (2016). The Global Gender Gap Report 2016. Geneva: World Economic Forum. Obtenido de http://www3.weforum.org/docs/GGGR16/WEF_Global_Gender_Gap_Re port_2016.pdf

Zahidi, S. (2014, 28 de octubre). 2095: El año de la equidad de género en el lugar de trabajo, quizá. Foro Económico Mundial.

Zenger, J., \& Folkman, J. (2012). Are Women Better Leaders than Men?. Harvard Business Review, 15, 80-85 